Florida International University

FIU Digital Commons

FIU Electronic Theses and Dissertations

University Graduate School

6-26-2020

\title{
Understanding the Individual and Organizational Attributes of Servant Leadership in Local Governments
}

\author{
Pallavi Awasthi \\ Florida International University, pawas001@fiu.edu
}

Follow this and additional works at: https://digitalcommons.fiu.edu/etd

Part of the Cognitive Psychology Commons, Industrial and Organizational Psychology Commons, Leadership Studies Commons, Organization Development Commons, Performance Management

Commons, Personality and Social Contexts Commons, Policy Design, Analysis, and Evaluation Commons, Public Administration Commons, Public Affairs Commons, Public Policy Commons, Training and

Development Commons, and the Urban Studies Commons

\section{Recommended Citation}

Awasthi, Pallavi, "Understanding the Individual and Organizational Attributes of Servant Leadership in Local Governments" (2020). FIU Electronic Theses and Dissertations. 4488.

https://digitalcommons.fiu.edu/etd/4488

This work is brought to you for free and open access by the University Graduate School at FIU Digital Commons. It has been accepted for inclusion in FIU Electronic Theses and Dissertations by an authorized administrator of FIU Digital Commons. For more information, please contact dcc@fiu.edu. 


\title{
FLORIDA INTERNATIONAL UNIVERSITY
}

Miami, Florida

\section{UNDERSTANDING THE INDIVIDUAL AND ORGANIZATIONAL ATTRIBUTES OF SERVANT LEADERSHIP IN LOCAL GOVERNMENTS}

\author{
A dissertation submitted in partial fulfillment of \\ the requirements for the degree of \\ DOCTOR OF PHILOSOPHY \\ in \\ PUBLIC AFFAIRS
}

by

Pallavi Awasthi 
To: Dean John F. Stack, Jr.

Steven J. Green School of International and Public Affairs

This dissertation, written by Pallavi Awasthi, and entitled Understanding the Individual and Organizational Attributes of Servant Leadership in Local Governments, having been approved in respect to style and intellectual content, is referred to you for judgment.

We have read this dissertation and recommend that it be approved.

Sharon Mastracci

Susannah Bruns Ali

Keith D. Revell

Ochieng F. Walumbwa

Sukumar Ganapati, Co-Major Professor

Meredith Newman, Co-Major Professor

Date of Defense: June 26, 2020

The dissertation of Pallavi Awasthi is approved

Dean John F. Stack, Jr.

Steven J. Green School of International and Public Affairs

Andrés G. Gil

Vice President for Research and Economic Development and Dean of the University Graduate School

Florida International University, 2020 
CC Copyright 2020 by Pallavi Awasthi All rights reserved. 


\section{DEDICATION}

Dedicated to AADIYOGI SHIVA, my mother, father, and all my joint family members for being there all along this journey 


\section{ACKNOWLEDGMENTS}

To my dissertation committee members, Dr. Sukumar Ganapati, Dr. Meredith Newman, Dr. Ochieng F. Walumbwa, Dr. Keith D. Revell, Dr. Susannah Bruns Ali, and Dr. Sharon Mastracci. Your contributions have shaped my intellectual development and reinforced my belief that this academic journey is worth it. I am forever grateful for your time, continuous encouragement, opportunities for learning, and substantive feedback to continuously improve and do better.

To my dissertation committee chair, Dr. Ganapati, thank you for allowing me to complete my Ph.D. dissertation under your supervision. Your direction and support have encouraged and challenged me to evolve and grow into a better academic. Without which I wouldn't have been able to come this far. As my mentor, you have taught me pushing my limits and many more than I could ever give you the credit here. I owe my doctorate to you. To my co-chair Dr. Newman, your presence and support has been a motivational force and inspiration. I have learnt immensely by observing and modelling your professionalism and leadership at every step of this journey.

Special thanks to each one of my committee members. To Dr. Walumbwa, as an external committee member, I couldn't have asked for more help. You have always been there when I needed. Your support during this research has allowed me to persevere, believe in this work, and consistently do better. I am always grateful for this. To Dr. Revell, your feedback has enriched my work and I have learnt immensely from your professional conduct. To Dr. Ali, your teaching style, dedication for students, and balanced approach to manage your academic and personal life has always inspired me. 
To Dr. Mastracci, you have given me time whenever I asked, mentored me, I learnt something new by observing you every time I met you. Thank you for that.

To all of the faculty and staff in the Department of Public Policy and Administration, you have supported me in every possible way and at every step. I have learned from each one of you during my time in the department. This has been an experience to remember for a lifetime. Thank you for that. I am thankful to many organizations, scholars, and practitioners who have helped facilitate my dissertation research along the way. First, I would like to acknowledge the gracious financial support that I have been fortunate to receive during my doctoral process. There are three organizations in particular that have provided substantial financial support towards my doctoral education and my dissertation research.

First, the Department of Public Policy and Administration's Graduate Assistantship, I am thankful for their monetary support, emotional support, and professional development opportunities. Second, the Florida International University's Graduate School, thank you for awarding me with the Dissertation Evidence Acquisition (DEA) and the Dissertation Writing fellowships (DYF). It gave me the freedom and opportunity to pursue research that I am truly passionate about. Third, the Robert K. Greenleaf Center for Servant Leadership Doctoral Scholar Fellowship. However, I acknowledge that the opinions, findings, and conclusions or recommendations expressed herein are those of the author and do not represent the views of the University Graduate School, Florida International University or the Greenleaf Center for Servant Leadership. I am immensely thankful to the two county administrators and a village manager in Florida for believing in my research and its value for your organizations. Without your 
support this research wouldn't see through its completion. I thank all your senior executive officers for taking out their valuable time from their busy working hours and participate enthusiastically in formal and informal conversations, meetings, and community events for countless hours to answer my queries with utmost honesty, that allowed me to complete this research. I am especially thankful to the Florida City-County Management Association (FCCMA), Florida Association of Counties (FAC), the MiamiDade City-County Management Association (MDCCMA), and International City-County Management Association (ICMA), thank you for your support during this research.

To my three mentors Dr. Charles Dhanaraj, Dr. Dipak Jain, and Dr. Lynda L. Moore whom I met during my time as a researcher at the Indian School of Business (ISB), Hyderabad, India. I thank you for seeding the passion for research and academia and encouraging me to pursue Ph.D. Your leadership, teaching style, creativity, simplicity, and energy seeded in me the motivation to become the first-generation doctoral student which I could have only dreamt and imagined. I am also thankful to Dr. Mary E. Guy, Dr. Aroon P. Manoharan, Dr. Shilpa Viswanath, and Dr. Meghna Sabharwal for their valuable time to provide advice whenever I needed during this phase. I am grateful to all the fellow students, both in the department and outside. Your companionship has been of immense value in my personal and professional growth. You have uplifted my spirits, motivated me, advised me, provided professional and personal suggestions when I needed the most. You have broadened my horizon in embracing diverse cultures, values, and traditions. Your friendship, I will cherish forever. A special mention to a few friends who were fellow travelers in this journey: Shawn Lorenzo (Lolo) Benaine, Sebawit G. Bishu, Christa L. Remington, Alexandra Castillo Escobar, 
Angie Nga Le, and Merlene-patrice Quispe. When I was new to this academic culture and was stuck, I came to you. You have always been there to support me. I have learnt so much from you. Thank you immensely. To all my friends, whom I have known for many years, thank you for encouraging and standing by me throughout this doctoral journey.

Above all, I bow down to AADIYOGI SHIVA, for being there and continuously challenging me to discover and rediscover my energies and full potential to know thyself, on which my journey is on. I am thankful to my values, culture, and traditions that has taught me and shaped me to stay grounded, believe in me, be humble and kind, and be mindful of my energies. You have nurtured me and kept up my spirits at all times. You have given me the courage to face adverse situations and uncertain times with utmost equanimity and peace. You have energized me to fulfill my duties and responsibilities with my best abilities. I am immensely grateful to you for this life.

Lastly, to my mother and father, Prema Singh and Chandra Bhan Singh, who have instilled in me a sense of pride for my roots, responsibility, commitment, and love and respect for people. That has shaped my evolution into a better human being. To my life partner, Peeyush, who's commitment has been forever a strength and support, my daughter Pranjali's perseverance to put up with me during this phase, my sister Preeti's unflinching support throughout this journey and sharing each bit of life with me, and my brother Anurag, for being the best companion and pillar of support, your countless intellectual conversations have helped me persevere, stay alive, and grounded. Thank you to each one of you for being in my life and walking along. To my late grandfather, you have instilled in me purity and compassion. That has kept my child curiosity alive to explore the mysteries of nature and universe. Thank you all for everything. 


\title{
ABSTRACT OF THE DISSERTATION \\ UNDERSTANDING THE INDIVIDUAL AND ORGANIZATIONAL ATTRIBUTES \\ OF SERVANT LEADERSHIP IN LOCAL GOVERNMENTS
}

\author{
by
}

Pallavi Awasthi

Florida International University, 2020

Miami, Florida

\section{Professor Sukumar Ganapati Co-Major Professor \\ Professor Meredith Newman, Co-Major Professor}

Servant leaders are driven by a natural feeling to serve first which manifests into a conscious desire to lead. The servant leadership style emphasizes internalizing ethical behavior, along with empathy and service orientation in creating value for the community which are critical in public administration. While the servant leadership concept has gained much interest among business management scholars, it has received little attention in public administration. This dissertation aims to fill this wide gap in public sector leadership scholarship by investigating the role of servant leadership in public administration.

Specifically, the dissertation seeks to understand individual (servant identity and moral potency) and organizational attributes (organizational social capital and coproduction of public service) of servant leadership in local governments. The study is empirically based in Florida, which is a large state with diverse population and local government characteristics. It uses a mixed-method approach, with complementary quantitative and qualitative analyses. The methods include an online statewide survey of 
county and city managers and their staff $(\mathrm{N}=241)$. The data are analyzed using hierarchical linear modeling (HLM). The HLM analysis is complemented with three indepth case studies of county and city governments to explain how the servant leadership manifested.

The study holds two key findings. First, servant identity (calling, humility, empathy, and agape love) and moral potency (moral ownership, moral courage, and moral efficacy) attributes are significant predictors of servant leadership behavior among county and city managers. Servant identity correlates with putting the interests of the employees, community, and the organization above their own. The quest for serving others drives the servant leaders' ethical actions. Second, county and city managers who are servant leaders enhance organizational social capital and co-production of public services by encouraging community centric approaches. They create a service climate that inspires a community engaged culture. They instill trust among both internal (employees, elected officials) and external organizational stakeholders (nonprofits, community organizations, and citizens) through continuous engagement.

Overall, this study shows the significance of servant leadership for public administration and management. It suggests that servant leadership offers advantages over traditional (e.g. transformational and transactional) approaches which are inwardly oriented. Servant leadership goes beyond to serve the community and could be instrumental in strengthening democratic governance. 


\section{TABLE OF CONTENTS}

CHAPTER

PAGE

CHAPTER 1: Servant Leadership in Public Administration: Extant Literature and Future Directions 1

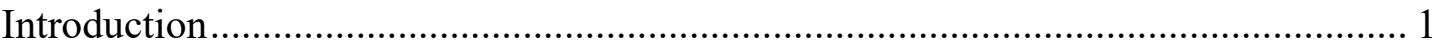

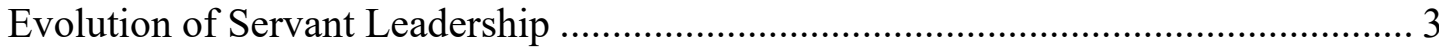

Extant Literature on Servant Leadership in Public Administration............................ 6

Servant Leadership vis a vis Other Leadership Approaches ................................. 10

Servant Leadership and Governance Debates................................................... 24

Servant Leadership as an Inclusive Approach for Local Governments..................... 28

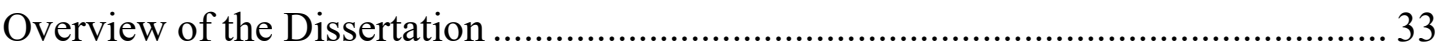

CHAPTER 2: Research Questions, Framework, and Methodology ............................... 36

Research Questions and Conceptual Framework .................................................... 36

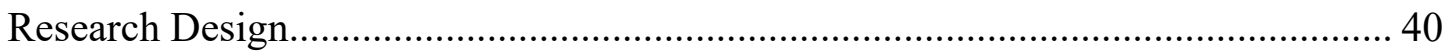

The Empirical Context: State of Florida's Local Governments .............................. 44

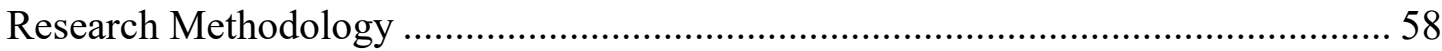

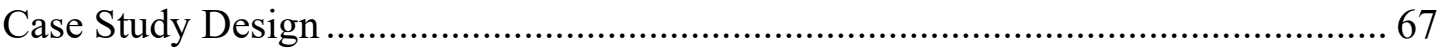

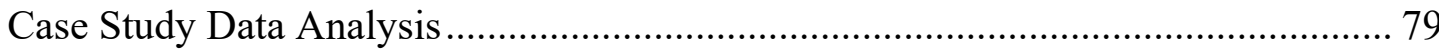

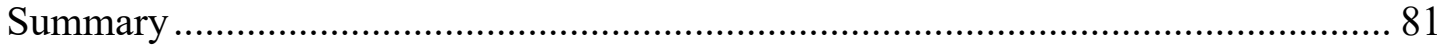

CHAPTER 3: Servant Leadership Behavior among Local Government Administrators: An Interpretation of Servant Identity and Moral Potency ....................................... 82

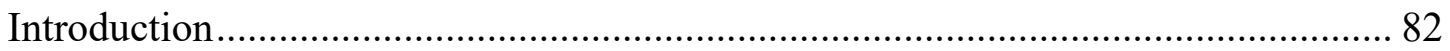

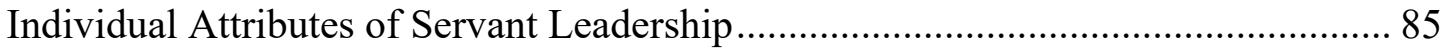

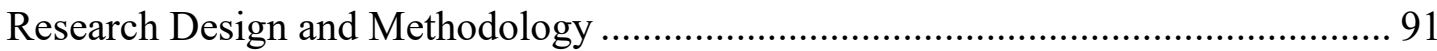


Hierarchical Linear Model of Servant Leadership Behavior ................................... 94

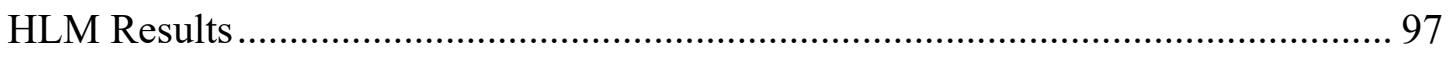

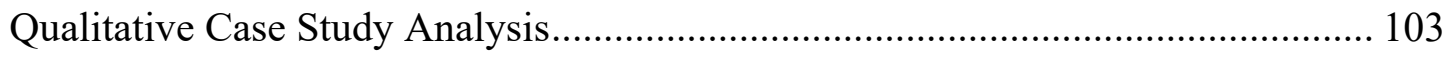

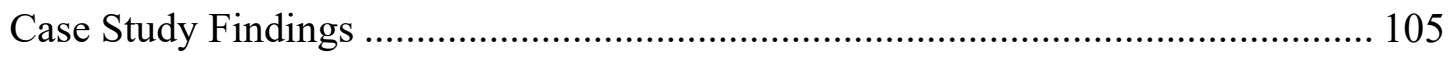

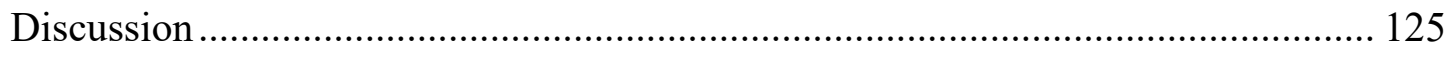

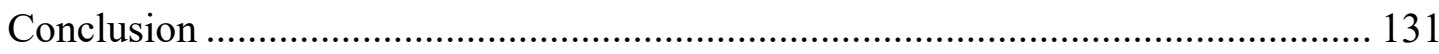

CHAPTER. 4: Servant Leaders as Community Custodians: Enhancing

Co-Production of Public Services in Local Governments .......................................... 134

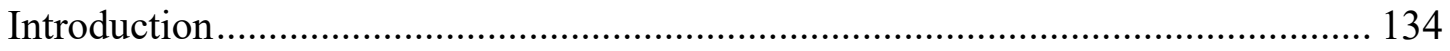

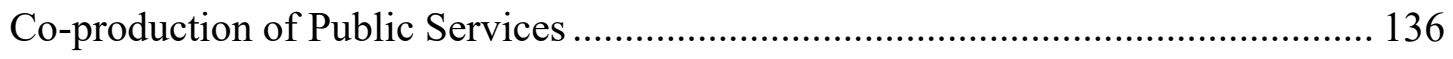

Leadership in the Co-Production of Public Services ........................................... 139

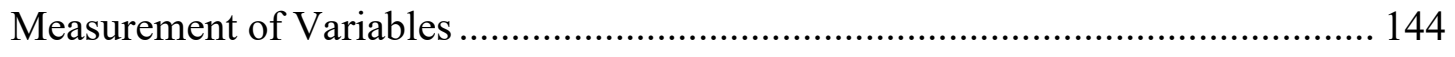

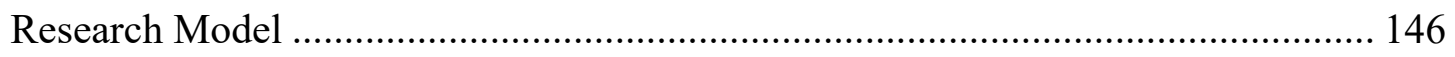

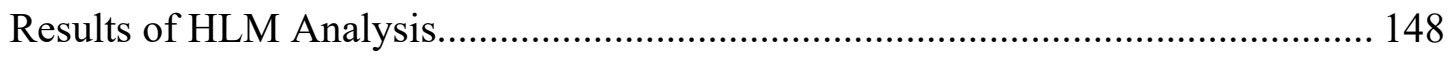

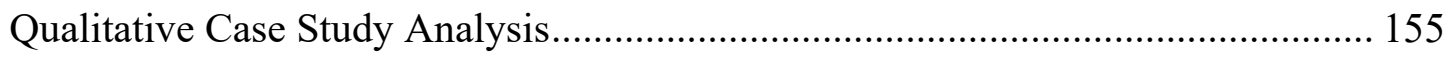

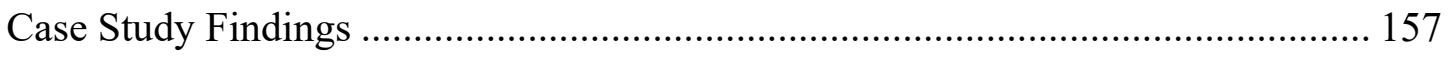

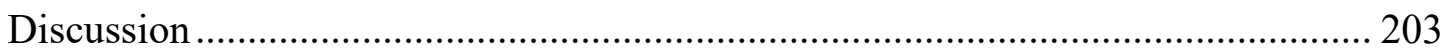

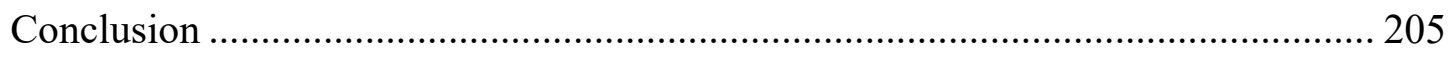

CHAPTER 5: Enhancing Organizational Social Capital in Local Governments: A

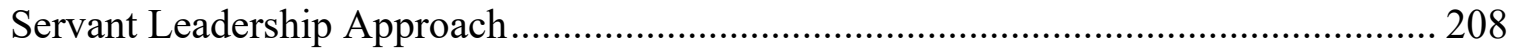

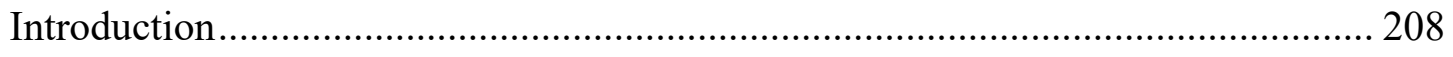

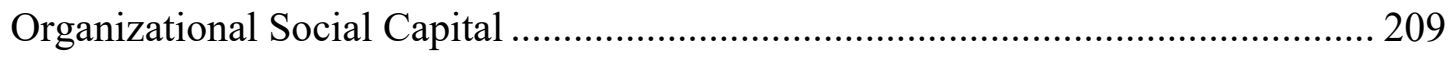

Role of Leadership in Fostering Organizational Social Capital ............................ 211

Theory and Hypothesis Development............................................................. 213 


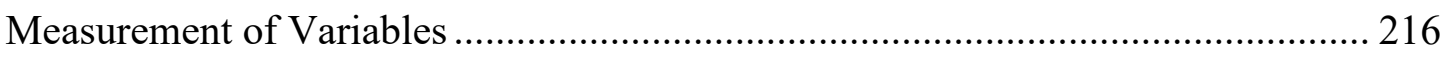

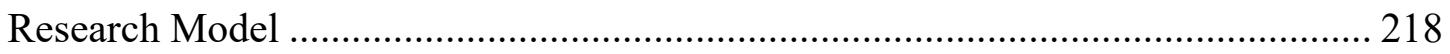

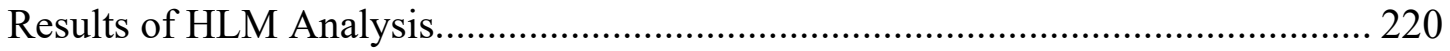

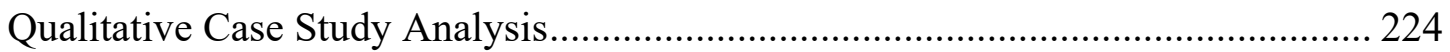

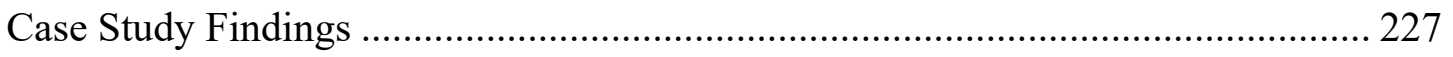

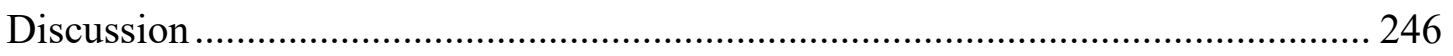

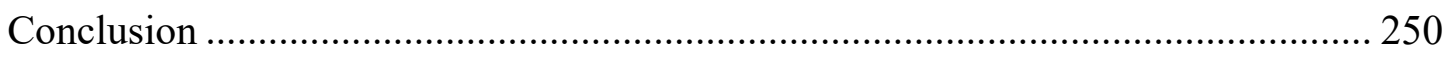

CHAPTER 6: Why, How, and What of Servant Leadership in Public Administration:

Lessons for Theory and Practice.............................................................................. 252

Individual Attributes of Servant Leadership ........................................................... 253

Organizational Attributes of Servant Leadership ……………………………...... 254

Quantitative vs Qualitative Findings of Servant Leadership Behavior .................... 256

Significance of Servant Leadership for Public Administration .................................. 257

Servant Leadership Framework for Local Governments: A Proposal...................... 266

Implications for Theory and Practice.................................................................. 270

Strengths, Limitations, and Directions for Future Research................................... 272

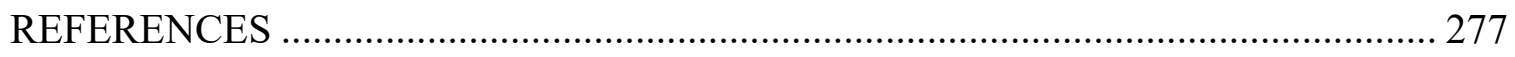

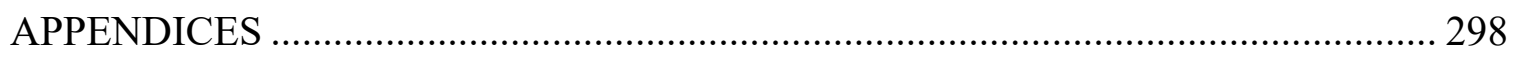

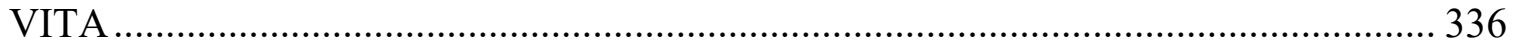




\section{LIST OF TABLES}

TABLE

PAGE

Table 1. Major Themes in Servant Leadership Research ............................................. 7

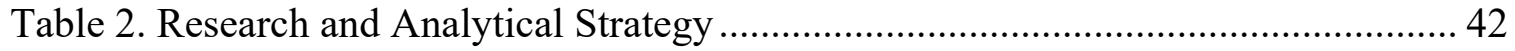

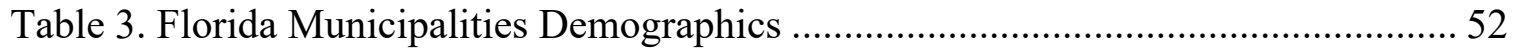

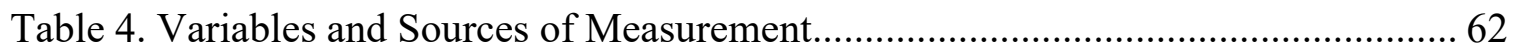

Table 5. Online Survey Score of Servant Leadership for the Selected Case Studies ....... 68

Table 6. Interview Sample Characteristic at County A, B, and Village C .................... 71

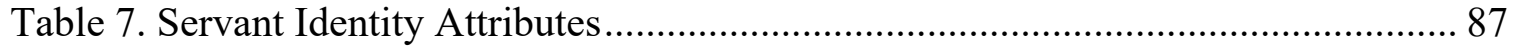

Table 8. Psychological Underpinnings of Moral Potency .......................................... 90

Table 9. Means, Standard Deviation, and Correlations Among the Variables ................. 97

Table 10. Hierarchical Linear Modelling Results .................................................... 102

Table 11. Individual Attributes (Servant Identity, Moral Potency) of Servant

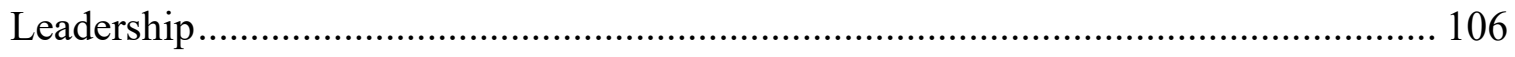

Table 12. Means, Standard Deviation, and Correlations Among the Variables ............. 149

Table 13. Servant Leadership and Co-Production: Results of HLM Analysis ............... 153

Table 14: Mediation Analysis: Effect of Service Climate on Co-Production ................ 154

Table 15: Connecting Servant Leadership and Co-Production................................... 159

Table 16: Co-production Scenarios and the Phases of Service Cycle ........................... 194

Table 17. Means, Standard Deviation, and Correlations Among the Variables ............. 220 
Table 18. Hierarchical Linear Modelling Results: Servant Leadership and

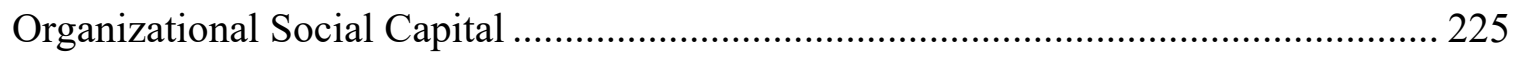

Table 19. Connecting Servant Leadership and Organizational Social Capital............... 228 


\section{LIST OF FIGURES}

FIGURE

PAGE

Figure 1. Number of Publications on Servant Leadership ............................................. 5

Figure 2: Comparison of servant leadership with other leadership styles in public administration.

Figure 3.Local Government Leadership Challenges ............................................... 29

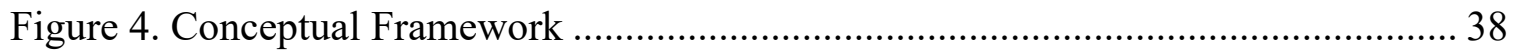

Figure 5. Counties in the State of Florida ............................................................. 51

Figure 6. Breakdown of Florida's Municipalities by Population ................................. 52

Figure 7: Special Districts in the State of Florida...................................................... 54

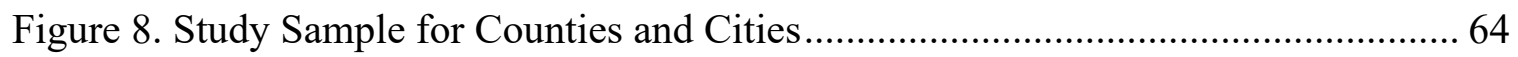

Figure 9. Case Study Data Collection Protocol ........................................................... 70

Figure 10. Job Positions Held by Interviewees........................................................... 72

Figure 11. County A’s Organizational Chart. Retrieved from Website. ......................... 74

Figure 12. County B's Organization Chart. Retrieved from Website............................ 76

Figure 13. Village C's Organizational Chart. Retrieved from the Website..................... 78

Figure 14. Confirmatory Factor Analysis for Servant Leadership Behavior (SLB) ........ 99

Figure 15. Confirmatory Factor Analysis for Moral Potency(MPC) and Servant

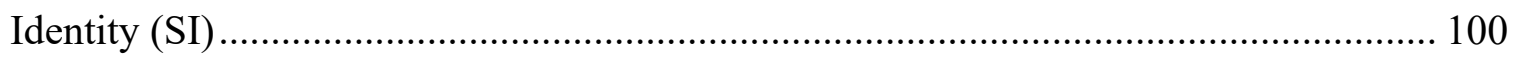

Figure 16. Word Cloud for Servant Identity-Moral Potency-Servant Leadership ........ 106 
Figure 17. Model Connecting Servant Identity and Moral Potency with Servant

Leadership Behavior. 130

Figure 18: Confirmatory Factor Analysis for Selected Variables 151

Figure 19. Word Frequency Cloud of Qualitative Interviews 158

Figure 20. Executive Dashboard of County A's Citizen Engagement, Oct 2018_-Jan 2019 178

Figure 21: Executive Dashboard of County A's Neighborhood Relations, Oct 2018 - Jan 2019 187

Figure 22: Strategies Objectives for Building Community Prosperity at County A ...... 196

Figure 23. Impact of Servant Leadership on Co-Production of Public Services 202

Figure 24. Word Cloud for Servant Leadership and Organizational Social Capital ...... 227

Figure 25. County A’s Community Prosperity Vision Triangle 242

Figure 26. County A’s Five Pillars of Community Prosperity 244

Figure 27: Impact of Servant Leadership on Organizational Social Capital 249

Figure 28. Servant Leadership in New Public Service 266

Figure 29. Servant Leadership Framework for Local Governments 267 


\section{ABBREVIATIONS AND ACRONYMS}

CFA

Confirmatory Factor Analysis

COPR

Co-Production

DoVA

Department of Veteran Affairs

FAC

Florida Association of Counties

FCCMA

Florida City-County Management Association

HLM

Hierarchical Linear Modelling

IAS

Indian Administrative Service

ICC

Intraclass Co-relations

ICMA

International City-County Management Association

IRB

Institutional Review Board

ISB

Indian School of Business

MAR

Missing at Random

MPC

Moral Potency

NPM

New Public Management

NPS

New Public Service

OCB

Organizational Citizenship Behavior 
OSC

SCI

SCL

SI

SIT

SL

SLB

UNDP

VIF
Organizational Social Capital

Science Citation Index

Service Climate

Servant Identity

Social Identity Theory

Servant Leadership

Servant Leadership Behavior

United Nations Development Program

Variance Inflation Factor 


\section{CHAPTER 1: \\ Servant Leadership in Public Administration: \\ Extant Literature and Future Directions}

\section{Introduction}

Robert Greenleaf (1970) originally outlined the basic traits of servant leadership. He argued that great leaders are driven by a natural feeling to serve first which manifests into a conscious desire to lead. The servant leadership style emphasizes internalizing ethical behavior, along with empathy and service orientation in creating value for the community which is critical in public administration. Although over five decades have passed since Greenleaf introduced the concept, scholarly interest in servant leadership has only recently emerged over the last decade. While the servant leadership concept has gained much interest among business management scholars, it has received very little attention in public administration.

This dissertation investigates the role of servant leadership in public administration. Specifically, the dissertation seeks to understand how leadership at the local government level can transcend the narrow political and organizational interests and holistically serve the community. In this, the study focuses on examining the individual and organizational level attributes of servant leadership behavior. The servant leadership theory emphasizes the development of service-oriented leaders with high integrity who can empower their employees to serve in the interest and well-being of the community. There is a need for such an inclusive leadership approach for public administration in the 21 st century.

This dissertation research is motivated by how the traditional models of leadership like the transformational, transactional, ethical, or collaborative styles are 
incomplete in public administration. While noble in their intent, these leadership styles centrally focus on promoting organizational goals, productivity, and efficiency. The local community stands out like a sore thumb, which is included only as an after-thought when problems arise. Unlike a transformational, transactional, or an ethical leader, a servant leader prioritizes the needs of the followers and the community above personal interests. Admittedly, collaborative leadership incorporates other external organizational actors through partnerships. Yet, even such partnerships are emblematic of how they are reactive solutions for problems arising in the community. Servant leaders put the community first as forethought and not as an after-thought.

This study focuses on investigating the servant leadership model in the local governments. Local democratic governance has been historically the hallmark of the American political economy. Municipal public administrators are the closest to their constituencies who need to listen and respond to the needs of citizens. The leaders need to serve the public ethically while keeping up the values of public service (Denhardt \& Denhardt, 2000; Nalbandian, O’Neill Jr., Wilkes, \& Kaufman, 2013; Hart, 1984; Rohr, 1989; Cooper, 1982; Svarra, 1987). The servant leadership approach offers good potential to achieve these goals. It has a multi-stakeholder focus on serving the employees, communities, and society as a whole by enhancing trust. It integrates the practice of ethics and instilling a serving culture in public service.

Florida is the empirical base for this study. The state offers several reasons for empirical research. It ranks the third largest in population behind California and Texas. It is one of the fastest-growing states in the United States in recent decades. It is politically a swing state, with very mixed ideological stances. Local governments are quite varied in 
their structure and have to contend with a range of ideologies and political leanings across the state. Florida thus allows the scope to explore a diversity of leadership skills and different levels of professionalism among county and city managers.

This chapter provides an overview of the literature on servant leadership in general and in public administration by comparing servant leadership with other widely studied approaches such as transformational, ethical, and collaborative. It situates the servant leadership in contrasting debates of new public service (NPS) and new public management (NPM). In this, servant leadership offers a comprehensive and inclusive approach in the context of U.S. local governments. With these arguments, this chapter underscores why an examination of servant leadership in local governments is warranted. It establishes the foundation for the empirical examination of servant leadership in local governments in the rest of the dissertation.

This introductory chapter is arranged as follows. The next section traces the evolution of the servant leadership concept. The subsequent sections highlight why public administration scholars should pay attention to servant leadership and compares servant leadership with other traditional leadership styles considered in public administration. After this, the servant leadership approach is located within the current theoretical debates of governance. The penultimate section considers how servant leadership holds an inclusive approach for local democratic governance. Finally, the chapter concludes with a summary roadmap of the dissertation.

\section{Evolution of Servant Leadership}

Servant leadership was first used by Robert Greenleaf in 1970 while he was an executive at AT\&T. He originally outlined the basic traits of servant leadership to guide 
business practitioners. He lectured in many business schools on the need and importance of servant leadership approach. Greenleaf created a Center for Applied Ethics, which has since evolved to be now known as the Greenleaf Center for Servant Leadership. The Greenleaf Center is an international nonprofit organization whose mission is "to advance the awareness, understanding, and practice of servant leadership by individuals and the organizations."

Greenleaf coined the phrase "servant-leader" in a landmark essay called "The Servant as Leader" in 1970, which also marked the launch of the modern servant leadership movement. He had then written a series of essays and books outlining how to become a servant leader, the role of trustees and institutions in servant leadership, and the power of servant leadership (Greenleaf, 1977). It must be emphasized that servant leadership has theological parallels, and Greenleaf's servant motif has been critiqued on moral, metaphysical, and biblical grounds. This dissertation takes the secular application of Greenleaf's approach. Although such an application traces its modern origins to Greenleaf's writings, there has been a significant evolution in the scholarly literature of servant leadership since then.

In the past decade, the literature on servant leadership has grown significantly. A simple Google search of books with "servant leader" in the title revealed over 259,000 books, most of which were published since 2008. Figure 1 shows the number of publications on Servant Leadership gleaned from the Web of Science (Core Collection), which is a database of all journals indexed in SCI. 


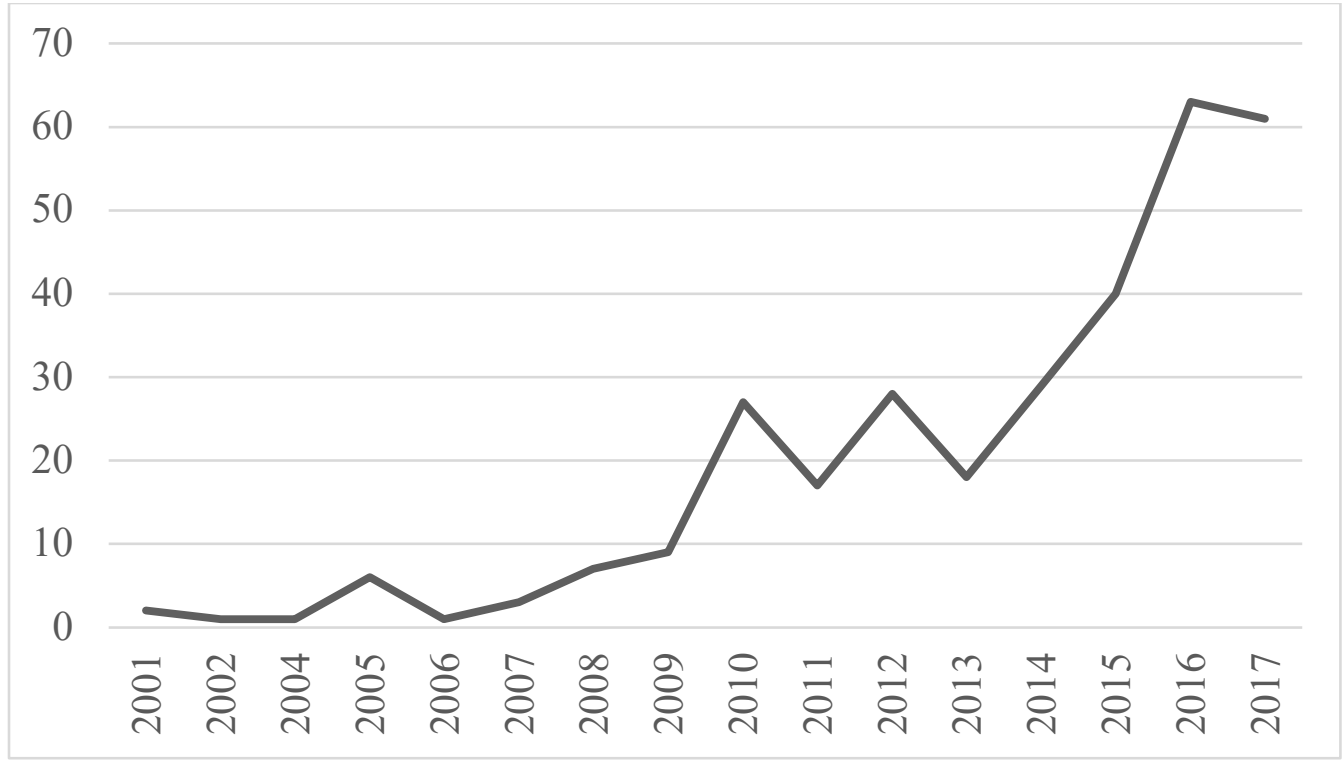

Figure 1. Number of Publications on Servant Leadership Source: Based on data obtained from Web of Science (Core Collection) with "Servant Leadership" in Topic Search (limited to articles and book chapters)

As the figure shows, the number of publications has surged in the last decade. Nearly $90 \%$ of the articles have been published in 2010 or later. Two journals squarely focusing on servant leadership have also emerged: the annual International Journal of Servant-Leadership started in 2012 (published by the State University of New York Press) and the bi-annual Servant Leadership: Theory \& Practice started in 2014 (openaccess journal, published by the College of Business at Columbus State University). Despite the broad growth and interest in the servant leadership approach, it is a curiosity that public administration has paid only lip-service to the concept. As outlined later, there is hardly any research published in leading public administration journals or textbooks about the concept. My dissertation contributes to this emerging research on servant leadership from a public administration perspective. 
According to Greenleaf (1977), a servant leader's ideology is to be a 'servant first', which is fundamentally different from the one who wants to be a 'leader first'. It begins with the natural feeling that one wants to serve, and the conscious choice to serve brings one to aspire to lead. A servant leader possesses self-awareness, is driven by the core value of serving and developing the community in all realms of life. The servant leadership approach emphasizes seven core dimensions, all of which are pertinent to the public sector. They are: putting sub-ordinates first, helping sub-ordinates grow and succeed, empowering, emotional healing, creating value for the community, behaving ethically, and conceptualizing (Liden, Wayne, Zhao, \& Henderson, 2008).

Servant leadership is significant for public administration since it centrally focuses on internalizing the ethical and service orientation of administrators in creating public value for the community. Servant leaders encourage kinship and belongingness among their followers and the larger community. They seek to empower and develop followers into servant leaders, who in turn will be ready to serve the interest of the community and the larger society. Application of servant leadership is critical in $21^{\text {st }}$ century public administration when public service values are increasingly coming under attack. Qualified public servants are needed who are reflective in their behavior and can nurture the next generation of servant leaders.

\section{Extant Literature on Servant Leadership in Public Administration}

Public administration scholars have paid scant attention to the servant leadership approach, despite its relevance to the field (Parris \& Peachy, 2013; Eva, Robin, Sendjaya, Dierendonck, \& Liden, 2019). Extant scholarship on servant leadership has mainly originated from the fields of business administration and psychology (Hu \& Liden, 2011; 
Van Dierendonck, 2011; Walumbwa, Hartnell \& Oke, 2010; Hunter et al., 2013;

Peterson, Galvin, \& Lang, 2012; Hoch, Bommer, Dulebohn, \& Wu, 2018; Walumbwa, Muchiri, Miasati, Wu, \& Miliani, 2018). Some recent studies have focused on applying the concept in the Chinese and Korean public administration agencies (Han, Kakabadse \& Kakabadse, 2010; Liu, Hu \& Cheng, 2015; Miao, Newman, Schwarz, \& Xu, 2014; Schwarz, Newman, Cooper, \& Eva, 2016; Shim, Park \& Eom, 2016). Three studies applied the servant leadership approach in U.S. National Parks Service, a suburban county in the State of Georgia, and fiscal administration in state and local governments (Chung, Chang, Kyle, \& Petrick, 2010; Reinke, 2004; Weinstein, 2013). Some recent studies have also applied servant leadership concept to the nonprofit management, schools, military, nursing, and fire or emergency services (Ebener \& O'Connell, 2010; Von Fischer \& Jong, 2017; Duffy, 2016; Reed, 2015; Russell, Broome, \& Prince, 2016). Table 1 shows the research themes on servant leadership in both business and public administration.

Table 1. Major Themes in Servant Leadership Research

\begin{tabular}{l|l}
\hline $\begin{array}{l}\text { Conceptualization and } \\
\text { Measurement }\end{array}$ & $\begin{array}{l}\text { Liden et al., 2008; Van Dierendonck, 2011; Hoch et } \\
\text { al., } 2018\end{array}$ \\
\cline { 2 - 2 } Organizational Outcomes & $\begin{array}{l}\text { Chen et al., 2015; Kwak \& Kim, 2015; Hsiao et al., } \\
2015\end{array}$ \\
\cline { 2 - 2 } Employee Outcomes & $\begin{array}{l}\text { Liden et al., 2014; Walumbwa et al., 2010; } \\
\text { Walumbwa et al., 2018 }\end{array}$ \\
\cline { 2 - 2 } $\begin{array}{l}\text { Individual Attributes } \\
\text { Contextuality of Servant } \\
\text { Leadership in West vs East }\end{array}$ & Liden et al., 2014; Beck, 2014; Hunter, et al., 2013. \\
\cline { 2 - 2 } & Han et al., (2010); Liu et al., (2015) \\
\hline
\end{tabular}


Although, the limited empirical research on servant leadership that exists in public administration holds promising findings (see Appendix A). Two studies examine the application of western servant leadership constructs in Chinese public administration. Han, Kakabadse, and Kakabadse (2010) studied how servant leadership is conceptualized in the Chinese government context as compared to western contexts. They asked government employees to provide examples of critical incidents in which they viewed they had used servant leadership. Their findings suggest that the Chinese and Western approaches are mostly similar ( $75 \%$ of the time), but there is a nuanced difference as well ( $25 \%$ of the time). Likewise, Liu et al., (2015) examine the generalizability of the western construct of servant leadership in the Chinese public sector and how it relates to public service motivation. They surveyed government leaders and their subordinates from various departments in a metropolitan city. Their study suggests that the replication of the western construct of servant leadership does not hold in the Chinese context and a culture-specific model of servant leadership is needed. These studies show how servant leadership needs to be contextually construed.

Additionally, six studies tested the impact of servant leadership on employee outcomes in Asian public organizations (4 in Chinese, 1 in Korean, 1 in Vietnamese). For instance, Miao et al., (2014) surveyed 239 full-time Chinese government employees on how servant leadership influences organizational commitment. The findings suggest that servant leadership impacts the affective and normative commitment of employees through effective trust-based mechanisms. This implies that servant leadership can enhance public trust in government organizations. Similarly, Schwarz et al., (2016) examined the impact of servant leadership on job performance using the survey data from 
249 supervisors and subordinates in a Chinese government agency. Results reveal that servant leadership drives job performance while public service motivation mediates this relationship. Tuan (2017) tested the positive impact of servant leadership on employee's organizational citizenship behavior (OCB) and knowledge sharing on the data from 572 Vietnamese government employees. Likewise, another study on the Korean local government employees found a positive impact of servant leadership on employee trust, OCB, and procedural justice (Shim et al., 2016).

However, in U.S. public organizations, only three studies appeared to date. Chung et al. (2010) explored two dimensions of servant leadership-leader trust and leader support in the U.S. National Park Service by using the data from the Federal Human Capital Survey, 2006. This study finds that servant leadership has a positive relationship with employee perceptions of procedural justice, which affects employee job satisfaction. The results establish that servant leadership is a significant predictor of justice, job satisfaction, and organizational performance. An early study published in the Global Virtue Ethics Review (Reinke, 2004), examined servant leadership constructs on a survey data of 651 employees in a County in the State of Georgia. The results show that servant leadership determines trust between employees and supervisors. Weinstein (2013) applied servant leadership in the fiscal administration of U.S. state and local governments From a theoretical standpoint, servant leadership resonates with Cooper's (1982) "Responsible Administrator" and Hart's (1984) "Honorable Bureaucrat" whereby leaders display ethical behavior, exhibit care and empathy for those who they serve, build trust among their team members, and work to serve and benefit their employees and the larger community rather than engaging in the self-serving behavior. Servant leadership theory 
synchronizes with Camila Stivers (1994) call for a "listening and a responsive bureaucrat" who is open-minded, willing to respond, but is also just, judicious, and uncorrupted. Additionally, servant leadership is coherent with the themes of Denhardt and Denhardt's (2000) New Public Service (NPS) paradigm which emphasizes serving citizens with an emphasis on public service values of equity, democracy, accountability, and citizen participation.

In addition to this, the problem of corruption is ubiquitous in government organizations. Recent scandals highlight the deteriorating values of integrity and ethics in many organizations. Small cities like Opa Locka in Florida, Bell in California, and Crystal City in Texas are just the three among many examples of corrupt leadership, which came in the national spotlight. The need for leaders who can ensure accountability and trust is paramount in governments more than anywhere else. In this, servant leadership resonates with the core of public administration by emphasizing ethical behavior and integrity which drives their commitment to the community service. Thus, the servant leadership approach offers a high value to public administrative leadership theory and praxis given its coherence with the values of public service.

\section{Servant Leadership vis a vis Other Leadership Approaches}

There has been a longstanding debate on how leadership differs between private and public sectors and which style of leadership suits the public context (Van Wart, 2013; Orazi, Turrini \& Valotti, 2013; Ospina, 2017). Orazi et al. (2013) suggest that in the past two decades public sector leadership has emerged as an autonomous domain, and there is a critical need for leadership approaches that focus on the distinctiveness of the public sector context. Vogel and Masal (2015) argue that public administration leadership 
should emphasize its distinctiveness by stressing the importance of 'public' over 'administrative' leadership. Likewise, Ospina (2017) argued for attention to relational and collective models of leadership in the public sector. Althaus (2016) posits that 'public service' is at the heart of public administration leadership and is different from the private sector. Van Wart (2013) noted that the public manager is an active creator of public value by conserving and facilitating the democratic, participatory, and inclusive processes. Nalbandian et al. (2013) argued:

the most prominent challenge for contemporary leadership in local government is connecting what is 'politically acceptable' and 'administratively sustainable' and the county and city manager must engage with both community partners and elected officials to facilitate the community and enable democracy - professionals help build community and support democratic values. (p. 567)

The extant literature on public administration leadership has principally focused on studying transactional, transformational, ethical, and collaborative leadership approaches (Bryson \& Crosby, 2006; Wright, Pandey \& Moynihan, 2012; Hassan, Wright, and Yukl, 2014; Crosby \& Bryson, 2010; Van Wart, 2013; Moynihan, Pandey \& Wright, 2013, Mastracci, 2017; Lu \& Guy, 2014). Transactional leaders provide a clear path to the followers by helping them correct operational ambiguity arising due to lack of instructions and unclear job responsibilities (Bass, 1990; House, 1996). Transformational leaders communicate goals by listening and minimizing political constraints to bring about reinvention, innovation, and change (Moynihan, Wright, \& Pandey, 2012; Trottier, Van Wart \& Wang, 2008). Ethical leaders demonstrate normatively appropriate conduct 
through personal actions and promote ethical conduct among followers by two-way communication and decision making (Brown, Trevino, and Harrison, 2005; Hassan et al, 2014). Collaborative leaders focus on mutual learning, power-sharing, and cooperative problem-solving to build stronger networks to enhance the common good (Crosby \& Bryson, 2010; Morse, 2010). See Figure 2 for a comparison of transformational, ethical, collaborative, and servant leadership in public administration.

While each leadership style is distinct and appropriate for specific situations, they do not take an integrated approach to the fundamental values of ethical and serviceorientation in 'public service' profession. They are more related to enhancing the internal organizational performance and to obtain alignment between the leader and the followers. They miss the community service orientation, which is critical to the public sector.

\begin{tabular}{|c|c|}
\hline $\begin{array}{c}\text { Transformational } \\
\begin{array}{c}\text { Focus on organizational goals, } \\
\text { sometimes can be narcissistic, } \\
\text { manipulative, abusive to followers }\end{array}\end{array}$ & $\begin{array}{c}\text { Collaborative } \\
\text { Create systems and processes to } \\
\text { facilitate cross-sector collaboration, } \\
\text { service is not the main concern. }\end{array}$ \\
$\begin{array}{c}\text { Leadership in } \\
\text { Public } \\
\text { Administration }\end{array}$ & $\begin{array}{c}\text { Servant } \\
\text { Ethical }\end{array}$ \\
$\begin{array}{c}\text { Promote normative ethical } \\
\text { behavior, what should be done, } \\
\text { follow rule of law, code of conduct }\end{array}$ & $\begin{array}{c}\text { Follower leadership development, } \\
\text { ability to take moral action in times } \\
\text { of adversity, empathy, healing, care, } \\
\text { serving the community at all times }\end{array}$ \\
\hline
\end{tabular}

Figure 2: Comparison of servant leadership with other leadership styles in public administration. 
Transformational leadership has come under much criticism lately for such a narrow focus on the internal agency (Stone, Russell, \& Patterson, 2004; Smith, Montagno \& Kuzmenko, 2004; Parolini, Patterson, \& Winston, 2009; Sendjaya, 2005).

Transformational leaders focus on developing followers to achieve organizational goals. However, they often run into the problem of narcissism and egotistical behaviors focused on maximizing personal goals and gaining short term profits. This ultimately holds disastrous consequences for the long-term success of the organization and employee well-being (Giampetro-Meyer et al., 1998).

Hoch et. al (2018) compared authentic, ethical, and servant leadership with transformational leadership. They found a strong correlation between the authentic, ethical, and transformational but low correlation between servant and transformational leadership. Transformational leadership arguably lacks the explicit ethical and service dimension. Transformational leaders can also become self-serving, unethical, and abusive to followers due to the narrow attention to ambition and achievement (Conger \& Kanungo, 1988). While servant leaders desire to serve the followers and prepare the followers to serve as well, transformational leaders desire to lead and inspire the followers to perform to fulfill personal as well as organizational goals (Barbuto \& Wheeler, 2006). Hoch et. al (2018) argue that the servant leadership approach shows "promise as an inclusive approach and is capable of helping leadership researchers and practitioners better explain a wide range of outcomes" (p. 502).

Servant leadership encapsulates the characteristics of humility, empathy, and interpersonal engagement, none of which are explicit to the transformational leadership approach. A good anecdotal example is Eric Shinseki, a transformational leader who was 
highly successful in the Military but was a failure in the Department of Veteran Affairs (DoVA) (Van Wart, 2015). Shinseki's command and control style leadership could not fix the internal culture of the department, resulting in low morale and corruption.

Ethical leadership offers advantages over the transformational and transactional approaches as it is morally situated. Leaders' actions are viewed through an ethical lens for their appropriateness. The leadership approach has a directive and normative focus on ethical behavior. However, ethical leadership is also distinctive from the consequential aspect of servant leadership towards the followers and the community. Ethical leadership focuses on how things should be done in the organizations within the bounds of the rule of law and norms of the organization. Unlike that, servant leadership focuses on how followers want to do things and whether they can do so (Van Dierendonck, 2011).

Servant leadership is arguably a more holistic approach with ethics as the core dimension while serving others. A servant leader possesses self-awareness and is driven by the core value of serving and developing the community in all realms of life. The personal identity of a servant leader is shaped by selflessness, empathy, and altruism to serve others. Servant leaders instill service-oriented ethical behavior among their followers. Apart from service to followers and the community, servant leaders act with honesty and integrity. Servant leadership is pertinent to the public sector since it centrally focuses on internalizing the ethical and service orientation of administrators in creating public value for the community.

The distinctiveness of servant leadership with the transformational, ethical, and collaborative approaches is further explored below. The comparison is useful because leadership in public administration has traditionally focused on these three approaches. It 
also shed light on the coherence of servant leadership with the New Public Service paradigm and its distinctiveness with Public Service Motivation.

\section{Transformational Vs. Servant Leadership}

Transformational leadership is the most researched theory compared to other theories of leadership in the past three decades. According to Bass and Barnard (1985), transformational leadership is the ability to achieve a follower's performance beyond ordinary limits. Transformational leaders engage in the four I's of behavior: inspirational motivation, intellectual stimulation, idealized influence, and individualized consideration. Bass (2000) draws several parallels of servant leadership with transformational leadership including trust, credibility, and influence. However, servant leadership has stronger effects in setting the needs of others with the highest priority beyond the transformational leadership. Likewise, Stone, Russel, and Patterson (2004) noted that the main difference between transformational and servant leaders is their foci.

A servant leader's focus is on the follower's well-being, and the transformational leader's focus is on the organizational goals and objectives. Hoch et. al (2018) tested the correlations between the moral leadership forms namely ethical, authentic, and servant leadership with transformational leadership. Their analysis suggests that both ethical (.70) and authentic leadership measures (.75) have a high correlation with transformational leadership. While the servant leadership's correlation was low (.52), which points toward an empirical distinction between the two. Therefore, ethical and authentic leadership show significant conceptual similarity with transformational leadership. In contrast, the servant leadership approach seems to be significantly different from transformational leadership both conceptually and also empirically. 
Considering the different foci of transformational and servant leadership, Choudhary, Akhtar, and Zaheer (2013) compared the effect of servant and transformational leadership on organizational learning, and performance. They found that transformational leadership may be more suitable for corporate managers since it has a higher estimated effect on organizational learning and performance in comparison to servant leadership. Therefore, transformational leadership is highly suitable for-profit making organizations rather than public service organizations.

\section{Ethical Vs. Servant Leadership}

Ethical leadership is focused on compliance with normative standards. Ethical leadership is defined as "the demonstration of normatively appropriate conduct through personal actions and interpersonal relationship, and the promotion of such conduct to followers through two-way communication, reinforcement and decision making" (Brown et al., 2005, p.120). Ethical leaders reinforce the compliance of rules, norms, and procedures in the organization consistent with their moral manager disposition. Ethical leaders, therefore, sometimes rely on rewards and punishments to hold the employees accountable for the organizational values and standards. Compliance with normative standards of organization in ethical leadership is measured by the item "my manager disciplines employees who violate ethical standards." In contrast to ethical leadership, servant leadership focuses on maximizing the benefit of multiple stakeholders. Servant Leadership is defined as:

the servant leader is servant first.... the difference manifests itself in the care taken...to make sure that other people's highest priority needs are being served...do those served, grow as persons? Do they, while being 
served, become healthier, wiser, freer, more autonomous, more likely

themselves to become servants? And what is the effect on the least

privileged in society? Will they benefit or at least not be further

deprived?" (Greenleaf, 1970, p.27).

The servant leadership concept focuses on those being served. For example, servant leadership as a practice places the interests of those being led over the interest of the leader (Laub, 1999, p.23); it is a style in which the leader recognizes his or her moral responsibility to the success of their followers, organization, and the community (Ehrhart, 2004). Greenleaf's definition of servant leadership and the later studies are centered on the outcomes that are achieved for the stakeholders (employees, organization, community). The most accepted theorization of servant leadership (Liden et. al, 2008; Ehrhart, 2004) is also similar in its focus on the outcomes, which is highlighted in its seven dimensions: emotional healing, creating value for the community, empowering others, behaving ethically, putting others first, helping others grow and succeed, and conceptual skills.

In addition to providing outcomes to the many stakeholders in the process, servant leadership is similar to ethical leadership in modeling moral/ethical behavior. For example, ethical leadership measures ethical behavior by the item: "my manager sets an example of how to do the right thing the right way in terms of ethics" (Brown et al., 2005); and servant leadership similarly measures ethical behavior by the item: "my manager holds high ethical standards" (Liden et al., 2008). Both servant and ethical leadership contain moral behavior as essential in a leader's behavior; however, they are based on distinct philosophies of ethics, mainly consequentialism and deontology. 
Servant leadership originated from the observation of the leaders over time. Greenleaf observed managers in business organizations and thereby constructed the concept of servant leadership as a style that seeks the benefit of the employees, organizations, and community at all times. Greenleaf conceptualized servant leadership as a set of behaviors that are rooted in caring and concern for others' well-being resulting in not only the good of the employee and organization but the larger community as well. Recent empirical studies on servant leadership measure the service-related outcomes for the organization and customers such as service culture, service performance, customeroriented citizenship behavior, customers' value-co-creation, and customer orientation (Liden et al., 2014; Ling, Lin \& Wu, 2016; Chen, Zhu, Zhou, 2015).

Similarly, many studies also examine follower-centric outcomes such as follower's work-family balance, workplace spirituality, meaningful work, and life (Wang, Kwan, and Zhou, 2017; Williams et al., 2017). Likewise, studies focused on servant leadership outcomes for the broader community predict that servant leaders enhance employee community-centric behaviors. Besides, servant leaders' concern and empathy for others predict followers being empathetic towards patients to manage their pain, enhance community building and communality (Washington, Sutton, \& Field, 2006; Neubert et'al., 2016; Parris \& Peachy, 2013). Servant leadership's overarching focus on serving various stakeholders is founded on the philosophy of consequentialism - that individuals' behavior (right or wrong) is judged based on whether it results in the greater good of the society or not. So, the resulting consequences decide if the leader's behavior is moral or immoral (Lemoine, Hartnell, \& Leroy, 2019). 
The most prominent perspective underpinning consequentialism is utilitarianismthat is the ultimate ends achieved. To put it differently, maximizing the greatest good to the greatest number of people in the society is what has to be achieved. In the service context, utilitarianism entails providing service to the society and not only the organizational members. Servant leadership's original conception by Greenleaf is similar to consequentialism asking what the effect of leader's behavior on followers and the larger community is, and if that effect is helping the least privileged in the society?

\section{Collaborative Vs. Servant Leadership}

Cross-sector collaboration is emerging as one of the most effective solutions to solve social problems. Crosby and Bryson (2005) sketch a leadership framework for collaborative leadership. Collaborative leadership is creating a common good framework, which has four elements:

(1) Acting per the dynamics of the shared power world;

(2) Wisely designing and using forums, arena, and courts;

(3) Effectively navigating the policy change;

(4) Exercising leadership capabilities.

Essentially, collaborative leadership focuses on creating effective systems and processes which facilitate a seamless collaboration among different stakeholders to resolve complex public problems. Collaborative leadership is also similar to the stakeholder theory focused on creating processes to resolve conflicts and gain stakeholder cooperation and support. Collaborative leadership theory, therefore, is very contextspecific and is successful in certain specific projects and situations when public officials collaborate with different sectors (private, nonprofit, etc.). So, the leadership for the 
common good framework is a useful place in understanding and researching what works best, under what circumstances, and types of collaborative settings (Crosby \& Bryson, 2005, p. 201). Morse (2014) describes critical leadership competencies to facilitate collaboration, such as personal attributes like the systems thinking and sense of mutuality, skills such as strategic thinking and group facilitation, and behaviors such as stakeholder identification and strategic issue framing.

Servant leadership contrasts with the collaborative leadership by emphasizing the follower and community empowerment and well-being in all its organizational processes. Servant leaders demonstrate ethical and service orientation and manifest these nonnegotiable public service values in all their actions. While collaborative leadership is focused only on creating systems and processes which facilitate cross-sector collaboration and is applicable in when leaders seek collaboration with different parties or organizations. Servant leadership is about having a servant and a moral identity at all times as public service leaders. Servant leaders also are good at conceptual skills, which is knowing the organization, their role, and the task at hand. So that they can assist and support followers. Research suggests that supporting followers and other stakeholders, servant leaders achieve the best outcomes for the community.

Due to servant leaders' understanding of the task at hand and organizational context, they can facilitate collaboration (Parris \& Peachy, 2013; Liden et al., 2008). Some studies also suggest that servant led organizations to foster trust and procedural justice, which opens communication channels among the members within and outside the organization and these conditions enhance collaboration among interested parties (Garber, Madigan, Click, \& Fitzpatrick, 2009, Sendjaya \& Pekerti, 2010; Walumbwa et 
al., 2010; Reinke 2004; Irving \& Longbotham, 2007). Therefore, servant leadership is a comprehensive approach especially for public sector organizations as it creates a community service-oriented environment of high integrity, which empowers followers and other members of the community to create conditions for successful collaboration across organizations.

\section{Servant Leadership vs Public Service Motivation}

Servant leadership and public service motivation could appear to be similar concepts on the surface, but there are significant differences in their theoretical dispositions. Public service motivation is defined as 'an individuals' predisposition to respond to the motives primarily or uniquely grounded in the public institutions and organizations' (Peery \& Wise, 1990, p.368). The motives are primarily psychological need-based dispositions to satisfy a particular unmet need. The motives fall in three distinct categories: rational motives grounded in utility maximization, normative motives based on conforming to norms, and affective/emotional motives which are grounded in the emotive responses to social situations or contexts (Perry, 2000; Perry, 1997). The underlying psychological needs manifest four characteristics intrinsic to employees with public service motivation. They are an attraction to public policy (rational motive), commitment to the public interest and civic duty (normative motives), and compassion and self-sacrifice (emotional motives). Public service motivation is thus a type of intrinsic motivation for an individual's predisposition towards public institutions.

Unlike public service motivation, servant leadership is a leadership behavior that is manifested in the interaction between the leader and the follower towards their personal and professional growth. Servant leaders put the needs, interests, and well-being 
of others above their own (Greenleaf, 1977). As posited by social learning theory, individuals learn by observing and emulating their role models. Similarly, followers led by servant leaders emulate to become servant leaders based on an authentic and trustworthy relationship between them (Liden et al., 2014; Ehrhart, 2004). Servant leaders showcase seven types of behaviors towards the employees and the larger community: empowerment, emotional healing, putting subordinates first, helping subordinates grow and succeed, creating value for the community, conceptual skills, behaving ethically (Liden et al., 2008; Ehrhart, 2004; Barbuto Jr. \& Wheeler, 2006; Stone, Russell, \& Patterson, 2004). From this social learning perspective, servant leadership is conceptualized as:

the other-oriented leadership approach manifested through one-on-one prioritizing of follower's individual needs and interests and outward reorienting of their concern for self toward concern for others within the organization and the larger community (Eva, et al., 2019, p. 114).

Eva et al. (2019) underscore three distinct and essential features of servant leadership as the three m's: motive, mode, and mindset. As Greenleaf envisioned, servant leadership theory is founded on the concept of defining 'servant as leader' and not the 'leader as the servant.' The underlying motive is to become a servant first while taking up leadership responsibility. This is different from other leadership approaches in which leaders focus on personal ambition and agenda for the organization and not service to others. Servant leader's self-concept is rooted in seeing themselves as an altruist and a moral person which is manifested into a strong character, psychological maturity, and 
sense of self. As such, those who aspire to lead first and are not inclined to serve are unlikely to be servant leaders.

Secondly, the model of servant leadership is based on prioritizing every follower's individual needs, interests, and goals above that of the leader considering individual differences. Servant leaders engage with followers both professionally and personally and invest in understanding their background, core personality, beliefs, values, needs, and interests. This holistic understanding and engagement allow servant leaders to help and support the growth of followers. In contrast to leadership approaches which primarily focus on organizational performance, and rallying behind the profit margins, servant leadership encapsulates the notion of stewardship towards the growth of followers in uplifting and empowering them to be their better selves.

Lastly, the mindset of servant leaders is all-encompassing in engaging stakeholders both within and outside the organization. In other words, servant leaders take the role of trustees to reorient their attention from self to others' interests both within the organization and the larger community outside the organization. In the role of a trustee, servant leaders ensure the growth of all organizational resources with much emphasis on human resource development for the benefit of the larger community. Broadly, servant leadership translates to a larger focus on developing and empowering productive and prosocial catalysts who are willing and able to repair the broken social systems to make a positive difference in their community and the nation.

In all this, servant leadership differs from public service motivation in their foci. Servant leaders orient to develop others into servant leaders. They constantly engage in developing and creating leaders whose self-concept is situated in making a difference for 
the larger community. Servant leaders demonstrate exemplary leadership which is high on integrity and service orientation and are the role models for the followers within the organization which is not the case with public service motivation.

\section{Servant Leadership and Governance Debates}

Denhardt \& Denhardt (2000) argued that current challenges in public leadership and management demand a shift from new public management (NPM) philosophy (Osborne \& Gabler, 1993) to that of new public service (NPS). As an efficiency model, new public management demanded public sector leaders to function as business entrepreneurs or as transformational leaders for implementing the much-needed reforms in the public sector. NPM's aim is efficiency is to make the government performance centric. However, such a singular efficiency orientation could undermine the values of service and ethical orientation, which are distinctive to the public sector (Pollitt, 1990; Osborne \& Plastrik, 1997; Pollitt \& Bouckart, 2004).

NPM is over a two-decade-old philosophy founded on the need for change in public organizations to bring more competition and incentives to the public sector. Contrasting to the NPM, Denhardt and Denhardt (2000) introduced the NPS paradigm by arguing that NPM has undermined the fundamental values of public service as it leans towards making government entrepreneurial and business-like. They use the boat analogy of public organizations to ask a critical question: do we want to serve or steer the boat in leading the public organizations? Steering makes the leader's in charge of the boat to give it the desired direction to meet the end goal. NPM is emblematic of the steering approach. However, in that process, public administrators miss the fundamental premise of serving the public and giving back. For Denhardt and Denhardt, the core responsibility of the 
public administrator is to serve and empower the citizens. Keeping the citizens at the center, the public administrator need not steer or row the governmental boat but create a culture of serving the public with high integrity and responsiveness.

Additionally, NPM encompasses the public choice theory, which is predominantly based on the premise that the relationship between the public agencies and the citizen is like the market and the customers, and they are self-interested parties engaging in transactions similar to the marketplace. NPM undermines democratic values such as justice, representation, fairness, and participation. Scholars have even argued that NPM is dead as some of its philosophies and models led to policy disasters and there is a need for an alternative philosophy that is embedded in the values of public service. While, NPS encapsulates putting citizens at the center and public interest and service at the heart of public administration (Waldo, 1968).

NPS is founded on the three foundational traditions of public service: theories of democratic citizenship, models of community and civil society, and organizational humanism and discourse theory. The theory of democratic citizenship views the citizens as the self-interested customers, however, there is also the larger role of citizens in the public service process. Citizenship is about having a constructive role in the community which encourages the sense of belongingness and participation in serving the public interest (Sandel, 1996; King \& Stivers, 1998; Mansbridge, 1990). The models of community and civil society are entrenched in the age-old tradition of engaged community life in America and are a backbone of American democratic principles.

Scholars like Putnam (1995) and King and Stivers (1998) strengthen the idea of strong democratic traditions in America by arguing that historically, the root of American 
civility lies in the engaged citizenry in all forms of associations, groups, and governmental programs. These civic associations are fundamental to democratic governance. Local governments are even more dependent on a culture of community participation in the public service process. The traditional hierarchical, control-based, positivist approaches do not provide an adequate guide for public administration. Rather, the bureaucratic culture should be viewed through the lenses of interpretivism, critical analysis, and discourse theories (Spicer, 2001; Miller \& Fox, 1997; Harmon, 1995) which emphasize interdependence and open discourse among different stakeholders in public service delivery process.

The current trends in public administration are caught in the throes of NPM and NPS debate. Bureaucrats following the NPM mode are criticized for working like the profit-oriented private sector agencies, and not public service-oriented with selfinterested public officials compromising the values of integrity, ethics, and service. Such an approach in governments negatively affects the public service values of the public administrators, resulting in the deterioration in service quality and serving the public interest (Doig \& Wilson, 1998). In such a context, public administration in the $21^{\text {st }}$ century era indeed demands the role of public servants and leaders to act as true custodians of public service. The present times are characterized by manor changes in the social, economic, and technological environment with new challenges emerging in public organizations (Dunleavy et al., 2006). The public sector has come under intense criticism for failing to perform, but there is also a danger in losing the central tenet of government to serve the public. Denhardt and Denhardt's NPS provides a refreshing approach to reset the government values toward public service focus. 
The theory of servant leadership aligns well with NPS to enhance the public service focus of public sector organizations. Servant leadership reinforces the idea of democratic citizenship and enhances the value of community and civic engagement among public administrators. The application of the servant leadership model reinforces NPS's demand for putting the service back into public service. When the leadership challenges are abounding posing complexities in public service delivery models, servant leaders are in need. Besides, public administrators need new moral guidance in the complex world of unexpected administrative and operational challenges, continued and increased demand for resources, and the advent of IT-enabled services which is bringing forth the demand for the transparent and accountable government (O'Neill \& Nalbandian, 2018; Murphy, Rhodes, Meek \& Denyer, 2016). This spells the need for servant leaders.

Thus, in complex public management and delivery systems, the leadership behavior must be based on serving the needs of the followers and the broader community both within and outside the organization. Servant leaders centrally focus on the development and empowerment of their employees to realize their full potential. There are four aspects unique to servant leaders which can directly apply to public service organizations: demonstrating ethical behavior at all times, relying on one-on-one communication strategies to build a strong long-term relationship with employees and community, focusing on service orientation in all their actions, and serving multiple stakeholders outside the organization - the community and society as a whole. 


\section{Servant Leadership as an Inclusive Approach for Local Governments}

Local governments face three crucial executive leadership challenges (Figure 3).

First, executive leaders need to be able to work at the intersection of politics and administration and approach it as complementary to each other. They need to negotiate between the elected political leaders and the administrative processes. Second, they need to create systems and processes of collaboration within and outside the local government settings. The managers do not only need to deal with internal organizational management but also need to serve the external community at large. Third, they need to take a comprehensive approach to engage citizens during the service delivery process. Taking a holistic approach to connecting political values and administrative processes are crucial for long-term and sustainable community development.

The extant literature on leadership research in local governments is concentrated in three areas: policy leadership role of the city managers (Zhang \& Feiock, 2010; Nalbandian, 1999; Svarra 1999a 1999b; Morgan \& Watson, 1992; Svarra, 1985; Ammons \& Newell, 1989; Zhang, 2014), leadership challenges and complexities in local governments (Hassett \& Watson, 2002; O’Neill \& Nalbandian, 2018; Nalbandian, O'Neill, Wilkes, \& Kaufman, 2013), and leadership styles and competencies of local government executives (Getha-Taylor \& Morse, 2013; Orr \& Bennett, 2016; GethaTaylor, Fowles, Silvia, \& Merritt, 2015; Hanbury, Sapat \& Washington, 2004; Parry, 1999; Sullivan, Downe, Entwistle, \& Sweeting, 2006). 
County and city managers as stewards, accountable, courageous, the narrative of a public good. Role models for department heads. Constellation of political logic, community dynamics, administrative mindset.

Administrative and

professional integrity.

Implementing staff initiative which is politically

unacceptable but is an

administrative imperative.
Third-party collaboration, fixing structures of authority, effective networks of responsibility, and sources of service delivery, how non-governmental structures of authority deal with public values. knowing whose values will prevail in cross-sector

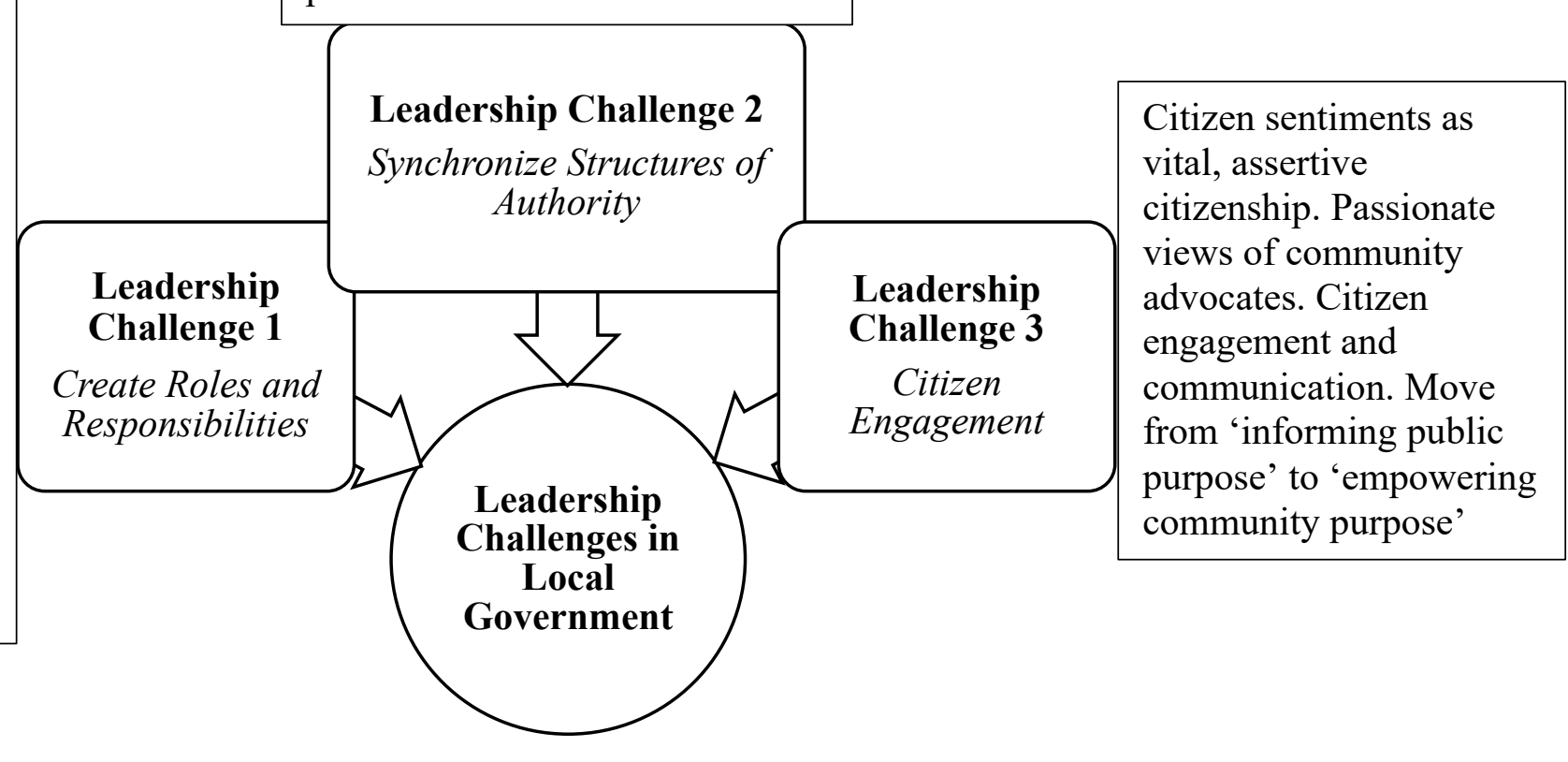

Figure 3.Local Government Leadership Challenges

Source: Nalbandian et al., 2013 
Effective leadership in a local government context is about the ability to bridge the elected political leaders, community leaders, and internal administrative processes. Few scholars have explored the leadership approaches and competencies needed for the local government administrators. O’Neill and Nalbandian (2018) suggest nine leadership characteristics needed to succeed in such a complex local government environment. They are symphonic skills, connecting the power of story, developing design literacy in all leaders, working small to achieve the larger vision, architecture for success, confronting the brutal facts but staying focused and persistent, creating spaces for innovation, being decisive, and the power of questions.

Getha-Taylor and Morse (2013) noted the increasing importance of developing collaborative leadership competencies in local government agencies. There is movement from hierarchical and 'great man' leadership theories towards facilitating collective and collaborative leadership competencies in the $21^{\text {st }}$ century. The collaborative competencies focus on developing systems thinking and sense of mutuality, strategic thinking and facilitation, stakeholder identification, and issue framing in government (Van wart, 2005; Getha-Taylor \& Morse, 2013). The collective leadership development takes place by narrative and leadership storytelling to facilitate the learning of leadership action among public administrators (Orr \& Bennett, 2016).

Likewise, Hanbury, Sapat, and Washington (2004) noted that personality type and leadership style is one of the major components of leadership effectiveness in local governments. The leaders who are fit within the context they serve are more successful than the others. In the council-manager form of cities, an introverted city manager (inwardly driven, perceptive leader, who is adaptable to change and chaos) will stay 
longer than the transformational leader (who is goal-oriented, vision-driven high achieving executive). This is consistent with the critique of new public management philosophy that radical and risk-taking entrepreneurial leaders pose a danger to democratic governance, trust, and accountability in governments.

Despite all of the above approaches, the quest for adequate leadership that takes the community needs into account has not yet been established. The community is secondary to the approaches articulated above. The community often comes across as an after-thought, an extraneous external actor that needs to be contended with. The community is not integral to the leadership approaches. Partnerships are established with nonprofits and private agencies for the teleological goal of efficiency of services, not as an inherent value in and of itself. All of the approaches are internally focused on the internal organizational aspects of public agencies. While they are noble in their approaches, they fall short in adequately accounting for the role of the community. We need a notion of the public agency that is fundamentally centered on the community itself. It is in this context that the dissertation is situated. The concept of servant leadership begins with putting the betterment of the community as a whole.

Hence, this study adds significant value to the sparse research on communityfocused leadership studies in local government agencies. It explores how servant leadership provides a comprehensive approach to county and city management. City and county managers serve as stewards of the values of governance and accountability. They act as role models for the department heads, have to stand up for employees. They need to understand the local configurations of political logic, community dynamics, and the administrative mindset. 
Servant leadership could potentially offer a compelling guide to local government administrators. They need to be nurturing (which is awaking, engaging, and developing) employees. The followers need to be engaged as whole individuals with heart, mind, and spirit and not merely the tools of performance to fulfill organizational goals (Van Dierendonck \& Patterson, 2010). This is a non-negotiable characteristic needed for county and city managers. They need to demonstrate ethical behavior and courage. They should also be able to manage the narrative of the public good. The seven dimensions of servant leadership are crucial in this respect: putting sub-ordinates first, helping subordinates grow and succeed, empowering, emotional healing, creating value for the community, behaving ethically, and conceptual skills.

The extensive focus on market oriented NPM reforms has led to a crisis of accountability and transparency in local governments. The new public service delivery models demand to reinvigorate the role of citizens in their communities beyond simply the voter or the customer (Levine \& Fisher, 1984; Denhardt \& Denhardt, 2000). City and county managers need to create stronger channels of communication and an unwavering focus on encouraging assertive citizenship as they are the closest custodians to the community needs. Servant leaders' role for doing good for the society and broader community emphasizes the pluralistic model of public service by enhancing the role of citizens in service delivery. Thus, the local government leadership role has rapidly evolved as citizens have become partners and producers of public services.

The local government environment has also been rapidly changing in the $21^{\text {st }}$ century. Warner (2010) noted that in the next decade, local government administrators will face major challenges in service delivery, finance, workforce management, and 
citizen engagement. The most complicated leadership task for county and city managers is bridging the gap between what is administratively sustainable and politically acceptable and thereby facilitating communities and enabling democracy (Nalbandian et al., 2013; Nalbandian, 1999). Similarly, Hanbury and Sapat (2004) highlight the need for creating an appropriate leadership model for the county and city managers because of their role of bridge-building between the elected council, administration, and the community. A critical factor in determining the managers' fit with the local government is their leadership style. In the above context, it is vital to identify what type of leadership style of the county and city manager is appropriate in the context of local government administration? Hence, this research investigates the application of servant leadership theory in local governments.

\section{Overview of the Dissertation}

The rest of this dissertation is organized as follows. The next chapter outlines the specific research questions and research design. It provides the conceptual framework through which the dissertation is viewed. It also elaborates on the empirical context of Florida in which the application of the servant leadership approach is examined. The study employs a mixed-methods approach, with complimentary survey and case study techniques. The survey encompassed city/county managers and their staff $(\mathrm{N}=241)$, which was then complemented with three in-depth case studies of county and city governments in Florida.

Chapter 3 is an empirical examination of servant leadership in Florida's local governments. It provides an individual-level analysis of servant leadership, drawing on social identity and moral development theories. The premise of the chapter is that we 
know a lot about the outcomes of servant leadership, but there is limited research on why some individuals behave as servant leaders and others don't. Using the empirical data on the county and city leaders in Florida, how the individual-level characteristics of servant identity and moral potency manifest servant leadership behavior are examined. This chapter has implications for servant leadership development among public administrators.

Chapter 4 is an empirical examination of whether servant leadership lends itself to co-production with the community actors. Co-production is an umbrellas concept in service delivery in which both the state actors (direct or indirect agents of government) and the lay actors (customers or citizen producers) work together in the design and delivery of public services. However, it is unclear that what kind of leadership approaches and organizational mechanisms facilitate such working relationships. In this chapter, I examine how county and city administrators who identify themselves as servant leaders create agile organizational processes, communication channels, and strategies to engage the community (nonprofits, community leaders, citizens) in the coproduction of service delivery?

Chapter 5 is an empirical examination of the influence of servant leadership on organizational social capital. Prior research has shown that servant leaders enhance employee commitment, and overall trust in organizations (Liden et al., 2014; Eva et al., 2018). Using the data from the counties and municipal governments, this chapter examines how servant leaders contribute to employee development and engagement. The premise is that servant leaders can arguably lead to a higher degree of social capital than other types of leaders. 
Chapter 6 concludes with the summary findings of the dissertation and the implications of the study. It sets directions for future research. The chapter considers the strengths and weaknesses of the servant leadership approach in comparison to the other traditional leadership approaches. 


\section{CHAPTER 2: \\ Research Questions, Framework, and Methodology}

This chapter outlines the research questions investigated in this dissertation. It provides the research design for the examination, and the conceptual framework used for the analysis. It also elaborates on the empirical context of Florida in which the application of the servant leadership approach is examined. The research questions are posed at two levels: the individual level and the organizational level. The research design incorporates a mixed-methods approach, with complimentary survey and case study techniques. The survey was conducted with county and city managers ${ }^{1}$ and their staff $\left(\mathrm{N}_{\text {city-county governments }}=241\right)$, which was then complemented with three in-depth case studies of county and city governments in Florida.

\section{Research Questions and Conceptual Framework}

To explore the role of servant leadership in local government organizations, this study aims to investigate two research questions. The first research question (RQ1) is at the individual level: What are the individual attributes of servant leadership behavior in local government agencies? This question focuses on the leaders' self-identity attributes that manifest in their servant leadership behavior. The second research question (RQ2) is related to the outcome of servant leadership at the organizational level: What are the organizational-level attributes of servant leadership in local government agencies? The empirical examination of these questions is carried out in the subsequent chapters 3,4 , and 5. Chapter 3 explores RQ1 on individual-level attributes of servant leadership in local

\footnotetext{
${ }^{1}$ City-county managers or city-county administrators is used interchangeably throughout this study. It means the appointed professional manager in a city or a county by the elected council. The city-county manager serves as the chief executive officer of the city or a county government.
} 
government: servant identity and moral potency. Chapters 4 and 5 explore RQ2 on two organizational level attributes of servant leadership in local governments: co-production of public service and organizational social capital.

\section{Individual Level Attributes}

There is scant research on individual factors that influence the manifestation of servant leadership behavior among leaders. Stemming from social identity theory, psychology scholars have argued that the individual level self-identities of being the servant first, i.e. 'servant identity' could affect the servant leadership behavior (Sun 2013). Hannah and Avolio (2010) argue that the individual's 'moral potency' is an influencing factor of the leader's moral action. Therefore, servant identity and moral potency attributes are investigated as the individual attributes of servant leadership behavior in local governments.

\section{Organizational Level Attributes}

Since the core focus of servant leadership is on employee empowerment, affective commitment, building trust, and service to the community, two organizational-level attributes are pertinent: organizational social capital and co-production. Organizational social capital refers to the characteristics of social relations internally within the public agency. It is comprised of three dimensions: structural (connections among actors), relational (trust among actors), and cognitive (shared goals and values among actors). Coproduction refers to the external community outreach of the agency in the co-production of public services. It is the collaboration between state and non-state actors (citizens) in the provision of public services. 


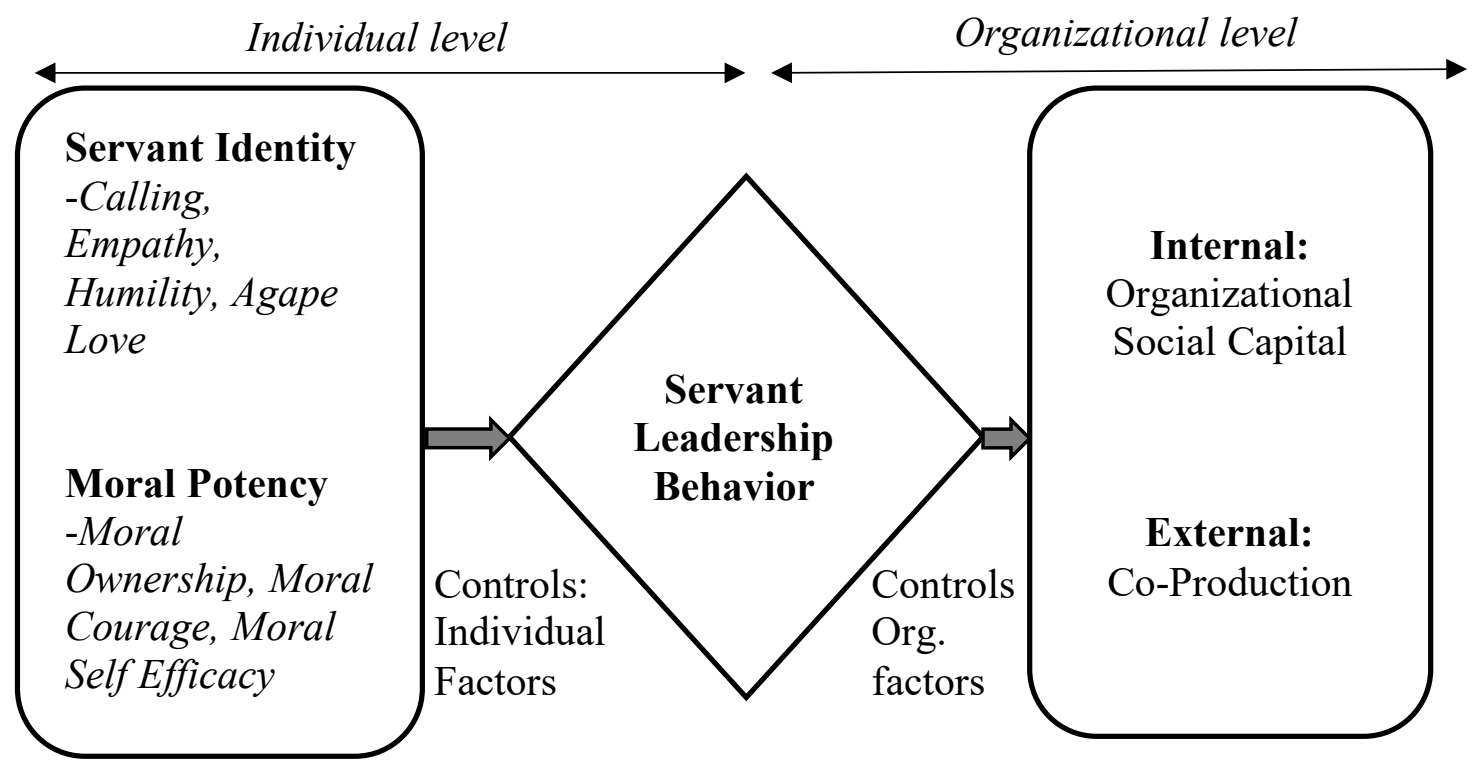

Figure 4. Conceptual Framework

Conceptual Framework

The conceptual framework is diagrammatically shown in Figure 4. The servant leadership behavior (SLB) in local government agencies is at the center of the inquiry. While the SLB is the dependent variable for the first question, it is the independent variable for the second question. Drawing on social identity literature, self-identified as well as follower perceived servant identity and moral potency attributes of the leader are hypothesized to impact SLB. Control factors include individual-level attributes such as age, gender, tenure in office. The SLB is hypothesized to influence the organization's internal social capital and external community outreach with co-production. The organizational level control factors include the type of organization. Since the SLB is usefully contrasted with other value-based leadership forms, ethical leadership will be used as control at both individual and organizational levels. 


\section{Operationalization of Variables}

Dependent and independent variables. The variables in the study are based on the two research questions: individual (RQ1) and organizational attributes (RQ2) of servant leadership in local governments. The individual attributes of servant leadership in RQ1 are servant identity and moral potency. The hypothesis is that leader's attributes of servant identity and moral potency (independent variables) will be positively related to their servant leadership behavior (dependent variable). The servant identity (SI) and moral potency (MPC) were obtained through an online survey administered to both the leaders (county and city administrators) and his directly reporting executives (e.g. department directors, deputy administrators, and assistant administrators). Servant leadership behavior (SLB) was assessed by the employees directly reporting to leaders.

In RQ2, there are two organizational attributes of servant leadership in local governments that are examined: the organizational social capital (OSC) and the coproduction of public services (COPR). Organizational Social Capital is an internal organizational attribute of the local government. It is the social capital perceived by employees in the organization. Co-Production of Public Services is an external organizational attribute, where external community members participate in public service provision. It leads to the hypothesis that local government agencies rated high on servant leadership (independent variable) will have a higher degree of organizational social capital and co-production of public services (dependent variables), which could be mediated by service climate in the organization. The servant leadership behavior is thus both a dependent variable (in RQ1) and an independent variable (in RQ2) (see Appendix C for all the variables and items included in the survey). 
This research uses a mixed-methods strategy, where the quantitative and qualitative methods are complementary for answering the questions. For the quantitative part, the variables are drawn from the online survey. Details about how the survey was administered are given in a later section. All the variables of interest were based on Likert scale responses in the survey $(1-7$, where $1=$ strongly disagree and $7=$ strongly agree, except the service climate was rated on a scale of $1-5$, where $1=$ poor, and $5=$ excellent).

Control Variables. The control variables in the study are individual characteristics of the respondents. These characteristics include education, age, gender, ethnicity, number of years of experience in local government, the number of years of experience in the current position. Additionally, ethical leadership was also added as a control variable to measure if servant leadership effects beyond ethical leadership (see Appendix C).

Within the extant servant leadership literature, there are overlaps with ethical leadership. Hence, including ethical leadership was essential to explain how it emerges different from servant leadership in the model (Lemoine et al., 2019).

\section{Research Design}

Historically, leadership study has been positivist in nature where leaders and managers can apply scientific principles to maximize organizational productivity. Taylor's (1912) principles of scientific management, for example, posited that the efficiency of a worker can be scientifically advanced through time management systems to govern the tasks. Such a positivist approach dominated American public administration in both theory and practice during the inter-war years. The premise was that scientific management would increase not only the opportunity for more work, but also the real wealth of the world, happiness, and improve workers' life. 
Studying leadership from a positivist approach poses challenges for fully conceptualizing the leadership phenomenon. Leaders are not just automatons who work singularly. They exercise considerable discretion and personal agency. The agency implies that they undertake actions in various situations. The scientific management approach does not allow for accommodating different motivations besides efficiency. Leadership study is a challenging endeavor due to its dynamic, multifaceted, and complex nature. According to J. Thomas Wren (1995):

because the issues relating to leadership cut across all types of human activity and thought, the true understanding of such a complex phenomenon requires a broadly conceived approach.

Barnard Bass (2008), a renowned leadership scholar underscores that to broaden the understanding of leadership, new paradigms combining the positivist and subjectivist approaches are needed. Using this rationale, this study undertakes the explanatory sequential mixed methods approach to answer the research questions. Explanatory sequential mixed methods design has two phases: first, the quantitative data collection and analysis; followed by a qualitative study to supplement the quantitative findings. Such a method is useful to build on quantitative findings and provide a further in-depth explanation with the qualitative studies (Stentz et al., 2012). Table 2 summarizes the research and analytical strategy used in this dissertation. 
Table 2. Research and Analytical Strategy

\begin{tabular}{|c|c|c|}
\hline Method & $\begin{array}{l}\text { Quantitative Study } \\
\text { Survey }\end{array}$ & $\begin{array}{l}\text { Qualitative Study } \\
\text { Multiple Case Studies }\end{array}$ \\
\hline Purpose & Theory testing & Theory exploration \\
\hline $\begin{array}{l}\text { Substantive } \\
\text { focus }\end{array}$ & $\begin{array}{l}\text { Effect of servant identity and } \\
\text { moral potency on servant } \\
\text { leadership behavior of county and } \\
\text { city administrators } \\
\text { Effect of servant leadership } \\
\text { behavior on organizational } \\
\text { outcomes of county and city } \\
\text { governments. }\end{array}$ & $\begin{array}{l}\text { 'How and Why' servant } \\
\text { identity and moral potency } \\
\text { attributes impact servant } \\
\text { leadership behavior among } \\
\text { county and city administrators? } \\
\text { 'How and Why' servant } \\
\text { leadership behavior impacts } \\
\text { organizational outcomes in } \\
\text { county and city governments? }\end{array}$ \\
\hline Sample & $\begin{array}{l}\text { Two levels: } \\
\text { For RQ1: Level } 1-337 \text { employee } \\
\text { responses } \\
\text { Level } 2-155 \text { organizational } \\
\text { responses } \\
\text { For RQ2: Level } 1-228 \text { employee } \\
\text { responses } \\
\text { Level } 2-101 \text { organizational } \\
\text { responses }\end{array}$ & $\begin{array}{l}50 \text { interviews, observations, } \\
\text { documents }\end{array}$ \\
\hline $\begin{array}{l}\text { Analytical } \\
\text { Method }\end{array}$ & $\begin{array}{l}\text { Multilevel regression analysis } \\
\text { Hierarchical Linear Modelling }\end{array}$ & $\begin{array}{l}\text { Content analysis, pattern } \\
\text { matching, cross-case analysis }\end{array}$ \\
\hline
\end{tabular}

From a positivist standpoint, the study employs an online survey using the Likert type scales validated in previous studies. The survey aims to explore the relationship between servant leadership and the individual and organizational attributes in local government agencies. The survey data are multilevel i.e. the employee responses nested in the county and city governments across the State of Florida. The survey data are analyzed using hierarchical linear modeling (HLM) (Molina-Azorin et al., 2019).

The survey is complemented by three explanatory case studies of the county and city agencies. The qualitative case studies aim to explain the nuances of servant 
leadership observed in instances with a high degree of such leadership. Thus, the case studies were selected based on high (over five on a scale of one to seven) servant leadership scores from the online survey. The three case studies comprised of two counties (called County A and County B) and one city (called Village C). The actual names of the counties and the city are withheld because of confidentiality reasons prescribed by the Institutional Review Board (IRB).

Explanatory case studies seek to explain the 'how or why' of a phenomenon on which the researcher does not have any control. Such case studies are conducive for: 1) descriptive data collection for an intensive examination of a phenomenon, 2) filling the gaps in theories, and 3) explaining the rarity as well as the complexity of a phenomenon (Fischer \& Ziviani, 2004; Boodhoo \& Purmessur, 2009). Using the multiple-case study design assures triangulation by studying the same phenomenon in three different organizations. Also, multiple case studies offer comparisons to find similarities or differences across the cases to explain broader mechanisms and theories. The qualitative data were analyzed using the Nvivo 12 software. The analysis covered content/thematic analysis, explanation building, pattern matching, and cross-case analysis (Yin, 2018).

\section{Unit of Analysis}

Since RQ1 measures the individual-level attributes of servant leadership in local government agencies, the unit of analysis is the individual municipal or the city-county managers and employees. For RQ2, the unit of analysis is the municipal or the county government agency, as the focus of the measurement is the organizational level attributes of the servant leadership in municipal or the county government agencies. The State of Florida's local governments forms the empirical basis for the study. 


\section{The Empirical Context: State of Florida's Local Governments}

Local governments in the State of Florida form a good empirical basis for the study. For this dissertation, the county and city governments in the state are considered as local governments. Special districts and other forms of local governments are not included in this study. This is because the county and the city governments are generalpurpose governments with a broad range of responsibilities across the board. In Florida, such general-purpose local governments are called a city, county, town, or village. The special districts have a much narrower scope for operations (generally single or multipurpose). Such special districts include boroughs and school districts. [The Florida Municipal Officials Manual (https://tinyurl.com/y9uqp3wx) provides a good overview of the different local governments in the state.]

Local governments are generally organized in two ways: Council-Manager and Mayor-Council. In the first arrangement, voters elect the council, including the mayor (chairman of the council), which, in turn, appoints the professional city or county manager. In the second arrangement, the elected mayor and council are responsible for the affairs of the government; they may not have a professional manager per se. Since the focus of the study is the leadership of appointed professional managers (i.e. public administrators), this study is focused on the Council-Manager form of local governments. A large majority of cities and counties have such type of government in Florida.

The Council-Manager form is the system of local government that combines the strong political leadership of elected officials in the form of a council or other governing body, with the strong managerial experience of the professional local government manager. The form establishes a representative system where all legislative decisions are 
vested with the elected council and where the manager oversees the day-to-day government affairs and the delivery of public services. The power to execute routine public service delivery functions are under the control of the appointed manager, referred to as the city or county manager. The administrative structure of the local governments is further explored later on in this chapter.

\section{Historical Context of Local Governments in the State of Florida}

A brief history of the State of Florida is required to understand the present configuration of the local governments in the state. Historically, Florida was a Spanish colony, discovered and named by the Spanish explorer Juan Ponce de León in 1513. England occupied Florida in 1673. The English divided the Florida peninsula into two distinct colonies East and West Florida (Allman, 2013). In contrast to Spanish colonizers, the British attempted to develop Florida as a trading platform and to increase Florida's population especially by recruiting Greek, Italian, and Minorcans. In 1783, Florida was restored to Spain from Britain, in 1821, the Spanish Crown yielded Florida to the United States of America, understanding that they would have been unable to defend against an American invasion, especially considering that Spanish South American colonies were demanding independence from their Motherland. The Territory of Florida was subsequently annexed to the United States of America and General Andrew Jackson became the first Governor of the new Territory.

The structure of the government in the Territory of Florida was very basic. In Florida, a three-year governor was appointed by the President of the United States of America. A small portion of Federal money was allocated to Florida. People elected a Territorial Council with limited powers over the Territorial Militia. In time, Florida 
became very similar to the other Southern States. Slavery became a major share of Florida's economy and many residents from Georgia and Alabama moved to Northern and Central Florida to start cotton plantations. Another important characteristic of Florida was the Seminole Wars which happened from 1816 to 1858 . Only a few Seminoles remained after the Indian Removal Act of 1830. Florida became the 27th State of the United States of America in 1845.

Florida seceded joined the Confederate States of America in 1861 after seceding from the Union. The highest percentage of soldiers in the Confederacy came from Florida, and it also suffered the highest percentage of casualties among the Confederate States. Most of the battles between the Union and the Confederacy occurred in the northern part. However, a few major battles occurred in the State of Florida as well. Republican Party's aims for Florida were twofold during the Reconstruction. The first was to guarantee political and economic power. And, the second aim was to transform into a more diversified economy from an agriculture-based economy.

In 1876, towards the end of the Reconstruction, southern Democrats regained both political and economic power. The Democrats in power took several steps to make Florida a conservative, agrarian, Southern State. The 'pig laws' were passed, and the Black-American voting rights were limited. By the end of the 19th century, Florida emerged as a significant regional economic power with the advent of the railroad. Entrepreneurs such as William D. Chipley (Panhandle); Henry B. Plant (Gulf Coast); and Henry F. Flagler (Atlantic Coast) were the pioneers of railroad construction promoting Florida as a newest tourist destination. These entrepreneurs were instrumental in 
developing not only the railroad system, but also hotels, roads, and villages. The railroad expansion facilitated the growth of agricultural trade and sugar plantations.

The 1920s was a time for the Great Florida Land Boom. Many people from different parts of America moved to Florida. This movement occurred either permanently to earn a living or temporarily for tourism. Post-world World War - I was a growth era for Florida. It became an integral part of the Union from being a peripheral territorial appendage in the South. As the population grew in Florida, the post-war economic growth spurred agricultural and urban growth across the state. A state-wide project was implemented by the conservative government in Florida to improve its transportation system and public services to favor the boom of visitors and the growing population during the 1920 s and onwards.

The conservatives passed a bill in 1924 in Florida that forbids the collection of a state income and inheritance tax. Florida emerged as among one of the early states to have no state tax. Since then, Florida's fiscal policy has shaped the state's economic infrastructure, boosting the state's population growth. During that time the real estate development boomed in Florida. Although Florida's economy was hit badly by the real estate bubble burst in 1926 and the Great Depression of 1929. Florida's new deal policy shaped the working environment by lowering the unemployment rate, increasing salaries. Florida played a significant role in the military and civil aviation system in World War II. Four decades after the war, Florida experienced record population and economic growth.

In the 1950s, Florida emerged as an urban society with tourism surpassing agriculture as Florida's major industry. The post-World War II infrastructure investment shifted from railroads to highways. Statewide highway projects, such as the Sunshine 
Skyway Bridge and the Florida Turnpike diminished the role of the railroad industry. Major social changes happened in Florida in the 1950s. The civil rights movement was a major event in transforming the lives of Black Americans. It was also a time for a political change in Florida with the first Republican Governor being elected since the Reconstruction Era. In 1968, a new constitution was framed to transfer the powers and responsibilities in the delivery of public services and public programs to counties and cities. There was a major power shift in the State Legislature from rural to urban areas.

During the 1970s and after, rapid growth in population occurred in Florida, making it a premier tourist destination. Walt Disney opened the first theme park in Orlando, setting the basis for a new tourist boom. However, in the 1980s, many urban problems such as poverty, crime, drugs started to emerge in Florida. The $21^{\text {st }}$ century Florida is faced with new challenges as well as opportunities. Today's Florida, although leans on its old economic roots of tourism and agriculture but has a more balanced and diverse economic portfolio. Florida is a continuously transforming and vibrant state, however not without its problems - like any other state or country.

\section{The rationale for the selecting State of Florida as a Study Context}

The State of Florida provides an ideal empirical basis for this dissertation. There are three important reasons to choose this state: geographical and socio-economic, political, and administrative. First, the State of Florida ranks third in the United States in population behind California and Texas. Florida's population surged past New York in the last decade. It has experienced a rapid and significant increase in its population, doubling from 9.75 million in 1980 to 18.8 million in 2010. Population increase, along with other factors (i.e., lack of state income tax and generally low taxes, lucrative 
homestead exemptions, and cheap land for suburban development) has made Florida one of the fastest-growing states especially in the service and real estate sectors of the economy (Kolo \& Watson, 1992). Florida's large size is an important consideration since it then offers a large sample of local governments to study. The large population size also enhances the likelihood of the citizens putting more demand on local governments and making them more competitive. The citizens are also likely to be more engaged in the coproduction of public services.

Politically, Florida is considered a swing state, although it still leans Republican. In the last five Presidential elections, Florida electoral votes have been assigned three times to a Democratic candidate (1996, 2008, and 2012) and two times to a Republican candidate (2000 and 2004), making Florida one of the ultimate battleground states. Political and ideological variation within Florida is also an interesting factor to be taken into consideration. South Florida and metropolitan areas are historically more liberalsupporting Democratic candidates - and Northern Florida and more rural areas tend to be conservative supporting Republican candidates (Griset, 2002).

Administratively, the State of Florida has 67 counties, 412 municipal governments, and overlapping special districts that provide services (Wu \& Hendrick, 2009). The counties are both urban and rural of varying sizes. The local government characteristics vary widely between the North, Central, and South Florida. North Florida local governments are typically small as compared to the Central and the Southern regions. Professional managers also have different roles among the local governments. Thus, studying the State of Florida allows exploring the diversity of leadership skills and 
professionalism among public managers and civil servants based on the needs of the variety and the forms of local governments.

\section{Types of Local Governments in the State of Florida}

Florida's state government provides statewide regulations for governing the state. Tax laws are made at the state legislature level. Most other decisions are, however, made by the local governments. Local governments make decisions on issues related to schools, parks, libraries, and police protection. These decisions are closer to the people than the state or federal government and are vital to the people who live in those communities. Over the years, the population growth of the state and advent of information technology made the role of local governments challenging on many fronts.

Florida has three types of local government organizations: counties, municipalities, and special districts. These three forms are further described below.

County Government. Florida is divided into 67 counties (Figure 5). Florida counties operate on a traditional commission form of Government. Residents living in each county elect a board of commissioners to make the laws for their county and run the county government. Elected positions in the county include the sheriff, tax collector, supervisor of elections, and county judges. By the $20^{\text {th }}$ century, counties started becoming more urbanized, and the progressive change-makers called for more power and independence to be given to the counties in local governance. 


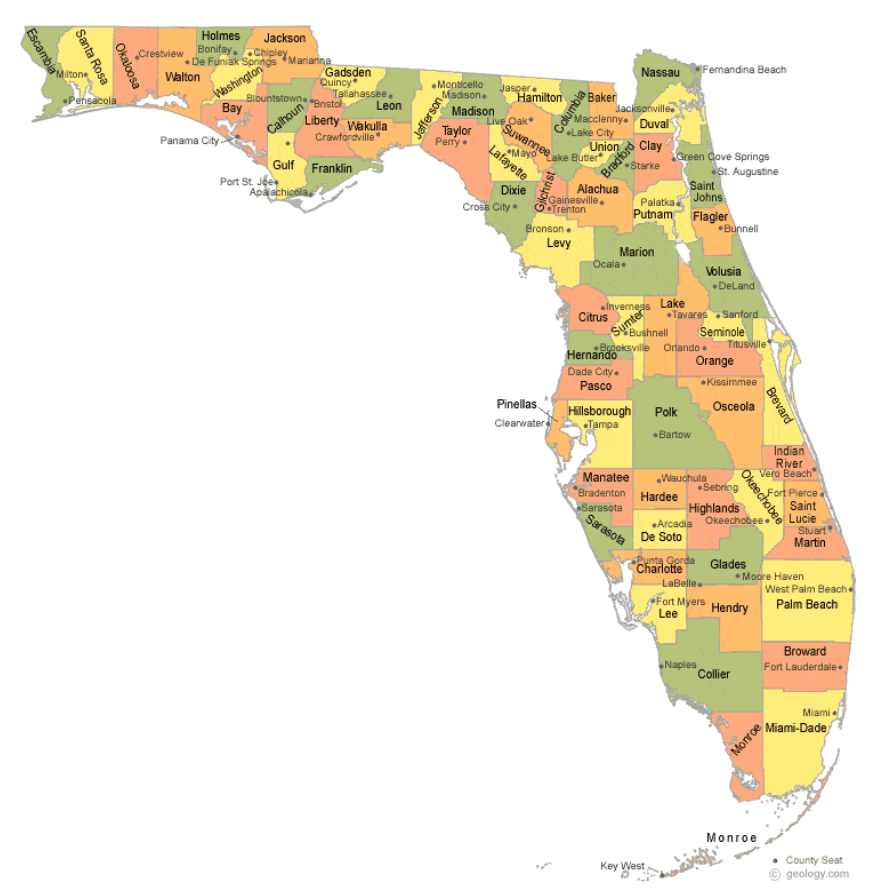

Figure 5. Counties in the State of Florida

Each county functions as the recordkeeper for its citizens. County employees run courts, prisons, parks, libraries, and health care services. The county courthouse contains offices for many of these county workers. Each county in Florida has its school district. The elected school board makes most decisions regarding the county's schools. Counties have an elected or an appointed superintendent of the schools.

Municipal Government. The municipal governments are contained within a county and are variously termed as city, town, or village. They are governed by an elected mayor, who the top official. A city council is elected (at large or representing a particular ward within the city) to make policies and decisions that impact the specific jurisdiction. The city charter and related laws guide the city council. The elected officials are supported by staff. Parks and recreation, arts and cultural affairs, sewer, and water are just some of the responsibilities of city workers. The city hall serves as the location for 
much of the municipal government's work. More than 50 years ago, Floridians voted to include municipal home rule powers in the state constitution.

Table 3. Florida Municipalities Demographics

Number of municipalities

412

Number of elected officials

2,251

Largest city

Jacksonville (Population 907,093)

Smallest city

Marine (Population 8)

Median municipal population

5,950

Floridian's living in city/town/village $\quad 50.7 \%$

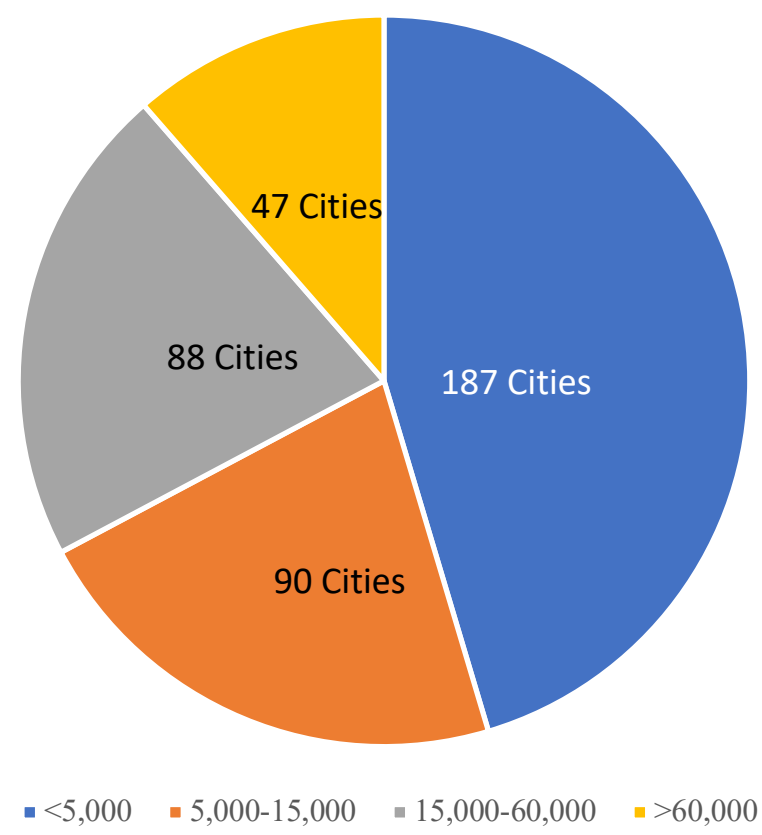

Figure 6. Breakdown of Florida's Municipalities by Population 
Florida has 412 municipalities. They range in population from Marineland (8) to Jacksonville $(907,093)$. Table 3 gives the summary characteristics of the cities and Figure 6 gives the distribution of cities by population size. The cities can be urban-like Miami and rural like Caryville. One size does not fit all when it comes to cities in the Sunshine State. Home Rule gives each city the flexibility to craft its laws specifically to meet its own unique needs. This is the embodiment of "local voices making local choices." This right means any city can adopt its laws so long as the law doesn't conflict with state or federal law. Even with constitutional Home Rule power, Florida's Constitution limits taxation authority to the Legislature, and several revenue sources for both counties and cities are capped in amount and restricted for use. Florida's cities receive an average of half of their revenues from user fees for service. The largest sources of tax revenue come from the property tax. Other sources are state-shared revenue, which includes a portion of the state sales tax and gas tax; and the public service tax also called utility tax. Cities also rely upon intergovernmental revenue, grants, license fees, and permit fees.

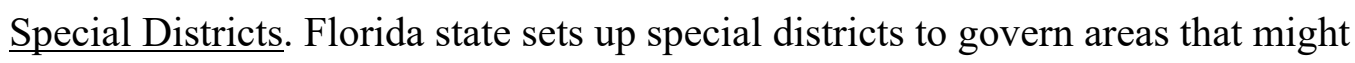
cover more than one county. These districts are spread throughout the state and serve special purposes, like flood control. District boards make the policies and decisions regarding the special-purpose programs. Today, there are over 1,700 independent and dependent Special Districts in the state, governed by more than 30 statutes, involving over 500 local governments (Figure 7). Special districts provide limited purpose government at the local level. Fire control, library, port \& inlet, mosquito, water control, community development, roads, hospital, and other districts-all providing unique 
services, but all with the same need to be accountable and accessible to the citizens they serve.

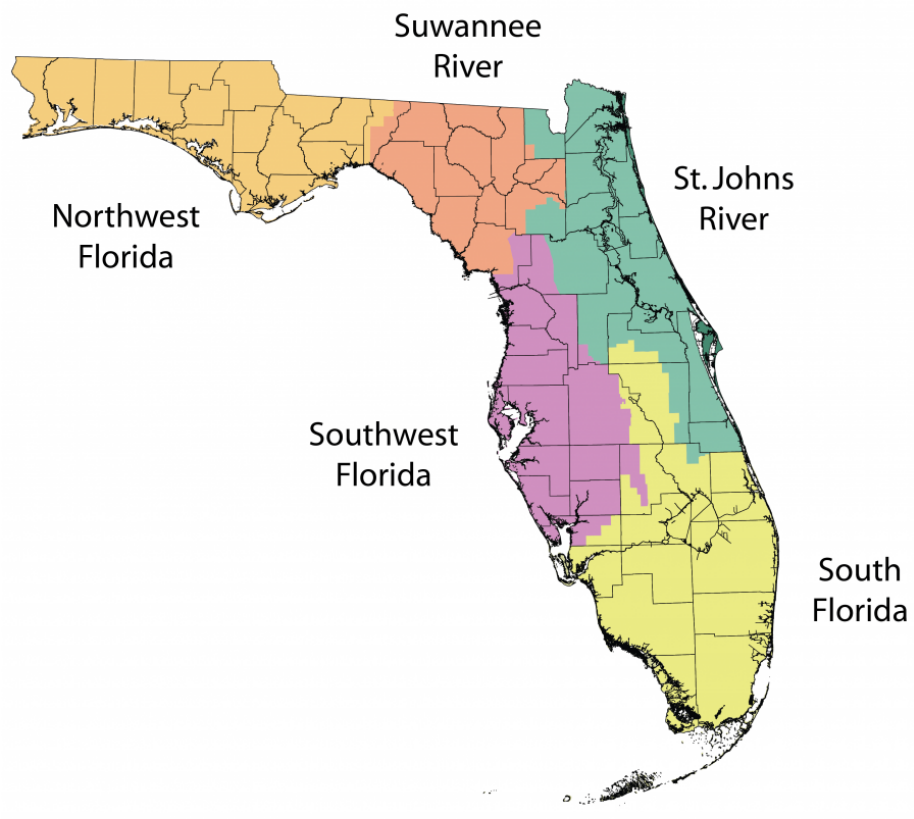

Figure 7: Special Districts in the State of Florida

The administrative structure of Florida Local Governments

In general, the United States local governments' administrative structures follow the English municipal model. The U.S. local governments are governed by a legislative body referred to as the city council (in some cases city commission). The municipality charter specifies the roles and responsibilities of the elected body as well as the appointed officials. Functions of the elected council members are to 1) make laws and ordinance;2) take budgetary and fiduciary responsibilities; 3) decide on the city's future and strategic plan. Local governments follow different functional structures and forms of government. In Florida, the common administrative structures of local government are the following. 
Council-Weak Mayor: This was the original form of the local governments in the United States and was almost universal in the nineteenth century. In such governments, the office of the mayor is rotated between all the elected council members. The council has control over municipal administration including the appointment of the municipal employees. The mayor has little authority. The department directors report to the council as a whole or the Mayor as a spokesman of the local government.

Council-Strong Mayor: In this form, the power between the mayor and the council is divided. Mayor is the chief executive officer who influences the policymaking process and has substantial control over the administration. The mayor has all the budgetary and appointment powers and can veto the legislative actions of the council. In some large local governments with a strong mayor form, the mayor appoints the manager to carry out the day to day task while still holding the policy leadership as well as administrative power under their control.

Commission Form: The commission form of the local government is a combination of both the legislative and the executive powers in the board of commissioners. The commissioners jointly serve as a policy-making body and run the departments. Many local governments with the commission form also elect a ceremonial mayor. The rationale behind the 'commission' was that the concentration of power between the elected commission will enhance government accountability and make the administration more effective. In Florida, many local governments use 'commission' and council as the same and do not differentiate between the two.

Council-Manager Form: The council-manager form is one of the key changes in the $20^{\text {th }}$-century local government reforms. The council-manager form was built on the 
foundation of centering the administrative power in a non-political appointed executive to run the administrative functions of the government. The majority of local governments in the United States adopted the council-manager form of local governments. In the councilmanager form, voters elect the council (elected board of council members), including the mayor (chairman of the board). They, in turn, appoint the manager (chief administrative officer). Unlike the two council-mayor forms which emphasize the importance of political leadership, the council-manager form emphasizes administrative competency, efficiency, and professionalism.

The appointed executive supervises and coordinates the departments, appoints and removes the directors, prepares the budget for the council to approve, and makes recommendations and reports for the council's consideration. The mayors' role is of an important political figure who presides over council meetings but has little role in the day-to-day administration. The manager is responsible for these daily administrative issues. The rationale for the council-manager form is to take the politics out of administration and the appointed manager stays out of politics. The elected council can hire or fire the appointed executive and is subject to the authority of the elected council, but the council members are not expected to interfere in the administration.

Hybrids: The 'hybrid' forms employ a combination of the four basic forms. But predominantly, the hybrids mainly share the characteristics of the council-weak mayor form. They exhibit some characteristics of the 'commission' form' as well. They may not have professional managers per se. 
In the case of the State of Florida, the most common form of local government is the council-manager form. About 270 municipal governments out of 412, function in the form of council-manager structure, with an appointed 'manager' or 'administrator.'

\section{Study's Focus on Council-Manager Form of Local Governments}

This study focuses on the council-manager form of local governments. Such a focus is appropriate because: 1) it is the predominant form in the State of Florida local governments, and 2) the manager plays an important role in the professional leadership of the local government. The manager holds the executive and administrative powers. The person wears both the administrative hat of running the various local government functions and the policy hat of interacting between the elected political leaders and the administration. Elected officials exercise their powers to effect community change through their policy leadership and veto power. Thus, in a council-manager form of local governments, the powers are balanced and shared between both the elected and appointed executive. The personality, leadership style, and the local political culture play a role in who (the elected or the appointed executive) is the dominant actor in policymaking.

The dualism of electoral politics and professional administration is balanced in the council-manager setting. Administrators accept the role of the elected official and elected officials respect what administrators do and how they do it (Svarra, 2006: 1081). In larger local governments, the powers of the elected and appointed official are balanced in comparison to the smaller governments in which the appointed city manager may exercise more power (Morgan \& Watson, 1992; Boynton \& Wright, 1971). 


\section{Research Methodology}

County and municipal government agencies form the empirical context of the research. The county or city manager is the subject of this dissertation's study for their servant leadership behavior. As such, the research is designed to capture the extent to which these managers exhibit servant leadership in local governments. The CouncilManager form of local government is, therefore, most appropriate for this study, as emphasized earlier. The research design included an online survey and a complimentary comparative case study based on the results obtained from the survey. The methodology for the survey and the case study is explained below.

\section{Online Survey Process}

To answer both research questions, an online survey instrument was administered to the county and city managers. The survey was developed in September-October-2018. The survey population encompassed the top-level county and city managers, and to the employees directly reporting to these managers. The rationale is that the managers can respond to self-identity questions concerning their leadership style, but their actual servant leadership behavior would be reflected only by the followers (i.e. the employees who directly report to such managers). Consequently, two survey instruments — one for the managers and one for the employees - were developed. Qualtrics, an online survey platform, was used to develop and deploy the survey. The managers and the employees were sent the appropriate link to the survey instrument through an email. The top-level survey question asked: Are you the administrative head (county/city/town/village manager)? If the respondent answered 'yes,' the survey instrument for the leader was deployed. If the respondent answered 'no,' the survey instrument for employees was 
deployed. Henceforth, for convenience, the county/ city manager survey is referred to as "leaders survey" (the managers are the leaders); the employee's survey is referred to as the "followers survey" (the employees are the follower).

The survey questions for both leaders and employees were designed such that the respondents would answer them on a 7-point Likert-type scale (e.g., $1=$ strongly disagree, 7 = strongly agree; or $1=$ poor, 7 = excellent). The demographic questions such as race, education, length of stay in the county government, length of stay in the current department, and age group were measured using a 6-point Likert-type scale. The followers' survey also featured multiple-choice questions about the department they worked for, their current job position, and whether they report directly to the county administrator.

The online survey was organized around thematic blocks of homogeneous questions. The leaders' survey was divided into three blocks, the first block of questions asked the leaders about their moral potency and servant identity behavior (leader-rated). The second block measured the organizational social capital and co-production of public services (leader-rated) in their organization as perceived by the leader. The third block was about the demographic variables. The leaders' survey had 45 questions.

The follower's survey was divided into three blocks. The first block was designed to assess the servant leadership and ethical leadership behavior of the leaders as perceived by the followers (i.e. leaders were rated by followers). The second block aimed to assess the organizational level variables such as organizational social capital, coproduction, and service climate (i.e. as rated by the followers). The third block focused on the demographic variables. The followers' survey had 82 questions. 
The survey questions themselves were drawn from previous studies that have had empirically validated measures for servant leadership behavior. The servant leadership and follower behavior are thus valid and reliable measures that have been psychometrically tested in previous peer-reviewed studies. The variables of interest were constructed as an index from the survey questions. Table 4 summarizes the variables obtained from the survey. Appendix $\mathrm{C}$ provides the survey questions and the variables.

To increase the survey instrument's face validity, the survey was first sent to dissertation committee members (Dr. Sukumar Ganapati, Dr. Ochieng F. Walumbwa) for their feedback. The preliminary feedback from the professors was necessary to avoid gaping problems that may otherwise arise from conducting surveys with local public managers and employees in Florida (Peat et al, 2002). The survey instruments were then pilot tested with three city managers within the Miami-Dade County who were willing to help in the study and who thought the study held much value for local government administration. These managers did not only respond to the online survey and provide constructive comments but also helped in sending the followers' survey across to their employees. These employees also provided important feedback for the first-hand feel, look, and ambiguities in the questions.

A further note about pilot studies is necessary here. In the social sciences, pilot studies are used in two different ways (Van Teijlingen, \& Hundley, 2002). To pre-test, a particular research instrument (Baker, 1994, p. 182) or feasibility studies which are "small scale versions or trial runs, done in preparation for the major study" (Polit et al., 2001: 467). Pilot studies offer plenty of advantages to researchers for a better understanding of the validity and reliability of the research instrument before 
administering the final study. Pilot testing allows researchers to understand whether the survey questionnaire is valid and reliable, and the survey answers measure the research concepts as they are intended to be measured (Peat et al., 2002).

Pilot studies in survey research can be used to "check to see if there are any ambiguities or if the respondents have any difficulty in responding" (De Vaus, 1993, p. 54). Similarly, Fink and Kosekoff (1985) affirm that a survey instrument needs to be revised if respondents fail to answer questions, if they provide multiple answers to the same question, or if they provide written comments to the proposed questions. Peat et al. (2002) state that "all surveys must be pilot tested before putting into practice" (p. 7). Peat et al. (2002) provide a useful step-by-step guide to conduct pilot studies.

All of these objectives were achieved with the pilot survey instrument. As a result of the pilot study, the introduction to the survey was changed to provide a better context. Specific questions and their responses were also modified based on the pilot survey. For example, response choices for the question 'what is your ethnicity, and what is your gender? was changed. The pilot study was carried out following the Peat et al. (2002) step-by-step guide. Subjects were asked to identify ambiguities and discard unnecessary or difficult questions. The respondents reworded some of the terminology used in the survey. In particular, they asked to replace the expression "manager" with "county/city/town/village manager." The feedback was useful in gauging the average time required to complete the survey. Time spent on the leader's survey was on an average of 5-7 minutes and the follower's survey took 12-15 minutes. 
Table 4. Variables and Sources of Measurement

\begin{tabular}{|c|c|c|c|}
\hline Variable & Respondents & Dimension & $\begin{array}{l}\text { Sources for Survey } \\
\text { Questions }\end{array}$ \\
\hline \multicolumn{4}{|l|}{ Individual Attributes of SLB } \\
\hline SLB (DV) & Follower Rated & 7 dimensions & $\begin{array}{l}\text { Liden et al. (2008) } \\
7 \text { items }\end{array}$ \\
\hline Servant Identity (IV) & $\begin{array}{l}\text { Leader and Follower } \\
\text { Rated }\end{array}$ & $\begin{array}{l}\text { Calling, Humility, } \\
\text { Empathy, Agape Love }\end{array}$ & $\begin{array}{l}\text { Sun }(2013) \\
13 \text { items }\end{array}$ \\
\hline $\begin{array}{l}\text { Moral Potency (IV) } \\
\text { Organizational Attributes of } S L B\end{array}$ & $\begin{array}{l}\text { Leader and Follower } \\
\text { Rated }\end{array}$ & $\begin{array}{l}\text { Moral Ownership, Moral } \\
\text { Efficacy, Moral Courage }\end{array}$ & $\begin{array}{l}\text { Hannah et al. (2010) } \\
12 \text { items }\end{array}$ \\
\hline SLB (IV) & Follower Rated & 7 dimensions & $\begin{array}{l}\text { Liden et al. (2008) } \\
7 \text { items }\end{array}$ \\
\hline Organizational Social Capital (DV) & Follower Rated & $\begin{array}{l}\text { Structural, Relational, } \\
\text { Cognitive }\end{array}$ & $\begin{array}{l}\text { Andrews }(2010,2011), \\
\text { Tantardini \& Kroll }(2015) \\
6 \text { items }\end{array}$ \\
\hline Co-Production (DV) & Follower Rated & $\begin{array}{l}\text { Purpose and Intensity of } \\
\text { Engagement }\end{array}$ & $\begin{array}{l}8 \text { Items Created based on the } \\
\text { Co-Production Literature }\end{array}$ \\
\hline & Follower Rated & Service Climate & $\begin{array}{l}\text { Schneider \& Ingram (1998) } \\
7 \text { items }\end{array}$ \\
\hline \multicolumn{4}{|l|}{ Control Variables } \\
\hline Ethical Leadership & Follower Rated & Ethical characteristics & $\begin{array}{l}\text { Brown et al. (2005), Yukl et.al } \\
\text { (2011) }\end{array}$ \\
\hline Demographic factors & $\begin{array}{l}\text { Leader and Follower } \\
\text { Rated }\end{array}$ & $\begin{array}{l}\text { age, education, gender, } \\
\text { ethnicity, tenure }\end{array}$ & \\
\hline
\end{tabular}




\section{Survey Administration}

The survey was conducted on Florida's county and city managers and their department heads to explore the relationship between servant leadership behavior and the associated individual and organizational attributes. Table 4 shows the variables and measurements included in the online survey. The sampling frame consisted of 330 county and city governments. Email addresses of the county managers and their department's heads were collated from the Florida Association of the Counties Website (FAC). A link to the survey was sent by email to the county and city managers and their department heads. The survey was sent to the respondents during January to March 2019 in two waves. The surveys were kept open until August 2019. About three reminders were sent to the respondents in a gap of two weeks each.

Several additional steps were taken to ensure a high rate of response. The dissertation adviser emailed the executive director of the FAC and followed up with them by a phone conversation to seek their support in administering the online survey through FAC channels. The FAC agreed to include a note about the survey in their regular newsletter. Support for endorsing the survey was also sought from the Florida CityCounty Management Association (FCCMA) leadership board for endorsing the survey. The FCCMA advertised the survey on its website. Besides, email addresses of the county and city managers and their employees were searched on the individual websites of the county and city to create an exhaustive email list.

The survey was sent to to 181 municipal and 60 county governments. The survey respondents were the county and city managers and their department's heads (see Appendix D and E for the list of cities and counties that responded to an online survey). 
Figure 8 gives a map of the jurisdictions across Florida from which the leaders and the employees responded to the survey. The map shows that the respondents are well distributed across the state. A list of county and city governments that participated in the survey is provided in Appendix D and E. To avoid common source bias, both leaders and followers within the organizations were surveyed. Individual traits of servant identity and moral potency are assessed about the leader. The survey questions were answered by the leaders as well as employees.

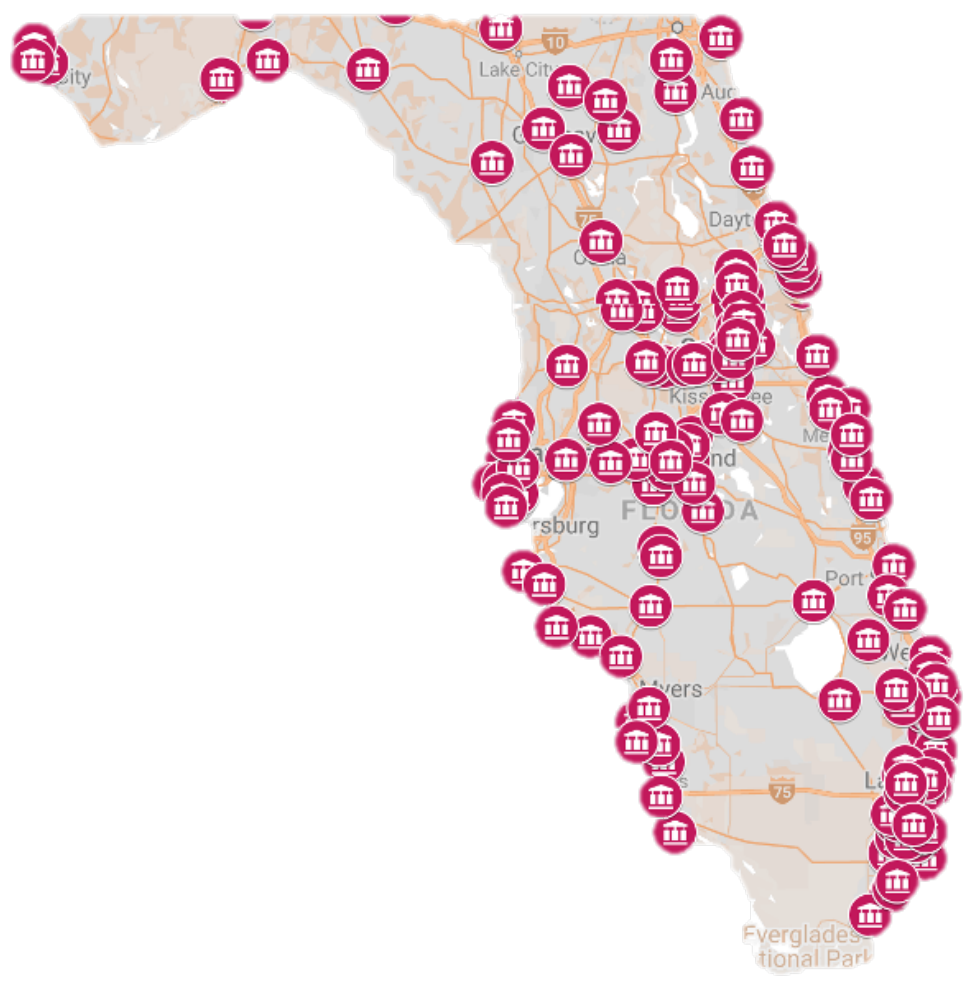

Figure 8. Study Sample for Counties and Cities 


\section{Survey Data Analysis Strategy}

For multilevel data in which employee responses are nested in organizations, Hierarchical Linear Modelling (HLM) is the appropriate method to use. In this study, the data are at two levels, individual ratings of the county and city managers and their executive team members (employee level) nested in city or county governments (organizational level) across the State of Florida. The two-level HLM was conducted using statistics software STATA 16. Data analysis and results are reported for RQ1 in chapter 3, and RQ2 in chapters 4 and 5. Findings are then consolidated to give an overall summary of the study in chapter 6 . The following strategies were followed before the actual HLM analysis.

Missing Values: If the data is not missing at random, methodological, and/or analytical problems may occur because bias may be introduced into the equation. Nonetheless, a variety of methods are available for dealing with missing data (e.g., case deletion, single imputation, multiple imputations). The complete case was deleted if the data was completely missing or if the observations were missing $50 \%$ or more for any of the variables. For additional partial missing values, when about $20 \%$ of the observations for variables were missing, multiple imputation method was used to give accuracy and rigor to the analysis. Overall about $10 \%$ of observations were imputed using the multiple imputation method. Since the observations were missing at random (MAR), the best method to use was multiple imputations. A potential problem with the deletion of cases with incomplete data is that the deletion may result in the sample selection bias due to the decreased sample size. However, the selection bias is taken care of, as the county and city governments in the sample represent broad geography across the State of Florida, 
covering about 155 county and city governments. For RQ1 to examine individual attributes, responses were recorded from 155 county and city governments and 228 employees, and 99 county and city managers (see chapter 3). For RQ2 to examine organizational attributes, responses were recorded from 101 county and city governments and 228 executive team members (see chapters 4 and 5).

Outlier Detection: An assessment of the data for potential outliers was conducted using Mahalanobis distance. However, all data were retained regardless of whether it was considered an outlier. The purpose of this was to preserve actual numbers and identify cases that were higher or lower for some variables (i.e., best or worse cases). Therefore, the identification of "extremes" was important. The rationale is that observations should not be omitted unless there is strong evidence to show that data points are false.

\section{Standard Diagnostic Techniques: Multicollinearity and Normality Tests: Before}

running the hierarchical regression models, the standard diagnostic tests were conducted. First, multicollinearity is a problem inaccurate estimation of relationships in the hypothesized models. To check multicollinearity in HLM, the variance inflation factor indicator was done (VIF). The VIF values for all the models were below 2.0, much lower than the accepted norm (the highest limit is 10). The VIF test ruled out the multicollinearity problem. Additionally, in the pairwise correlations, none of the values exceeded the highest limit of 0.75 . The normality of the residuals was tested using a variety of statistical and graphical tests such as a test for skewness-kurtosis and the Shapiro-Wilk test. This showed a normal distribution. The graphical plots included standardized normality plots, kernel-density plot, and normal quantile-quantile plots showing normal distribution of residuals. For heteroskedasticity, residuals vs. predicted 
values plots and the Breusch-Pagan test were used. The error terms show constant variance across all the models.

\section{Case Study Design}

The qualitative design used in this research is multiple case studies following the survey (Yin, 2009). The case studies were conducted on-site. The survey findings revealed servant leadership behavior across jurisdictions. The counties and cities with a high degree of servant leadership behavior were chosen for in-depth case studies. Three case studies - two counties and one city—were conducted. The case study methods included: semi-structured interviews and participant observation (in departmental formal meetings, employee informal meetings, organizational networking, and social events, council meetings, and community meetings; see Appendix H). In addition, during the site visits, secondary documents were collected from the concerned staff. The secondary documents included memos, leader email communication with employees, organizational vision, mission, and strategic documents (see Appendix I). Besides, some documents related to the organizational history, organization structure, and strategic documents were accessed directly using the internet search and websites.

\section{Case Study Site Selection Protocol}

Based on the survey scores, three county and city governments were chosen which depicted high scores on the SLB. As per the IRB protocol, the identity of the case study sites was kept anonymous and is referred to as County A, County B, and Village C in the study. Two County Managers who took the online survey replied saying that the study is highly relevant and that they appreciated and recognize the value of this research. 
These counties received high scores on the servant leadership behavior in the online survey: County A's SLB score was 6.1 (13 executive team members responded) and County B's SLB score is 5.8 (14 executive team members responded).

The County Managers from these two counties were contacted to ask if they would allow conducting in-depth case studies to understand the deeper dynamics of how SLB is manifest in their agencies about the individual and organizational outcomes (Yin, 2014). The two County Managers (County A and B) responded positively and agreed to allow the conduct of in-depth case study analysis in their county governments. As part of the case study protocol, the first step was to send a request letter from the professor on behalf of the researcher explaining the requirements of the case study research to the county managers. Subsequently, the case study site visit schedule was provided by the County A's Human Resource Director and the County B's Human Resources Manager. Table 5 shows the online survey score on servant leadership for the case study sites.

Table 5. Online Survey Score of Servant Leadership for the Selected Case Studies

\begin{tabular}{lll}
\hline Case Study Sites & $\begin{array}{l}\text { Servant Leadership Score } \\
\text { (Out of 7) }\end{array}$ & Team Response \\
\hline County A & 6.1 & 13 responses \\
County B & 5.8 & 14 responses \\
Village C & 5.9 & 9 responses \\
\hline
\end{tabular}

The third case study site was the Village C. Village C's Manager received a high servant leadership score in the online survey, 5.9 out of 7 ( 9 team members responded) allowed the in-depth case study analysis in the Village C. Contact with the Village C's Manager was established at the Florida City-County Management Association's (FCCMA) Annual Conference in Orlando, in June 2019. Village C's Manager 
remembered the survey and showed interest in further in-depth case study analysis of servant leadership. Following-up on the FCCMA meeting, Village C's Manager was formally contacted by sending a request letter seeking permission for the study. Village C was then included as a part of the case study.

\section{Case Study Data Collection}

There are multiple data collection strategies followed in this study. According to Yin (2014), the data collection strategies in case study research include interviews, observations (direct/participant), questionnaires, relevant archival documents, pictures, and artifacts. In the case studies, multiple types of data enable a thick description and an in-depth understanding of the studied phenomenon (Cresswell, 2013). In this study, given the complexities in understanding the leadership phenomenon, multiple types of data enable an in-depth understanding of the subjective realities of the leadership execution in a real-world context. Following Yin's (2014) guidelines, the data sources in this study were: semi-structured interviews, direct observations, archival documents, and pictures accessed on-site relevant for the study. Besides, some documents were already available on the city/ county site websites. Figure 9 depicts the data collection protocol at two levels (individual and organization) followed in this study.

All the interviews were audio-recorded with the respondent's permission and were supplemented with the recorded field notes and mental notes at the end of the day as well as pictures taken during the events. Data was collected either through voice recordings, notetaking, documents received, and/or pictures were taken. Figure 9 illustrates the data collection protocol followed in this study. All the case study sites function with a council-manager form of government and follow the 'Home Rule Charter 
'as per the Florida constitution giving the rights to its residents for local self-government through the elected officials. Home Rule Charter in Florida gives powers of local decision making, self-government, and citizen-centric solutions to local governments. The Home Rule is a kind of a local government constitution that gives the county and municipal governments authority to enact ordinances, codes, plans, and resolutions without prior state approval.

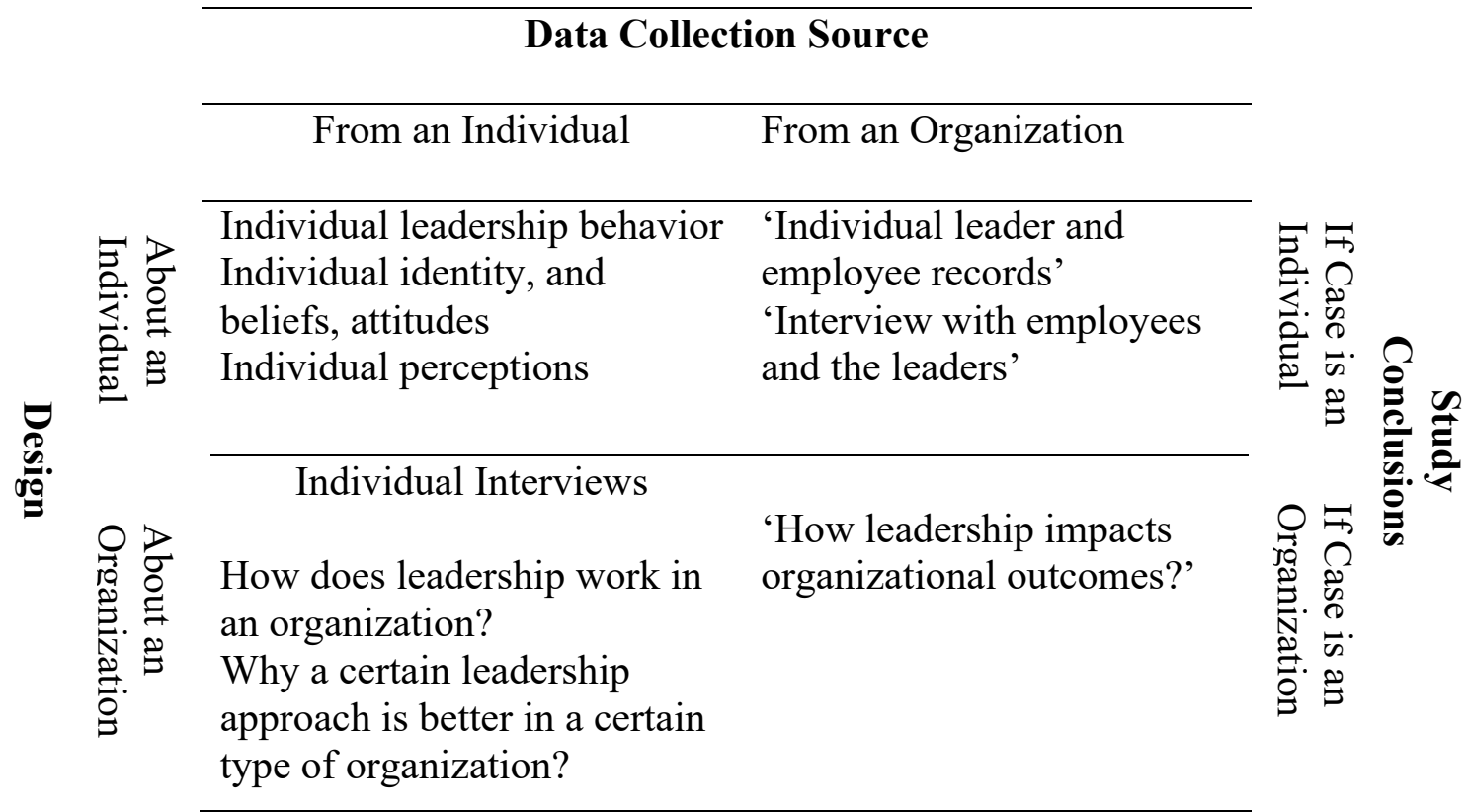

Figure 9. Case Study Data Collection Protocol Source: Yin (2018, p. 143)

The case study involved a total of 50 face to face semi-structured interviews conducted on-site during a span of 5 months (April 2019 - August 2019). The characteristics of the interviewees are presented in Table 6 . Figure 10 shows the job positions held by the interviewees. Direct participant observations included those of council-meetings, employee formal and informal meetings, community events, and study 
of archival documents such as vision, mission, and strategic plan documents, leaders' emails to the employees, and pictures gathered and taken during the case-study site visits. (See Appendix F, G, H, I for details on data collection - Interview questions, observation, and archival documents). Specific details of data collection strategies during interviewing, observations, and archival documents are elaborated in the individual chapters. For example, chapter 3 elaborates on what questions were asked to explore individual attributes of servant leadership behavior? Likewise, chapters 4 and 5, elaborate on questions asked and observations completed to explore the organizational attributes of the servant leadership.

Table 6. Interview Sample Characteristic at County A, B, and Village C

\begin{tabular}{ll}
\hline \multicolumn{1}{c}{ Sample Characteristics } & \\
\hline Ethnicity & 26 \\
White & 9 \\
Black & 10 \\
Hispanic/Latino & 5 \\
Asian & \\
American Indian/Alaskan Native & \\
Gender & 29 \\
Male & 21 \\
Female & \\
Education & 2 \\
Some College or Associate Degree & 10 \\
Bachelors & 32 \\
Masters & 4 \\
Doctorate & 2 \\
Professional & \\
Age in Years & 1 \\
25-34 & 10 \\
35-44 & 30 \\
$45-54$ & 5 \\
55-64 & 4 \\
$65-$ or older & \\
\hline
\end{tabular}




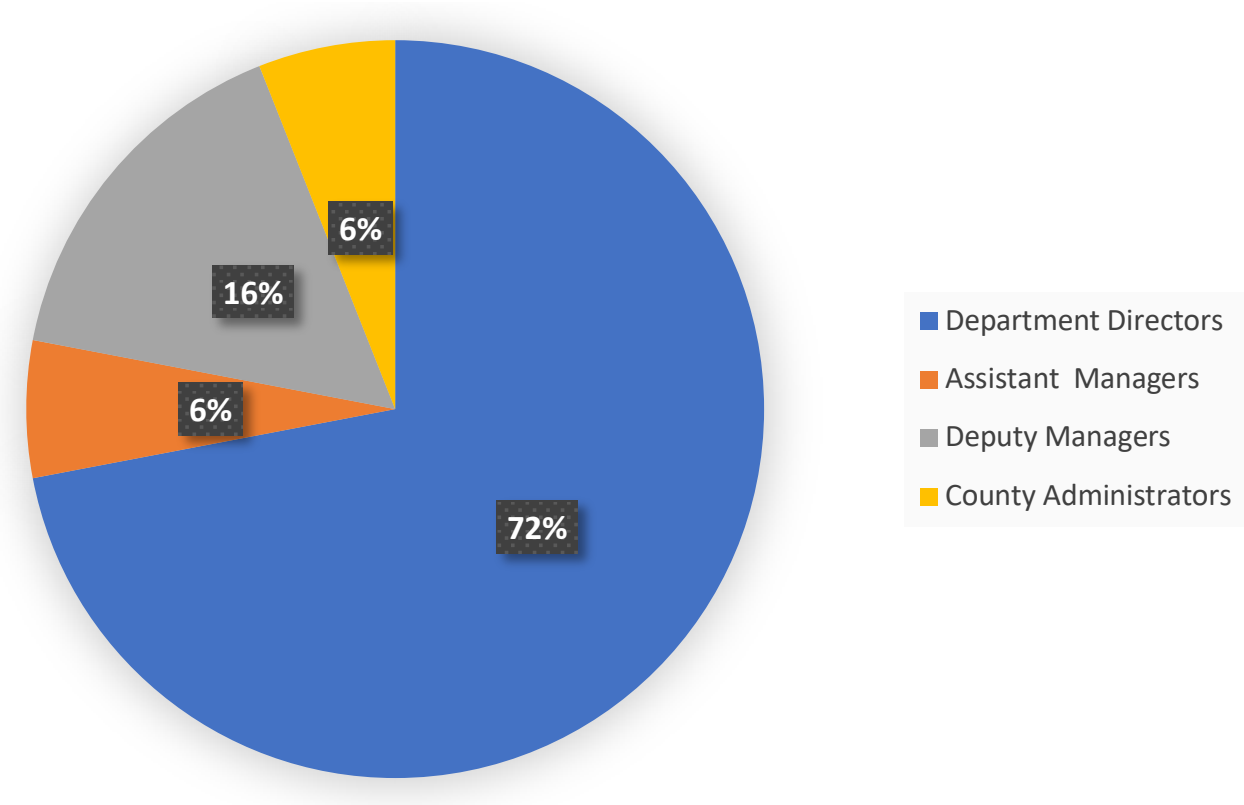

Figure 10. Job Positions Held by Interviewees

\section{County A Data Collection}

County A is located in the west-central region of the State of Florida and is one of the five most populous counties in the State. According to the 2010 census, County A's population was approximately $1.5 \mathrm{M}$ and the median household income was $\$ 58,000$. The ethnic and racial demographics in the county was: $48 \%$ whites, $15.6 \%$ Black, $29.2 \%$ Hispanic or Latino, 3.4\% Asian, .4\% American Indian/Alaskan Native. About $15 \%$ of people live below the poverty line.

County A is governed by a home rule charter. The responsibilities of the executive branch (county administrator) and the legislative (county commission) are specified, and neither of them can exercise the powers on the other. The county runs under the guidance of the 7-member board of county commissioners who represent 7 districts in the county. The board of county commissioners is a legislative body of the 
county to enact laws, adopt ordinances and resolutions, and make public policies. The board also recommends community members to serve on various committees.

The County A's county administrator is the chief executive officer. Figure 11 gives the organizational chart of the county. The county administrator ensures the implementation of public policy and laws. On behalf of the board of county commissioners, the county administrator runs the day to day administration of all the departments, divisions, and agencies of the county government. County A is fairly large with nearly 5000 employees working in County A's administration. The current County A's administrator has been serving for close to 9 years in this position.

The County A site visit was conducted from April $8^{\text {th }}-12^{\text {th }}, 2019$. A conference room was assigned from 8:00 am to 5:00 pm during the scheduled dates. The researcher spoke with each interviewee based on a pre-assigned schedule. The human resource director at County A facilitated the site visit. There was a total of 18 semi-structured interviews at County A. The interviewees included: county administrator, two deputy county administrators, two assistant county administrators, one chief innovation officer, one chief communications officer, one chief operation and legislative officer, and ten department directors.

Besides, direct observations lasted for approx. 13 hours which included a leaderemployee formal meeting, two community events organized in collaboration with the county government and nonprofits, and an employee informal meeting. Besides, several informal conversations with county administration staff were also undertaken. The archival documents examined include the county's vision, mission, and strategic planning, a customer service annual review report, and departmental executive 
dashboards, and three leader's emails to employees. Additionally, 24 pictures included community events, employee meetings, leader's strategic conference room pictures, and other pictures relevant for this study.

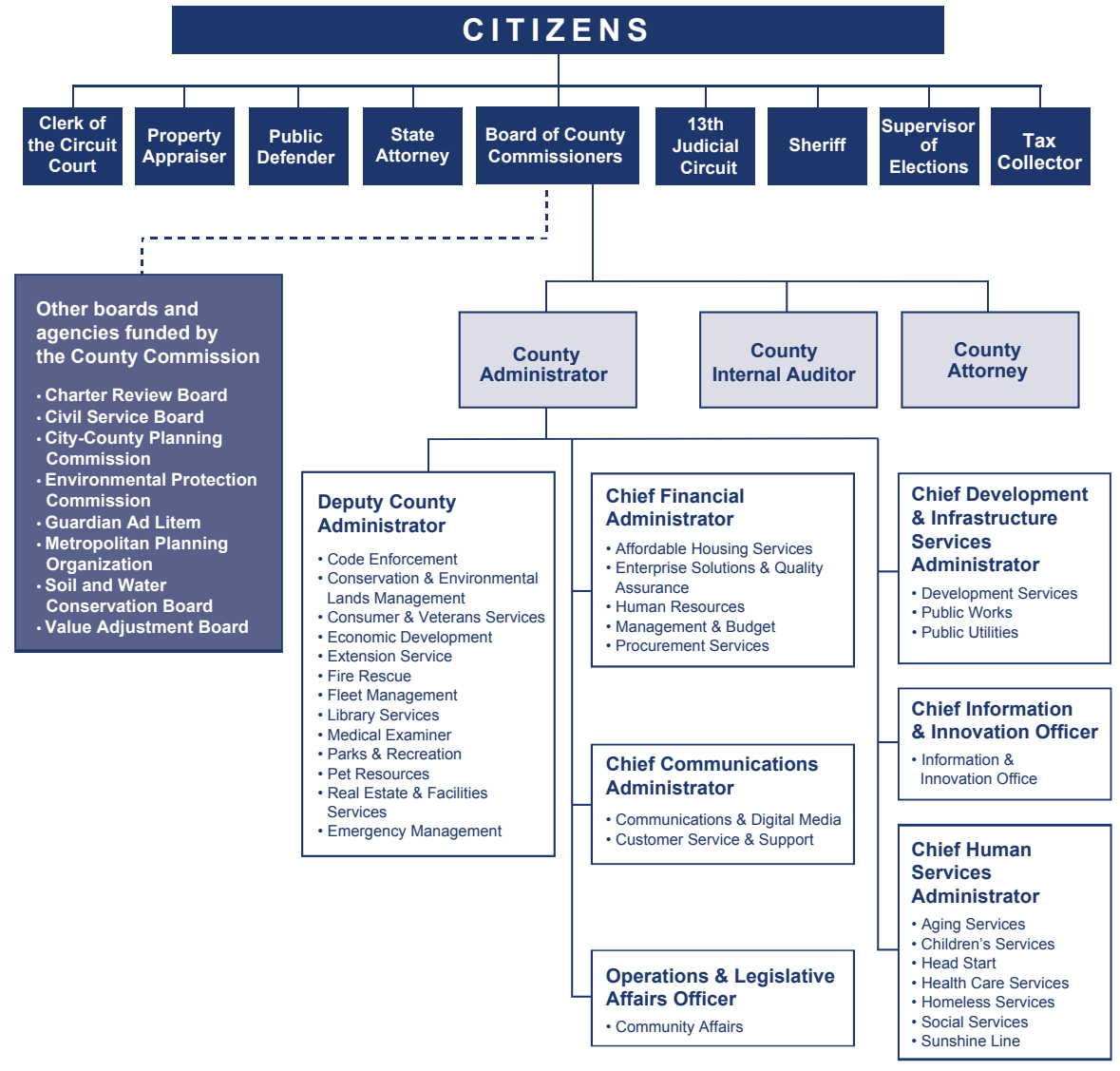

Figure 11. County A's Organizational Chart. Retrieved from Website.

\section{County B Data Collection}

County B is located between the central and the south-east region of the State of Florida and is considered as one of the fastest-growing counties in the state. The population is projected to grow from 80,000 in 2000 to roughly 328,000 in 2020 . County B's median household income was $\$ 54 \mathrm{~K}$. The ethnic and racial demographics in the 
county was: $56 \%$ whites, $19.8 \%$ Black, $19.8 \%$ Hispanic or Latino, $1.6 \%$ Asian, $.4 \%$ American Indian/Alaskan Native. About $16 \%$ of people live below the poverty line.

County B is also governed by a home rule charter. The responsibilities of the executive branch (county administrator) and the legislative (county commission) are specific; neither of them can exercise the powers on the other. County B operates under a 5-member Board of County Commissioners. Each board member represents one of the five districts. The board of county commissioners is a legislative body of the county which enacts laws, adopt ordinances and resolutions, and make public policies. Board recommends community members to serve on advisory committees.

The County B's county administrator is the chief executive officer. The county administrator ensures the implementation of public policy and laws. On behalf of the board of county commissioners, the county administrator runs the day to day administration of all the departments, divisions, and agencies of the County Government. County B has approximately 750 employees. Figure 12 gives the organizational chart of the county. The County B's administrator has been serving for 6 years now.

The County B site study happened from August $19^{\text {th }}-23^{\text {rd }}, 2019$. A conference room was assigned to the researcher from 8:00 am to 5:00 pm for use during the scheduled dates. The interviewees visited the researcher in the conference room for a conversation as per their assigned schedule. The human resource manager at the County A facilitated the site visit. A total of 15 semi-structured interviews were conducted at the County B. The interviewees were the county administrator, two deputy county administrator, one chief technology officer, and 11 department directors. One interview was also conducted with the director of a non-profit agency, which was working with the 
County B in several service delivery initiatives (the county administrator served as the chair of the non-profit agency). 10 hours of participant observation was conducted.

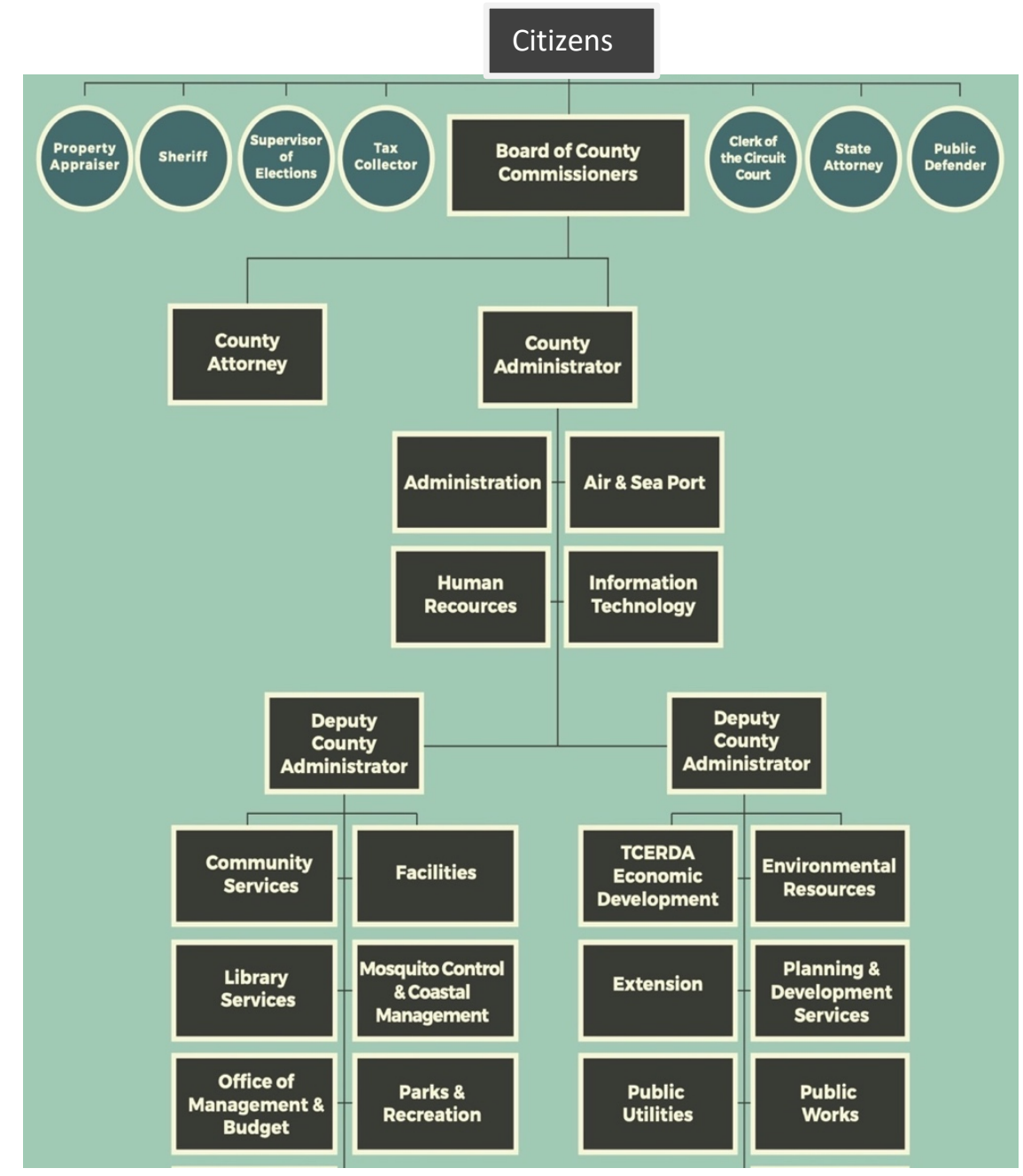

Figure 12. County B's Organization Chart. Retrieved from Website

\section{Village C Data Collection}

Village $\mathrm{C}$ is a suburban municipality in Miami-Dade County in South Florida. According to the 2010 census, the Village had a population of 18,223 , which is estimated to increase to 20,000 by 2020 . The median household income was $\$ 130,000$. The ethnic 
and racial demographics in the village were: $43.3 \%$ whites, $47 \%$ Hispanic or Latino, $6.8 \%$ Asian. About $6 \%$ of people live below the poverty line.

Village $\mathrm{C}$ is a home rule charter municipality. The responsibilities of the executive branch (county administrator) and the legislative (county commission) are specified, and neither of them can exercise the powers on the other. Village $\mathrm{C}$ runs under the council-manager form of government. It is governed by the five-member village council with a nominated mayor. The village council elections are non-partisan. The village council is the legislative body of the village and determines policy, adopts the annual budget, and enacts laws.

Village C's manager is the chief executive officer of the village and ensures the proper implementation of laws, policies, and provisions of the village charter. He/she acts on behalf of the village council to run the day to day administration of all the departments, divisions, and agencies of the municipal government. Village C's administration has about 200 employees. The current Village manager has been serving the village for close to 10 years as a Village manager. Figure 13 shows the village's administrative structure. The Village C site visit occurred from July $15^{\text {th }}-$ July $25^{\text {th }}$, 2019. The village manager's administrative assistant facilitated the site visit. A conference room was assigned during the scheduled dates. Some interviews were conducted in the conference room and some in the interviewees' offices. There was a total of 17 face to face semi-structured interviews conducted on-site. The interviewees were with the village manager, one assistant village manager, and 15 department directors. Also, about 15 hours of participant observation was done, which covered: one village manager-department directors formal meeting, one village council meeting, and 
one community event organized in collaboration with the village government and an external technical support services firm. The researcher also participated in informal lunch meetings with employees. There were several informal conversations with the village administration staff.

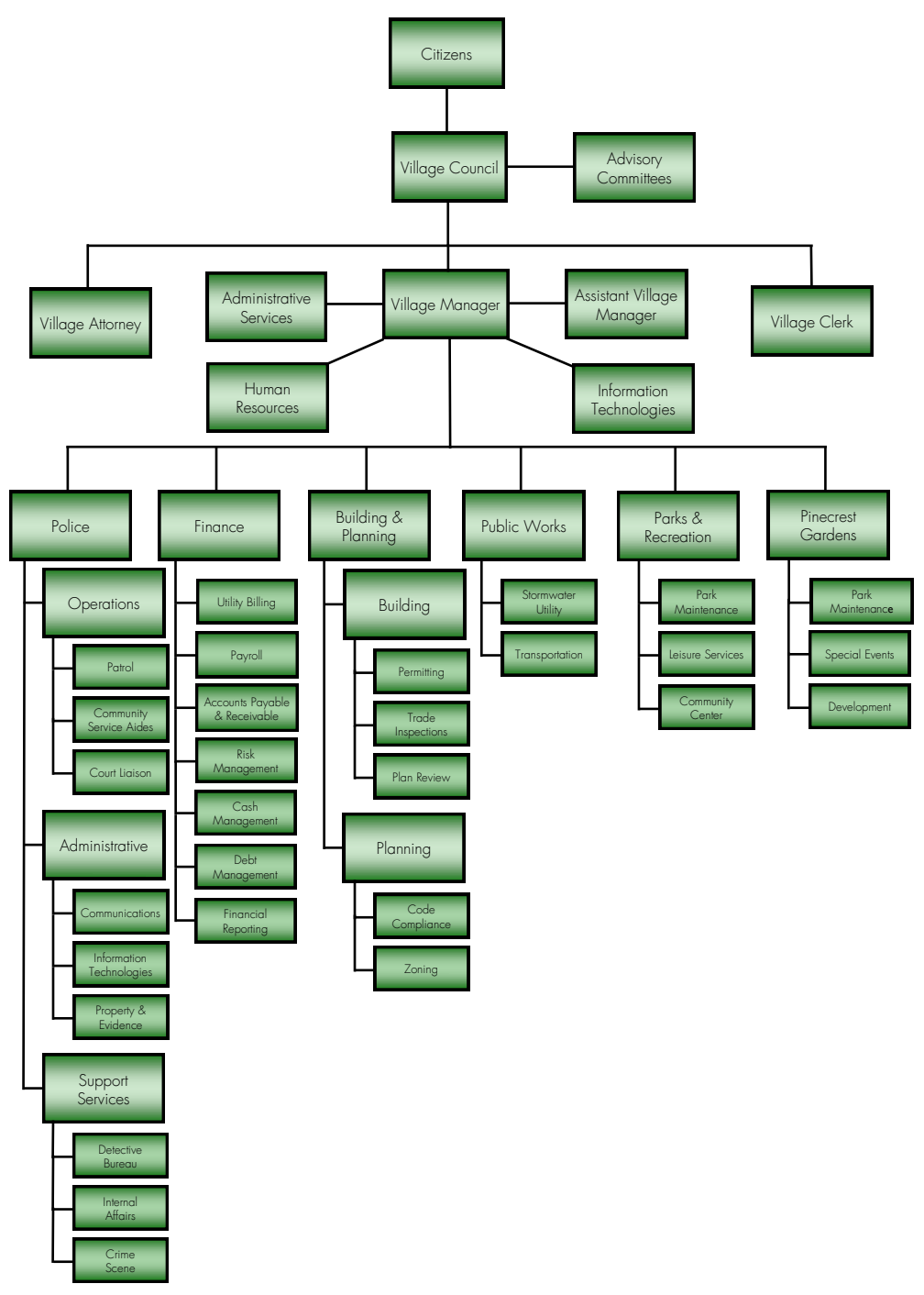

Figure 13. Village C's Organizational Chart. Retrieved from the Website. 


\section{Case Study Data Analysis}

Case study interview data were transcribed using an online software Temi. Subsequently, each interview transcript was checked and verified, proofread, and edited for accuracy concerning the words spoken in the audio (see Appendix $\mathrm{J}$ for interview transcription strategy). Transcript data was then re-arranged based on the research questions. NVivo 12 software was used for the case study data analysis. NVivo is a qualitative data analysis software that allows for data storage and organization, in-depth data analyses (of transcriptions, videos, voice, notes, or pictures), and data visualizations. Case study data analysis techniques used were content/thematic analysis, explanation building, pattern matching, and cross-case analysis for comparisons.

NVivo is useful for creating codes, identify themes, and run queries to assess the prevalence of and relationships between words, concepts, and themes. Utilizing qualitative data analysis software was particularly important to reveal how codes and themes on individual and organizational attributes of servant leadership were related or unrelated. The use of this software provided an assessment of all the data in a highly systematic and holistic way. Additionally, manual coding of the transcript data was also done using the identified words, codes, or concepts.

\section{Content/ Thematic Analysis}

Content or thematic analysis is a qualitative method used to identify and analyze patterns across the data. These patterns then become recognized as themes in the data to provide an organized and detailed description of the data (Braun \& Clarke, 2006). Broad themes were identified using the categories of the questions in the interview guide, the existing literature on servant leadership, and its individual and organizational attributes. 
The predetermined themes included: servant leadership behavior, servant identity:

calling, empathy, humility, spiritual love for people (agape love), moral potency: moral courage, moral ownership, moral self-efficacy. Additionally, the themes explored were social support, formal-informal networks, employee engagement, community engagement, collaboration, public service, community meetings.

\section{Explanation Building}

Explanation building is a qualitative analytic technique that is used to identify causal links or inferences and to explain what is happening in a given case (Yin, 2009). Attention was devoted specifically to which explanations were provided by the respondents about their leadership experience in their organization. Special care was given to exploring what employees perceive about the individual leader and how does leadership in the organization translates into employee relationships, trust, and organizational outcomes. Codes and themes were identified at a semantic (or explicit) level, where the "surface meanings of the data" were most important and "the analyst is not looking for anything beyond what a participant has said or what has been written" (Braun \& Clarke, 2006, p. 84).

This analysis was focused on the descriptions given in the document and the interpretations thereof, rather than on examining latent and underlying ideas or assumptions (Braun \& Clarke, 2006). In the findings section, quotes that illustrate themes consistently found throughout the data are presented. The quotes used are not uncommon unless it is explicitly stated that a small number of respondents shared these views. The special focus was on identifying themes grounded in qualitative data. 


\section{Pattern Matching}

Pattern matching involves comparing the empirically-based patterns - that is to observe if the predicted patterns made before the data collection were manifest in the data. In a multi-case study context, pattern matching during data analysis strengthens the internal validity of the research when empirical patterns emerge similar to the predicted pattern (Trochim, 1989). In the context of this study, there were several predicted patterns to be tested. If they manifest across several case study sites, there is a likelihood of a broader generalization of the pattern. For example, if propositions regarding servant leadership behavior are predicted by certain individual attributes of the leader, and the pattern is replicated across the three cases, it would strengthen the conclusions to explore 'how' and 'why' this occurred in one case or the other.

Cross-Case Analysis

Cross-Case Analysis technique is applied specifically in multiple case studies. In a cross-case analysis, the useful approach is to identify within case patterns, then look for replication of the patterns across the multiple cases for similar relationships. Specifically, 'how' or 'why' an individual would engage in servant leadership behavior was explored. Subsequently, literal and theoretical replications of the phenomenon are checked in multiple cases (Yin, 2014). A cross-case analysis is meaningful in a deductive sense when case studies are conducted for certain theoretical propositions.

\section{Summary:}

This chapter outlined the research methodology of the dissertation. It explains the research design. The study uses a mixed-method approach, complementing an online survey with three case studies and is empirically based in the State of Florida. 


\section{CHAPTER 3: \\ Servant Leadership Behavior among Local Government Administrators: An Interpretation of Servant Identity and Moral Potency}

\section{Introduction}

Servant leadership is an emerging concept in organizational leadership literature (Eva et al., 2018; Liden et al., 2008). Mainstream research on servant leadership emerges from business administration. Public administration discipline has paid scant attention to servant leadership. To date, scholars in business management have examined conceptualization and measurement issues, as well as outcomes of servant leadership while paying very little attention to the individual attributes that manifest servant leadership behavior. In other words, research is scant on exploring the individual factors that are a precursor to the servant leadership behavior (Eva et al., 2018; Liden et al., 2014; Beck, 2014; van Dierendonck, 2011).

Examining Individual factors ascertain the understanding of why some individuals behave as servant leaders and others do not. This is of utmost importance in public organizations to acclimatize the values of integrity, service orientation, and citizen empowerment. Servant leadership qualities are entrenched in empowering followers with an overarching goal to benefit the community and in turn the larger society (Van Dierendonck, 2011, Liden et al., 2014; Eva et al., 2019). Therefore, servant leadership is a promising and comprehensive approach to public organizations. Understanding the individual attributes of public sector leaders who behave as servant leaders will uncover the psychological basis of developing servant leaders in public organizations.

The limited research on individual factors has focused on exploring the leader's personality and gender as determinants of servant leadership. Personality attributes such 
as agreeableness, extraversion, core-self-evaluation, mindfulness, and narcissism explained the manifestation of servant leadership behavior (Hunter et al., 2013; Flynn, Smither, \& Walker, 2016; Verdorfer, 2016; Peterson et al., 2016). For example, one study found an insignificant relationship between an individual's emotional intelligence and servant leadership (Barbuto, Gottfredson, \& Searle, 2014). Similarly, two studies found that female leaders are more likely to display servant leadership behaviors such as emotional healing, altruistic calling, and organizational stewardship in comparison to their male counterparts (Beck, 2014; de Rubio \& Kiser, 2015).

Despite some initial research and promising findings on individual attributes of servant leadership, knowledge about what factors influence an individual to behave as a servant leader is limited. Examining individual attributes of servant leadership is critical in understanding how to develop servant leaders. Especially in public organizations, the need for servant leaders is of high value as the concept is embedded in public service values such as integrity, service orientation, and justice. The original conception of servant leadership is founded on Robert Greenleaf's (1970) definition that "servant leadership begins with the natural feeling that one wants to serve first, then the conscious choice to serve brings one to aspire to lead" (p.4). The evolutionary basis of servant leadership according to Greenleaf (1970) is:

the servant leader is sharply different from the one who is a leader first. ...the difference manifests itself in the care taken by the servant to make sure that other people's priority needs are being served. The best test, and difficult to administer, is: do those being served, become healthier, wiser, freer, more autonomous, and more likely to become servants? And, what 
is the effect on the least privileged in society: will they benefit, or at least, not further deprived? (Greenleaf, 1970, p.3).

The core of servant leadership lies in the desire to serve first. It epitomizes the selfless service orientation of leaders (Greenleaf, 1977; Liden et al., 2014). Sun (2013) argue that individuals engage in servant leadership behavior due to personal identification with self-less service. In other words, it is referred to as 'servant identity'. Leaders' servant identity is defined by their core self-concept (Obodaru, 2012; Shamir, Hourse, \& Arthur, 1993). Therefore, servant identity emerges as a vital individual attribute to manifest servant leadership behavior.

Along with the identity to serve first, servant leadership theory has strong moral foundations as well (Liden et al., 2008; Liden et al., 2014; van Dierendonck \& Nuijten, 2011). The basis of morality in servant leadership can be better explained by understanding the moral process that entails the moral behavior of servant leaders. Moral potency is one such potential attribute that enables servant-leaders to take moral action in times of adversity. Moral potency is defined as the responsibility for moral action (moral ownership), belief that one can act in a moral way (moral efficacy), and the tenacity to engage in moral behaviors and overcome obstacles to moral action (moral courage). Moral potency emerges as another individual attribute for servant leaders while enacting ethical behavior. Thus, servant identity and moral potency are complimentary individual attributes that form the basis of servant leadership (Greenleaf, 1977, Liden et al., 2014; Hannah, Avolio, \& May, 2011, Hannah, Avolio, \& Walumbwa, 2011). This study examines the individual attributes which are precursors to the servant leadership behavior among local government managers. 


\section{Individual Attributes of Servant Leadership}

To understand the leader's identification with service and ethics, two individual attributes are examined in this study: servant identity and moral potency. Identifying precursors to servant leadership behavior is vital. It uncovers the psychological processes that facilitate the development of servant leadership characteristics. Specifically, in public administrative leadership, this study enables the understanding of leadership models that entail both service orientation and ethical orientation as prerequisites for effective leadership in public organizations. In particular, understanding individual factors of servant leadership sheds light on why some individuals adopt this style of leadership.

\section{Servant Identity Attributes}

In public organizations, the identity of leaders is challenged during complex decision-making situations (Horton, Caron, \& Giauque, 2006). Especially, in the $21^{\text {st }}$ century corporate world, 'public servant's identity' is geared more towards enhancing agency performance rather than serving the public interest. As a result, public leaders become another competitor in the market compromising the values of honesty, integrity, probity, and dedication to public service (Horton et al., 2006; Horton, Bockel, \& Noordegraaf, 2006). The public servant's responsibilities of augmenting democratic engagement, citizen empowerment, and informed policymaking take a backseat. Thus, developing the identity of a public servant to act in the public interest is paramount for public organizations in the $21^{\text {st }}$ century.

Liden et al., (2014) proposed that servant leaders possess a prosocial identity. Such an identity drives an individual's self-concept towards serving, caring, and empathizing with others with a overarching goal of benefitting the community (Grant et 
al., 2009). These characteristics facilitate the individual to see himself or herself as prosocial; someone who cares and wants to serve others (Stryker \& Burke, 2000). Identity is defined as the individual's desire to express who they are, their feelings, and values that guide a certain display of behaviors and actions (Hannah, Woolfolk \& Lord, 2009; Reynolds \& Ceranic, 2007).

From a social identity theory (SIT) standpoint, individual behavior is entwined in multiple identities of the actor (Tajfel \& Turner, 2004; Ashforth \& Meal, 1989). A person's self-concept is shaped by personal (personal character, bodily attributes, psychological traits) and social identity (perception of oneness and belongingness to others). The psychological rationale for leaders to engage in servant leadership behavior is dependent on their identification as a servant first. Public service is central to their selfconcept. Self-concept is a cognitive structure, which is dynamic and constitutes a person's self-representation shaped by life experiences (Campbell, et al., 1996). Thus, the personal identification of servant leaders with 'service first' is enacted intra-personally, and social identification is enacted interpersonally when servant leaders are recognized as servants by the followers (Liden et al., 2008).

Likewise, Sun (2013) proposed that servant leaders possess multiple identities. Socio-cognitive processes act as facilitators while enacting such identities. The behavioral complexities of servant leaders can be understood based on these subtle sociocognitive processes (Hannah et al., 2009). Servant leaders activate servant identity and other types of identities and behaviors based on situational demands. For example, in a situation when servant leaders are faced with a dilemma of serving the self-interest or the public interest, their calling to serve the attribute of servant identity will get activated. It 
would act as a deterrent from engaging leaders in self-serving actions. Thus, servant identity is critical for developing the public sector leaders, who can balance public service values of service and ethical orientation with managerial values of organizational efficiency and productivity. According to Sun (2013), there are four attributes of servant identity: calling to serve, humility, empathy, and agape love that constitute the basis for manifesting servant leadership behavior. Their definitions are provided in Table 7.

Drawing from Sun (2013), it is hypothesized that servant identity is a precursor to servant leadership leading to the hypothesis below:

H1a: Local government administrators who possess servant identity attributes (calling to serve, humility, empathy, and agape love) will be rated high on servant leadership behavior.

Table 7. Servant Identity Attributes

\begin{tabular}{l|l}
\hline $\begin{array}{l}\text { Servant Identity } \\
\text { Attributes }\end{array}$ & Definition \\
\hline Calling & $\begin{array}{l}\text { The vocation of leader to be of service to others, one which } \\
\text { provides purpose to life. }\end{array}$ \\
\hline Humility & $\begin{array}{l}\text { Attribute that orients leader to consider others above oneself. } \\
\text { Ability to put aside (or abandon) his or her position, } \\
\text { accomplishments, and talents, to benefit the talents of others. It is } \\
\text { the ability to hold one's position and capability in proper } \\
\text { perspective so as not to permit an inflated sense of self to get in } \\
\text { the way of fulfilling one's calling. }\end{array}$ \\
\hline Empathy & $\begin{array}{l}\text { The attribute that enables a leader to put themselves in another } \\
\text { person's shoes and understand the position and situation they are } \\
\text { coming from. }\end{array}$ \\
\hline Agape Love & $\begin{array}{l}\text { An altruistic form of love that is selfless, unconditional, and } \\
\text { deeply spiritual. }\end{array}$ \\
\hline
\end{tabular}

Source: Sun (2013) 


\section{Moral Potency Attributes}

Unethical practices have plagued government agencies leading to the decline in public trust (Pew Research Center, 2015). The need for ethical behavior of leaders has attracted global importance due to frequent scandals and integrity violations in public organizations (Hassan, Wright \& Yukl, 2014; Mastracci, 2016; Lasthuizen, 2008). Leaders are role models of ethical action that promotes ethical conduct among followers. The question of why some leaders act morally and others do not is a complex one and has many dimensions (Beeri et al., 2013; Menzel, 2015). Mayer et al. (2012) argued that moral identity influences the ethical behavior of leaders which is based on traits such as caring, compassion, fairness, friendliness, generosity, helpfulness, and honesty. The servant leadership approach is promising and inclusive in this regard. It encompasses moral action and service identification, which sets it apart from other leadership theories (Greenleaf, 1970; Sendjaya et al., 2008; Dierendonck \& Nuijten, 2011).

Servant leadership is distinctive from the ethical leadership model since it internalizes both the service as well as ethical orientation among leaders rather than just following a normative expectation to abide by the codes of conduct and the rule of law (Sendjaya, Sarros, and Santora, 2008; Graham, 1991). Ethical leadership focuses on only one dimension of ethics, while servant leadership is inclusive in embracing the values of not only ethics but service and accountability. Although servant and ethical leadership overlap in their moral conceptualization, their definitions are distinct. Ethical leadership is defined as the leader's compliance with normative standards, while servant leadership's focus is on benefitting the multiple stakeholders. The framing of servant leadership is different from ethical in terms of their outcomes (Lemoine et al., 2019). 
Previous research has shown how transformational leadership lacks the developmental side of moral behavior when compared with the servant leadership style (Liden et al., 2008; Dierendonck, 2011; Hoch et al., 2016; Russell \& Stone, 2006). According to Dierendonck (2011), the primary allegiance of transformational leadership is organization development and not follower development. The personal growth of the followers is seen by transformational leaders as an after-thought, to perform better in enhancing organizational performance and the not the follower's well-being. To achieve organizational goals, transformational leaders sometimes turn manipulative and risk their moral behavior. While the servant leaders focus on follower's development and trust followers to do what is necessary for the organization.

Liden et al., (2014) theorize that ethical behavior in servant leaders is attributable to their moral potency (also referred to as moral conation). Moral potency is defined as a psychological state marked by an experienced sense of moral ownership over the moral aspects of one's environment, reinforced by belief in the capacity to act morally, and the courage to remain ethical in the face of adversity (Hannah \& Avolio, 2010, p.291). Public sector leaders are often put in adverse conditions facing moral conflicts and dilemmas. The inability to deal with moral conflicts gives rise to self-serving behavior among public servants. Such self-serving tendencies turn into corrupt leadership practices. Given that servant leaders, moral behavior is based on their moral potency, such leaders can confront moral conflicts more efficiently (Liden et al., 2014).

Hannah et al., (2011) noted that the capacity and courage to act morally during adverse situations are essential for the exhibition of strong moral behavior among the leaders in general. A leader's character is not about whether he/she thinks morally; it is 
about whether he/she acts morally in challenging and adverse situations (where the scope to be self-serving is very high). Unlike moral identity emphasized in ethical leadership (Mayer et al., 2012), moral potency emerges as a vital individual attribute of servant leadership given its consequential focus in benefitting multiple stakeholders. Moral potency is about not just the moral identification and moral judgments in the face of competing for moral conflicts and values, but it is the ability to take moral actions in situations that pose moral challenges to leaders. There are three components of moral potency- moral courage (resilience and tenacity to behave morally during personal dilemma), moral ownership (responsibility for moral action), and moral efficacy (selfbelief to act morally) (Hanna \& Avolio, 2010; Hannah, Avolio \& May 2011). The three moral potency constructs are complementary and the absence of anyone will jeopardize the development of moral potency as a whole (see table 8).

Table 8. Psychological Underpinnings of Moral Potency

\begin{tabular}{c|l}
\hline Moral Potency Attributes & Definition and Psychological Basis \\
\hline Moral Ownership & $\begin{array}{l}\text { The sense of ownership and responsibility for the } \\
\text { ethical conduct of oneself (theory of human agency } \\
\text { and psychological ownership - Bandura, 1991, 1992, } \\
\text { 2002; Kohlberg \& Candee, 1984; Van Dyne \& } \\
\text { Pierce, 2004. self-complexity theory - Hannah, } \\
\text { Woolfolk \& Lord, 2009) }\end{array}$ \\
\hline Moral Courage & $\begin{array}{l}\text { Fortitude to convert moral intentions into actions } \\
\text { despite pressures from inside or outside } \\
\text { organization/commitment to moral principles, } \\
\text { awareness of dangers involved, and endurance to } \\
\text { overcome these dangers to act ethically or resist } \\
\text { pressure to act unethically required to maintain those } \\
\text { principles (Kidder, 2003; May et al., 2003; Hannah, } \\
\text { Avolio \& Walumbwa, 2011; Osswald et al., 2009) }\end{array}$ \\
\hline
\end{tabular}




\begin{tabular}{l|l}
\hline Moral Efficacy & $\begin{array}{l}\text { One's belief (confidence) in one's capabilities to } \\
\text { organize and mobilize the motivation, cognitive } \\
\text { resources, means and courses of action needed for } \\
\text { moral performance, within a given moral domain, } \\
\text { while persisting in moral adversity, depends on both } \\
\text { external and internal self-efficacy (Eden, 2001; } \\
\text { Bandura, 1997; Stajkovic \& Luthan, 1998) }\end{array}$ \\
\hline
\end{tabular}

Source: Hannah \& Avolio, 2010

Menzel (2015) argued that government leaders need to pursue high standards of integrity which is not a simple and easy task but is a long-term commitment to stay ethically competent. The moral potency dimensions of servant leaders are quite important here. The development of moral potency is not only important to be tested for servant leadership behavior in the public sector but is also critical in the face of recent ethical scandals in local governance. An ethically behaved leader is of the utmost importance to local governments. Drawing on Liden et al. (2014), the following hypothesis tests moral potency as a precursor to the servant leadership behavior among local government administrators.

H1b: Local government administrators who possess moral potency attributes (moral ownership, moral courage, moral efficacy) will be rated high on servant leadership behavior.

\section{Research Design and Methodology}

The study relies on a mixed-method research design - an online survey and three case studies of county and city governments that rated high on servant leadership behavior in an online survey. The unit of analysis is county and city governments with a council-manager form. 


\section{Sample and Data}

Online survey data was conducted on the State of Florida's local governments. The state of Florida is diverse in demographics in terms of race, population, and political representation. Municipalities (cities, towns, and villages) and the county governments were included in the online survey and not the boroughs or special districts. Out of the 67 counties in the State of Florida, only 60 counties were included in the survey. Similarly, 181 municipalities in the State of Florida with a council-manager form of government were included in the survey. Municipalities and the counties were surveyed based on the availability of email contacts of the employees on the official website of the municipality. Some email addresses were made available requesting the concerned municipality-county public records office.

\section{Procedure}

The survey respondents in this study were county and city managers and their executive team members (department directors, deputy county and city managers, or assistant county and city managers). The online survey link was sent on the official emails of the respondents from a total of 241 county and city governments in the State of Florida. Completed surveys were returned from at least 155 county and city governments with a response rate of $63 \%$. Minimum 1 and a maximum of 14 executive team members responded from the county and city government. There were 54 government agencies from which only the county or the city manager responded but there were no responses from their executive team members. In total, 99 county and city managers and 228 executive team members responded. Thus, a total of 327 complete employee responses 
were recorded. The list of county and city governments included in the survey is provided in Appendix D and E. A copy of the online survey is available in Appendix C.

\section{Operationalization of Variables}

The variables of interest in this study are servant leadership behavior (outcome variable), moral potency, and servant identity (predictor variables). Additionally, the demographic variables used as control are education, age, gender, total tenure in local government, ethnicity, and tenure in the current position. The predictor variables were rated by the leader and their executive team members, and the outcome variable was rated by the executive team members across the county and city governments in the State of Florida. Responses for the servant leadership behavior, moral potency, and servant identity were recorded on a scale of 1 (strongly disagree) to 7 (strongly agree).

\section{Dependent Variable -Servant Leadership Behavior}

The dependent variable for this study is servant leadership behavior. To measure servant leadership, 7 items were taken from Liden et al. (2008). The sample items are: My manager emphasizes the importance of giving back to the community, my manager puts my best interests ahead of his/her own. The Cronbach's Alpha for servant leadership behavior is .86. A full list of items is available in Appendix C.

\section{Independent Variable - Moral Potency and Servant Identity}

Since the focus of the study is exploring the impact of individual attributes such as servant identity and moral potency on servant leadership behavior (SLB). There are two predictor variables: moral potency (MPC) taken from Hannah et al. (2010) and servant identity (SI) taken from Sun (2012). Examples of the moral potency items for the 
county and city managers are 'I confront my peers if they commit an unethical act,' I do not accept anyone in my group behaving unethically,' I am confident that I can take decisive action when addressing a moral/ethical decision. Likewise, moral potency items for the executive team members were worded as "My manager can confront his/her peers if they commit an unethical act,' My manager does not accept anyone in his/her group behaving unethically,' My manager is confident that he/she can take decisive action when addressing a moral/ethical decision.' The Servant Identity items are 'I strongly believe that one's vocation and mission in life is to serve others,' My position and accomplishments do not stop me from learning or receiving criticism from others,' I am aware of the emotional states of others even if they do not explicitly disclose them to me.'. The servant leadership behavior items are 'my manager can tell if something workrelated is going wrong,' my manager puts my best interests ahead of his/her own,' my manager would NOT compromise on ethical principles to achieve success.' The 'Cronbach' Alpha score for servant leadership behavior is .86, for moral potency .95, and servant identity .93 .

\section{Hierarchical Linear Model of Servant Leadership Behavior}

The data is obtained at two levels: county and city managers and their executive team members nested within county and city governments across the State of Florida. For multilevel data, the recommended method of data analysis is Hierarchical Linear Modelling (HLM). The hierarchical regression equation for the model in this study is: Null Model or Unconditional Means Model:

$(\text { Servant Leadership Behavior })_{\mathrm{ij}}=\beta_{0 \mathrm{j}}+\varepsilon_{\mathrm{ij}}$ 
The model with Predictors:

$(\text { Servant Leadership Behavior })_{\mathrm{ij}}=\gamma_{00}+\gamma_{1 \mathrm{ij}}($ Servant Identity $)+\gamma_{2 \mathrm{ij}}($ Moral Potency) $+\gamma_{3 \mathrm{ij}}($ Control Variables $)+\varepsilon_{\mathrm{ij}}$

where $\beta_{0}$ and $\gamma_{00}$ are the intercepts, and $\gamma_{1}, \gamma_{2}$, etc. are the coefficients to be determined.

Data Aggregation, Inter-Rater Reliability, and Intraclass Correlations

Data aggregation is essential since the data are collected at an individual level and the dependent variables of interest are conceptualized at the organizational level.

Additionally, employees are nested in the organization, so aggregation is necessary to determine if the multilevel modeling is appropriate. Conceptual aggregation, however, is best accompanied by statistical justification (Klein, Dansereau, \& Hall, 1994). First, it is necessary to calculate inter-rater agreement $r_{w g}$ to justify aggregation. The accepted threshold for the inter-rater agreement is .70 (LeBreton \& Senter, 2008). Additionally, Intraclass correlation, ICC (1), and ICC (2) are the statistics commonly used to justify aggregation of data to higher levels (e.g., Bartko, 1976; Shrout \& Fleiss, 1979).

The ICC (1) compares the variance between units of analysis (agreement between employee responses across the county and city governments in the State of Florida) to the variance within units of analysis (agreement between employee responses within the same county and city government) using the individual ratings of each respondent. The ICC (2) assesses the relative status of between and within variability using the average ratings of respondents within each unit (Bartko, 1976). 
Within-group agreement $\left(\mathrm{r}_{\mathrm{wg}}\right)$ is calculated using the uniform null distribution. The average $r_{\mathrm{wg}}$ score for moral potency is .73 $(\mathrm{Mdn}=1)$, servant identity is .79 $(\mathrm{Mdn}=1)$, and servant leadership behavior is $.79(\mathrm{Mdn}=1)$ indicating the empirical justification of aggregating the individual employee scores to the organization level. In the unconditional null model, to see if there is an agreement in employee responses across organizations, the ICC (1) value for our data was .12, and the average ICC (2) value was .73. Although there are no strict standards of acceptability for either ICC (1) or ICC (2) values, James (1982) reported a median ICC (1) value of .10 in the organizational literature, and Glick (1985) recommended an ICC (2) cutoff of .60.

The values are well within the recommended levels and justify aggregation. These values were greater than the recommended cutoff for ICC1 and ICC2 indicating highlevel agreement between a group of employees within the same county and city government. Thus, the intraclass correlation statistics justify aggregation. Besides, the ANOVA model indicating the variation in employee responses across the county and city is significant $(\mathrm{p}<.01)$, justifying the aggregation.

Additionally, there is a theoretical justification for aggregating the variables. The outcome variable servant leadership behavior and the predictor variables servant identity, and moral potency is measured at the individual level, but their responses are nested across the county and city government agencies in the State of Florida, justifying aggregation of individual responses to the organizational level. The county and city managers servant identity and moral potency manifesting the servant leadership behavior is measured in this study. Thus, the unit of analysis is the county and city managers. 


\section{HLM Results}

Table 9 shows the descriptive statistics of all the variables at the individual level and their correlations. The data for this study came from the leaders and the employees of 155 county and city governments in Florida. A total of 327 leaders and employee responses were received. ANOVA was used to examine whether there were significant differences between the organizations (county and city governments) in terms of the main variables concerning this study. No significant differences were found.

\section{Descriptive Statistics and Correlations}

In table 9, variable means are above the middle of the range (3.0), and the correlations between predictor variables (servant identity and moral potency) are not very high. Correlations justify the theoretical foundations of the concepts of servant leadership, servant identity, and moral potency.

Table 9. Means, Standard Deviation, and Correlations Among the Variables

\begin{tabular}{lllllll}
\hline Variable & $\mathrm{M}$ & $\mathrm{SD}$ & 1 & 2 & 3 & 4 \\
\hline 1.Servant Leadership & 5.50 & 1.13 & 1 & & & \\
2. Servant Identity & 5.23 & 1.11 & .73 & & & \\
3. Moral Potency & 6.0 & 1.03 & .63 & .65 & 1 & \\
\hline
\end{tabular}

Note. $\mathrm{N}=327$. All correlations are at the individual employee level to assess individual attributes (i.e. servant leadership behavior, servant identity, moral potency)

\section{Confirmatory Factor Analysis - Measurement Issues (CFA)}

Because the data was collected from different county and city governments across the State of Florida, the multigroup CFA was conducted to establish the validity of the measures. CFA was conducted in STATA 16 on the county and city managers and their executive team members reported items of moral potency, servant identity, and servant 
leadership behavior, allowing the items to load on the proposed latent construct (Figure $14 \& 15)$. This is supported by the findings from empirical research that servant leadership is explored best when examined as an overall construct due to the high correlation between items (Sendjaya \& Cooper, 2011).

The CFA model for all the three scales fits the data well: for servant leadership behavior, the model fit was $\chi^{2}(14, \mathrm{~N}=327)=52.84, \mathrm{p}<.000$; comparative fit index $(\mathrm{CFI})=$ .95 , tucker-lewis index $(\mathrm{TLI})=.93$, root mean square $($ RMSEA $)=.091$. root mean square error $(\mathrm{SRMR})=.03$. For servant identity, the model fit was $\chi^{2}(54, \mathrm{~N}=327)=352.24$, $\mathrm{p}<.000$; comparative fit index $(\mathrm{CFI})=.91$, Tucker-Lewis index $(\mathrm{TLI})=.89$, root mean square $(\mathrm{RMSEA})=.13$, root mean square error $(\mathrm{SRMR})=.09$. For moral potency, model fit was $\chi^{2}(54, \mathrm{~N}=327)=447.09, \mathrm{p}<.0000$; comparative fit index $(\mathrm{CFI})=.89$, TuckerLewis index $(\mathrm{TLI})=.86$, root mean square $($ RMSEA $)=.14$, root mean square error $(\mathrm{SRMR})=.05$.

\section{HLM hypotheses tests}

As stated earlier, the model tested in this hypothesis is multi-level. First, a null model was tested to understand the between-group variance among employee respondents across the county and city governments for servant leadership behavior. The results reveal a $54 \%$ predicted variance across the county and city governments, and the chi-square test revealed that between-group variance was significant $\left(\chi^{2}=152.56\right.$, $\mathrm{p}<.001)$. 


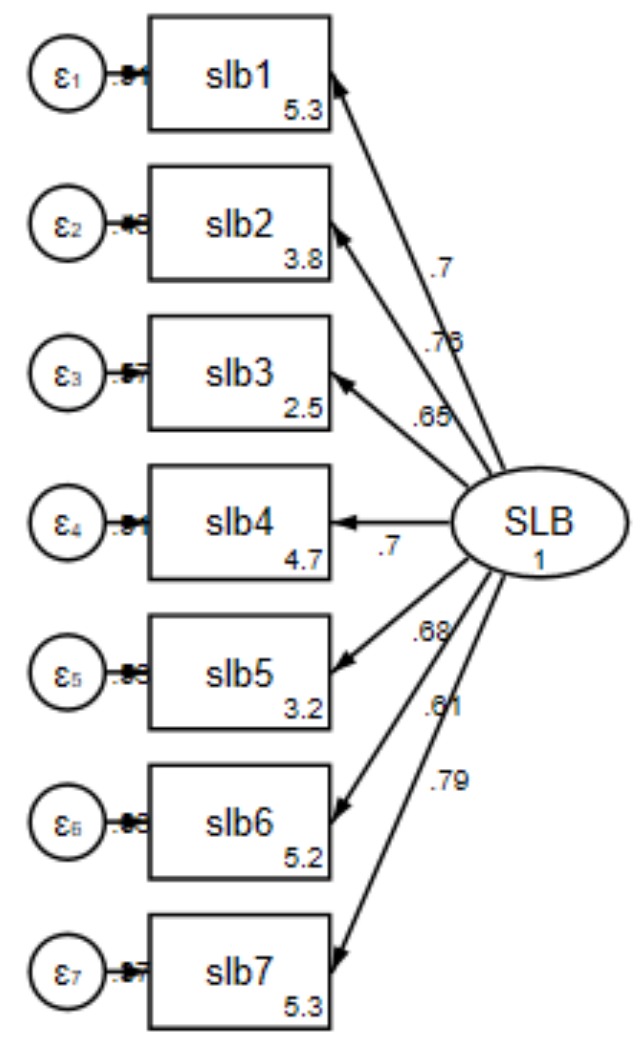

Figure 14. Confirmatory Factor Analysis for Servant Leadership Behavior (SLB) 


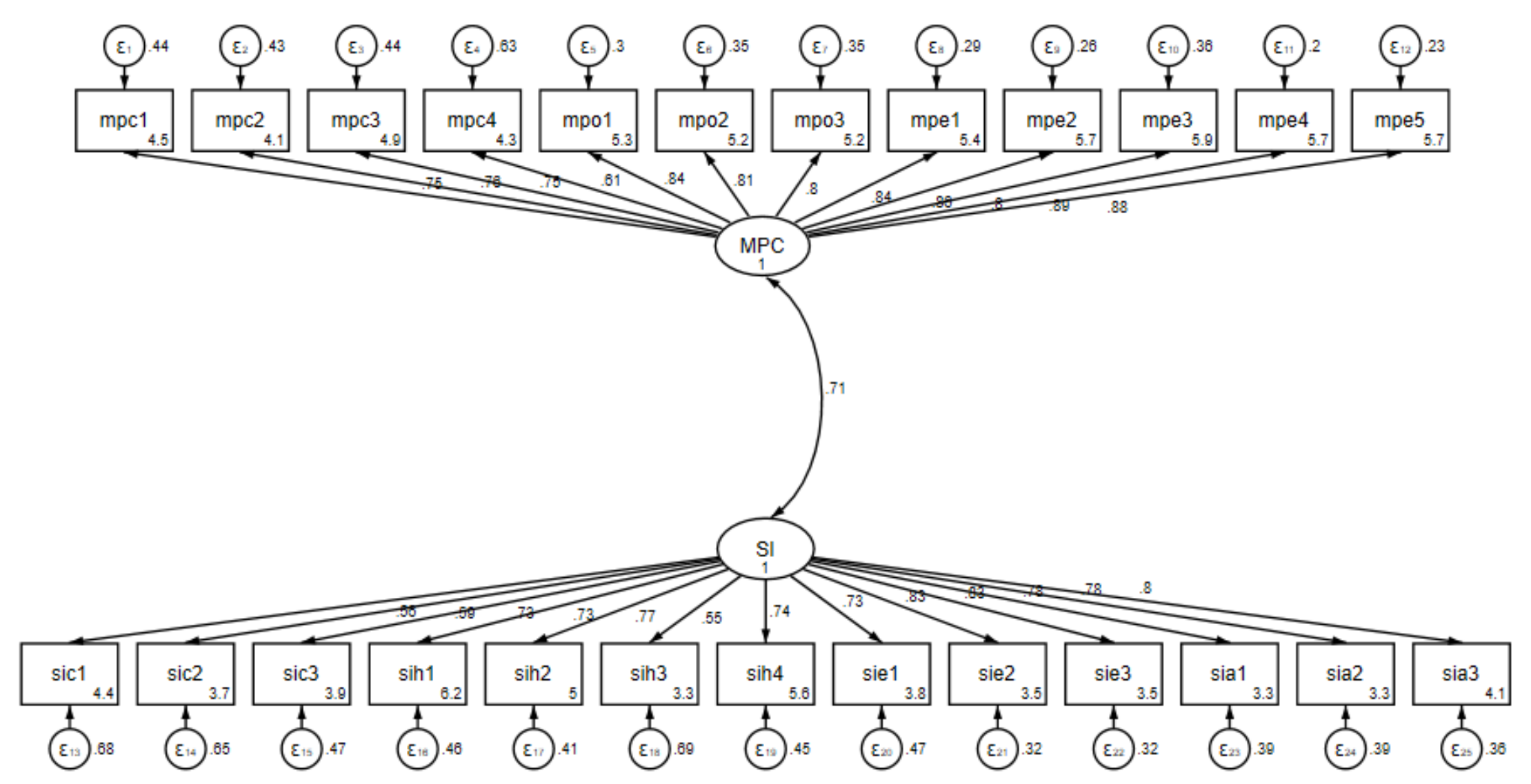

Figure 15. Confirmatory Factor Analysis for Moral Potency (MPC) and Servant Identity (SI) 
Two hypotheses are tested in this study: 1) H1a - county and city managers servant identity attribute will be positively related to their servant leadership behavior; 2) $\mathrm{H} 1 \mathrm{~b}$ - county and city manager's moral potency attribute will be positively related to their servant leadership behavior. All responses were at the individual employee level nested in county and city governments. In addition, there was a significant variance across the county and city governments as depicted in the intercept (Table 10).

Hypothesis $1 \mathrm{~b}$ predicted a significant positive relationship between moral potency and servant leadership behavior. Table 10 shows the hierarchical linear modeling results. In Model 1, moral potency is significant and positively related to the servant leadership behavior of the county and city managers $(\gamma=.64, \mathrm{p}<.000)$. Thus, hypothesis $1 \mathrm{~b}$ is supported. In Model 2, hypothesis 1a tested the relationship of servant identity with servant leadership behavior, it showed a significant positive relationship $(\gamma=.73, \mathrm{p}<.000)$. Subsequently, in Model 3, both moral potency and servant identity are entered together, both relate positively to servant leadership $(\gamma=.24, \mathrm{p}<.000, \gamma=.57, \mathrm{p}<.000)$. However, the effect of moral potency is reduced in presence of servant leadership.

Including different models in the analysis, supports the broader argument of servant leadership fit in local governments, given the nature of its relationships. In addition to the main variables, none of the demographic variables were significant in model 1. However, in model 2, gender and ethnicity are significant. In model 3, only ethnicity is significant. 
Table 10. Hierarchical Linear Modelling Results

\begin{tabular}{|c|c|c|c|c|c|c|}
\hline \multirow{2}{*}{$\begin{array}{c}\text { Variable } \\
\text { Employee Responses Nested within } \\
\text { Organizations }\end{array}$} & \multicolumn{2}{|c|}{$\begin{array}{c}\text { SLB } \\
\text { Model 1 }\end{array}$} & \multicolumn{2}{|c|}{$\begin{array}{c}\text { SLB } \\
\text { Model 2 }\end{array}$} & \multicolumn{2}{|c|}{$\begin{array}{c}\text { SLB } \\
\text { Model } 3\end{array}$} \\
\hline & Estimate & $\begin{array}{l}\text { Standard } \\
\text { Error }\end{array}$ & Estimate & $\begin{array}{l}\text { Standard } \\
\text { Error }\end{array}$ & Estimate & $\begin{array}{l}\text { Standard } \\
\text { Error }\end{array}$ \\
\hline \multicolumn{7}{|l|}{ Level 1 Variables $(n=327)$} \\
\hline$\overline{\text { Age }}$ & -.021 & .051 & -.025 & .044 & -.019 & .043 \\
\hline Education & -.004 & .034 & -.014 & .029 & -.015 & .028 \\
\hline Gender & .056 & .082 & $.12^{\wedge}$ & .071 & .083 & .069 \\
\hline Ethnicity & .061 & .053 & $.12 *$ & .045 & $.11 * *$ & .043 \\
\hline Tenure in Local Government & -.003 & .043 & .005 & .037 & -.004 & .036 \\
\hline Tenure in Current Position & -.034 & .046 & -.006 & .039 & .001 & .038 \\
\hline \multicolumn{7}{|l|}{ Level 2 Variables $(n=155)$} \\
\hline Intercept (null model) & $5.47 * *$ & 0.061 & & & & \\
\hline Moral Potency & $.64 * * *$ & .043 & & & $.24 * * *$ & .048 \\
\hline Servant Identity & & & $.73 * * *$ & .036 & $.57 * * *$ & .046 \\
\hline
\end{tabular}

Note: Entries for the predictor variables are fixed effects with robust standard errors.

$\mathrm{SLB}=$ Servant Leadership Behavior, ${ }^{\wedge} \mathrm{p}<.05 * \mathrm{p}<.01,{ }^{* *} \mathrm{p}<.001,{ }^{* * *} \mathrm{p}<.000$ (two-tailed test). 


\section{Qualitative Case Study Analysis}

The case study data for this study come from 50 interviews conducted at County A, B, and Village C. There were 2 county managers, 1 village manager, and 47 executive team members. Individually, at County A 18 interviews were conducted, County B 15 interviews, and Village C 17 interviews. Besides, there were 10 emails and memos sent by the county administrator to his employees sharing organizational direction, resources, and details. The data from observations were also utilized. While analyzing the case study data for hypotheses $1 \mathrm{a}$ and $1 \mathrm{~b}$, the focus was on exploring how servant identity and moral potency of the county and city managers relate to their servant leadership behavior.

Servant identity and moral potency are latent psychological constructs and difficult to be observable. A broad approach is taken by using the data from interviews, observation, and the leader's biography to understand the nuances associated with these constructs in the leader's behavior. Interviewees did not understand when asked about words servant identity, moral potency, or servant leadership. Therefore, during the semistructured interviews, the questions were rephrased. The main focus was on exploring the proposition: city-county managers who possess servant identity and moral potency will be rated high on servant leadership behavior.

To assess the moral potency attribute - leader's moral ownership, courage, and efficacy, the most reliable sources came from asking the executive team members about a leader's moral behavior and the ability to deal with moral conflicts - how the leader acted in those situations. To assess leader's moral potency as explained in his own words, the leader was asked the questions such as what is your background, why did you choose to serve in government, what do you understand by moral conduct and how important it is 
while exercising your responsibilities and duties as a leader? And how do you confront situations of moral dilemma, give some examples?

Similarly, to assess servant identity which includes traits such as - calling to serve, humility, empathy, and agape love, respondents were asked to comment on the leader's identity as a servant, describe leader's personality attributes, what are the leader's belief and values which have been observed while working with him/her? Similarly, leaders were asked to describe their personality and identity, what values shaped him/her the most? The underlying assumptions of these questions were rooted in cognitive dispositions of calling to serve, empathy, humility, and agape love when confronting various situations as a county and city Manager. These cognitive dispositions lead to behavioral dispositions as expressed in their behavior such as 'what I do' is based on who am I'. To assess the servant leadership behavior of leaders, the focus was on understanding the 7 dimensions that emerged from interviews and observations. The 7 dimensions are emotional healing, conceptual skills, behaving ethically, empowering, helping subordinates grow and succeed, putting subordinates first, and creating value for the community (Liden et al., 2008).

The analysis was done for both leaders and followers: 1) what was the leader's opinion about their personality characteristic, values, beliefs, and self-identity; and (2) what the executive team members (department directors, deputy managers, and assistant managers) reflections were about county and city leader's behavior, personality characteristics, values, beliefs, identity. In particular, the focus was on understanding how the underlying individual attributes of servant identity and moral potency translate into the behavioral disposition of servant leadership. 


\section{Case Study Findings}

The case study findings provide an understanding of 'how servant identity and moral potency attributes manifest servant leadership among county and city managers? The data were coded in themes such as servant identity, moral potency, and servant leadership behavior. The content analysis of the data was based on understanding the county and city managers' servant identity in terms of their beliefs, values, and selfidentity, ethical behavior as mentioned by both the leaders and employees. Also, pattern matching, and cross-case analysis were utilized to understand if there was any similarity in themes across all the case studies (Yin, 2014).

A word cloud (Figure 16) was created using the interview codes for servant identity, moral potency, and servant leadership behavior. Word clouds graphically represent frequently used words by respondents during interviews (Ramsden \& Bate, 2008). The logic for the word cloud is based on the size of the text. Larger the size, more frequently the word has been used by the respondent's ${ }^{2}$. It is of relative importance in the qualitative findings as it presents an overview of the content in the data. The top 20 frequently used words by respondents during the interviews were: just, right, get, leadership, county, government, kind, work, mean, departments, employee, position, manager, public, differs, service, team, development, feel, person, understand.

\footnotetext{
${ }^{2}$ Words used in the everyday lexicon and without any meaning to the context were excluded from the word cloud analysis (e.g. and, the, it, that, whether, whatever, much, end, first, one, two, sometimes).
} 


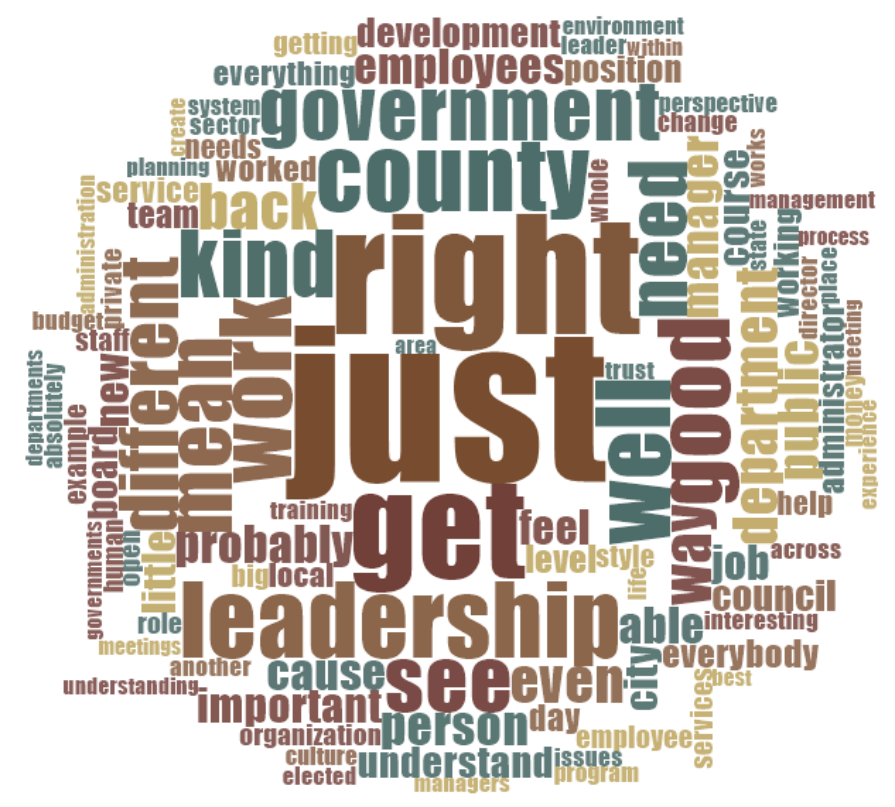

Figure 16. Word Cloud for Servant Identity-Moral Potency-Servant Leadership

Table 11 shows references for individual attributes mentioned by respondents: servant identity (44\%), Moral potency (66\%), servant leadership (45\%). Three organizational factors emerged important to impact leadership: changing the nature of local governments (30\%), politics and administration (67\%), learning and training (48\%).

Table 11. Individual Attributes (Servant Identity, Moral Potency) of Servant Leadership

\begin{tabular}{lcc}
\hline Themes & Percentage & Total (N) \\
\hline Individual Attributes & & \\
Servant Identity & 44 & 16 \\
Moral Potency & 66 & 32 \\
Servant Leadership & 45 & 18 \\
Organizational Factors & & \\
Changing Nature of Local Governments & 30 & 17 \\
Politics and Administration Issues & 67 & 43 \\
Learning and Training & 48 & 22 \\
\hline
\end{tabular}




\section{Servant Identity}

The qualitative findings suggest that servant identity is developed by life experiences and is not necessarily an attribute to be born with. While serving in public service, individuals may develop servant identity over time. Individuals who possess servant identity value the personal and professional growth of others as well as self over monetary growth. The notion of service to others is not mutually exclusive to the service to self. But the difference is the vantage point. This perspective consistently came up during interviews. Besides, there were several factors such as a leader's personality type, character, values, and professional as well as personal background translating into their self-identification of being a servant in a lifetime. And this has a continuum.

You are not in the Public Sector to Get Rich: Initiative, Loyalty, and

Commitment. The village $\mathrm{C}$ manager started her career as a secretary, then served as an assistant to the city manager, subsequently as an assistant manager, and finally went on to become the village manager. Her principle values were having a growth perspective, volunteering, and taking initiative when opportunities come. She wanted to grow herself while also helping others to grow. But it hasn't come easy. She always looked for opportunities to work and volunteer even if it was not her formal job responsibility. As a secretary she was making $\$ 14$ an hour, which was less than $\$ 18,000$ a year to now becoming a village manager. She mentioned:

A lot of people do not want to take on work that they do not get paid for. But that was not my attitude in my career. I would go beyond. I would always take it on, but it was selfish in a way too, because I wanted to build my resume, and I wanted to aspire. [...] I never stopped myself and I 
never took the approach that, well, they don't pay me to do this, I'm not going to do it. On the contrary, I was doing whatever needed to be done, I would be the volunteer and I would take on the initiative. [...] A lot of times I would see things and I would ask if I can do it before it was even assigned to me.

Village C manager cited an example from her professional life about how she would take initiatives beyond the call of duty. And how she valued personal growth over monetary growth. While she gave importance to her aspirations and wanted to grow, it all happened while being a good Samaritan, showing citizenship, caring, and respecting people and the community. She noted:

If I saw a grant application, I will say, we can apply for this. I would go and say, do you mind if I write this grant? I want to get experience. And they would let me do it and then I would do it and then I would be able to build my resume because I always aspire to go higher up. But the way I did it, I would ask for the title change but not the salary increase. [...] So, I would tell my boss, you do not have to pay me more money, but I just want you to change my title. And I would beg until he would finally give me the title change. But that allowed me then to grow in the organizations where there was not a lot of upward mobility because people did not leave.

Sense of Wanting to make the Community better. Servant identity gets formed over life experiences and is a dynamic and multifaceted concept of self. It develops on a continuum of past experiences and present as well as future life perspective. Thus, an 
individual may not have an interest in public service at the beginning of their life but can develop over time based on his/her life experience (Hannah, Woolfolk \& Lord, 2009). Some people work in the private sector but later join the public service sector. There can be many reasons for it. But the majority who work in the public sector do not want to be rich. Public service leaders are inclined to give back to the community and their environment. An employee from county A responded:

You could be an engineer or an architect within a governmental entity and not have that much contact with people because you are doing the technical, you are building the streets, you are designing the roads, you are designing buildings. [...] I think though, for the most part, people coming in the public sector, they are not working here to get rich. but I think there is inherent compassion for others and your environment and your community that you feel $[\ldots]$ that you can make an impact to make things better. So, I would agree that, for the most part, people having the interest to work in the public sector have a sense of wanting to make the place better and there are multiple ways to get to that point.

\section{Moral Potency}

County and city governments operate in a complex and dynamic environment. Leaders in government are faced with moral dilemmas in decision making. Despite knowing that ethical action is warranted, leaders sometimes fail to act. The moral potency attribute addresses this gap between knowing and doing the right thing. Especially county and city managers who are servant leaders, they behave ethically. During the interviews, several examples were provided by employees as well as leaders that everything we do is 
bounded by ethics, integrity, and moral behavior. However, understanding the nuanced differences in knowing ethics and how it translates into real action was limited during the interviewing and observation phase.

\section{A Good Administrator with Higher Ethic has to Reconcile How to Get from Point}

A to B: Good Administrators Act Ethically. Ethics and moral behavior emerged as a key theme in about $80 \%$ of the interviews. Respondents agreed that ethics and government are complementary to each other. It is foundational for the public sector to not only be aware that ethics is important but also to act ethically during situations of moral conflict is critical. A good administrator is skilled in handling situations posing moral conflicts. It is not about compromising on ethical standards but finding a straighter and more efficient path to get the issue resolved. Governments by nature of the dichotomy of politics and administration tend to lean towards the longer path, which means unnecessary delays. An employee echoed this sentiment by stating that:

I do not think it is an issue of compromising on ethical or moral guidance. or even, I use the word fiduciary a lot. [...] that is financial guidance. But certainly, sometimes, there are short ways to get to the end and there are long ways to get to the end. And so, I think that is really what a good administrator has to deal with. [...] there is no prevalence of issues asking someone to compromise on their morals or their financial fiduciary.

Public administration is an art, with the changing scenario and dependency on technology, there is a new normal where governments have to be lean and efficient. Thus, a good public administrator is an artful administrator, who can deal with the new normal. An employee affirmed this point: 
I do think that a good administrator with higher ethic, have to reconcile with how to get from point A to point B. And I think sometimes we can see a straighter, more efficient path, but the political environment requires you to take the longer path. So that is the art form of public administrator, and you have to recognize those. There can be times when you $[\ldots]$ are confronted with a right or wrong, and the good thing about this is what you talked about the new normal.

Local Governments are More Transparent than Before. Historically, local governments were more bureaucratic and isolated from the public, but trends are changing. Local governments are far more transparent than ever. However, there is always a scope to do better. An employee echoed this perspective:

I think local government is more transparent than it was 10,20 , or 30 years ago. The meetings are public. The conversations are public. You cannot have elected officials talking in the back rooms. I know some people would debate me on that, but I think that the government is more transparent than it is ever been. [...] Could it be better? Sure. [...] And so, I think what that does is that it lessens the burden.

Ethics is a culture and a necessity in government (Menzel, 2014). Unlike the private sector, public administration is unforgiving of mistakes. The government works on public money and therefore should function much more transparently than the private sector. The County B Administrator echoed: 
The larger dilemma in public administration and this isn't unique to us, I've been seeing it all my life, that government is not necessarily forgiving of mistakes? I think the private sector is better at that. And again, it goes back to that transparency issue. We in government in many respects are so transparent that when you make a mistake, it is evident for everybody. Tell me how many times do you know whether our private sector persons made a mistake? Do you know? No, you don't, because it is not public.

\section{Servant Leadership}

While analyzing the qualitative data, to assess the servant leadership behavior, the focus was on understanding the seven dimensions such as: emotional healing (being sensitive to the personal setbacks of the followers), creating value for the community (such as encouraging employees to engage in volunteer activities that benefit the local communities), conceptual skills (problem-solving and task knowledge as a prerequisite to providing help to the followers), empowering, helping sub-ordinates grow and succeed, putting subordinates first, and behaving ethically.

During interviews and the observations, the seven dimensions of servant leadership (Liden et al., 2008) manifested among county and city governance in the form of the following characteristics: for emotional healing-many interviewees and the leaders mentioned that 'emotional healing' perhaps is a very strong word in the context of city and county management and instead they emphasized on 'empathy and genuinely caring for people' as appropriate, for 'putting subordinates first'-respondents said it is the same as 'empowering and helping subordinates grow and succeed', 'behaving ethically' was 
confirmed by many respondents, 'creating value for the community' and 'conceptual skills' were affirmed in interviews as well as observations.

In addition to the seven dimensions, four intermediary processes that emerged as important were: listening, negotiation, communication, and symbolic leadership. The ability to listen, effectively negotiate, and communicate is the intermediator processes or tools that servant leaders use to exercise their leadership. These findings suggest an alternative model of servant leadership in county and city governments. Besides, servant leadership manifests in employee and organizational outcomes by creating a serving culture. Apart from individual attributes, some organizational factors intervene while servant leadership takes into effect.

Servant Leaders Set Up the Serving Culture.

County and city Managers who behave as servant leaders set up a culture of service (Peterson, et al., 2012). During the case studies, this dimension was observed in all the three-county and city governments. For example, in county B, the Administrator's concern and care for employees was visible in his first initiative for revising the pay structure. The county employees were underpaid. Despite the ongoing pressures in governmental spending and budget prioritization, the administrator was determined to revise the pay structure, and this originated from his concern for his employees. One employee recounted:

The big part of setting up the employee engagement culture was acknowledging that the pay structure needed revision. We had not done any real pay studies here for a long time, but we were underpaid, we are about $20 \%$ under when you look at other local governments. And so, he 
said, even though we are in a deficit spending situation, here is my fiveyear plan to get us out and we are going to increase the pay rate every year for five years. It is not going to get us up to $20 \%$ because we cannot afford that. But it is going to be incremental. We are going to do small increments and we are going to dig ourselves out of this financial hole and we are going to start paying our employees better.

One employee compared the previous county administrator and the current county administrator saying that previously our culture was fearful and punitive like a carrot and stick approach. The previous administrator was old school, authoritarian, and not open for any disagreements. However, after the current county administrator came, things changed totally. The first thing the county administrator did was created an informal and engaging environment by simple gestures and symbolism such as name-calling by first name only. The employee affirmed:

Let us talk about how he [administrator] started setting up that culture up. Because our culture before him was really challenging. It was a very old school, kind of a punitive culture, a head-down culture more stick approach. It was kind of fear based. there was a lot of fear. Previous county administrator was very old school, like about respect, you had to call her by her last name Mrs. so and so. There you cannot disagree with her. It was a conventional traditional authoritarian approach. And it was one of the things he [administrator] did immediately was that he would not allow anyone to call him by his last name. 


\section{Negotiation and Conceptualization.}

A leader's ability to successfully negotiate the needs of the employees and the community with the elected officials appeared a critical factor for servant leadership to manifest. Also, the leader's task knowledge and problem-solving abilities were vital in timely and effective decision making. The concern for the community starts from employees first. Such an approach of formal leadership creates a feeling that employees

are valued and are at par with their contemporaries. An employee from county B affirmed this sentiment:

This year we are doing a pay study to see across the organization how much good we are. And so that the employees perceive that as we are valued because if that is a very important need for everybody, you should be at least divided at par with your contemporaries in other departments and not feel underpaid. The good quality employees don't want to stay in the underpaid environment. [...] And in five years he [administrator] got us out of this. We are now out of our deficits spending. Unbelievable. I can't believe he got it done with all the push that he had to reduce the millage because there is always pressured to reduce the millage and we can't afford it. We cannot afford to reduce the millage. I am super impressed.

\section{Empathy and Genuine Concern for People.}

Concern for people was manifested in both the county B and village C manager's behavior. But there were some contradictory responses for county A. Some employees from A expressed that county A's administrator is introverted and does not mingle with 
people. Sometimes the cognitive and emotional dimensions may not manifest into behavioral dimensions due to the personality type. An employee responded about how the county B administrator has a concern for the whole individual and not just about the employee's role in the organization. A county administrator who is a servant leader develops a personal connection with the employees. An employee echoed the administration's concern for the personal wellbeing of employees:

I [administrator] want to get here, I want to move this ball here, but how is your [employee] son doing? You know, like it is not always about we have to get better, or I need this [job] to get done but at the same time support, you [employee] as you get there. And it is also, he's[administrator] not kind of ignorant of your reality that you are maybe dealing with some things and stuff and he shows that personal touch that you don't feel left out and like pressed up or stressed out or something of that kind.

\section{Empowering and Helping Subordinates Grow and Succeed}

Valuing and empowering employees was a major finding that came up in most of the interviews. All the county and city managers in the interview sample reiterated that the employees are the most important asset and the force multipliers. Leaders must recognize the talents of the employees by facilitating them with resources to become servant leaders themselves.

Hire Good People and Let them Do their Job, Your Force Multipliers are Your Key Staff: Trust, Flexibility, and Clear Direction. The county B's administrator stated that his philosophy is to hire good people, trust them, and let them do their job and not 
micromanage them. This also includes giving authority to employees so that they can execute their job well. He shared:

My philosophy is to hire good people and let them do their job. I would say in general; the government doesn't do that very well. So, there's this, push and pull between empowering your team to go do what they know and do well and trust them. Also, give them authority as long as it works. Likewise, a good public administrator has to be flexible and adaptable to the consistent change and complexities. The county A's administrator noted:

When coming into the public sector, I had an element of purity to me that still is important, but it doesn't govern all [...] and the other, I think you have to learn to be a good administrator, that is your ideas are always not going to be the endorsed ideas. So, you have to be flexible, because I've seen people that said I'm right. This is the way to go, and that can be contrary. And so, you have to be adaptable.

Communication about an organization's direction and facilitating employees to reach the goal was another important servant leadership characteristic that respondents spoke about. A deputy county administrator at county A highlighted the importance he gives to employees. This is a cascading effect of the county administrator's leadership about how servant leaders' mentor their employees into becoming servant leaders by facilitating their growth:

Your [leader] key is to make sure they understand what the outcomes are what direction we're trying to get or what are we trying to execute. [...] 
But you know, if you have to do everything, your organization is going to become paralyzed. That's why you call them force multipliers, $[\ldots]$ your force multipliers are your key staff. So, my philosophy is building a good team around and make sure they have a clear direction on where you want to get to. You can work with them on the path, but then you let them do it.

\section{Building External Relationship through Negotiation.}

During interviews and observations, one of the most vital leadership characteristics that emerged for county and city managers was negotiation. County and city administrators spend a large part of their time negotiating and building partnerships with the private sector, community, and non-profit organizations. This is possible only when employees are given freedom, authority, and are empowered but not controlled. The county B administrator explained:

The higher you go, the more you should be dealing with, [...], particularly, external relationships, the private sector nonprofits. So, you hire good people to execute. So that's my philosophy. Some are comfortable with that, some are not. Some are much more controlling, everybody's different. [...] But again, I would say in defense of that push and pull, and I said these many times in public settings, the government doesn't encourage that initiative.

Likewise, servant leadership is manifested as the loyalty and commitment for people, organizations, and the community. The village manager who was interviewed rightly mentioned that 'my sense of loyalty to the organization is really strong': 
Like I've worked here for over 18 years. I don't move around a lot. Unlike the younger generation. They stay at our job for two years, three years and then they move. That's not how I was taught. My sense of loyalty to an organization is really strong and so it is hard for me to move from one job to another. The only time I relocated and changed jobs was when I felt I couldn't grow any further in that organization.

\section{Conceptual Skills}

Servant leaders are organizational stewards - problem solvers, like to be challenged and avoid stagnancy. In all the three case studies, county and city manager's leadership emerged as open, creative, community and problem solving oriented. This is consistent with the conceptual skills dimension of servant leadership that servant leaders should have the ability to uncover the complexities associated with their role and organizational problems.

Encourage Creativity and Problem Solving. The village C manager shared about how her leadership approach is problem-solving oriented. She shared that she looks for challenging and new opportunities to implement:

Once you stop feeling challenged in your work, if you aspire to continue to grow professionally, you have to look for challenges. Because if it is easy and you're not being challenged, then you're going to be stagnant. I look for the problems that I could solve. I enjoy that. My favorite thing is having a problem and trying to solve the problem. Like a problem solver. That is me. 
The leader has the Day; He is not Always very Kind; He can be Tough as Well. Often servant leaders are criticized that they are too kind and sometimes are taken for granted by employees who can manipulate. However, on the contrary, effective servant leadership is about smart servant leaders who can take tough decisions for the benefit of the organization and community. An employee shared an incident about the county administrator's tough decision making. The county administrator fired the two directors who were messing up with some critical ethical issues. He gave time and opportunity to improve, but the directors did not improve and got fired. The employee noted: He [administrator] didn't do anything for like three or four months. He gave them time and just watched and then he fired the two directors. That sucked. [...] He gave them space. The leader has the day that he can be tough as well. It is not that he's always very kind. He's quiet, but don't cross him and do your job. So, I think that set up the respect level that he was going to look for the people who weren't performing and he was going to move them out. [...] And it wasn't this big dramatic thing. They were just gone, and he brought someone else in.

Despite being friendly, the leader must keep a certain distance from the employees. Good administrators know how much to mingle and how much to keep a distance. The employee stated:

But you do not cross that man [administrator] because when he stood in front of me and he looked at me and said, my name is [administrator]. Okay. There was not one chance I was gonna call him. How do I 
communicate then? You better listen to that. no, there was no question, I'm done with you calling me Mr. [administrator].

There is not much Space for Trial and Error in Government. Public administration by its very nature does not offer many opportunities for mistakes and is not so much open for risks. Many people join governments with a desire to help the community and public service. They want to be creative and innovate but, in the end, it doesn't happen like that. Government systems can be fatal for someone who makes mistakes. There is not much space for trial and error. In such a context, leadership can be exercised in an environment of bounded rationality. For leadership to be effective in a bounded environment of governments, public leaders need much more flexibility and adaptability in their behavior than their private counterparts. An employee echoed this sentiment:

I don't want to say this government, but I'm just saying in general [government] does not encourage initiative. And that's tied hand in hand with. It is usually very fatal for someone that makes a mistake. Put those two together. [...] So, what you [administrator] get is go back and tie it to your desire to help your community and what motivates you in public administration. Those two works against each other. You come in, you care a lot, you have ideas, you want to implement and then you have the system that kind of says don't take too much risk, don't get too far out there. So, there's a real-life dynamic in government that works against your premise. Because you want to go out and conquer the world. 
A good administrator who is a servant leader would still give space for mistakes, learn from them, grow, and succeed. Servant leaders create a flexible environment and empower employees even in restricted government settings which are not open to trial and error or risk-taking. The county administrator noted:

And now what I'm talking about here is not incompetence or gross negligence, but I'm talking about just people make mistakes as they execute their job. And my philosophy is to empower these folks to be independent and take initiative

\section{Servant Leadership in the Politics of Public Administration.}

In county and city governments, managing politics is a central part of the administrative leadership. The servant leadership of county and city managers is affected by the political nature of leadership. City and county managers are appointed by the elected officials. They execute the agenda and vision of elected officials. They have to continuously engage with the political representatives and find administratively sustainable solutions for the community's well-being. One of the county administrators shared that "it is just that public administration has the dynamic of the political element of policymaking and interaction and we have to consistently engage with them for whatever we do." A good administrator uses multifaceted approaches to deal with the politics-administration dichotomy embedded in the nature of administrative leadership:

Well, I will start by saying no good public administrator can operate one way. Because you are in a political environment [...] So, you know, that's the art form of a good administrator. Which is not only administering the government but also administrating politics. 
One of the deputy administrators describes the political complexities involved in administrative leadership in county and city governments. Listening to the elected officials is crucial for a sustainable administrative leadership as well as sustainable administrative outcomes. An administrator who is not adept at managing the agenda of elected officials will be unable to sustain and get successful in county and city government. Thus, political acceptability and administrative sustainability are complementary to each other. The employee affirmed:

I would think so as you reversed the mirror and you look kind of upward, complexities become much more political. So, it is not about technical, it is not necessarily about how you get from A to B. It is really about making sure you can translate the conversation with your elected body and continue to ensure that you're hearing them. Because the problem you get with public administration versus politics is [...] I've used the term 'politics.' I mean it is about inconsistency. As much as you say that you do policy, it is really about in any given day, it is the Wild West. And so that's the dilemma as you [administrator] go up - is making sure your management team is hearing what was said today because it won't be the same as it was said last week, sometimes.

Another employee stated that the art of negotiation and communication is vital for a successful county and city leadership. An administrator as a servant leader can build relationships across the board. Listening, communication and negotiation is a constant job of the administrator to deal with the priorities of multiple stakeholders. It is the process of effectively managing the politics of administration: 
I know that especially if it is on a strategic thing, whether it is budget or a large project that is fast-moving and challenging, is fraught with danger. He [administrator] is in their offices all the time talking through it, understanding what he has support for and what he doesn't. So, he doesn't generally choose a lot of battles that he knows he's not going to get support from elected officials. So, he's going to see what he did get a move on. It is doable if there are so many things that need to be done and how do we present this in such a way that we can get it done. So, by the time I see him negotiating with the commissioners, he's done most of his negotiating. [...] He does well because he's able to convince them that this is what is best for the communities.

\section{Training and Development}

Providing training to the employee's leadership development and succession planning in city-county governments emerged as an important function of leadership. However, not many county and city governments have structured training and leadership development programs. In small cities, there is little upward mobility. But large county governments and also some large cities need structured training and development to prepare employees' leadership position. For example, in village $\mathrm{C}$, which was very small with just 250 employees, it wasn't an issue due to low upward mobility. However, for county A and B, which are very large sized with about 1000 to 4000 employees, leadership training is vital to develop mid-career managers to move up in the hierarchy. An employee reaffirmed this sentiment by stating: 
I think one of the things we're successful at is providing staff with the training they need to do their jobs. [...] Yes. we're a small organization, so we don't want to have the benefit of having that middle layer of people that could come up. Although many people in our organization do come up. I and the current manager came up in our organization, our current police chief came up in our organization. So, there are some, but there's limited room to grow. [...] But it does happen. And I think just, making sure that our workforce is well-trained, understands our mission and is happy to be here, makes huge differences in having a good organization.

Another employee highlighted the training as an essential part to sustain the complex leadership terrain of city-county governance:

And the training part $[\ldots]$ is so important because we always joke about it, we throw people in the deep end of the pool as the way we put it when they come in the door, someone new, we throw them in the deep end and we'll see if they can swim, But I mean, providing the training is essential.

\section{Discussion}

With the growing importance of servant leadership, both in business and public administration, it was warranted to understand what are the individual attributes that manifest into servant leadership among organizational leaders. This chapter sought to understand the individual attributes of servant leadership, specifically, servant identity and moral potency, which are the leader's character traits essential for government organizations. To do so, data from a survey of 155 county and city governments and three 
qualitative case studies were used to test hypotheses relating to individual attributes of servant leadership among county and city administrators and the theories of social identity and servant leadership. In particular, this chapter investigated whether servant identity (calling, humility, empathy, and agape love) and moral potency attributes (moral ownership, moral courage, and moral efficacy) impacted servant leadership behavior of county and city Administrators. Both the individual attributes predicted servant leadership behavior. In quantitative analysis, using the HLM, three separate models were tested to explore these relationships.

The model assessing the relationship of moral potency (MPC) with servant leadership focuses on moral dilemmas of public administrators while addressing the competing needs and values of multiple stakeholders such as elected officials, employees, and the community. Due to heightened ethical consciousness, many public organizations need to create cultures and organizational systems that facilitate not only ethical understanding but also the courage to standby moral values and demonstrate ethical action in situations of an ethical dilemma. MPC is in line with theories of public service ethics and the new public service paradigm.

Theories of public service ethics demonstrate the need for ethical and leaders of character in public administration (Bailey, 1964; Hart, 1984; Cooper, 1984; Cooper \& Wright, 1992; Wright \& Goldstein, 2007). The relationship of MPC with servant leadership was predicted in the findings. Moral potency was tested in model 1 and model 3 including control mechanisms. In model 1, moral potency impacted a $64 \%$ variance in servant leadership. While model 3 , which tested the impact of moral while controlling for 
servant identity, the variance was reduced to $24 \%$. Out of the five control variables, the only ethnicity was significant in model 3 .

The findings for MPC predicting servant leadership suggests that individuals who are servant leaders understand ethics as well as demonstrate ethical behavior in their actions. However, the reduced effect of moral potency in the presence of servant identity suggests that servant identity central for servant leadership to manifest. This is in alignment with the servant leadership's core focus on serving employees and the community. However, servant leaders rely on ethical behavior to keep their broad focus on service orientation (Eva et al., 2018; Liden et al., 2014). This finding reaffirms the that servant leadership is an inclusive approach for public administration as it squarely focuses on serving the employees and the community, of which ethics is just one part.

This supported the argument made in this study that servant leadership in comparison to ethical leadership, is holistic and inclusive for public administration (Beck, 2014; Lemoine et al., 2019). It underscores the servant leadership's dimensions of serving others before self and the broader community at all times, which is the fundamental role of public administrators. The second hypothesis to examine servant identity (SI) as a predictor of servant leadership was significant. Two models were tested to assess this relationship. In model 2, servant identity explained $73 \%$ variance for servant leadership. In model 3 , servant identity was tested along with moral potency. In this model, servant identity predicted a $57 \%$ variance in servant leadership. In model 2, both gender and ethnicity were significant, and model 3 , the only ethnicity was significant.

The finding supported that servant identity is a predictor of servant leadership among county and city Administrators. Till now, the majority of work on servant 
leadership has been focused on understanding the concept, dimensions, and outcomes of servant leadership behavior. This study sheds light on why servant leaders behave the way they do. SI as an individual attribute of servant leadership provides an opportunity to address the long-drawn question on identifying mechanisms to develop public administrators who will put the interests of the community, employees, and the organization above their own (Hanbury et al., 2004). Liden et al., (2014) proposed that prosocial identity, which is a dimension of self-concept focused on helping and benefitting others is at the core of servant leadership theory. This is not merely a cognitive disposition showing the concern for people but is a prerequisite for individuals to engage in servant leadership behaviors.

The findings are in alignment with the new public service paradigm's focus that public servants must look beyond their self-interest to serve the larger public interest. They should envision a long-term perspective of the knowledge of public affairs, a concern for the whole, and a moral bond with the community (Denhardt \& Denhardt, 2000). Administrators should see the stakeholders, including citizens as an effective collaborator in service delivery mechanism to make the governance process more responsive and accountable to the broader community (Stivers, 1998; Sandel, 1996). This finding lays the foundation for understanding the psychological factors and underlying mechanisms that constitute the servant identity of public administrators (Figure 17).

To develop servant leaders and servant leadership to gain prominence in local governments, the key question is how to design leadership programs that facilitate the development of servant leadership. The qualitative findings suggested a link between moral potency with servant leadership. Both leaders and employees in local governments 
understand the importance of ethical action and it is a prerequisite for county and city administrators who behave as servant leaders (Figure 17). Although, interviews provided a limited understanding of the moral action dimension of moral potency-which is how and when servant leaders act ethically. Overall, moral potency findings are consistent with the ethics studies in public administration. It is easier to talk about why ethics are important but challenging to discuss ethical dilemmas and subsequently develop ethically acting public managers (Menzel, 1997; West \& Berman, 2004). The findings revealed that the county A and B administrators are moral leaders and give importance to ethics training. The same was confirmed by village $\mathrm{C}$ employees about the village manager.

Also, in-depth interviews revealed two intervening processes for the formation of servant identity attribute that manifest into servant leadership behavior (see Figure 17). First, an individual's servant identity is a result of his/her self-concept that revolves around 'being a servant first' (Greenleaf, 1977). Second, this identification is facilitated by his/her beliefs and values that get formed as a result of life experiences and constant reflection that revolves around defining oneself (who am I and what I do).

A servant leader's identity is marked by the constant desire to be a servant. Servant leaders are service-oriented, therefore, also imbibe moral behavior (Graham, 1995). Therefore, moral potency is natural for individuals who possess a servant identity and is not mutually exclusive. This underscores the argument that servant leadership is an inclusive approach in comparison to ethical leadership because servant leaders define their identity as a servant to their followers and the community and thereby, they elevate the moral and ethical behavior of their followers. This is not the case in ethical leadership which only prioritizes compliance and alignment with ethics standards. 


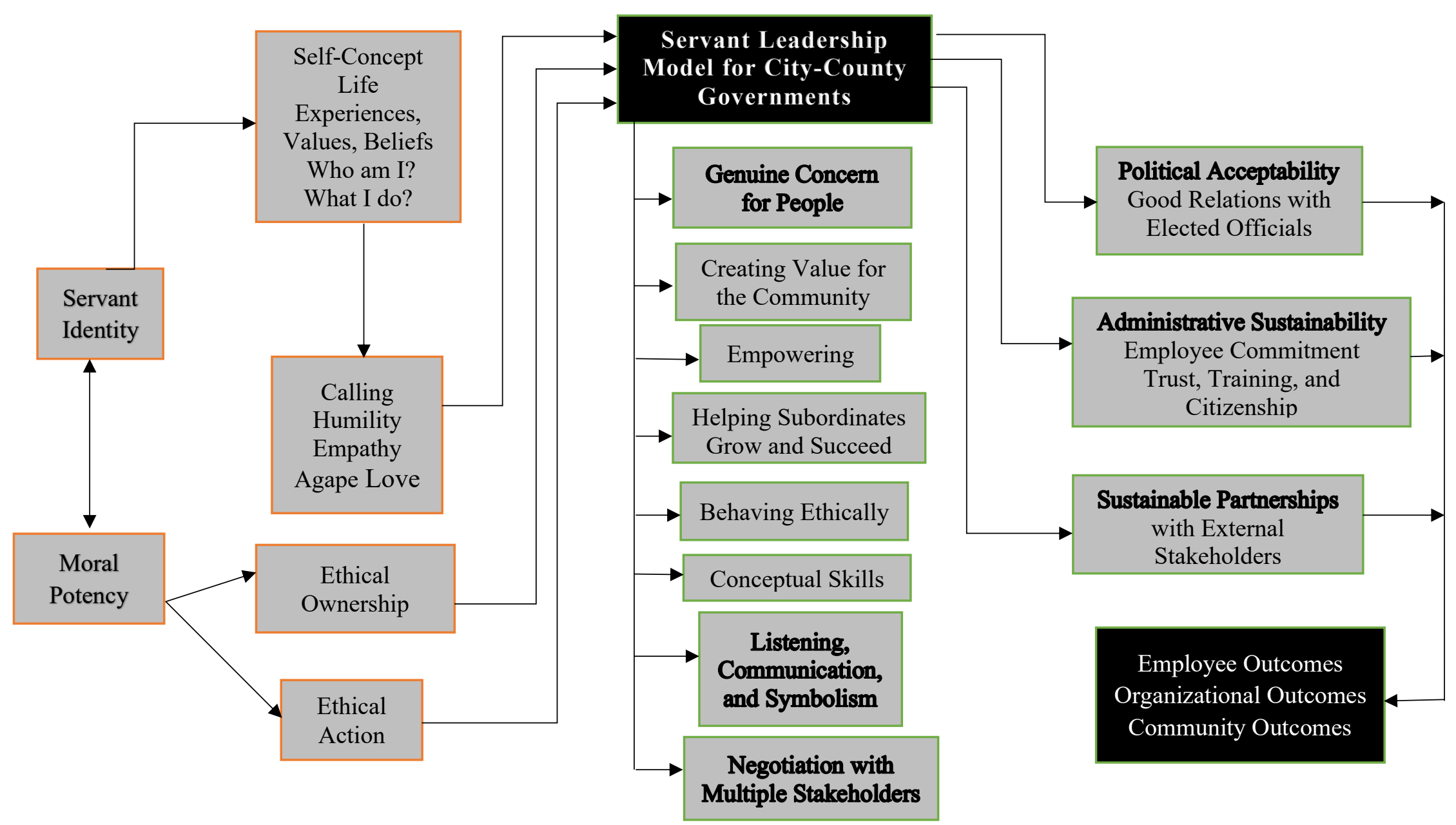

Figure 17. Model Connecting Servant Identity and Moral Potency with Servant Leadership Behavior 
Another important finding from the qualitative data analysis was a revised model of servant leadership for local governments (Figure 17). The existing model of servant leadership (Liden et al., 2008) constitutes 7 core dimensions: emotional healing, putting sub-ordinates first, helping subordinates grow and succeed, creating value for the community, behaving ethically, empowering, and conceptual skills. Both the leaders and employees reflected that perhaps emotional healing does not apply in the context of local governments. Instead, empathy and genuine concern for people is more appropriate. Similarly, putting subordinates first and helping subordinates grow and succeed are similar behaviors.

Additionally, four intermediary behaviors emerged as vital for effective servant leadership to manifest in county and city governments: listening, communication, negotiation, and symbolism. Since county and city administrators deal with multiple stakeholders, the intermediary processes deem essential. These processes facilitate sophisticated servant leadership behaviors to manifest into political acceptability, administrative sustainability, and developing sustainable partnerships with external stakeholders. Likewise, creating value for the community, conceptual skills, and empowering emerged as important servant leadership behaviors.

\section{Conclusion}

Overall, findings demonstrated that servant leadership is a comprehensive approach for local governments in comparison to other widely studied approaches such as transformational, ethical, or collaborative. Both the quantitative and qualitative findings suggest that the servant identity and moral potency attributes manifest servant leadership behavior among county and city managers. However, individuals' work and family 
background are vital in developing their servant identity. County and city managers who identify as servant leaders in a council-manager form of governments, display four additional attributes: listening, communication skills, negotiation skills, demonstrating leadership by symbolism, and genuine concern for people.

The mixed-method approach utilized in this study facilitated exploring the causal relationships between individual attributes of servant identity, moral potency, and servant leadership behavior among county and city administrators. The findings of this study have implications for both research and practice. For practice, this study offers policy recommendations to improve the recruitment and training processes of administrative leadership positions in local governments. County and municipal governments, in particular, can consider two ways to set up such policies: 1) hiring evaluation tools to assess servant leadership dimensions among the employees, and 2) establishing an inhouse servant leadership development training program for mid-career managers.

Utilizing critical and emotional reflexivity methods to uncover the self-identity of public servants concerning their self-concept, moral values, empathy, service orientation, and their relationship with the community might be insightful. Similarly, training for negotiation skills, communication abilities, and how it manifests in dealing with competing interests of the multiple stakeholders in local governments might be beneficial. However, training should be based on an interactive approach in the form of a workshop with enough space for one on engagement with the facilitator followed by evaluations for its effectiveness.

Besides, the servant leadership development program can be established as a formal workshop under the International City-County Management Association (ICMA) 
for local government leaders. The regional ICMA associations can utilize having such programs as well. For research, this study is a step forward in extending the examination of individual attributes that manifest into servant leadership both in business as well as public administration. The study is also the first empirical application of servant leadership in public administration and extends the theory of servant leadership, specifically in county and city governments. 


\section{CHAPTER 4: \\ Servant Leaders as Community Custodians: Enhancing Co-Production of Public Services in Local Governments}

\section{Introduction}

Co-production is an umbrella concept that has gained popularity in the last decade. Specifically, 'co-production emphasizes the direct involvement of citizens in the commissioning, design, delivery, or assessment of government services (Bovaird, 2007; Brudney \& England, 1983; Nabatchi, Sancino, and Sicilia; 2017; Bovaird, 2007; Alford, 1998). In recent times, for local government leaders, co-production has become a necessity for effective service delivery (Folz, 2006; Jackobsen \& Andersen, 2013).

The 'co' side of co-production signifies the involvement of two types of participants: (1) The state actors as direct or indirect agents of government serving in a professional capacity (i.e. the 'regular producers') and (2) lay actors as the members of the public, serving voluntarily as citizens, clients, or customers (i.e. the 'citizen producers'). Public service is no longer a one-way process but is a result of the interaction of many stakeholders and systems. The co-production results in increased service quality (Marschall, 2006; Brannan, John, and Stoker, 2006), improved democratic citizenship (Wilson, 1981), and increased social capital (Schneider, et al., 1997).

Local government leaders continuously engage with various stakeholders (nonprofits, private sector, community members) to co-produce public services (Agranoff, 2006). However, it is unclear that what kind of leadership approaches and organizational mechanisms facilitate the co-production of process. More specifically, the leadership styles that facilitate citizen and community participation in co-production are not known to us. Extant evidence suggests that leadership is significant for nurturing 
citizen involvement in co-producing public service. Such citizen engagement may not occur due to the lack of open and flexible leadership by the county or city managers (Getha-Taylor, 2016; Philips-Brown, \& Head, 2019). Leadership can also be challenging in the pluralist context of co-production where multiple stakeholders are involved and who have unequal power relations (Bovaird \& Loeffler, 2007; Boyle, Coote, Sherwood, \& Slay, 2010). Government leaders are challenged to move away from being at the center of power. They need to exercise distributed leadership style based on the principles of trust, interdependence, and facilitating new roles and participants in solving community problems (Ansell \& Gash, 2008; Keast \& Mendell, 2014).

This chapter hypothesizes that the servant leadership approach is effective for coproduction. Servant leadership is instrumental in county and city governments in building successful long-lasting relationships with multiple stakeholders, especially community members and nonprofits. Servant leaders focus on the relational dynamics of leadership and empowerment while engaging with various stakeholders such as employees, citizens, and partner agencies. This results in increased collaboration and creativity among the employees, organizations, and the community to gain a competitive advantage (Neubert, Kacmar, Carlson, Chinko, \& Roberts, 2008; Jaramillo, Grisaffe. Chonko, and Roberts, 2009). Moreover, servant leadership is squarely centered on community betterment.

The next section outlines the concept of co-production in public administration. Then the role of leadership for co-production is examined, especially comparing servant leadership and collaborative leadership styles (which lend themselves to co-production). Next, the research hypotheses and the methodology are explained. After this, the empirical analyses (hierarchical linear model and case study) are presented, followed by 
the results of these analyses. The final section concludes with the implications of these findings for co-production in particular, and public administration in general.

\section{Co-production of Public Services}

Elinor Ostrom, the noted Nobel prize winner in economics, introduced the term co-production in the 1980 s to explain the role of citizens in the production of public services (Ostrom \& Ostrom, 1977; Percy, 1978). Some examples of co-production are the engagement of parents and the students in school initiatives to improve the student's scholastic performance. If the parents and students are not motivated to help their children, school initiatives could fail. Similarly, if citizens are vigilant and report accidents and crimes diligently, public safety could improve considerably (Jacobsen, 2013). Nonprofits could deliver services for the homeless, which would reduce the burden on public agencies to undertake the effort on their own. Such co-production is a departure from both the traditional model of public service in which only public agencies deliver the services and the market-based models (as suggested by NPM) in considering citizens as passive consumers (Ostrom, 1996).

There has been a resurgence of scholarly interest in co-production in the last two decades (Alford, 1998; Huxham \& Vangen, 2005; Verschuere, Brandsen, \& Pestoff, 2012). This resurgence is partially a reaction to the overemphasis on NPM and consequent decline in the sense of community and citizenship (Terry, 1998; Denhardt \& Denhardt, 2000). The concept of co-production gained more popularity in the $21^{\text {st }}$ century which spelled the need for inter-organizational networks, partnerships, and collaborations in public service delivery and policymaking (Emerson \& Nabatchi, 2015; Kickert, Klijn, and Koppenjan, 1997; Agranoff \& McGuire, 2003). Also, the global financial crisis in 
2008 reinforced the need for co-production when governments were forced to do more with less. The role of citizens as active partners in the service delivery mechanisms became more pronounced.

The literature on co-production is divergent and is not unified on what exactly the term signifies (Brandsen \& Honingh, 2018; Bovaird, 2007; Verschuere et al, 2012; Sicilia, Sancino, Andreani, \& Ruffini, 2016; Nabatchi et al., 2017). For this study, The two definitions of co-production are used: (1) it is a process involving two types of participants: the state actors, who are (direct or indirect) agents of government serving in a professional capacity (i.e. regular producers) and the lay actors, who are the members of the public, serving voluntarily as citizens, community members, clients, and customers (i.e. citizen producers) (Nabatchi et al., 2017, P. 769). (2) it is a collaborative effort where public agencies, service users, and volunteers make better use of each other's assets and resources to achieve effective delivery of services and improve service outcomes (Loeffler \& Bovaird, 2016, p.1).

Co-production differs from public participation and consultation. It emphasizes making the citizens as empowered and effective contributors by utilizing their knowledge, innovation, and creative capability in public service provisions. It is an intensive form of engagement in which the state and citizen actors jointly act to better the public service experience of both. Co-production also can occur at the individual, group, or the collective level (Brudney \& England, 1983). Individual co-production occurs mostly at the personal level in which the public officials and the citizens engage as a service provider and a customer to benefit personally (Wybron \& Paget, 2016). An example of this would be when a resident (lay actor) drops off (or pays someone to do so) 
the trash in a municipal dump (the state actor). Besides personal benefits, this kind of activity has spillover effects for the overall community residents in terms of cleanliness, public health, and resource conservation.

The group co-production process entails a group of state actors (different government agencies) working directly with a group of lay actors who share some common characteristics (such as the residents of a community or users of social service). An example of this is when the officials of the transportation department work with the disabled community members to make their riding experience better. The benefit is to the disabled community and has contributed positively to social equity (Nabatchi et al., 2017; Copestake, Sheikh, Jognson, \& Bollen, 2014).

Collective co-production is about engaging multiple state actors within and across organizations to work directly and simultaneously on a range of issues. The focus of collective co-production is to engage diverse state and lay actors on a range of issues for the collective benefit of the community. An example of this kind of co-production activity is when the municipal officials work with community members to set budget priorities for the community. Municipal and community leaders may also jointly prioritize the community's needs for the development of services such as transportation, public health, environment conservation, and management (Van, Damme, Caluwaerts, and Brans, 2016; Barbera, Sicilia, and Steccolini, 2016).

This study takes the collective approach to co-production, in which the diverse set of community members engage with a single or multiple municipal departments or agencies to address an issue for the collective benefit of the community. The collective approach is appropriate because of its broader benefits as compared to parochial benefits 
of individual or group co-production. Research on citizens' involvement in the coproduction of service emphasizes the resources that citizens need to actively engage in the co-production process (Alford, 2002; Percy, 1983; Marschall, 2004).

Government leaders can take initiatives to increase co-production by providing relevant resources, increasing their motivation, empowering them, and accommodating their pro-active participation (Sharp, 1980; Brudney, 1983). Co-production requires nurturing leadership. Conventional leaders who are inwardly oriented toward organizational management only could create bureaucratic hassles for co-production. Such leaders lack the willingness to shift from the traditional government-centric approach. They could hinder new and innovative ideas from co-producers as they are unlikely to be open and accommodate citizen participation in service provision or delivery (Getha-Taylor, 2011).

\section{Leadership in the Co-Production of Public Services}

For leadership to be effective in the co-production process, empowerment, sharing, and trust is the key for the leaders to establish good relations with community partners. Such a leadership style implies a distributed model, which is about creating reliable and trustworthy relationships among a range of actors. Issues of dysfunctional leadership arise when there is limited sharing of power (Grint, 2005; Currie, Grubnic, \& Hodges, 2011). To avoid leadership conflicts, the development of a common purpose is vital (Thorpe, Gold, \& Lawler, 2011). Moreover, government leaders like county and city managers wield a lot of power over their local communities. In such a context, equitable sharing among the public managers and the community partners is hard. 
A public manager's leadership role has rapidly evolved as citizens have increasingly become producers of public services. Cooper (1984, p.143) noted that administrators need to work as professional citizens who 'seek power with' and not 'power over citizens.' Public managers need to see themselves as partners in service development and delivery process. For effective engagement with the public, it requires public managers to be able to listen, help, and be courteous to nurture the core of public service (Thomas, 2013). Public managers should be able to revise their perception as the sole producers of public service and should be willing to share their authority. Extant research shows that public managers need to be cognizant of four aspects of coproduction: keeping the public interest high, gaining legitimacy, enhancing trust, and engaging with frontline bureaucrats (Brendsen \& Honingh, 2013; Fledderus, Brenden, Honingh, 2014). I argue, that in the context of co-production, a high community, and follower centric leadership approach referred to as servant leadership is most appropriate.

It is important to explore the alternative forms of leadership which emphasize shared leadership with followers and community leaders to reconcile the overlapping values and goals of co-production. Two models of leadership provide a guide in this regard. The first is the model of collaborative leadership put forward by Bryson, Crosby, and Stone (2006), which provides a useful framework for distributed leadership. Its focus is on aligning conditions, processes, structures, governance, contingencies, constraints, outcomes, and accountabilities in collaboration to create public value (Crosby \& Bryson, 2010; Morse, 2010). The collaborative leadership framework's primary focus is on coordinating the processes at different levels to foster collaboration. It does not focus on the public manager's leadership role per se to enable the co-production of public services. 
The second is the servant leadership model, which is an inclusive leadership approach. As explained in Chapter 1, the servant leadership model fundamentally starts with the betterment of the community. It is focused on the leader's integrity and serviceorientation. It aims to facilitate the core values of co-production: keep the public interest high, engage and empower employees to enhance service quality climate which in turn will foster community motivation and engagement in the public service, and enhance trust and relationship building to encourage community initiatives and motivation to participate in the co-production of public services. The following section compares collaborative and servant leadership models for co-production.

\section{Collaborative Vs. Servant Leadership in Co-Production}

Crosby \& Bryson (2005) presented collaborative leadership as an element of the common good framework. This framework highlights eight capabilities in a shared power world - an understanding of the social and political context, building workgroups, communicating a shared vision, effectively implementing policy decisions. The framework emphasizes engaging multiple actors at different levels, with shared and distributed power (Fernandez, Cho, and Perry, 2010). The cross-sector collaborative leadership framework has four elements:

(1) Acting per the dynamics of the shared power world;

(2) Designing and using forums, arena, and courts wisely;

(3) Navigating policy change processes effectively; and

(4) Exercising the distributed leaders' capabilities.

Essentially, collaborative leadership focuses on creating effective systems and processes which facilitate seamless collaboration among different stakeholders to resolve 
complex public problems. Collaborative leadership is also similar to the stakeholder theory focused on creating processes to resolve conflicts and gain stakeholder cooperation and support. Collaborative leadership theory is context-specific and is successful in situations where public officials actively collaborate with different sectors (private, nonprofit, etc.). Morse (2014) identified the following as critical leadership competencies of a collaborative leader: personal attributes like systems thinking and sense of mutuality, skills such as strategic thinking and group facilitation, and behaviors such as stakeholder identification and strategic issue framing.

Servant leadership contrasts with the collaborative leadership by emphasizing the follower and community empowerment and well-being as a core value in all its organizational processes. It is inherently externally oriented toward the community. Servant leaders demonstrate ethical and service orientation and manifest these as nonnegotiable public service values in all their actions. Collaborative leadership is focused only on creating systems and processes to facilitate cross-sector collaboration and is applicable when leaders seek collaboration with different parties or organizations. Unlike collaborative leadership, servant leadership is always about having a servant and a moral identity. Servant leaders are good at conceptual skills, which is having the knowledge of the organization, their role, and the task at hand. They are oriented toward assisting and supporting followers. Servant leaders aim to achieve the best outcomes for the community by supporting followers and other organizational stakeholders,

Since servant leaders understand the task at hand and organizational context, they can facilitate collaboration (Parris \& Peachy, 2013; Leiden et al., 2008). Besides, servant led organizations to foster trust and procedural justice, which opens communication 
channels among the members within and outside the organization. These conditions enhance collaboration among interested parties (Garber et al., 2009, Sendjaya \& Pekerti, 2010; Walumbwa et al., 2010; Reinke 2004; Irving \& Longbotham, 2007). Therefore, servant leadership is a comprehensive approach especially in a co-production context as it creates a community service-oriented environment of high integrity, empowers followers, and members of the community to engage in the co-production of public services.

\section{Servant Leadership and Co-production: Hypothesis}

Hunter et al. (2013) posit that servant leaders sow the seeds of service among followers and the community by influencing a range of variables. Servant leadership inherently includes a community ethic. Servant leaders motivate followers to serve their peers, customers, and community. The followers are encouraged to be engaged in the community. As a result, followers become more active in serving the community. The followers exhibit great concern for the community's well-being and actively engage in enhancing social bonds and relationships with the residents (Graham, 1991). Given that the servant leadership behavior has a strong community ethic, servant leaders in local government agencies will arguably be engaged in co-production.

Servant leaders achieve the co-production goal indirectly by creating a service climate conducive to co-production. Service climate is defined as the shared perceptions of the policies, practices, and procedures that are oriented toward customer service (Schneider, Salvaggio \& Subirats, 2002, p.222). Leadership is a crucial factor in creating such an organizational climate (Ehrhart, 2001; Litwin \& Stringer, 1968). Servant leadership facilitates such a climate by taking an inclusive approach to work: servant leaders promote power-sharing in decision making and promote a sense of community 
among the followers (Spears, 1998; Liden et al., 2008). Walumbwa et al. (2010) found that servant leadership was positively correlated with the service climate in organizations. Followers in a conducive service climate will create a positive service experience and engage with multiple stakeholders. Servant leaders thus enhance co-production through the intermediary mechanism of service climate. Thus, the hypothesized relationship between servant leadership and co-production is as follows:

H2a: Local government agencies that rate high on servant leadership will have a higher degree of co-production of public services, and this relationship is mediated by the service climate.

\section{Measurement of Variables}

The study uses a mixed-method research design - an online survey and three case studies of county and city governments that rated high on the servant leadership behavior scale in an online survey. The unit of analysis is the local government organization (municipalities and the counties) with a council-manager form of government.

As outlined in Chapter 2, an online survey was conducted on the State of Florida local governments (county and city governments). The survey respondents were the department directors, deputy (or assistant) county and city managers. These officers report directly to the county or city administrator. The online survey link was sent on the official emails of the respondents from a total of 241 county and city governments in the State of Florida. Completed surveys were returned from 101 local governments with a response rate of $42 \%$. Of these, a total of 228 executive team members (i.e. followers) responded (the follower response ranged from 1 to 14 from the county and city governments). 
The variables of interest for this chapter are the co-production of public service (outcome variable), servant leadership behavior (predictor variable), and service climate (mediator variable). The measurements of these variables and the control variable are described below.

Measurement of Dependent Variable (Co-production of Public Services)

To measure the co-production of public service, 8 questions from the survey instrument were used to create a composite index. The questions for the variable were created based on extant literature about co-production. The questions were as follows: 'In this organization, there is a high level of community outreach', 'In this organization, authorities and staff seek feedback from community members to improve public services', 'In this organization authorities and staff provide useful information to the community to make informed decisions.' The Cronbach's Alpha for co-production index is 0.94 , which is very high (well about the threshold 0.8 ).

\section{Measurement of Independent Variable (Servant Leadership Behavior)}

Servant leadership behavior is also a composite index based on responses to seven statements from the survey. The responses were on a Likert scale. These statements were drawn from the psychometrically tested study by Liden et al., (2008). Examples of the statements are 'My manager can tell if something work-related is going wrong', my manager emphasizes giving back to the community', and 'My manager would not compromise ethical principles to achieve success.' The Cronbach's Alpha for servant leadership behavior index is 0.88 (also above the threshold level of 0.8 ). 


\section{Measurement of Mediator Variable (Service Climate)}

The index for service climate was based on responses to seven statements in the survey. These statements were drawn from Schneider, White, \& Paul (1998). Examples of the statements are: 'The job knowledge and skills of employees in your organization to deliver superior quality work and service', 'The recognition and rewards employees receive for the delivery of superior work and service in your organization', 'The effectiveness of your organization's communication efforts to both employees and citizens', 'The leadership shown by management in your organization in supporting the service quality effort.' The Cronbach's Alpha for service climate is 0.91 .

\section{Control Variables and their Measurements}

Demographic indicators used as control variables include education, age, total experience in local government, ethnicity, and experience in the current position. All variables were rated by followers, i.e. the direct employees of the county/ city managers across the state. Responses for co-production of public service, servant leadership behavior were on a Likert scale of 1 (strongly disagree) to 7 (strongly agree). Responses for the service climate variable were given on a scale of 1 (poor) to 5 (very good).

\section{Research Model}

Hierarchical Linear Modelling (HLM) is used for analyzing the relationship between servant leadership behavior and co-production. The data are at two levels, individual ratings of the department directors and managers (employee level) aggregated at county and city governments (organizational level). The Hierarchical regression equation for this model was as follows: 


\section{Null Model or Unconditional Means Model}

$(\text { Co-Production of Public Services })_{\mathrm{ij}}=\beta_{0}+\varepsilon_{\mathrm{ij}}$

The model with Predictors:

$(\text { Co-Production of Public Services })_{\mathrm{ij}}=\gamma_{00}+\gamma_{1 \mathrm{ij}}($ Servant Leadership $)+\gamma_{2 \mathrm{ij}}($ Service Climate $)+\gamma_{3 \mathrm{ij}}($ Control Variables $)+\varepsilon_{\mathrm{ij}}$

where $\beta_{0}$ and $\gamma_{00}$ are the intercepts, and $\gamma_{1}, \gamma_{2}$, etc. are the coefficients to be determined.

\section{Data Aggregation, Inter-Rater Reliability, and Intraclass Correlations}

In the HLM model, aggregation of data is required since the data are collected from individuals, and the dependent variables of interest in this study are conceptualized at the organizational level of analysis. Followers are nested within the organization. It is also necessary to determine if the aggregation of the individual level outcomes to the organizational level is appropriate for the multilevel modeling. The aggregation needs to be both theoretically and statistically justified (Klein, Dansereau, \& Hall, 1994).

Theoretically, the aggregation can be justified because the dependent variable of co-production and the mediating variable of service climate are conceptualized and defined at the organizational level. County and city governments are the units of analysis, where the county/ city manager is the leader and the employees directly reporting to the manager are the followers. Aggregation of the followers' responses for both servant leadership behavior and service climate, therefore, justifies measures at the organizational level of the county or city (George \& James, 1993; Schneider \& Bowen, 1985). 
There are several statistical tests also to check the appropriateness of aggregation. First, inter-rater agreement $\left(\mathrm{r}_{\mathrm{wg}}\right)$ among the followers needs to be determined at the organizational level. The acceptable threshold for the inter-rater agreement is 0.70 (LeBreton \& Senter, 2008). Intraclass correlations, ICC (1), and ICC (2) are also used as statistical tests for aggregating to a higher level of analysis (e.g., Bartko, 1976; Shrout \& Fleiss, 1979). The ICC (1) compares the variance between units of analysis (county and city governments) to the variance within units of analysis using the individual ratings of each respondent. The ICC (2) assesses the relative status of between and within variability using the average ratings of respondents within each unit (Bartko, 1976).

Within-group agreement $\left(\mathrm{r}_{\mathrm{wg}}\right)$ is calculated using the uniform null distribution. The average $r_{\mathrm{wg}}$ score for servant leadership is $0.76(\mathrm{Mdn}=1)$, co-production of public services is $0.81(\mathrm{Mdn}=1)$, and service climate is $0.89(\mathrm{Mdn}=1)$. These values suggest that the aggregation of the individual employee scores to the organization level is appropriate. The ICC (1) value is 0.35 and the ICC (2) value is 0.70 . Although there are no strict standards of acceptability for either ICC (1) or ICC (2) values, James (1982) suggested a median ICC (1) value of 0.12 threshold and Glick (1985) recommended an ICC (2) threshold of 0.60 . The $r_{\mathrm{wg}}$, ICC (1) and ICC (2) scores for the service climate is 0.85 , 0.42 , and 0.89 respectively. The statistical tests for both servant leadership behavior and service climate meet the criteria for justifying the aggregation to the organizational level.

\section{Results of HLM Analysis}

The HLM analysis was preceded by ANOVA tests to examine any significant differences between the organizations (i.e., the county and city governments) in terms of the main organizational level variables. The main organizational level variables are the 
dependent variable (co-production), the independent variable (servant leadership behavior), and the mediator variable (service climate). The ANOVA results showed that there are no significant differences among the county and city governments.

\section{Descriptive Statistics and Correlations}

The descriptive statistics and correlation matrix between the dependent variable (co-production), the independent variable (servant leadership behavior), and the mediator variable (service climate) are shown in Table 12. The table shows that the means of the variables are above the middle of the range (3.0), and there are not very high correlations among most variables, except servant leadership and ethical leadership (.86). It shows the overlap between ethical and servant leadership styles.

Table 12. Means, Standard Deviation, and Correlations Among the Variables

\begin{tabular}{lcccccc}
\hline \multicolumn{1}{c}{ Variable } & M & SD & 1 & 2 & 3 & 4 \\
\hline 1.Co-Production of Public Services & 5.86 & 1.07 & 1 & & & \\
2. Servant Leadership & 5.50 & 1.13 & .69 & & & \\
4. Service Climate & 3.5 & 0.84 & .71 & .58 & .57 & 1 \\
\hline
\end{tabular}

Note. $\mathrm{N}=228$. All correlations are at the individual employee level, with organizationallevel variables (i.e. co-production of public service, servant leadership, and service climate, ethical leadership is used as a control variable in the study).

\section{Confirmatory Factor Analysis}

Since the data were collected from different county and city governments across the State of Florida, multigroup CFA was conducted to establish the validity of the dependent, independent, and mediator measures. The CFA was conducted on followers' responses to servant leader leadership, co-production, and service climate. The CFA allows index items to load on the proposed latent construct. It is a tool to confirm or reject the measurements (see Figure 18). 
The CFA model for all the three variables fit the data well: for servant leadership, the values for the model's fit are: $\chi^{2}(14, \mathrm{~N}=228)=40.84, \mathrm{p}<.0001$; comparative fit index $(\mathrm{CFI})=.96$, Tucker-Lewis index $(\mathrm{TLI})=.94$, root mean square $($ RMSEA $)=.09$. root mean square error $(\mathrm{SRMR})=.03$. For co-production, model fit was $\chi^{2}(20, \mathrm{~N}=228)=$ 152.44, $\mathrm{p}<.0000$; comparative fit index $(\mathrm{CFI})=.92$, Tucker-Lewis index $(\mathrm{TLI})=.89$, root mean square $($ RMSEA $)=.17$, root mean square error $($ SRMR $)=.03$. For service climate, the model fit was $\chi^{2}(14, \mathrm{~N}=228)=70.84, \mathrm{p}<.0000$; comparative fit index $(\mathrm{CFI})=.94$, Tucker-Lewis Index $(\mathrm{TLI})=.91$, root mean square $($ RMSEA $)=.13$, root mean square error $(\mathrm{SRMR})=.04$.

HLM - Main and Mediating Effects

The null model was tested to examine the group variance among followers in the county and city governments. The results reveal a $42 \%$ variance. Chi-square test revealed that between-group variance is significant $\left(\chi^{2}=195.56, \mathrm{p}<.001\right)$. 


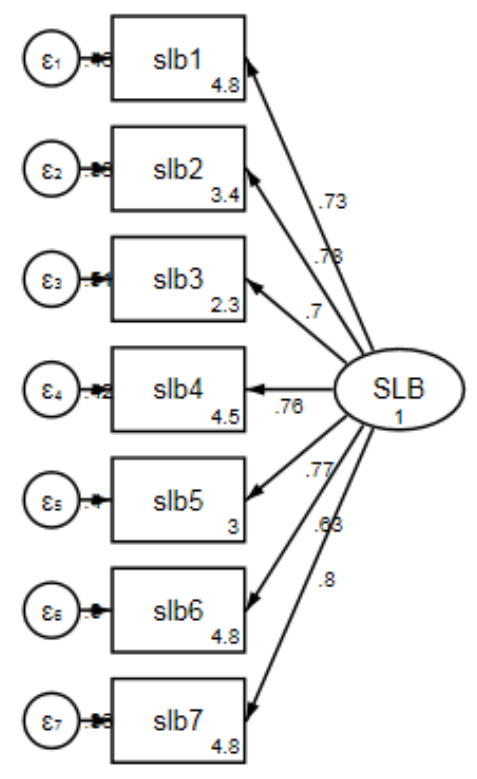

Servant Leadership

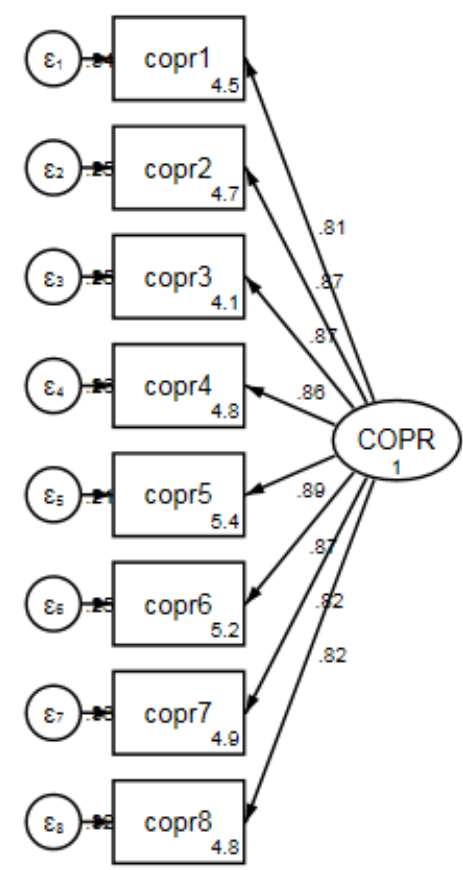

Co-Production of Public Services

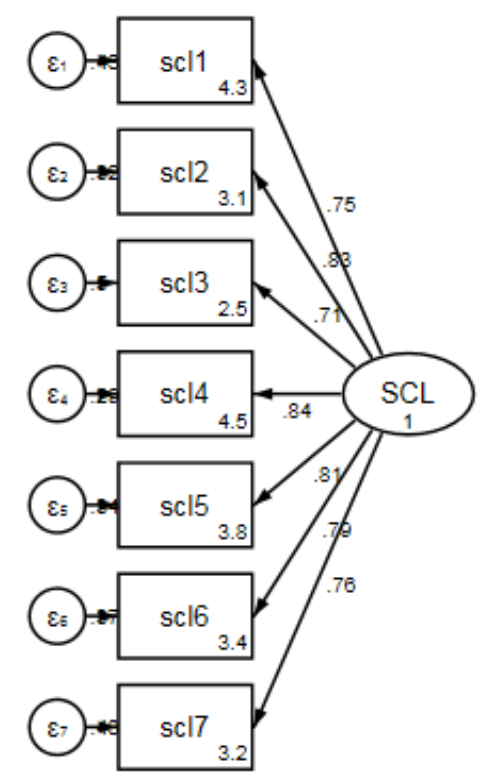

Service Climate

Figure 18: Confirmatory Factor Analysis for Selected Variables 


\section{Hypothesis Testing}

The hypothesis $\mathrm{H} 2 \mathrm{a}$ tests that county and city governments with higher servant leadership will have a higher level of co-production of public service, mediated by service climate. Table 13 shows the results of hierarchical linear modeling. In Model 1, servant leadership is significant and positively related to the co-production of public services in the county and city governments $(\gamma=.63, \mathrm{p}<.001)$. The hypothesis H2a is therefore empirically supported.

In Model 2, the relationship of servant leadership behavior with co-production is tested while controlling for the service climate (service climate's mediating effect is examined in the next section using the Barron \& Kenny, 1986). Servant leadership behavior $(\gamma=.38, \mathrm{p}<.001)$ as well as the service climate $(\gamma=.6, \mathrm{p}<.001)$ are significant.

The null model, as well as the other models with mediator and control variables, show the significance of servant leadership behavior for co-production. Other demographics related control variables such as age, education, ethnicity, and gender are not significant. Tenure (in local government, and the current position) shows to be significant, which implies that the experience of a leader is another determinant for coproduction. 
Table 13. Servant Leadership and Co-Production: Results of HLM Analysis

\begin{tabular}{|c|c|c|c|c|}
\hline \multirow{2}{*}{$\begin{array}{c}\text { Variable } \\
\text { Employee Responses } \\
\text { Nested within } \\
\text { Organizations }\end{array}$} & \multicolumn{2}{|c|}{$\begin{array}{c}\text { COPR } \\
\text { Model } 1\end{array}$} & \multicolumn{2}{|c|}{$\begin{array}{c}\text { COPR } \\
\text { Model } 2\end{array}$} \\
\hline & Estimate & Standard Error & Estimate & Standard Error \\
\hline \multicolumn{5}{|l|}{ Level 1 Variables } \\
\hline \multicolumn{5}{|l|}{$(n=228)$} \\
\hline Age & .023 & .060 & -.027 & .051 \\
\hline Education & -.072 & .054 & -.057 & .046 \\
\hline Gender & -.023 & .095 & -.042 & .081 \\
\hline Ethnicity & .031 & .060 & -.049 & .051 \\
\hline $\begin{array}{l}\text { Tenure in Local } \\
\text { Government }\end{array}$ & $-.077^{\wedge}$ & .050 & $-.082 *$ & .042 \\
\hline $\begin{array}{l}\text { Tenure in Current } \\
\text { Position } \\
\text { Level } 2 \text { Variables }\end{array}$ & .066 & .054 & .019 & .046 \\
\hline$(n=101)$ & & & & \\
\hline Intercept (null model) & $5.80 * *$ & 0.094 & & \\
\hline Servant Leadership & $.63 * * *$ & .045 & $.38 * * *$ & .046 \\
\hline Service Climate & & & $.60 * * *$ & .063 \\
\hline
\end{tabular}


Table 14: Mediation Analysis: Effect of Service Climate on Co-Production

\begin{tabular}{|c|c|c|c|c|}
\hline Variables & $\beta$ & SE & $\mathbf{t}$ & $\mathbf{R}^{2}$ \\
\hline Step 1: DV=Co-Production & & & & .49 \\
\hline \multicolumn{5}{|l|}{$\overline{\text { Level } 1 \text { Variables }}$} \\
\hline Age & .005 & .062 & .08 & \\
\hline Education & -.071 & .056 & -1.25 & \\
\hline Gender & -.026 & .099 & -0.26 & \\
\hline Ethnicity & .030 & .060 & .51 & \\
\hline Tenure in Local Government & -.065 & .051 & -1.28 & \\
\hline Tenure in Current Position & $.082^{\wedge}$ & .055 & 1.50 & \\
\hline \multicolumn{5}{|l|}{ Level 2 Variables } \\
\hline Servant Leadership & $.66 * * *$ & .045 & 10.89 & \\
\hline${\underline{\text { Step 2: }} \mathrm{DV}=\text { Service Climate }^{\mathrm{c}}}$ & & & & .38 \\
\hline \multicolumn{5}{|l|}{ Level 1 Variables } \\
\hline Age & .078 & .053 & -0.81 & \\
\hline Education & $-.024^{\wedge}$ & .048 & -1.15 & \\
\hline Gender & .033 & .084 & -0.57 & \\
\hline Ethnicity & $.13 * *$ & .052 & -.89 & \\
\hline Tenure in Local Government & .011 & .044 & -1.62 & \\
\hline Tenure in Current Position & $.092 *$ & .047 & .41 & \\
\hline \multicolumn{5}{|l|}{ Level 2 Variables } \\
\hline Servant Leadership & $.43 * * *$ & .040 & & \\
\hline Step 3: DV = Co-Production & & & & .64 \\
\hline \multicolumn{5}{|l|}{ Level 1 Variables } \\
\hline Age & -.027 & .051 & .36 & \\
\hline Education & -.057 & .046 & -1.57 & \\
\hline Gender & -.042 & .081 & -.37 & \\
\hline Ethnicity & -.049 & .051 & .28 & \\
\hline Tenure in Local Government & $-.082 *$ & .042 & -1.13 & \\
\hline Tenure in Current Position & .019 & .046 & 1.07 & \\
\hline \multicolumn{5}{|l|}{ Level 2 Variables } \\
\hline Servant Leadership & $.38 * * *$ & .046 & 3.25 & \\
\hline Service Climate & $.60 * * *$ & .063 & 4.82 & \\
\hline
\end{tabular}

To test the service climate as a mediating variable in the relationship between servant leadership behavior and co-production, a three-step mediation analysis suggested by Barron and Kenny (1986) is used. The first step is an ordinary least squares regression 
model testing the relationship between servant leadership behavior and the co-production of public services. However, here the three-step HLM is applied since the data are multilevel. The result shows significant positive relationship $(\gamma=.66, \mathrm{p}<.001)$. The second step tests the relationship between servant leadership behavior (independent variable) and service climate (mediator variable). It is also a significant and positive relationship $(\gamma=.43, \mathrm{p}<.001)$.

In the third step, the relationship of servant leadership behavior with coproduction is controlled with the service climate. For the service climate to be a complete mediator, servant leadership behavior should have no effect on co-production when the service climate is controlled. The HLM result, however, shows that servant leadership has a significant and positive relationship with co-production $(\gamma=.39, \mathrm{p}<.001)$. We cannot then postulate that service climate is a complete mediator. Service climate is only a partial mediator since the magnitude of $\beta$ has reduced with the service climate as a control variable.

\section{Qualitative Case Study Analysis}

The qualitative case studies seek to complement the quantitative analysis by examining the relationships between servant leaders and the co-production of public services in a more nuanced way. As explained in Chapter 2, three case studies were undertaken in County A, County B, and Village C. In all three cases, the servant leadership behavior is high. Therefore, it is reasonable to expect that the co-production of public services would also be high. The case studies reveal how the servant leaders 
enabled such co-production, and to what extent service climate contributed to the coproduction.

The leader's initiatives to increase citizen co-production is required to understand how servant leadership affects co-production in county and city governments. These initiatives could encompass providing relevant resources, motivation, empowerment, and an invitation to citizens to participate (Sharp, 1980; Brudney, 1983). Semi-structured interviews were conducted with both the leaders and the followers to understand the initiatives undertaken toward such co-production enabling activities. The leaders were asked questions about the initiatives that they directed to enable co-production. Followers were asked these questions: (a) what personal abilities and organizational resources did the leader use to facilitate co-production? (b) did the leader support community engagement in public service design or delivery processes? and (c) what is the administrator's leadership style?

The interviewees were asked further probing questions to elaborate on coproduction activities undertaken by their organization. For example, they were asked to give an example of how the leadership supported their co-production activities. Interviewees illustrated co-production activities in various settings, such as budget decision-making process, strategic planning, or developing infrastructure in their community. This type of questioning led to a conversation about 'how and what' leaders do in local governments. The main focus of the conversation was to explore the proposition that servant leadership behavior would result in a higher degree of coproduction of public services. 
The analysis of interview transcripts was conducted at two levels: 1) leadership level, where the leaders' interviews were analyzed for the co-production initiatives that they undertook; and (2) follower level, where the directly reporting officers' (department directors, deputy managers, and assistant managers) account of co-production activities was analyzed. The two levels of analysis at the leader and follower levels provide a wholesome portrait of the co-production initiatives in the three cases. These interview analyses were then supplemented with the content analysis of secondary documents obtained from each case study site. Common themes among the cases were identified through pattern matching with cross-case analysis (Yin, 2014). The case study findings report the common themes that emerged across all three cases.

\section{Case Study Findings}

Figure 19 presents the word cloud of all the interviews (there were 50 interviews conducted in total across all three cases). The word cloud graphically represents the most frequently used words by the interviewees (Ramsden \& Bate, 2008). The larger the size of a word in the word cloud, the more frequent the usage of the word. The word cloud is conceptually useful in identifying the common concepts that arise among all interviews. The common concepts can reveal important themes that the interviewees are highlighting in their conversations. As the figure reveals, the top 25 frequently used words by respondents during the interviews are people, just, right, community, leadership, needs, managing, personally, governments, wellness, county, means, good, departments, administrators, understand, employees, differs, service, kinds, development, giving.

Interviewees did not directly use the terms 'servant leadership' and 'coproduction.' These are technical terms that have come into use in an academic 
environment; they are not yet popularly used in common conversations. Hence, it is not surprising that these words are not reflected in the word cloud. Yet, there are several community themes related to co-production revealed in these top words. The interviewees' emphasized 'community', 'leadership,' 'people,' 'employees,' 'giving,' 'development,' and 'right'. More than a quarter of the top 25 most frequent words were associated with community issues. The interviewees often brought up their relationships with the 'people' and 'community', the top two frequently used words. As the later analysis reveals much of this usage is for the co-production of public services.

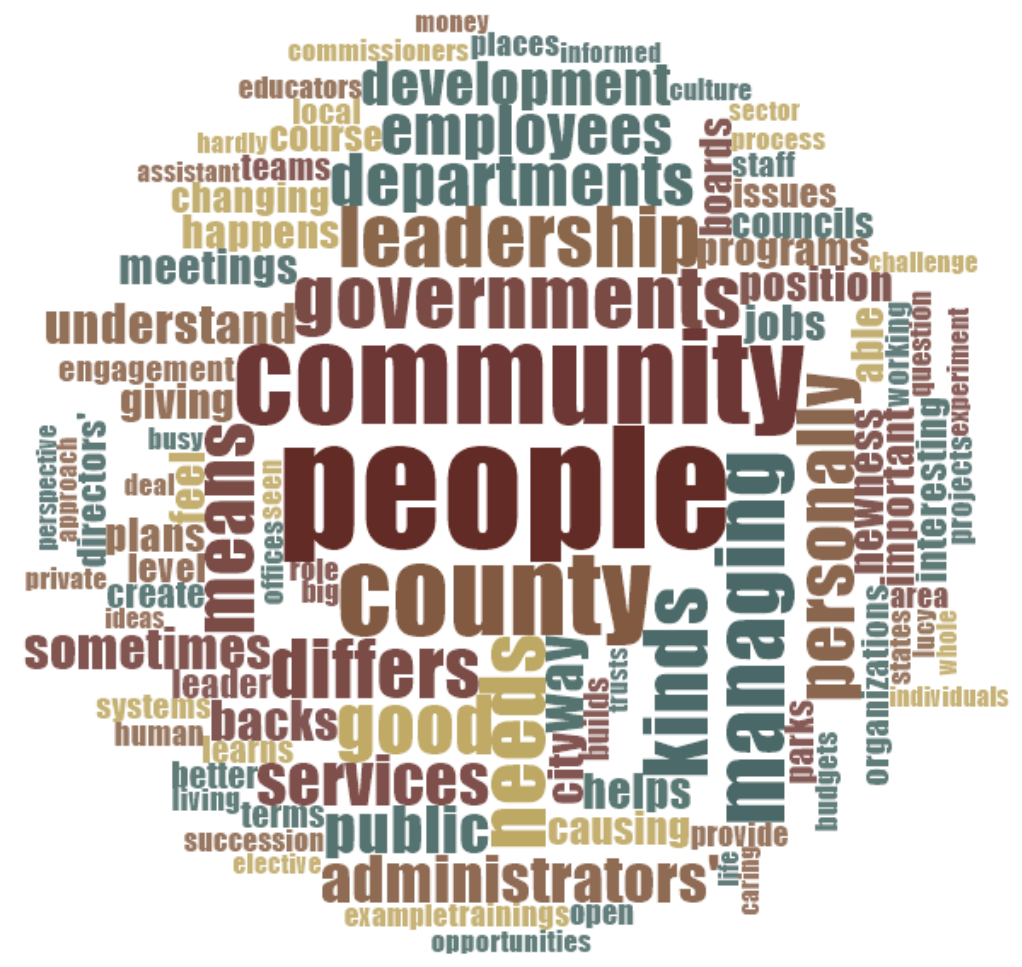

Figure 19. Word Frequency Cloud of Qualitative Interviews

The followers often recognized their leader's role in playing a highly supportive role in engaging citizens in the public service decision-making process. They said that the leaders took pro-active initiatives for community outreach and participation. The 
interviewees often said that 'everything that they are doing is for their people and the community'. They continuously tried to find ways to engage community members, who are the central drivers of their actions. Analysis of archival records and documents collected from all three case study sites (County A, County B, and Village C) consistently showed that 'creating a service environment and maintaining service quality' is a key performance indicator. All three locations have also placed great emphasis on community surveys to gauge community feedback and satisfaction.

They interviewed officials highlighted the relationship between servant leadership and the co-production of public services under two main thematic categories (Table 15). These are 1) community-centric leadership and 2) co-production activities, resources, and challenges. In community-centric leadership, the interviewees spoke about servant leadership characteristics. They highlighted the compassionate and caring leadership, employee empowerment, and collaborative leadership. In the second theme, interviewees spoke about the role of community organizations (such as neighborhood associations and citizen advisory boards) in co-production. They highlighted the opportunities and constraints of co-production with these organizations.

Table 15: Connecting Servant Leadership and Co-Production

\begin{tabular}{lcc}
\hline Themes & Percentage & Total (N) \\
\hline Community Centric Leadership & & \\
Leadership Style & 67 & 38 \\
Negotiating the Politics of Administration & 71 & 41 \\
Size of the Organization & 30 & 17 \\
Leader's Tenure in the Organization & 35 & 22 \\
Co-production Activities, Resources, and Challenges & & \\
Community Engagement & 59 & 34 \\
Communications Strategy, and Use of Social Media & 44 & 30 \\
Neighborhood Associations and Citizen Advisory Boards & 23 & 15 \\
Limitations to Intensive Community Engagement & 32 & 19 \\
\hline
\end{tabular}


In addition to the above themes, officials also illustrated different scenarios in which co-production occurred. The implementing departments undertook these activities in conjunction with the community at all levels (individuals, groups, as well as community leaders). The county and city managers played a proactive role in enabling such co-production in all three case study sites. The officials stressed how the activities would not have happened without such pro-active involvement. The principal findings under the two themes and the scenarios are discussed below.

\section{Community Centric Leadership}

There is broad consistency between what the leaders and followers said about the need for community-centric leadership for co-production. Leaders expressed their happiness in working with the people and being engaged with the community. Followers also reiterated similar sentiments and often spoke about following the leaders' footsteps. This consistency of community-centric leadership between leaders and followers is exemplified in both county A and county B. The followers in county A mentioned about how their leader (county manager) is honest and fair to everyone and a good listener. They gave examples of how the leader uses the same elevator as others and is always available to anyone of them. The leader was upfront in admitting that he did not join public service because of any deep interest. Once he began working for the government, he liked the job and he felt that he makes a difference. He worked in the public sector for over 31 years. When asked about what values made him stay in public service for so long, he noted:

I think the trust of course. And then I would say just being honest and direct about beliefs and feelings and opinions and so forth. Being 
respectful, direct, and then really have an organization that is focused on serving customers. Okay. So that's probably the three biggest.

In county B, the manager said that 'he genuinely cared about people'. He expressed his love for the job as it gave him a lifetime opportunity to make a difference in people's lives. Many followers at county B echoed the same sentiment saying that 'we have a very good county manager.' They mentioned how the manager inspired them by demonstrating qualities such as being authentic, genuine listening, and truly caring about the employees. They said they try to emulate his example. The leaders inspired the followers and created a service climate conducive to community engagement and coproduction. Leaders from the three case study sites consistently emphasized public service values as the core drivers of their actions. The followers (i.e. the directly reporting employees) reinforced the public service values.

Of course, community-centric leadership does not directly foster co-production overnight. Many factors are crucial for a leader to become community-centric to engage the community in co-production processes. Based on the interviews, the following common factors are critical for community-centric leadership: leadership style, leader's trust within the community, size of the organization, the leader's tenure, and ability of the leader to negotiate with elected officials. Style, trust, and tenure are critical elements for the long-term sustainability of community-centric leadership. The government leaders need to be open, innovative, and capable to negotiate with community and other elected political leaders to have fruitful community outreach activities. These community-centric leadership themes are further explored below. 
Visionary leadership style (sell the vision of community engagement to all levels).

As per the Greenleaf (1970), servant leadership is about employee empowerment and instilling in them a desire to serve others at all levels of the organization. Engaging employees in such behavior is substantially influenced by the upper-level leadership. Many followers recognized how community-centric leadership is about selling the vision of community engagement to the lower levels of the organization. Leaders should create a vision and culture of community service that is shared by the frontlines of the organization. An official of county A said:

My experience $[\ldots]$ usually what you find in the organization is big. It is usually driven top-down, and it is a matter of selling it to the lower levels. And making them believe that this is where we ought to be going. Yeah. You know, like for example, because visions are always created like five, 10 years down the line, for example, vision 2025 or 2020 something like that. And what are you doing the vision for, you're doing for the community? So, the community has to get involved and who is implementing $[\ldots]$ These people that also need to get involved and the people who were making the policies and vision [...] things like that. So, it is like the multi-stakeholder process and if that engagement happens, I think that can put a very good structure, you know.

Local governments are multifaceted and need to engage with multiple stakeholders such as elected officials, private agencies, and community organizations. Leaders should take a collaborative approach and focus on bringing everyone to the same 
level. Employee empowerment is a central theme for community-centric leadership. The vision of top leadership needs to trickle down all rungs of the employee levels, from senior-level managers to the front-line employees interacting with the community. All employees are instrumental in the community engagement process. Ideas generated from the frontline employees can be crucial for enhancing co-production since they interact with the community directly. An official from county B noted the bottom-up and topdown employee engagement as follows:

You know, if you [leaders] took the time to do it right, it should be something that it should kind of meet in the middle. So, you have it bubbling up from the ground up, you have it trickling down from topdown and have policymakers, and commission having input. And if you [leaders] really want to do it, if really want to be comprehensive, you get the community involved. So, you have multiple inputs, and you mesh all that together and come up with something that everybody can buy into.

The county B's administrator stressed the importance of employee collaboration as well. He argued that creating a team-oriented culture is crucial for the overall success of the organization. He emphasized the importance of working with each other, building relationships, and collaboration to succeed. Creating a team-oriented culture also means a conscious effort in training people to be team players:

We have been more of a team-oriented culture, which means it is good training. You know if you are on a team. If you are on a debate team, we all have to work together to win. I think this: as we move to more of individual competition, it does hurt because we don't have the 
relationships. If you win, you think you've done everything on your own. But the fact is, that's what I think a team always teaches you. I tell people in orientation here: you can't do it all by yourself; we all need each other.

Sometimes officials referred to community-centric leadership orientation as customer service or community service. An official from county A stated:

We are in the customer service business. Governments do not always think about this. Our county administrator is really good about saying make no mistake. The taxpayer is our customer. They value service.

The county A's administrator stressed that his primary goal as the county administrator was to define the county's primary purpose as serving the customers and people first, which was not the case before his tenure. It took time to change the work culture toward a service-oriented one. The administrator highlighted how a serviceoriented approach opened doors for creativity, doing things differently, and applying new methods technology in public service delivery systems. He continued:

When I took over nine years ago, there really was not a belief pervasive in the organization that customers were first. We, we didn't even think of them as customers. When I took over, I purposely said we are going to begin referring to the people we serve as customers because that means something in our culture. Then the next question is if we are going to serve people as our primary purpose, what is it that we're going to provide them? How do we measure and how do we deliver it most efficiently? And so, it really took the first five years just to change the culture and the 
belief system. Once that started happening, people became more open to thinking about doing things differently, bringing in technology. I changed a lot of the leadership here.

Village C's manager shared a different perspective of community-centric leadership by linking it to political leadership. He said that the elected officials get elected because they have to push the community's agenda. The appointed manager has an advisory role to implement the agenda. So, the elected village leaders represent the community. The appointed village managers must, however, be careful in how they execute the agenda and not start advocating like an elected official. So, while both the appointed and elected leaders have vital roles to play and work as a team, the appointed village manager's role is not above the elected officials. The village $\mathrm{C}$ manager reiterated, "we have to be careful to not provide an impression that somehow. we are more than the elected officials.”

Village C's manager demanded high-performance standards from employees. Although demanding, the manager also took pride in her employees. She showed compassion and caring that went beyond the call of duty to support the employees' personal and professional needs. An official from the village $\mathrm{C}$ reflected about her leadership as follows:

She sets high standards for herself and us. And so, I don't take offense when she's critical of me for a mistake or something like that. I do what I can to do to improve because I accept the criticism. As I mentioned earlier, I'm not perfect. Her main reason for doing so is because she is committed to doing the best she can for the community. And that's why 
she's a little intolerant. She is so proud of all her department's employees and the work they do, and she always wants to put us in the best light.

Increasing Public Trust (Find Common Ground through Negotiation and

Diplomacy). Government leaders need to build effective bridges between the political and the administrative, which is often a challenging task (Nalbandian et al., 2013). Gaps in communications and understanding between the two sides could stymie organizational policies and initiatives, even if the community were to benefit from such policies. This is a major leadership challenge that recurred in many conversations. Some county and city managers have also lost their jobs within 3-4 years due to such a gap.

Public administrators need to be able to balance between politics and administration. Neill and Nalbandian (2018) call it the 'bilingual leadership team.' Such a team can communicate across the bridge, understand the political constellations, community dynamics, and the administrative culture (p. 312). An official at County A mentioned how the administrator had to navigate the multiple interests of commissioners, employees, and the community needs. According to him, the administrator is a good listener, who gives importance to all the stakeholders while keeping the interest of the residents at the center.

I think that public trust increases when they [public] see things happening quicker [...]. Sometimes the public doesn't see things happening as quickly as they would want because it is essential to take all the commissioners on board for any decision to implement. But it takes a leader like our [county administrator] who will take a beating for us to be successful. He is very methodical and conscientious. He really is talented 
at it. He may have acquired it over time, you know. He can make things happen. It is just a little slower.

Trust emerged as an important leadership attribute to build collaboration and relationships for community building. One of the county B employees compared the current and the previous administrators to show the importance of trust. The previous administrator was punitive, insecure about authority, and fearmongering, which was unhealthy and created an untrustworthy culture. Such an insecure leadership undermined trust and collaboration with community members in building long term partnerships for co-production.

We had a previous administrator; employees perceived that fairness was not coming from the leadership. He [new administrator] started setting that [trust] culture up. Because our culture before him was really challenging. It was a very old school kind of a punitive culture, a head-down culture, more stick approach. And it is kind of fear based. [...] There was a lot of fear. The previous county administrator was very old school, you had to call her by her last name. [...] You can't disagree with her. She had a conventional traditional authoritarian leadership approach. And you know, one of the things our current administrator did immediately is that he wouldn't allow anyone to call him by his last name.

Communications, diplomacy, and negotiations are hallmarks of an effective public administrator for trustworthy community-centric leadership. The village $\mathrm{C}$ manager enthusiastically shared her affinity for diplomacy and negotiation and how that 
helped her to do the manager's job effectively and take decisions in favor of the community. She narrated an example of a new community conversation initiative she implemented. Due to trustworthy and good relations with elected council members, she was able to sell the idea and execute it. The manager noted, I love to like to negotiate and I like diplomacy, trying to find common ground between people, $[\ldots]$ but it is critical that we don't become, that we don't get sucked into the politics because that can hurt you as a manager. But we are political in the sense that we have to navigate dealing with multiple, a lot of people that have, maybe competing political agendas. [...] And you have to try to find where you can bridge because we're there to facilitate and to help. I guess we implement whatever policies come out of the decisions that the elected officials are doing. So, we are advisors and facilitators.

Likewise, an official from county A shared the differences between the politics and administration and the decision making can be slow when there are seven commissioners. An administrator needs to be skilled in managing the agenda of the commissioners. The official said,

The county administrator is a great leader. He's very cautious and methodical with the commissioners. I worked for very methodical mayors as well, but it is a big difference working for one administrator who sets the course versus the seven commissioners. I think this structure is much better. It is just that the consensus-building is much slower-slower because you have seven commissioners. 
In addition to the interviews, the researcher also observed the modes of diplomacy and negotiation during the direct observations of a board of county commissioners public meeting at county B, and a council meeting at the village C. The county B administrator was a listener, his responses were objective when answering the questions raised by the public and the board members. Likewise, the village $\mathrm{C}$ manager's attention to detail, cordial relationships with all the elected council members, and public engagement was apparent while negotiating issues raised by the community representatives.

Tenure (Administrators become better community-centric leaders over time). An administrator gains skill in community-centric leadership with experience and longer tenure. An administrator who stays long (8-10 years) than the average tenure (3-4 years), has more space and time for developing and implementing a sustainable approach to community engagement. For example, the county A administrator served over 9 years in the position. During his tenure, he took many new initiatives such as implementing a county-wide community survey, a community prosperity exercise, vision and strategic planning exercise, county department scorecards to set performance benchmarks for various departments, and the county consolidated service index. An official from county A shared that "[...] it takes a while to build that [public] trust. You [administrator] can do that in the community and having a long stint really helps." Likewise, another official from county A noted that,

Our county administrator will retire after 10 years of service as an administrator. [...] That is pretty remarkable considering more than twice the longevity of most County administrators in a County that is evolving as quickly as this. The last two predecessors were here for 4 years or less. 
[...] I will tell you that in the instances of his two predecessors, the end of their tenure was not in great standing. Our administrator still has the confidence of the elected board and will likely have when his time is up.

Administrators with longer tenure know the needs of the community better and can hone the skills of being a community-centric leader. They interact with the community more and can strategize the government's direction based on their residents' needs. As an official from county B mentioned, "The longer you [administrator] have a tenure the more people interact with you, and the more they are [residents] going to discover what's important for you and how you react, how you act." At county B, the administrator has been serving for close to 6 years. The administrator implemented several co-production initiatives, including a formal engagement with several nonprofit and faith-based organizations. The administrator actively serves on boards of two nonprofit organizations. This helped in creating a culture of volunteerism for community service among employees. Additionally, the county administrator started the county's first citizen's academy, an interactive civic and public information program aimed at allowing the residents to learn about the county government. A county B official recounted, Longer tenure is more effective because the [administrators] understand the system better. I've watched some administrators who didn't last 15 months. The critical aspect is understanding the political role that the administrator is actually playing because he has five bosses (commissioners) and he's trying to please the public. These five control his destiny and if he can't navigate political waters, he's not going to last. 
Similarly, a village $\mathrm{C}$ official stated that "the average tenure of this managerial position is not more than three to four years in general across the board. Yes, she's [manager] exceeded that." If a leader stays longer, she can know the community and elected officials better, build relationships, and create organizational strategies for community prosperity. This results in establishing a stronger community connection and meeting the community needs. A long-term leader can be a part of the community. She can take budget decisions in an embedded way. An official from the county A echoed that because administrator lasted for a long time, he could build strong connections with elected officials that resulted in budgeting strategically for the community's well-being:

Lots of county administrators don't last very long. The average tenure for a county administrator is probably two to five years in most places. He [county administrator] has been doing this since 2010, and he'll retire next year, so he will have been here 10 years. That's unusual. So, what that means is he, he is very good at, making his bosses happy. And so, when you talk about that, you talk about their politicians and we meet with them. That always comes back to money too, because they want to be responsive to their constituencies. And that means new community centers, new parks, new libraries, which means we have to figure out how to balance that with a budget where we have limited dollars. It becomes very challenging. So, yeah. So that's one of those things where, you know, he [administrator] is somebody that wants to always satisfy them the best that he can. He realizes that he may not always agree with their decisions, but, you know, he tries to meet. 
Organizational size (Community-centric leadership in smaller cities). The jurisdiction's size in terms of both the population and the number of employees matters for community-centric leadership. In large jurisdictions such as counties, it is hard for the administrators to directly engage with the residents frequently. In small jurisdictions like cities, the administrators have opportunities to directly communicate and engage with the community members.

The case studies revealed the importance of size. In county A, which has approximately 5000 employees, the administrator could hardly meet all employees and be present in every community meeting. Perhaps, due to this reason, many employees opined that the county administrator was invisible and an introvert. However, the sentiment was not shared by the administrator. He thought he was very strategic and knew the community very well. He had spent close to 30 years working in the same county, ten of which were as a county administrator. He could orient his decisions based on community needs.

In contrast, county B has about 750 employees. Here the administrator was perceived as more approachable. The size of the county is a plausible explanation. The administrator could attend more, though not all, employee and community meetings. The Administrator was perceived as one who tries to be there for most employee and community initiatives. This perception is also possible because the administrator is a very active member of many nonprofit and faith-based organizations in the community and participates in their activities as well.

In village $C$, a jurisdiction with about 200 employees and 19,000 residents, the close-knit employee connections with the administrator was easily palpable. Many 
community members visited the administrator to talk about the community's needs. Most of the departments were in the same building which made it easier for the administrator to interact with employees more often. The administrator was able to implement a community conversation initiative in collaboration with the elected council members. Many community members participated in the agenda-setting and strategic planning exercises as a result of community conversations. One official in village $\mathrm{C}$ noted, "It is easier to deal in city government than the county because the geography is small."

Although small jurisdictional size allows for more personal community and employee connections, community-centric leadership can still be achieved in large jurisdictions through delegation. The sentiments were expressed by both county A and B employees. They said that if the county administrators can empower their employees at all levels to take decisions in the best interests of the community, the organization is community oriented. An employee from county A narrated an anecdotal story about how private organizations such as Disney World engage and empower their frontline employees,

In smaller organizations, smaller cities, it is a little easier because you are dealing with a couple of a hundred folks versus 5,000 people. You look at places like Disney or Nordstrom's, where you know, they value customer service and they do certain things where people down to the frontline employees are empowered to make real decisions. So, you don't have to float the question up top, $[\ldots]$ then take it two or three levels and it comes back down to them [employees]. So, they [employees] can take action right there. They're [frontline employees] at ground zero. If something 
happens, they [frontline employees] can take the decision. Empower the employee and move on.

\section{Co-Production Activities, Resources, and Challenges.}

Co-production involves a range of activities that require resources. Several examples of co-production activities and processes emerged across all three case study sites. Although officials did not use the term co-production per se, they often referred to it as community engagement to achieve results. Other themes such as community prosperity and community awareness also recurred often. For example, in county A, collaboration with multiple stakeholders was mentioned by many officials in their reflections on direct public engagement. Some department directors mentioned the link between administrative and elected leadership as a catalyst for community engagement. Such departments invested more in building partnerships with citizens and organizations. Overall, in the interviews, the following themes emerged as determinants of coproduction: effective communications strategy, use of social media, the role of neighborhood associations and citizen advisory boards, and challenges in fostering community engagement.

Community Engagement (Devise a formal community engagement plan)

Direct community engagement emerged as a consistent theme among the officials in the three case study sites. The officials mentioned that the leadership, as well as the department heads and other top officials, needed to be continuously engaged with the community. The public administrators empowered the employees to undertake engagement activities whenever possible. For example, county A's administrator stressed how everything they did was about customer service and customer engagement. The 
administrator empowered the department chiefs to be out in the community to directly communicate with them. He noted,

I think customer service is our primary driver - customer service and customer engagement. But a lot of it is just face to face. I expect my directors to be out in the community, going to community meetings.

Likewise, a department director at the county A highlighted the importance of leadership, training, tools, and a culture of continuous dialogue to engage the community in a strategic planning process. He said the leadership has to create an environment for engagement and create a culture of continuous dialogue. These points conform to the finding of the service climate as a mediator variable. Leaders can foster a service-oriented climate by creating incentive systems for community engagement. A successful community engagement process occurs by creating an environment for open and trustworthy communication and dialogue. The frontline staff should be empowered to hear from customers and provide support. The department director at county A noted, It has a lot to do with constant dialogue. We engage regularly with the public through a strategic planning process to make sure that we're meeting their service demands. So, we're offering what the community needs, what our community wants. We do the same thing internally at the library. We have a lot of community engagement. It is almost strategic planning, but there's a lot of discussion and communication and sharing and vetting of ideas. We've put safety valves in place so that if the communication has been bad, we have completely anonymized ways for people to say, "I have a problem with that, we don't get that. Please help." 
And it is a constant dialogue. It is almost like it is ongoing strategic planning for our staff. You have to. Otherwise, if I can't be with every customer every day, neither can our leadership. We have people [frontline staff] that do that. We have to hear what they are hearing from the customers as well as hear directly.

One aspect that strengthens the culture of continuous community engagement is having a formal policy. However, traditionally, local governments have not had such a formal citizen engagement policy. Some governments have begun to recognize the importance of having an organization-wide policy. In the past decade, they have slowly formalized such engagement policies. The administrators have a central role in designing the engagement policy. In county A, for example, the communications strategy for citizen engagement and community surveys were only recently adopted. The administrator was keen on building a community-engaged government. Similarly, in county B, a formal policy on community engagement was a new endeavor. The county's Parks and Recreations department's director said that they had been doing employee engagement surveys, but they had not been involved in community engagement. He stated, Employee engagement is something we have been doing. Community engagement is something we're working on. I'm about to start a park master plan. I've hired a consultant — an outside consultant — to come in. It is a 10 -month process. So, it is in terms of community. A part of my job is to identify who the stakeholders are, who are the decision-makers, who are out there that can help steer us in that direction. Of course, they are going 
to have their interests, but part of the process is to get through that and then rank everything.

Figure 20 shows an exemplary executive dashboard of county A's strategic communications focused on community engagement. According to the county's newly formulated policy, "citizen engagement works in establishing public meetings throughout the county. We support all departments under county administration in their mission of engaging citizens with programs, policies, and projects that could have an impact on communities throughout the County." The county's investment in citizen engagement doubled in a few months, going up from $\$ 79$ in October 2018 to $\$ 178$ by January 2019 . An official from County B indicated how their work changed during the last 10 years after adopting a formal community engagement plan. They became more community and problem centric. Leadership played a key role. The official stated, He [county administrator] has been the best thing that ever happened to this county. I swear to God, he has invested so much into the staff. He listens, he responds. It is not like, okay, we're going to do this. And then put it on a shelf or anything like that. We take community surveys and develop solutions using those responses. And I think the majority of the county has responded wonderfully. Since he [county administrator] is here now, we are taking a problem-solving approach and becoming more community centric. 


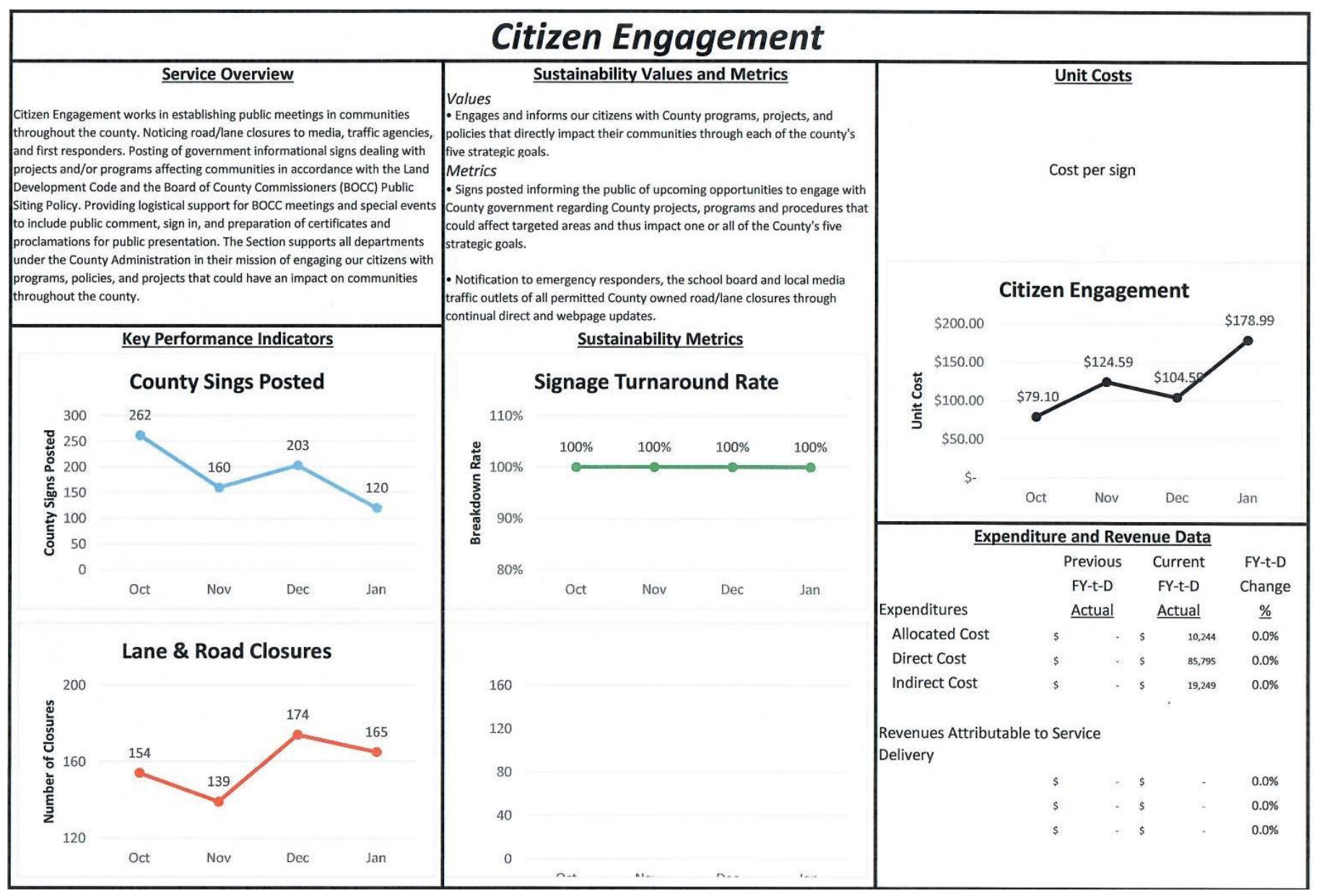

Figure 20. Executive Dashboard of County A's Citizen Engagement, Oct 2018—Jan 2019 
Many examples of community engagement approach were evident in village $\mathrm{C}$ as well. The village manager agreed about the importance of creating a strategic plan every 5 years which drives the core value of the sense of community spirit and pride. The village's strategic plan is explicit on this point:

Sustain a vibrant Village that builds a sense of community spirit and pride with fiscally responsible government, the highest quality municipal services and infrastructure, a responsive and efficient staff, and innovative leaders who engage our residents.

The department chiefs in the village are empowered to take creative citizen engagement measures. One department director shared an example of how he came up with the idea of creating a community hashtag to create a community spirit. Another department director recounted her trust and confidence in the village manager to sustain the community spirit. Although she said she may have had their disagreements, the community-oriented problem solving was paramount for both.

Indeed, community engagement is not without its problems. There are disagreements between leaders and followers. The engagement with the community could even be contentious and heated. Yet, these dialogues are necessary for the community to formulate a strategic vision. The assistant county administrator from county A said that there are occasions when community members do not engage constructively in the strategic planning exercises. Strategic plans for 10 years or 15 years ahead, which do not directly impact their day-to-day lives immediately. Community members are generally anxious to see immediate changes. They cannot comprehend long 
term changes. Although communications can be difficult, they are required for the community to comprehend long-term changes. According to him:

We do these strategic plans and we'll be talking about a 2030 plan or 2025 plan. But if you relate it to you [...] your everyday personal life, you don't do that. An average person doesn't plan. They can't plan that way. They are planning the day to day or paycheck to paycheck. So, it cannot be easily translated when we say, "Oh, we're going to do a 2030 plan.” You know, they are not there. They have their lives now. The way they operate normally isn't based on long term planning. That's hard if you think about it, that's a hard connect. That's a difficult connection.

Innovative Communications (Use of social media and other tools).

The use of innovative communications tools tapping on information technology platforms (e.g., social media, instant communications, etc.) align well with formal communications strategy. The new technological tools can be especially critical in engaging the millennials and the later generations. They use social media platforms like Facebook, Twitter, Instagram, and other platforms that have arisen over the last two decades. Administrators play an important role in deploying such platforms in local governments - they have to see the potential for communications and engagement through these platforms. Indeed, engaging in these new platforms requires a new set of skills and a dedicated person (e.g. social media coordinator) to deal with such communications. In county A, for example, the administrator adapted to the new platforms by instituting a new 'chief of communications' position with a dedicated staff 
assigned to the office. direct engagement of the county with residents. In my interview, the chief of communications said:

The position was created because there were some communications issues and he [county administrator] felt like communications weren't where it needed to be. There were neighborhoods here, but they weren't engaged in outreach. He had the right tools; they just weren't being used effectively. I have worked with the community for so long in different facets. He brought me on and he's at the point where he doesn't have to worry about it. He just knows I'm going to do my job and my team is going to succeed at doing that job.

County A's administrator shared similar sentiments. He narrated:

I think though that we have a much broader and deeper reach now than we did nine years ago, and that's intentional, but it is also because of the tools. So, now we have social media. We measure it. We know exactly who we're getting to and how successful we are.

The chief of communications was empowered by the county administrator to innovate and create an aggressive communications strategy using diverse approaches and a variety of resources. County A has a dedicated online TV newsroom to share information with the residents. The chief noted:

We've launched an online newsroom where we put out our content. We have a television station where we put out content. Then we try to market 
across all the platforms together. We have some old school flyers. We've got a whole host of things that we do. We put on special events.

Designing and building a community-oriented communications strategy requires knowledge of the community and what is important for them. In consultation with the administrator, the new communications chief changed the communications strategy from a department focused on a service-focused one. All the departments then aligned with the service approach. The chief maintained that information should be shared through digital platforms. The chief explained further:

It just depends. So, everything is customized. We don't have a one size fits all and we work to understand our community and have a pulse on the community to know how to communicate and when and what's important, what's not. There's a balancing act that you have to find. Communication is a big part of how you engage with the community. Previously it was more print media but now it is all about technology and social media and digital platforms and the website is huge for us. We redid it a couple of years ago. I got here maybe three or four years ago, we redid the website and rebranded the County design. We went from a department focus to a service focus. So, we've worked with all of the departments to get them to understand that it has to be citizen focused. We focused on the search function because we figured that's how most people navigate websites these days. 
The importance of effective communications and digital platforms emerged during the interviews with County B officials too. The County B Administrator said that he intentionally kept the office of Technology, Communications, and Public Relations under his direct supervision:

We have a public relations strategist and a communications strategist.

They are on my team and they are on the communication side. We say to all the departments that everything starts with them. So, they are communication strategists who got to come up with a PR plan.

The information era has pressured the local governments to develop aggressive community outreach through their communication strategies. The Chief of Technology and Communications in County B mentioned that the administrator championed the idea of creating a 'smart community' through smart technologies. He argued that the new communications can empower the underprivileged communities to voice their needs directly and allow them to be involved in strategic communications:

He (the administrator) has been a champion since the day I walked in here for developing what is best termed as a smart community in an underprivileged area. We were at a new area called Lincoln Park, which is mostly low income. And he said, can't we become a smart community? It is a broad term that has a lot of different levels. For example, in LA, they've got a smart community. And in that case, it includes the fact that you've got people at the parks. Trash cans at the park have a connection that notifies someone in an administrative office when they are full. It shows that they are a smart and aware community. 
The administrators' vision for the community and service can reinvent the way governments function. The county B administrator envisioned using communications for automatic community notification. The administrator emphasized reading as an important factor for the development of underprivileged kids. It came from his compassion and his quest to provide the best service experience to the people. A smart community is about facilitating underprivileged kids' access to the internet. The administrator prioritized helping the low-income areas for providing internet access, to enabling small businesses and other service providers to locate there. An employee not

He just wants something where $[\ldots]$ we've got a smart community for these people in this area so that kids who don't have access to the internet can have it in their house, and don't have to go to the library or only use it at school. [...] For small businesses, we provide some type of bandwidth for them in this community to attract businesses to move into this less desirable area. I gave them some incentives to come here and help generate jobs in the community and sustain that community. He has been very much pushing that agenda. It reflects his vision for the community.

Village C's communications approach was also aggressive. The village manager was very creative and open to new ideas. The village had a dedicated communications officer and IT manager. The village manager conducted a community conversation initiative to engage community members directly to develop a strategic plan for the village. The community members were invited face to face at a community center. Digital platforms were used aggressively to broadcast and record community feedback to create a strategic plan. 


\section{Neighborhood Relations (Role of citizen boards).}

Enhancing neighborhood relations by forming volunteer citizen boards or councils recurred in most of the interviews across the case study sites. The officials highlighted the role of traditional citizen advisory boards as a way to reach out to the community. Besides, neighborhood associations can also be engaged with the city through their officers. Counties often have a dedicated neighborhood relations department to strengthen community engagement. An official at county A stated:

Our neighborhood relations group does public outreach related to projects. So, let's say public works are going to do a street repaving in a certain neighborhood. [...] We would work with them to come up with a public engagement plan on how we do that and what meetings we need to have.

Should we have a public meeting, or could they just be direct meetings within the neighborhood? Like that, we engage with neighborhoods.

A similar sentiment was shared by the county A's administrator about how much importance they give to reaching out to neighborhood associations and strengthening the neighborhood relations departments. The role of neighborhood relations has become more structured and expanded over the years. This has resulted in the county having more public and stakeholder meetings. The citizens have become more engaged now than they were in the past. The county A administrator noted:

Well, $[\ldots]$ we've always been aware of emphasizing outreach to citizens. Whether it is through neighborhood groups or trade groups or whatever. We have a whole neighborhood relations group. [...] It is their job to maintain the bridge between neighborhood associations and the county. 
And we have a lot of public meetings, stakeholder meetings, that kind of thing. So, I would say, we've moved the needle pretty significantly in the last few years for sure. We've always been focused on it. Now I think citizens are becoming more engaged. 


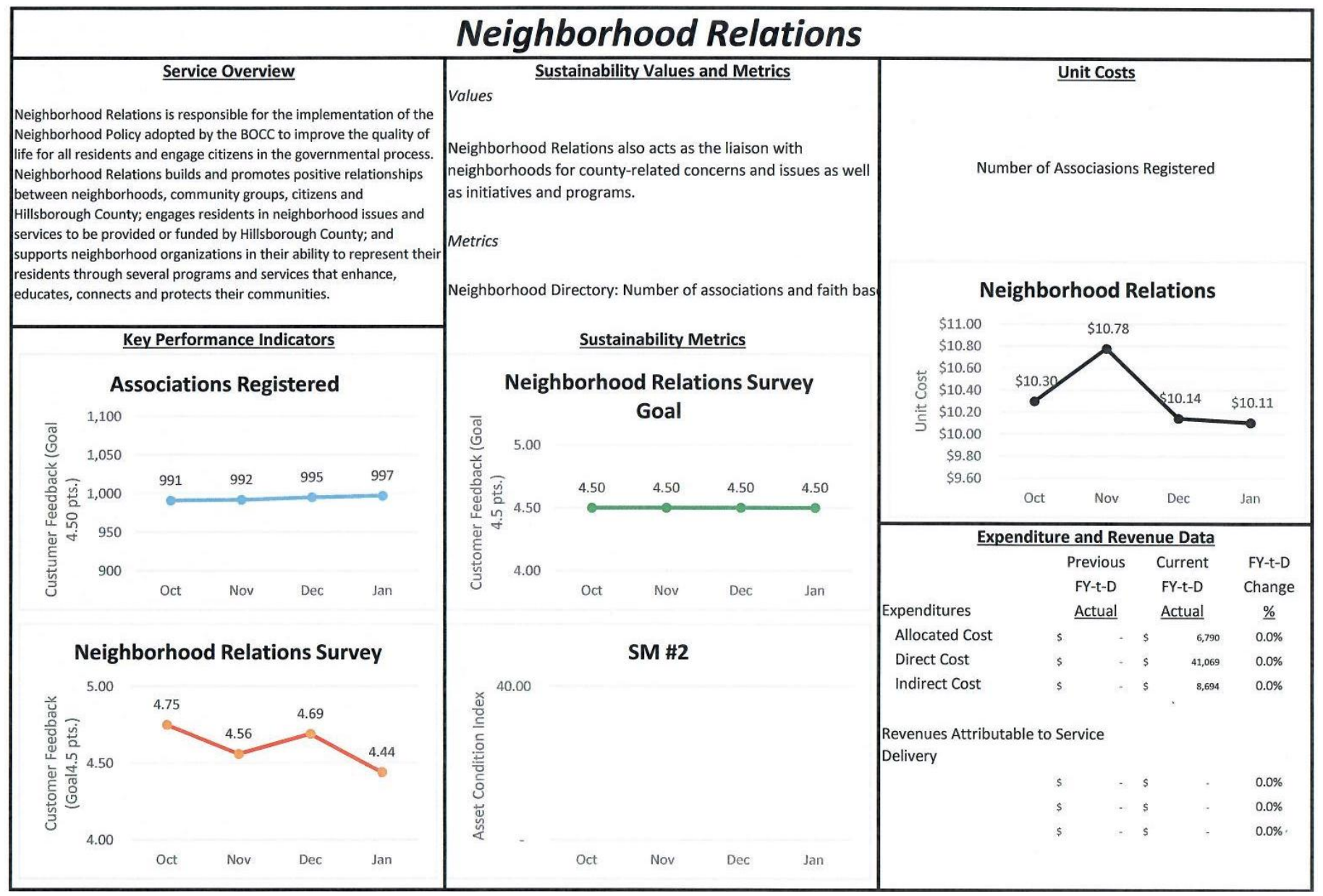

Figure 21: Executive Dashboard of County A's Neighborhood Relations, Oct 2018 - Jan 2019 
Neighborhood relations in county A is a sub-unit within the customer support services. The neighborhood relations vision is to "work towards engaging citizens in the governmental process." They are in charge of devising the strategy to strengthen community relations and engagement in the governmental process. The department conducts a monthly survey to understand the needs of the community. By January 2019, the department had about 997 community, nonprofit and faith-based organizations registered. Figure 21 exhibits an executive dashboard of the neighborhood relations department.

In addition to the county-wide approach to neighborhood relations, many departments have their citizen advisory boards. These boards are a traditional way to encourage citizen participation through service to promote good governance and effective delivery of services. For example, county A has 24 citizen's advisory councils. The councils vary in scopes such as aging (which advocates for older county residents) and a diversity council (which facilitates communication between the county and diverse communities). Similarly, county B has 20 citizen advisory boards. Village $\mathrm{C}$ has a youth council, transportation council, etc. These advisory boards and committees have elected council members and residents who volunteer to serve the community. Some departments have like environment, parks and recreation, transportation, human services, etc. have extensive engagement with the communities through such advisory bodies. As an official from county A stated:

It depends on what you're talking about. It depends on the subject matter. If you're talking about transportation issues, or if you're talking about an environmental issue, there's a lot of engagement. We have a lot of public 
meetings here. The commission holds a lot of workshops. A lot of our departments have individual advisory boards. So, there's a lot of contacts. There's a lot of discussion about communication with various members throughout the community.

The role of the citizen advisory council, however, is not always functional and helpful. Counties have yearly budget priorities that could conflict with what these citizen representatives want. When there are emergencies and uncertainties, inputs from the citizen boards may not be fully heeded (especially concerning budget revisions). Also, not all citizen boards are very active and functional. Therefore, citizen participation also depends on the voluntary participation of the members. However, citizen inputs are valued, and their voices are heard. An official from the county B said:

We have committees here with representatives from the community members. One is the citizen's budget committee. So that's a group of retirees or older, but not all. And it is a big group of maybe about 12, 13 people, maybe 15, because some of them don't always show up. And when we discuss our budget, our priorities of funding, they give input to our commissioners and recommend different things. Like, we should put more money into reserves if we have a hurricane. Or we shouldn't be spending as much money on fire equipment. So, it may not work sometimes, but it is about engaging the community. They have a voice in the process for our budgeting. 
The role of faith-based organizations in citizen engagement is quite important. Local governments pay attention to them. Their engagement is typically issue-based. An official from County A said:

So, let's say we're having a meeting related to an issue that's going on in a neighborhood, we would make sure that we're reaching out to the faithbased organization and make sure that they are at the table as well representing their congregation or their parishioners, whichever, you know, their, community. So, we want to make sure that they are at the table as well and have a voice.

Traditional Public Meetings (Effective participation in policymaking).

Public meetings are one of the traditional means for local governments to engage with citizens. Attendance in the meetings typically varies, depending on the issue under consideration. The officials interviewed in the case study sites said that there has been an increase in public participation in these meetings. They said more people are showing up in public meetings; the people are more aware and vocal about their rights and social issues. The public is prepared and tactically approach the issues to influence the policies. The county administrator at County B said:

I've found in the last few years that the types of public comment during board meetings are changing. It used to be that every time the Board of County Commissioners needed 30 minutes or 45 minutes set aside for public comment. People would come in, sign up for a particular item on the agenda about a road or whatever. Very rarely would someone come and just kind of go on about some political issue or some social issue. It is 
kind of changing now. More people are showing up, just wanting to sort of getting it out of their system. They don't like taxes. They don't like Confederates. They don't like this or that. They are more organized. So, I won't call it social resistance. It was, but not really a revolution, although I don't know, maybe that's what it is bordering on. But more organized groups are tactically coming into the board room and prepared to deliver a message with all kinds of strategies and tools and so forth. Which is different. Whatever is the reason, there is more of it.

Local governments are adopting new technologies to facilitate public meetings. The meetings are advertised over the website and all the documents are publicly available. Citizens have much information at their disposal. They can get themselves informed about issues to a greater extent than they could before the Internet age. This has changed the nature of public meetings. The chief of communications at County A noted: We are going to be implementing a more technology-based approach to public meetings. I've been in and out of government for about 20 years. So, when I look at how people communicated before and how people were engaged and attended the meeting, it has completely changed. It is just such a fast-paced society.

The outcome of public meetings due to citizen engagement depends on multiple factors. Sometimes the citizens are well educated and informed and they pressure the government. In that case, the county administrators' role becomes complex, as they have to balance multiple factors at the same time. The administrators need to play a bridging 
role to balance the competing interests of the parties. Some members of the community are not well informed and educated. They may not have a voice and could be helpless. The government has to play the role of protector and voice for them. Lastly, some people join meetings solely to promote their self-interest. In all of this politics plays a central role. Multiple competing interests and challenges could surface in public meetings. An official from County A demonstrated the balancing game that the officials have to play in public meetings:

I think you're balancing a whole bunch of balls at one time. You know the community wants what it wants and sometimes members of the community that you're dealing with are very informed and educated and sometimes they are not. And you know, it is a mixture. You have the vocal folks, and they know how to maneuver the system and get what they want and what they need. And you have those folks out there that are pretty much helpless, and they don't have that voice. You end up being n certain situations where you have to advocate or become a voice for them. Then you have the political factor. Sometimes it is good, sometimes bad. Sometimes folks are just in it for their selfish purposes.

A key aspect of public meetings is that people attend then if they are really against an issue. Some may not participate at all because of personal constraints. In that case, governments need to come up with innovative solutions (e.g., using technology, the internet, or social media) to engage the public. An official from county B shared about how they had to sometimes reschedule public meetings so that a greater number of people can participate and provide their feedback. Additionally, using social media has changed 
the nature of public participation. The official mentioned that they created a new app to enhance the participation of residents. They employed the app for polling on issues, receiving feedback, and pushing public service announcements to residents. The employee mentioned:

Unless they are really against an issue, they are not going to show up at a public meeting. But I think they still want to be engaged and give their feedback. So, we're looking at a new platform. I think it is called public input. [...] I can't remember the one we've secured, but it is designed by actually two public works engineers and it allows us to geo-target an area and message out to them. [...] So, instead of having a public meeting on a Tuesday night, we may be able to host the online version over a two-week period where they are gathering information and engaging and giving feedback. There are ways to take polls. So, it is a way for us to get information from the public if they couldn't make it in that Tuesday night's meeting.

My observations of public meetings during case study site visits revealed that public engagement occurs in two ways. First, there are interested parties from the public that are affected by a certain issue and advocate for a policy stance. Second, there are volunteers from the community who willingly show up for public meetings to stay informed. The volunteers sometimes provide feedback on some facilities or services provided by the government. For example, at the village $\mathrm{C}$, a local free electric public transportation service "Freebee" was started based on citizen requests at a public meeting. 
Of course, such requests are not easily satisfied. The village manager and the elected council members need to find resources to meet such citizen requirements.

\section{Co-Production Scenarios}

Several co-production scenarios emerged from the three case study sites. They exemplify co-production. A majority of the scenarios were about citizen engagement in strategic activities to prioritize public services by residents in the future. Nabatchi et al.'s (2017, p.771) four phases of the service cycle is used to categorize co-production scenarios in this section. The phases are co-commissioning (engaging citizens in strategic prioritization of public services), co-designing (incorporating the experience of users in creation, planning, or arrangement of public services), co-delivery (joint activities between the state and lay actors that are used to directly provide services or improve the provision of public services), and co-assessment (monitoring and evaluating public services - state and lay actors work together to assess service quality).

Table 16: Co-production Scenarios and the Phases of Service Cycle

\begin{tabular}{ll}
\hline Co-production Scenario & Type of Co-production \\
\hline Strategic Vision 2020 & Co-commissioning \\
Community Prosperity & Co-commissioning; Co-designing \\
Community Survey & Co-commissioning \\
Community Conversation & Co-commissioning; Co-designing \\
People Mover & Co-designing \\
Citizen's Academy & Co-commissioning \\
Nonprofit Service Delivery & Co-delivery \\
\hline
\end{tabular}

Table 16 outlines the co-production scenarios that emerged from the three case study sites. There are seven co-production scenarios highlighted here. There were many additional scenarios that the officials explained. However, these seven scenarios capture the essence of co-production. These scenarios are strategic vision 2020, aligning 
community prosperity, community survey, community conversation, freebee, citizen's academy, nonprofits in service delivery. The co-production involved in each scenario is explained below.

\section{Strategic Vision 2020 (County A)}

The strategic vision 2020 was developed by the department of library services at county A. It was a county-wide initiative to understand the needs of library users firsthand. The exercise was intended to set budget priorities for the library department and in understanding the community aspirations. It was conducted across all the libraries in the county by holding open forums with citizens (both library users and non-users).

The core community aspirations were as follows:

- Discover: well organized and easily accessible materials in a variety of formats;

- Engage: assistance and instruction on using library collections, technology instruction, and cultural events; and

- Transform meaningful engagement in the community by bringing our resources and services directly to our citizens.

Subsequently, these community aspirations led to four strategic service priorities for a public library: 1) embedded in technology and information, 2) provider of education that embraces a broader definition of literacy, 3) culture and leisure that includes the artistic and literary creativity of the community, and 4) community engagement - serving as a vibrant and active hub for civic discourse and participative democracy, building relationships, and bridging gaps in all segments of the community. This also aligns with 
the library departments scorecard to measure the department performance on the five core values of community prosperity ${ }^{3}$.

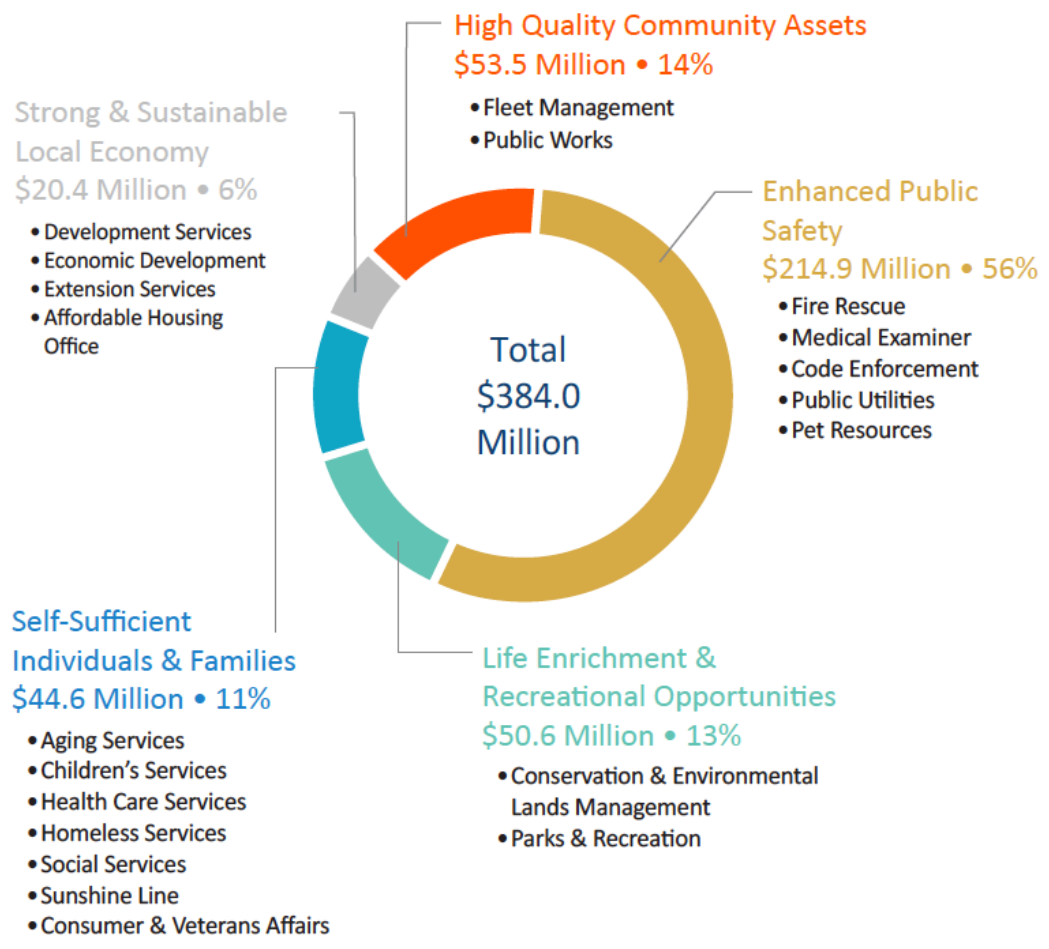

Figure 22: Strategies Objectives for Building Community Prosperity at County A Community Prosperity (County A)

Building community prosperity was a county A's core initiative to define the county's vision, mission, and strategic outcomes for a prosperous community (Figure 22). The initiative aimed to align community service needs with the county budget priorities. It involved extensive citizen engagement, including implementing a community survey.

\footnotetext{
${ }^{3}$ Library Departments Strategic Plan and Vision 2020 was a classic example of a holistic County-wide approach to align the department's direction with the County's building community prosperity's five core values: strong and sustainable local economy, enhance public safety, life enrichment and recreational opportunities, self-sufficient individuals and families, and high-quality community assets. It is a good example of co-commissioning in which extensive citizen engagement forums were organized to get feedback and suggestions for setting the departments' future direction to address community aspirations. This entails leader-follower-community engagement in the co-production of public service.
} 
There initiative intended to provide policy directions in five areas of the county's priorities: high-quality community assets, strong and sustainable local economy, enhanced public safety, self-sufficient individuals and families, and life enrichment and recreational opportunities. Building community prosperity was initiated by the county administrator.

\section{Community Survey (County A and County B)}

The community survey was implemented by both counties A and B for the first time. The main goal of the survey was to understand the needs of the citizens. community surveys are recent phenomena. They were aimed to identify gaps in community services and thereby design strategic outcomes based on community needs. The communications and technology officer at county B described the launch of its first community survey as follows:

The county is launching its first online county-wide survey. If you look at it community-wide, it is 1300 respondents and it' 11 have a plus or minus $2 \%$ accuracy. We'll be able to break it down by district and we'll have 325 respondents in each district with a plus or minus $5 \%$. We're using a research firm. We're such a big county, but we only have 1300 people. It just shows how online is the community, and they really want to participate. I think the public input platform we're going to use is really going to serve us well. I think this is just scratching the surface.

Likewise, in county A, the community satisfaction survey was implemented for the first time in the spring of 2019. About 3700 responses were collected. The survey 
measured residents' trust in the county, favorite place to live, retire, raise children, work, vacation, and open a business. In addition, the survey also measured how frequently residents engage the county government and respondents could rate their engagement experience. The county intended to use the survey findings to gain insights into the key areas that impact the community's life and setting their priorities in the future. The chief of communication noted:

We ask them some demographic questions. How long have you lived here? Would you recommend it as a place to live, work, retire, vacation kind of thing? We have survey questions about everything from a nature preserve to bicycle safety to pedestrian safety. The first question is how important it is for a community to possess this? Because of funding changes. You know if we value parks and green space. This is our first baseline survey and it helps in more data-driven information for us to make decisions. It is kind of getting a pulse of where we're at. We have a question in the online survey that asks, have you engaged with the county in the last year? And if so, how was that engagement?

\section{Community Conversation Campaign: Participate, Contribute, Engage (Village C)}

Village $\mathrm{C}$ began conducting a series of face to face community conversations to develop the strategic plan and to set priorities to better fulfill the needs of the community in the future. This campaign was initiated by the village manager, in consultation with the village council's members. She launched the community conversation campaign to obtain a variety of ideas through community participation, focusing on topics that mattered most to the residents. With the community conversation campaign, the village's residents were 
asked to share ideas on how to enhance their community and meet their needs over the next 20 years. Thoughts about potable water, power lines, trees, safety, and more were voiced at the first community conversation. The second community conversation collected information about what is important to the residents. The community conversation campaign invitation read as follows: "MEET with Village staff for an informal Q\&A about what matters to YOU. Share your IDEAS on how we can ENHANCE our COMMUNITY."

The campaign received inputs on areas such as mobility, powerlines, water, resiliency, and character of physical assets, landscapes, and infrastructure. During the face to face community conversation campaign, the village manager and all the village council members were present. This boosted the confidence of the village residents and they thought their opinion mattered for the village government. As a result of the community conversation, the village identified that 740 homes did not have potable water connections.

\section{People Mover-Freebee (Village C)}

Due to citizen complaints about the need for transportation to move in and around the community, village $\mathrm{C}$ initiated a people mover called Freebee. It was designed as a free green transportation service for the village's residents. The Freebee provides free ondemand rides around popular destinations in the village. This initiative was the result of the multi-stakeholder partnership: village - the county transportation planning organization, and Freebee-a private transportation agency. 


\section{Citizen's Academy (County B)}

County B initiated a citizen's academy to enhance citizen engagement with county residents. Citizen's academy is an interactive civic and public information program aimed at giving residents an opportunity to learn more about their county government. The program focuses on how local government works, promotes open communication, and offers an understanding of how employees work to serve the public. It is conducted as a free 6-week course.

Department managers and the county staff conduct the unique and informative sessions designed to give citizens hands-on experience in county government operations. Citizens Academy sessions are held at various locations throughout the county. Participants who attend a minimum of four out of six classes receive an end of course graduation.

\section{Engaging Communities through Nonprofits (County A and County B)}

Nonprofits are generally engaged in the local communities where they operate. They deliver services that are otherwise not available in the community through the public or private sectors. As such, they form good partners for civic engagement. They can enhance the quality of life for the community.

The case studies revealed two examples of how nonprofits could enhance coproduction in conjunction with public agencies. In county A, the library department works in close collaboration with the Friends of the Libraries. The partnership is fruitful since the nonprofit champions the cause of the library. The nonprofit is instrumental in fundraising for special library events, getting political support from the elected representatives, and providing the much-needed logistical support to the library staff. 
In county B, the nonprofit United Way partners with the county government to provide child services and youth engagement activities. The county administrator serves as a chair of the United Way board; hence establishing the partnership was facile. An official from county B narrated how the administrator helped to build a culture of voluntary community service among the staff too. The official noted:

He's at every place I've seen him, even when I wasn't working for him. He is one of the chairs of the United Way. And that's the thing -- it sends a message to everybody else who says, "money is important, but time is even more important." And he commits a lot of time to the community through non-work-related activities. And I think that speaks volumes because he's attending meetings for community service. What he does on his own time speaks more to the community than what he's doing during his hours of pay. And he does a lot of philanthropic things. This sends a message to others as well.

Overall, findings from the case studies are consolidated in Figure 23. The main servant leadership characteristics that manifest into co-production are a genuine concern for people and creating value for the community. However, these characteristics result in co-production by intervening mechanisms such as a shared vision for community engagement and prosperity, culture of volunteerism and community service, and service climate. Besides, the organizational size, leader's tenure, and elected official's community orientation act in favor of or against co-production. Organizational resources such as effective communications strategy act as a facilitator for co-production to occur. 
$\underline{\text { Organizational Limitations }}$

-Organization Size

-Leaders Tenure

-Elected Officials Lack of Interest

in Community Engagement

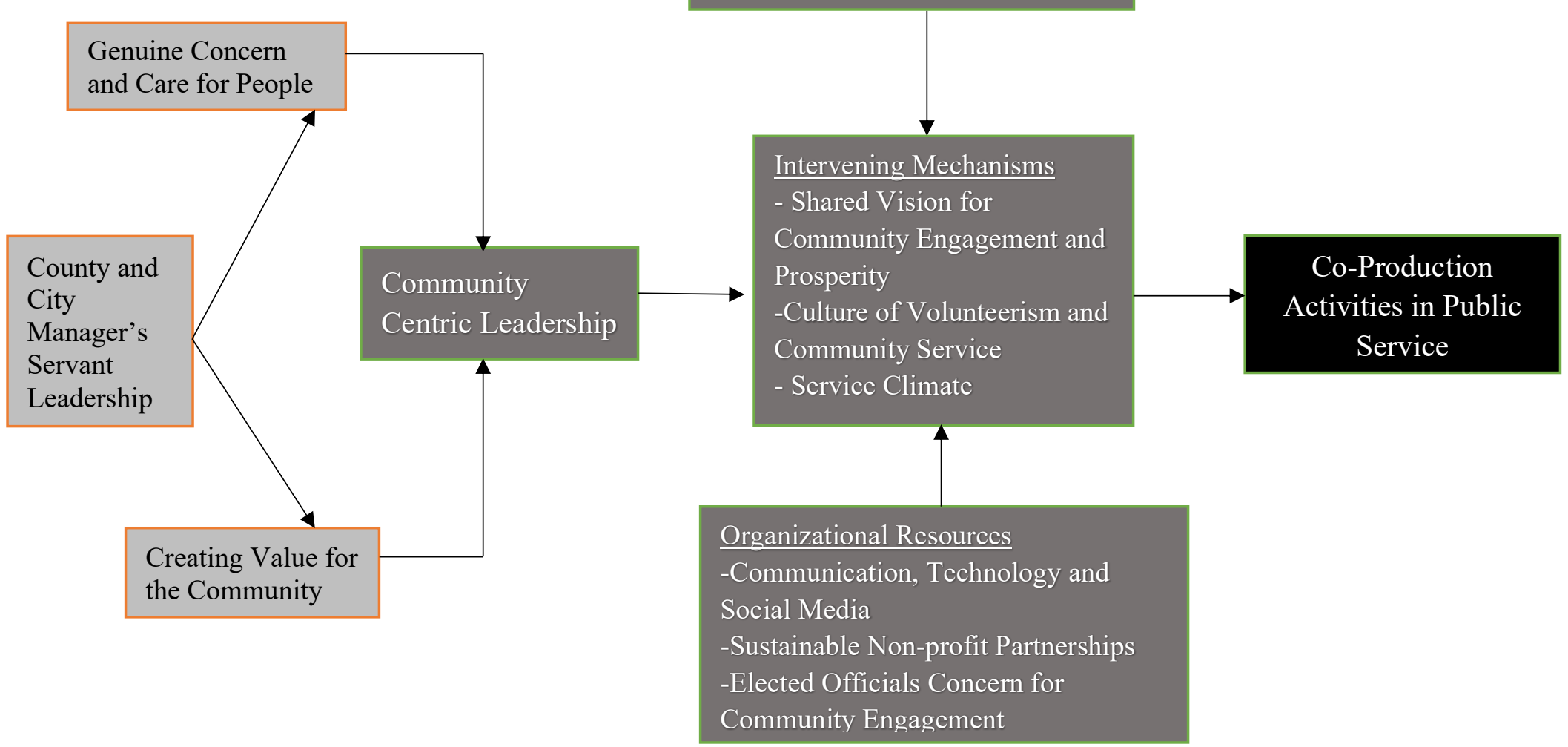

Figure 23. Impact of Servant Leadership on Co-Production of Public Services

Note: Orange outline represent servant leadership dimensions, the green outline is for intermediary processes 


\section{Discussion}

Since servant leadership is about creating value for the community, it is important to explore the community-oriented outcome of servant leadership in local governments. This chapter focused on understanding the impact of servant leadership behavior (SLB) on the co-production of public services (COPR). To examine this, data from the survey of local governments and three qualitative case studies were utilized. Specifically, the hypothesis tested if servant leadership theory facilitates co-production (King \& Stivers, 1998; Etzioni, 1988; Denhardt, 2000; Nabatchi, 2017).

The HLM analysis shows that servant leadership does contribute to co-production in a significant way. The service climate is a partial mediator in this process. Servant leadership behavior surpasses ethical leadership qualities in enhancing co-production. Four models were used to test the relationship. In model 1, SLB predicted $63 \%$ of the variance in COPR. In model 2 , SLB predicted $38 \%$ of the variance in COPR while controlling for the service climate. In model 3 , SLB predicted $29 \%$ of the variance in COPR while controlling for ethical leadership. In model 4, the effect of SLB was significant and predicted a $12 \%$ variance while controlling for both service climate and ethical leadership.

The findings are consistent with the servant leadership theory's focus on community well-being. One of the core principles of servant leadership is creating value for the community (Greenleaf, 1977; Liden et al., 2014; Liden et al., 2008). Servant leaders are custodians and the trustees of the organizations and the larger community. They create opportunities and encourage followers to engage in volunteer activities that facilitate local communities (Liden et al., 2014). This also shows how servant leadership 
holds positive outcomes for both employees and the community (Greenleaf, 1977; Eva et al., 2018; Lemoine et al., 2019). The servant leadership approach provides a new way for public administrators to revise their approach in the way they engage with citizens (Neill $\&$ Nalbandian, 2018). Thus, this finding underscores the expectation that county and city government managers should get involved with community partners and elected officials to engage with the community (Nalbandian, 2013). The community-centric servant leadership shares the 'building community and civil society' dimension of the new public service paradigm, which can help to rebuild the sense of community (Gardner, 1991; Denhardt \& Denhardt, 2000).

The qualitative analysis sought to understand the connection between servant leadership and co-production in the context of the three case studies. The findings suggest three aspects of servant leadership broadly construed as important to affect the coproduction (see Figure 23). First, it revealed that servant leaders are community-centric leaders due to their genuine concern for people and a broader focus on creating value for the community. These beliefs translate into community-centric leadership as stressed by the employees in all the case study sites. The community-centric approach of the county and city managers creates a shared vision for community engagement and prosperity.

Second, servant leaders are innovative and creative. They encourage citizen engagement in various ways. They are open and create mechanisms to integrate new methods such as modern technologies in public service provisions. Such a leadership approach facilitates co-production activities to occur. Servant leaders are adept at developing sustained partnerships with external stakeholders such as non-profits, faithbased organizations, and neighborhood associations. 
Third, the following common factors are critical for community-centric leadership: leadership style, leader's trust within the community, size of the organization, the leader's tenure, and ability of the leader to negotiate with elected officials. Style, trust, and tenure are critical for the long-term sustainability of community-centric leadership.

\section{Conclusion}

In all, the results are consistent in both the quantitative as well as qualitative findings. The quantitative findings suggest that servant leaders enhance co-production with a partial intervening effect of service climate. The results predict that servant leadership promotes co-production even beyond the effect of ethical leadership, through its focus on creating value for the community. Similarly, case studies reveal the mechanisms that servant leaders utilize and create in organizations to enhance community outreach and engagement in public service. The results are a significant contribution towards our understanding of leadership approaches and intervening mechanisms that might be conducive to the culture of local governments in terms of enhancing citizen engagement in public service.

From a theoretical perspective, the findings of this study have implications on the new public service proposition that community building and citizen engagement is a basic tenet of public administration. The role of public servants is not merely to respond to the 'customer' needs but also to consider them as 'citizens' and active partners in the public service provision by forging trusting relationships with multiple stakeholders. In local governments especially, the role of the county and city manager is critical for community building and strengthening democratic values. In that aspect, the servant 
leadership theory is promising. Servant leaders internalize ethical behavior, empathy, and service orientation with an overarching vision of creating value for the community. Thus, county and city managers who are servant leaders create effective mechanisms to facilitate citizen's engagement in co-production. They add value to the long-term sustainability of public service organizations.

From a practical standpoint, the findings add to the understanding of the critical local government leadership needs in the $21^{\text {st }}$ century. Local government leaders, especially county and city managers are the custodians of democracy as they work for the needs of the local community. They have to create mechanisms and systems for citizen engagement and for forming partnerships with multiple stakeholders. In addition, local government leaders have to integrate innovative communication methods for better outreach to citizens and to encourage participatory governance. In this regard, the servant leadership approach offers immense value.

Local government organizations can implement hiring systems that emphasize the values of servant leadership. Perhaps, during the new hiring process for managerial positions in local governments, the testing mechanisms should also focus on assessing the servant identity and moral attributes (which are crucial qualities of servant leaders). In addition, structured training programs can be devised and implemented periodically for assessing and developing servant leadership qualities in local government leaders.

Lastly, the bridging role of county and city managers is the core of effective leadership in context. This study suggests that these administrators should be willing to negotiate and be diplomatic. They should use their listening and communication skills to resolve the competing interests of multiple stakeholders (employees, elected officials, and 
the community) while prioritizing the larger interests of the community at all times. Local governments can organize servant leadership development workshops on 'servant leaders as negotiators, communicators, and listeners' to prepare them for their roles as effective bridge builders. Administrators are also visionaries. They create a shared vision of community prosperity among all the stakeholders. This enables trustworthy relationships and sustainable understanding and collaboration among all the stakeholders such as elected council members, community partners, citizens. It also helps in the sustained efforts of the local governments to enhance their co-production. 


\section{CHAPTER 5: \\ Enhancing Organizational Social Capital in Local Governments: \\ A Servant Leadership Approach}

\section{Introduction}

Servant leadership is a people centric approach. It facilitates the growth and wellbeing of employees (Eva, Robin, Sendjaya, van Dierendonck, Liden, 2018). This, in turn, results in overall organizational health and community well-being. Servant leaders engage their followers along the multiple dimensions (relational, ethical, emotional, and spiritual) to help them utilize their full potential (van Dierendonck, 2011). They engage in the growth of their followers by taking a unique approach to building one on one relationship. They take into consideration each follower's unique needs and address their growth according to their specific interests, belief, and core values. Servant leaders take a unique approach to building relationships and trust. It facilitates organizational members by serving and empowering them.

This chapter investigates the impact of servant leadership behavior in building organizational social capital (OSC). Organizational social capital is a widely discussed construct which reflects the qualities of shared relationships, mutual trust, information sharing, and collective action among organizational members (Putnam, 1993; Nahapiet \& Ghoshal, 1998; Leana \& Buren, 1999; Leana \& Pil, 2006; Andrews, 2010). Encouraging OSC in organizations is about providing conducive organizational structures, processes, and systems to facilitate employees to work in harmony, grow, and build organizational competitiveness (Leana \& Pill, 2006; Krebs, 2008). In public administration, OSC is consistent with new public service (NPS) paradigm which states that the central role of government is to help and create a vibrant community and civil society consisting of 
engaged citizenry which is active in groups, associations, and governmental units (Denhardt \& Denhardt, 2000; Putnam, 1995; King \& Stivers, 1998).

Previous studies in the public-sector context have examined the impact of OSC on government performance, organizational size, decentralization, collaborative governance, performance information use, and the attitude or behavior of public servants (Coffe \& Geys, 2005; Brewer, 2003; Leana \& Pill, 2006; Knack, 2002; Tantardini \& Kroll, 2015; Andrews, 2010, 2017). There is very little research to understand how leadership impacts the level of OSC in public-sector organizations, especially in local governments. The context of local governments is particularly important for understanding the application of servant leadership since local government leaders engage with the community on a routine basis. It builds trust and thereby impacts the community's well-being and enhances government accountability.

This chapter is organized as follows. The next section expands on the concept of organizational social capital. It is followed by explaining the hypothesis and the research design. Then, the quantitative data analysis and the results are presented. After this, the case study findings are presented. The last section concludes with the chapter's implications for local government organizations.

\section{Organizational Social Capital}

Organizational social capital is "a resource reflecting the character of social relations among the members within an organization" (Leana \& Van Buren, 1999, p. 538). Organizational social capital, therefore, is an asset that creates positive effects for employees and the overall organization (Leana \& Van Buren, 1999). Inkpen and Tsang (2005) defined organizational social capital as a public good which the members of the 
organization can utilize to tap into the resources derived from the organization's network of relationships without necessarily having participated in the development of those relationships. In general, the organizational social capital theory states that members of a social network create value as a result of positive and productive interactions among themselves (Andrews, 2011). The value created by the network can benefit all the members as well as the organization. Nahapiet and Ghoshal (1998) identified three dimensions of organizational social capital (OSC): structural (connections among actors), cognitive (shared goals and values among actors), and relational (trust between actors). All three dimensions could result in organizational benefits.

In public sector, the research on organizational social capital is scant. However, the limited research showed promising findings. For example, Leana and Pill (2006) linked the three aspects of OSC to the high performance of students in urban public schools. Their research showed that schools with high academic achievements measured the presence of internal (relationships among teachers) as well as the external social capital (relation between the principal and external stakeholders). Likewise, Tantardini and Kroll (2017) linked the three dimensions of social capital (structural, relational, and cognitive) in fostering the collection, dissemination, and usability of performance data in local governments. Andrews $(2010,2011)$ showed that OSC is positively related to the performance of public bureaucracies and decentralized decision making and negatively to centralized government agencies. In recent research, Kim (2018) found a positive relationship between OSC and knowledge sharing, mediated by public service motivation in the South Korean public sector. 


\section{Role of Leadership in Fostering Organizational Social Capital}

To date, research on OSC has investigated its benefits to organizations, but not on the factors which enhance OSC per se. That is, there is little research on what the antecedents of OSC are or how OSC emerges in organizations. This chapter contributes to the emerging literature on how leadership can foster OSC in the public sector. It particularly examines the role of servant leadership in promoting OSC in local governments. The examination is pertinent to understand which leadership model is conducive to OSC in public administration. This examination is also important because OSC can contribute to enhancing the performance of local government agencies (Andrews, 2011; Kim, 2018).

There are a few studies on the link between leadership and OSC in the private and nonprofit sectors. Purdue (2001) studied social capital in a community leadership context. He found community leaders act as social entrepreneurs and transformational leaders who create a shared vision, which is useful for fostering entrepreneurial skills in the community. The trusting relationship between leaders and community members enhance the communities' social capital.

Hitt and Duane (2002) found that strategic leaders enhance internal and external social capital by demonstrating humility and by building productive relationships among teams. Pastoriza and Arino (2012) examined the impact of ethical leadership of supervisors on organizational social capital among private sector firms in Spain, France, and Portugal. They found that ethical leadership is positively associated with the structural, relational, and cognitive dimensions of the firm's organizational social capital. 
Specifically, in the context of servant leadership, Linuesa-Langreo, RuizPalomino, and Elche-Hortelano (2018) examined the relationship between servant leadership behavior and group social capital. Their empirical context comprised of hotels in Spain. They found a significant positive relationship between servant leadership behavior and group social capital, mediated by group citizenship behavior. This study suggests that applying an employee-friendly leadership approach can create a socially integrated, committed, and cohesive workforce and contribute to the overall organizational health.

This chapter builds on Pastoriza and Arino (2012) and Linuesa-Lingero et al., (2018) in examining the relationship of servant leadership and organizational social capital in local governments. The empirical context of this study comprises of county and city governments in Florida. Studying servant leadership's scope in fostering organizational social capital is vital in building internal organizational trust, collaboration, and sharing. It is broader than ethical leadership, which focuses only on the moral and ethical constructs of leadership. Servant leadership is highly comprehensive as it lends benefits to the employee, organization, and the overall community (Neubert et al., 2016; Greenleaf, 1970; Sendjaya, 2015, Walumbwa et al., 2010; Liden et al., 2008;

Walumbwa et al., 2018; Miao et al., 2014).

In the public sector, servant leadership positively impacts organizational commitment, public service motivation, and job satisfaction (Miao et al., 2014; Swartz et al., 2016; Chung et al., 2017). The concepts of organizational commitment and motivation are closely linked with OSC as well. We could thus conceptually hypothesize 
that servant leadership behavior could enhance OSC too. The theoretical basis of the hypothesis and its formulation is further explored in the next section.

\section{Theory and Hypothesis Development}

Social capital is an inherent value embedded in close relationships among the organizational members. The value is generated by knowledge and information sharing, trust-building, and a common understanding of the organization's mission, goals, and objectives (Nahapiet \& Ghoshal, 1998; Leana \& Pil 2006). According to Maak (2007), responsible leadership is vital in building social capital within and outside the organizations. Responsible leaders have to deal with moral dilemmas and complexities in decision making while engaging with multiple stakeholders to build mutually rewarding relationships.

Servant leadership is one such kind of responsible leadership approach. Servant leaders possess service orientation and moral potency (Liden et al., 2014). These qualities of servant leaders help them build relationships with multiple stakeholders (employees, citizens, community, and other sector partners). Servant leaders cultivate a sense of shared vision and community service in their organization (Liden et al., 2008; van Dierendonck, 2011). Servant leaders set aside their self-interest and pursue selfless leadership while engaging with followers (Liden et. al, 2008; Greenleaf, 1970).

\section{The Servant Leadership Approach}

The servant leadership qualities of being follower centric, shared goals, and service orientation are compatible with enhancing organizational social capital among the followers. It can significantly impact both the internal and external organizational 
outcomes (Liden et al., 2014; Hunter et al., 2013; Yoshida et al., 2014). Servant leader's focus is on others' interests and their core identity revolves around the philosophy that 'a great leader first wants to serve, and the conscious desire to serve brings him/her to aspire to lead' (Greenleaf, 1970). Servant leaders build trust among the multiple stakeholders (followers, citizens, community) while serving them first and thereby building longlasting and trustworthy partnerships (Graham, 1991; Liden et al., 2008).

Servant leadership is distinctive from other leadership styles such as transformational, ethical, and authentic (Parolini et al., 2009; Lemoine et al., 2019; Hoch et al., 2018; Chaudhary et al., 2013). Transformational leaders focus on utilizing the energies of their followers to fulfill organizational goals, while servant leaders focus on serving their followers to nurture their full potential. Servant leadership has some common traits with authentic and ethical leadership. However, authentic and ethical leadership uses a distinct theoretical approach to morality referred to as morality contentthe criteria an individual utilizes to determine what is right or wrong (Lemoine et al., 2019). For example, authentic leadership takes a virtue ethics approach for transparent expression and action in cohesion with the leader's beliefs (Avolio et al., 2004).

Ethical leadership takes a normative ethics approach to comply with laws and normative ethics requirements (Brown et al., 2005; Brown \& Trevino, 2006). In contrast, servant leadership takes a consequentialist approach suggesting that servant leaders constantly work for the greater good of society by serving the needs of the multiple stakeholders. Servant leadership benefits the employees, organizations, communities, and societies (Greenleaf, 1977; Ehrhart, 2004; Liden et al., 2008). Servant leadership offers a 
wholesome approach to leadership as compared to authentic and ethical styles. Thus, it is highly relevant in building organizational social capital.

\section{Organizational Social Capital}

Research on organizational social capital has flourished in the last two decades. Much of the research has focused on the benefits of OSC, but the literature on the antecedents of OSC is still emerging. In this vein, Andrews (2010) examined how organizational structures facilitate OSC and organizational performance in the empirical context of English local governments. He found that less hierarchical organizational structures enhance OSC and performance. Rupasinga et al., (2006) suggest that fair pay, opportunities for career growth, training, education, and employee attachment enhances OSC. Ellinger et al. (2010) noted that a public manager's need to develop connections, enables trust and cooperation among employees in their organization.

In terms of the relationship between leadership and social capital, De Clercq et al. (2014) studied the impact of servant leadership on work engagement and how the social capital inherent in leader-follower connections influences this relationship. LinuesaLangreo et al. (2017) examined the relationship of servant leadership with group social capital and found that servant leaders lead businesses in a socially friendly manner and build group social capital. In turn, they create dutiful and responsible employee workforce for attaining competitive advantage for their businesses.

In line with Linuesa-Langreo et al. (2017) on the effect of servant leadership on social capital, this chapter investigates how servant leadership impacts organizational social capital in public organizations at the local level. Relying on the premise that OSC is a measure of structural (connections among actors), relational (trust between actors), 
and cognitive (shared goals and values among actors) dimensions of social capital in organizations, the hypothesis is that servant leadership is likely to enhance organizational social capital in local governments. Servant leadership theory is consistent with enhancing all three dimensions of social capital. Structurally, servant leaders enhance employee social relations and encourage followers to have a service orientation. From a relational perspective, servant leaders enhance trust among the followers by following consequential ethics. Cognitively, servant leaders espouse shared goals focusing on the employee's benefits. Hence, the hypothesis to be tested is:

H2b. Local government agencies rated high on servant leadership behavior will have a higher degree of organizational social capital.

\section{Measurement of Variables}

The study takes a mixed-method research design - an online survey and three case studies of county and city governments that rated high on the servant leadership behavior scale in the online survey. The unit of analysis is council-manager form of county and city government. As explained in chapter 2, the quantitative analysis draws on the online survey data administered to Florida county and city government officials. The survey respondents in this study were county and city managers (considered as leaders) and their executive team (followers, who directly report to the managers; such employees include deputy or assistant managers and department directors).

\section{Operationalization of Variables}

The variables of interest for this chapter are organizational social capital (outcome variable), servant leadership behavior (predictor variable), and ethical leadership is taken 
as a control variable. Other control variables include demographic characteristics such as education, age, tenure in local government, ethnicity, and tenure in the current position. All variables were constructed as an index from likert scale responses given by the employee. Responses for the organizational social capital, servant leadership behavior and ethical leadership were measured on a scale of 1 (strongly disagree) to 7 (strongly agree).

Dependent Variable - Organizational Social Capital

Survey questions for measuring OSC were drawn from Andrews (2010, 2011). There were six statements in the survey related to OSC. Examples of these statements are: 'In this organization, coordination and joint working with other departments is a major part of the approach to the organization of the services', 'In this organization, there is a high level of trust between the top management and staff', 'In this organization, the authority concentrates on achieving its mission values and objectives.' (see Appendix C). The OSC variable is constructed as an index from followers' responses to the statements. The Cronbach's Alpha for organizational social capital is 0.89 , which is above the accepted threshold level.

Independent Variable - Servant Leadership Behavior

Since the focus of the study is exploring the impact of servant leadership behavior on organizational social capital, servant leadership behavior is an independent variable. SLB is measured by Liden et al., (2008) 7 item scale. Examples of the statements are 'My city or county manager can tell if something work-related is going wrong', my city or county manager emphasizes giving back to the community', and 'My city or county 
manager would not compromise ethical principles to achieve success'. The Cronbach' Alpha score for SLB is 0.88 , above the threshold acceptable level.

\section{Research Model}

Hierarchical Linear Modelling (HLM) is used in this chapter since the data are at two levels: individual and organizational. The individual ratings of the followers need to be aggregated to the organizational level of the county or city government. The HLM equation for the model is as follows:

Null Model or Unconditional Means Model

$(\text { Organizational Social Capital })_{\mathrm{ij}}=\beta_{0}+\varepsilon_{\mathrm{ij}}$

\section{Model with Predictors}

$(\text { Organizational Social Capital })_{\mathrm{ij}}=\gamma_{00}+\gamma_{\mathrm{ijj}}\left(\right.$ Servant Leadership $+\gamma_{2 \mathrm{ij}}($ Ethical

Leadership $)+\gamma_{3 \mathrm{ij}}($ Control Variables $)+\varepsilon_{\mathrm{ij}}$

where $\beta_{0}$ and $\gamma_{00}$ are the intercepts, and $\gamma_{1}, \gamma_{2}$, etc. are the coefficients to be determined.

Data Aggregation, Inter-Rater Reliability, and Intraclass Correlations

In the HLM model, aggregation of data is required since the data are collected from individuals and the dependent variables of interest are conceptualized at the organizational level of analysis. Followers are nested within the organization. It is also necessary to determine if the aggregation of the individual level outcomes to the organizational level is appropriate for the multilevel modeling. The aggregation needs to be both theoretically and statistically justified (Klein, Dansereau, \& Hall, 1994). 
Theoretically, the aggregation can be justified because the dependent variable of organizational social capital is conceptualized and defined at the organizational level. County and city governments are the units of analysis, where the county and city manager are a leader and the employees directly reporting to the manager are the followers. Aggregation of the followers' responses for both servant leadership behavior and organizational social capital, therefore, justifies measures at the organizational level of the county or city (George \& James, 1993; Schneider \& Bowen, 1985).

There are several statistical tests also to check the appropriateness of aggregation. First, inter-rater agreement $\left(\mathrm{r}_{\mathrm{wg}}\right)$ among the followers needs to be determined at the organizational level. The acceptable threshold for the inter-rater agreement is 0.70 (LeBreton \& Senter, 2008). Intraclass correlations, ICC (1), and ICC (2) are also used as statistical tests for aggregating to higher level of analysis (e.g., Bartko, 1976; Shrout \& Fleiss, 1979). The ICC (1) compares the variance between units of analysis (county and city governments) to the variance within units of analysis using the individual ratings of each respondent. The ICC (2) assesses the relative status of between and within variability using the average ratings of respondents within each unit (Bartko, 1976). Within-group agreement $\left(\mathrm{r}_{\mathrm{wg}}\right)$ is calculated using the uniform null distribution. The average $r_{\mathrm{wg}}$ score for servant leadership is $0.76(\mathrm{Mdn}=1)$ and organizational social capital is $0.89(\mathrm{Mdn}=1)$. These values suggest that the aggregation of the individual employee scores to the organization level is appropriate. The ICC (1) value is 0.23 and the ICC (2) value is 0.75 . Although there are no strict standards of acceptability for either ICC (1) or ICC (2) values, James (1982) suggested a median ICC (1) value of 0.12 threshold and Glick (1985) recommended an ICC (2) threshold of 0.60. The statistical 
tests for both servant leadership behavior and organizational social capital meet the criteria for justifying the aggregation to the organizational level.

\section{Results of HLM Analysis}

The HLM analysis was preceded by ANOVA tests to examine any significant differences between the organizations (i.e., the county and city governments) in terms of the main organizational level variables. The main organizational level variables are the dependent variable OSC and the independent variable servant leadership behavior. The ANOVA results showed that there are no significant differences among across the county and city governments.

\section{Descriptive Statistics and Correlations}

The descriptive statistics and correlation matrix between the dependent variable (organizational social capital), the independent variable (servant leadership behavior) are shown in Table 17. The table shows that the means of the variables are above the middle of the range (3.0), and there are not very high correlations among most variables, except servant leadership and ethical leadership (.86). It shows the overlap between ethical and servant leadership styles.

Table 17. Means, Standard Deviation, and Correlations Among the Variables

\begin{tabular}{lcccccc}
\hline Variable & $\mathrm{M}$ & $\mathrm{SD}$ & 1 & 2 & 3 & 4 \\
\hline 1.Organizational Social Capital & 5.65 & 1.18 & 1 & & & \\
2. Servant Leadership & 5.50 & 1.13 & .71 & & & \\
3. Ethical Leadership & 6.0 & 1.03 & .72 & .86 & 1 & \\
\hline
\end{tabular}

Note. $\mathrm{N}=228$. All correlations are at the individual employee level, with organizationallevel variables (i.e. organizational social capital, servant leadership, and ethical leadership is used as a control variable in the study). 


\section{Confirmatory Factor Analysis}

Since the data were collected from different county and city governments across the State of Florida, multigroup CFA was conducted to establish the validity of the dependent and independent variable measures. The CFA was conducted on followers' responses to servant leadership behavior and organizational social capital. The CFA allows index items to load on the proposed latent construct. It is a tool to confirm or reject the measurements (see Figure 15).

The CFA model for the variables fit the data well: for servant leadership, the model fit was $\chi^{2}(14, \mathrm{~N}=228)=40.84, \mathrm{p}<.0001$; comparative fit index $(\mathrm{CFI})=.96$, Tucker-Lewis Index $(\mathrm{TLI})=.94$, root mean square $($ RMSEA $)=.09$. root mean square error $(\mathrm{SRMR})=.03$. For organizational social capital, model fit was $\chi^{2}(9, \mathrm{~N}=228)=$ 159.36, $\mathrm{p}<.0000$; comparative fit index $(\mathrm{CFI})=.84$, Tucker-Lewis Index $(\mathrm{TLI})=.73$, root mean square $(\mathrm{RMSEA})=.27$, root mean square error $(\mathrm{SRMR})=.09$. For ethical leadership, the model fit was $\chi^{2}(14, \mathrm{~N}=228)=70.84, \mathrm{p}<.0000$; comparative fit index $(\mathrm{CFI})=.94$, Tucker-Lewis Index $(\mathrm{TLI})=.91$, root mean square $(\mathrm{RMSEA})=.13$, root mean square error $(\mathrm{SRMR})=.04$

\section{HLM-Main effect}

The null model was tested to examine the group variance among follower responses across the county and city governments. The results reveal a 33\% variance. Chi-square test revealed that between-group variance is significant $\left(\chi^{2}=300.49, \mathrm{p}<.001\right)$. 
Hypothesis Testing

The hypothesis $\mathrm{H} 2 \mathrm{~b}$ measured the positive relationship of servant leadership with the OSC. Table 18 shows the results of hierarchical linear modeling. In Model 1, servant leadership is significant and positively related to OSC in the county and city governments $(\gamma=0.77, \mathrm{p}<.001)$. The hypothesis $\mathrm{H} 2 \mathrm{~b}$ therefore, is empirically supported. 


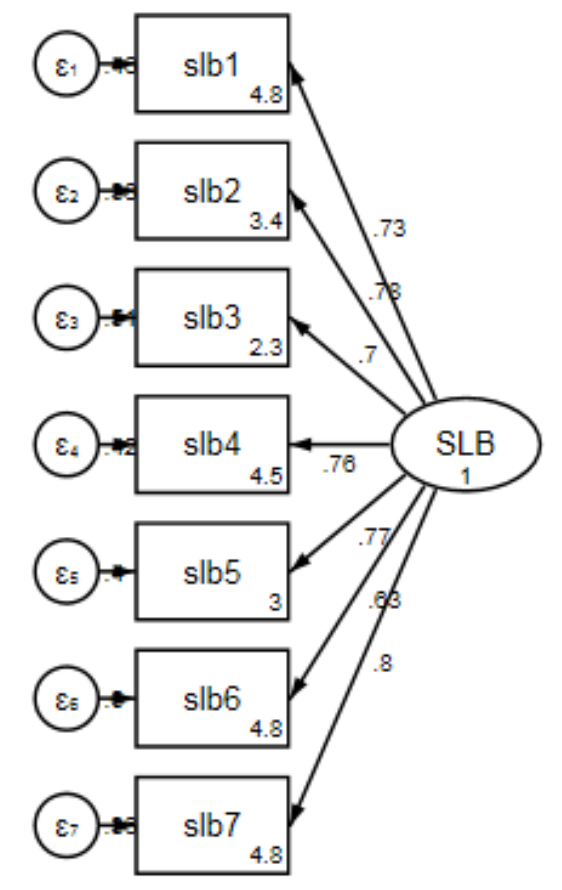

Servant Leadership

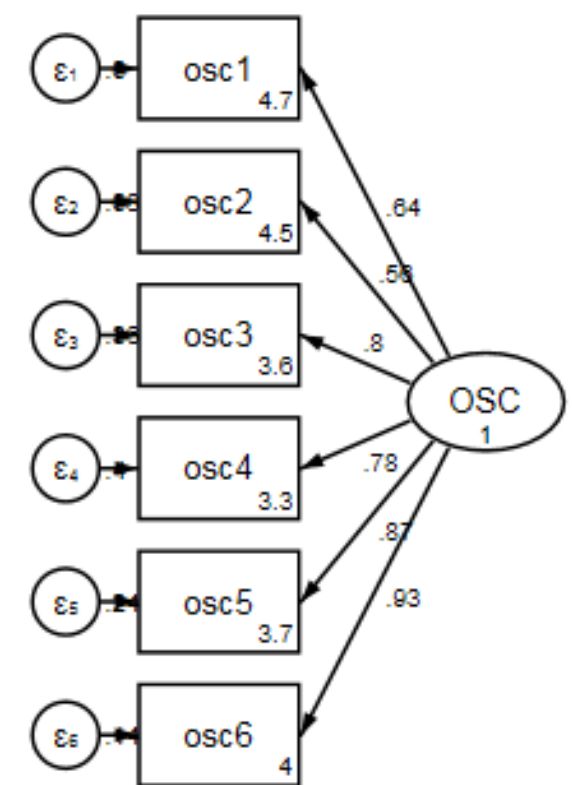

Organizational Social Capital

Figure 15: Confirmatory Factor Analysis for the Variables in the Study 
In Model 2, the relationship of servant leadership behavior with OSC is measured when controlled for ethical leadership. Servant leadership behavior $(\gamma=0.28, \mathrm{p}<.001)$ as well as ethical leadership $(\gamma=0.62, \mathrm{p}<.001)$ are significant. The results show that servant leadership significantly and positively relates to OSC even when the effect of ethical leadership is controlled for in the model.

The null model, as well as the other models including the control variables, show the significance of servant leadership behavior for organizational social capital. Other demographics related control variables such as age, education, ethnicity, and gender are not significant. Tenure shows to be significant, which implies that the experience of a leader is another determinant of organizational social capital.

\section{Qualitative Case Study Analysis}

The qualitative case studies seek to complement the quantitative analysis by examining the relationships between servant leaders and organizational social capital in a more subtle way. As explained in Chapter 2, three case studies were undertaken in County A, County B, and Village C. In all three cases, the servant leadership behavior is high. Therefore, it is reasonable to expect that the OSC would also be high. The case studies reveal how servant leaders enabled high OSC.

The leader's initiatives to increase OSC is required to understand how servant leadership affects OSC in county and city governments. Semi-structured interviews were conducted with both the leaders and the followers to understand the initiatives undertaken that enhanced OSC. The leaders were asked questions about the initiatives that they directed to enable OSC. 
Table 18. Hierarchical Linear Modelling Results: Servant Leadership and Organizational Social Capital

\begin{tabular}{lllll}
\hline \multicolumn{1}{c}{$\begin{array}{c}\text { Variable } \\
\text { Employee Responses Nested within Organizations }\end{array}$} & \multicolumn{2}{c}{$\begin{array}{c}\text { OSC } \\
\text { Model 1 }\end{array}$} & \multicolumn{2}{c}{$\begin{array}{c}\text { OSC } \\
\text { Model 2 }\end{array}$} \\
\cline { 2 - 5 } Level 1 Variables (n=228) & Estimate & Standard Error & Estimate & Standard Error \\
\hline Age & -.024 & .062 & -.006 & .057 \\
Education & -.075 & .056 & $\mathbf{. . 0 9 1}{ }^{\wedge}$ & .052 \\
Gender & .043 & .093 & .043 & .091 \\
Ethnicity & .009 & .061 & -.002 & .056 \\
Tenure in Local Government & -.034 & .051 & -.021 & .047 \\
Tenure in Current Position & $\mathbf{. 0 0 2 *}$ & .054 & .025 & .051 \\
Level 2 Variables (n=101) & & & & \\
Intercept (null model) & $\mathbf{5 . 5 9 * *}$ & .097 & & .085 \\
Servant Leadership & $\mathbf{. 7 7 * * *}$ & .046 & $\mathbf{. 2 8 * * *}$ & .096 \\
Ethical Leadership & & & $\mathbf{. 6 2 * * *}$ & .093 \\
\hline
\end{tabular}

Note: Entries for the predictor variables are fixed effects with robust standard errors.

OSC $=$ organizational social capital, ${ }^{\wedge} \mathrm{p}<.05 * \mathrm{p}<.01,{ }^{* *} \mathrm{p}<.001,{ }^{* * *} \mathrm{p}<.000$ (two-tailed test). 
Followers were asked these questions: (a) what personal abilities and organizational resources did the leader use to facilitate OSC? (b) how do you collaborate with other departments to facilitate your department's work and service delivery needs? and (c) what is the administrator's leadership style?

The interviewees were asked further probing questions to elaborate on OSC related activities undertaken by their organization. Such questions were as follows: How often does the executive team meet? Does that facilitate joint and cross-departmental working? Do you trust your leadership and co-workers in your department and organization? How engaged and connected are you as a member of the organization? Do you know what are the objectives and mission of your government? Does your leadership engage the executive team in mission building and sharing? This type of questioning led to a conversation about 'how and what' leaders do in local governments to enable OSC. The main focus of the conversation was to explore the proposition that servant leadership behavior would result in a higher degree of OSC.

The analysis of interview transcripts was conducted at two levels: 1) leadership level, where the leaders' interviews were analyzed for the OSC initiatives that they undertook; and (2) follower level, where the directly reporting officials' (department directors, deputy managers, and assistant managers) account of OSC activities was analyzed. The two levels of analysis at the leader and follower levels provide a wholesome portrait of the OSC initiatives in the three cases. These interview analyses were then supplemented with the content analysis of secondary documents obtained from each case study site. Common themes among the cases were identified through pattern 
matching with cross-case analysis (Yin, 2014). The case study findings report the common themes that emerged across all three cases.

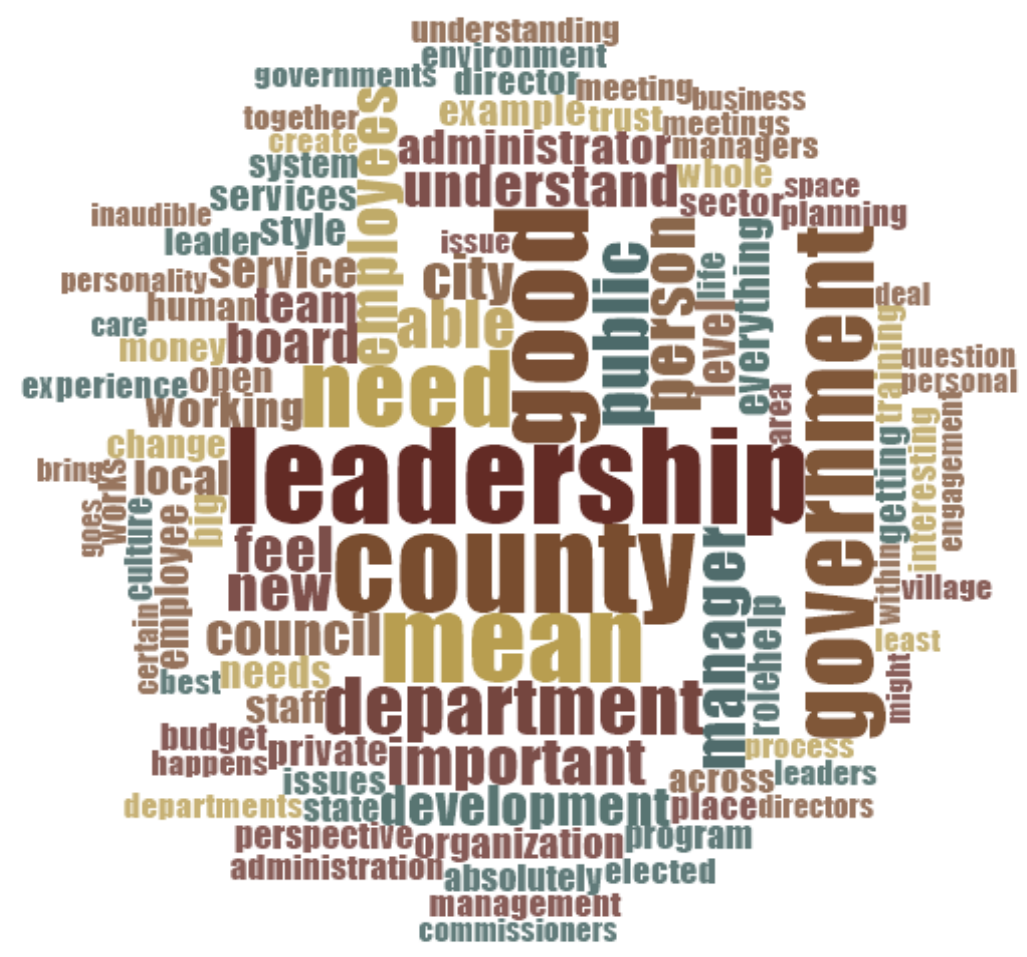

Figure 24. Word Cloud for Servant Leadership and Organizational Social Capital

\section{Case Study Findings}

Figure 24 presents the word cloud of all the interviews (there were 50 interviews conducted in total across all three cases). The word cloud graphically represents the most frequently used words by the interviewees (Ramsden \& Bate, 2008). The larger the size of a word in the cloud, the more frequent the usage of the word. The word cloud is conceptually useful in identifying the common concepts that arise among all interviews. The common concepts reveal important themes that the interviewees are highlighting in their conversations. As the figure reveals, The top 20 frequently used words by respondents during the interviews with regards to OSC were: leadership, county, good, 
department, government, employee, service, team, human, feel, new, council, important, development, manager, public person, administrator, understand, leader, style, example, trust. Interviewees did not directly use the terms 'servant leadership' and 'social capital.' These are technical terms that have come into use in an academic environment; they are popularly used in common conversations. Hence, it is not surprising that these words are not reflected in the word cloud. Yet, there are several themes related to social capital revealed in these top words. The interviewees emphasized trust, team, service, human. About a quarter of the top 20 most frequently used words were associated with social capital concepts. The interviewees often brought up their relationships with the 'leadership' and 'trust', which are central to servant leadership and social capital respectively.

Table 19. Connecting Servant Leadership and Organizational Social Capital

\begin{tabular}{lcc}
\hline Themes & Percentage & Total (N) \\
\hline Employee Engagement & & \\
Social Connections & 62 & 32 \\
Communication & 68 & 40 \\
Trust & 82 & 44 \\
Employee Engagement Survey & 30 & 20 \\
Organizational Culture & & \\
Collaboration & 69 & 35 \\
Shared Vision, Mission & 35 & 27 \\
Employee Performance & 41 & 13 \\
\hline
\end{tabular}

Table 19 shows the dominant themes that emerged from the qualitative data analysis. There are two sets of themes that connect servant leadership and organizational social capital. The first set is related to employee engagement, where employees mentioned the following phrases: social connections $(62 \%)$, the importance of communication (68\%), trust among organizational members (82\%), and employee 
engagement surveys $(30 \%)$. The second set is related to organizational culture, which includes phrases such as joint working and collaboration (69\%), shared vision and mission (35\%), and employee performance (41\%). These two sets of themes are further explored below.

\section{Employee Engagement}

The case studies reveal employee engagement as a prominent theme connecting servant leadership and organizational social capital. Within this category, employees and the leader mentioned about social relationships, personal connections, formal and informal relationships, communications, symbolism and gestures, trust across the board, and employee engagement survey. City-county managers who identify as a servant leader played a critical role in enabling these features of organizational social capital to emerge.

\section{$\underline{\text { Social Connections (Engage and empower) }}$}

Servant leaders foster social connections between the employees so that they feel a belonging to the organization. They facilitate employee engagement and empower them. Social connections provide organizational members access to resources embedded in colleagues' experience and knowledge. Frequent meetings and interaction among the employees influence mutual learning and enables cooperation and social support. Social relations nurture a feeling of family, which is important for psychological safety. An official from Village C said:

I feel I get a lot of support from the manager, and I do the same thing. I try to translate to others. We almost behave like a family. We have activities even afterward when we get together, celebrate birthdays. That creates a 
bond between employees. We are only here; we see each other a lot. We see each other at social events. We didn't have that before.

Similar sentiments were shared by another official from county B, who said that they work as a family and they get together on birthdays. He mentioned that the administrator usually will send holiday greetings and birthday wishes to employees. These simple gestures and symbolism create a personal connection between employees. The administrator also showed that he valued employees who may be lower down in the organizational hierarchy. Employees learn such behavior of care and compassion from their leaders and they could themselves emulate the leader. The nurturing relationship could thus permeate across the organization. According to the official, Everybody gets friendly, whatever the holiday is, or a birthday. Just basic things, it is just a little stuff. It is just a personal word from the [administrator] to the whole organization. That is just one of the things, in fact he does so many. I don't know if he does this for other people because I don't know how many other people copy him, but I'll copy him. We'll get really great kudos from him.

Leaders should treat employees as human beings, rather than another cog in the organizational wheel. It would show that they value employees. In county B, even fellow employees are treated as customers. According to an official from county B:

I find that a lot of our divisions or departments in the county that serve the employees just understand that their fellow employees are the customers. Just like we recognize that with the citizen. I think everybody recognizes it 
with a citizen, but it is not always recognized that the employee is the customer too.

\section{Communications (Formal and Informal)}

Communications among employees facilitate social ties and relationships. Both formal and informal communications are necessary. Formal communications (e.g. in meetings) are structured and convey official information that needs to be disseminated across the organization. Informal communications (e.g. coffee breaks) are unstructured and happen organically when people get together. Both communications connect people within the organization. When employees are connected, they can leverage each other's knowledge resources to solve organizational problems. In county A, for example, the director's retreats are formal training sessions with a facilitator in charge. Although formal, these events also provided opportunities for staff members to informally communicate among themselves during breakout sessions. Employees across different departments established social ties for both personal and professional support. One official narrated:

We haven't had one in a while, but we'll have a facilitator. Then sometimes we'll do like a big event and then the facilitator could be internal or external. I've done it both ways. We may break up into smaller groups to help. For example, the groups help define community prosperity.

Similarly, another official highlighted the importance of communications across different levels of the organization to engage employees and to build trust. He recounted 
how the administrator was very approachable and was interested in bridging the gap across different levels in the county. He would drop by the staff rooms and meetings and share some pertinent information. These actions motivated employees at different levels of the organization and built familiarity with the administrator:

The [administrator] wanted to know when all of my staff meetings are so that he can drop in on when he can. He'll come into my staff meetings. If he has time, he'll drop by and say hello. He would give an update on something that's going on in the county and take some questions. He is great about that. One of the good things that really helps people connect with him is that he will send out mass emails to the entire organization around holidays talking about the holiday. He can talk across the levels.

\section{Trust in Public Organizations}

Trust emerged as a strong theme in all three case study sites. Two types of trust relationships emerged in these sites. The first is inter-organizational bridging trust between the appointed officials, elected officials, and community members. The second is intra-organizational bonding trust among the employees working for the local government. In both these relationships, the administrator (i.e. the city or county manager) had a crucial role to play. On one hand, the administrator could facilitate bridging trust and social capital by engaging with the elected officials and community stakeholders. On the other, the administrator could increase organizational bonding trust and social capital among the subordinates. The dual role of the administrator in the three case study sites is explored below. 


\section{Bridging Trust (Between administrators and elected officials)}

Developing trust in a multi-stakeholder environment of local governments is challenging. Yet, trust can strengthen inter-organizational bonds when it permeates across all three levels of elected officials (e.g. commissioner), appointed managers, and the external community members. Building a good relationship with elected officials is essential for public administrators. As professionals, public administrators need to maintain their independence to devolve their duties. At the same time, they must address the concerns of elected commissioners' concern and listen to community needs. In this sense, the public administrator plays a bridging role, connecting the concerns of the elected officials, the external stakeholders, and the internal organizational employees.

Public administrators often have to traverse a fine line while engaging with elected officials. The administrators are expected to support the agenda and vision of the elected officials but also maintain their professional integrity. The administrator needs to be engaged in continuous communication to build the bridging trust with the elected officials and community stakeholders. Professional integrity and ethics guide the extent to which public administrators can meet or balance the demands of multiple stakeholders. As the administrator from county B noted:

So, we can be prepared and, and be well-researched on any concerns that they have because we can't make them look good if we don't have their answers. I think we do a good job at bridging that, walking that fine line between being very connected to the commissioners so that they feel like they can trust staff to do what we're going to do. But, without them saying, I want you to go do this because that is inappropriate. Occasionally 
you'll have like a new commissioner who doesn't quite get it or wants to push the limits a little bit. And so, I try to meet that person, especially if I know that a particular commissioner has an issue.

Balancing the needs of the elected commissioners with the internal organizational constraints is tricky. Public administrators spend a lot of time understanding the needs of the commissioners and their agenda for the community. However, they also need to oversee the day-to-day affairs of the county or city government. Once again, they play the bridging role, reconciling the external demands of the electorate and the internal organizational processes. Dealing with these nuances of the county and city governance is essential to establish long term trust across both sides. An official in county B noted that the new county administrator was very good at promoting such a perception of trusting relationships and to build a culture of working together. According to him:

We work together. We had the commissioners working with the staff and he [the administrator] helped promote that. And, and I loved that because I like to think of my bosses as part of the process. The openness and freedom are always good but not compromising on integrity and ethics is a part of it. A lot of times it can happen. They [commissioners] may have their interest. They start implementing it and then it backfires sometimes. But I'm seeing with him [administrator] we have that [working] environment again. He is not a micromanager at all. And he is different in that style. He does promote working together. 
Traditionally, communication in local governments flows along a vertical channel. Elected commissioners communicate with only the top-level administrator and the administrator interacts with the staff. More open communication channels between the staff of the elected and appointed officials could break the silos and fosters a free flow of information and knowledge transfer. Such open communication could enhance trust and bridging social capital across different levels. An official from county A noted:

Generally, communication goes from the Board through the county administrator to the directors and then down to staff in some organizations. [...] That is a very defined way of interaction where the board only talks to the administrator and the administrator talks to his staff. It is not so much like that here. The culture of this County is for it to be very congenial even between the board and staff. And so even before he [administrator] came, it was typical for staff to meet one on one with the commissioners. It is our practice in our department to meet with all commissioners every two weeks because we want to make sure the commissioners are fully briefed on every agenda item that they are going to be hearing before we get there so that we know what their questions are going to be.

A similar perspective about the open communication style was shared by another official from county B. he narrated:

I don't see him [administrator] all the time but I do know that he spends quite a bit of time making sure that he understands what their [elected officials] concerns are and spends a lot of time on one on one meeting 
with them in their offices, finding answers to things. He doesn't have to do that much in my department because I hear more so directly from the commissioners myself.

\section{Bonding Trust (Between administrators and employees)}

Bonding trust among employees is crucial to enhance organizational performance.

Leaders can create a high trust environment in organizations by strengthening associability, sense of obligation, and commitment among the employees. Trust can engender reciprocity among the employees. It can be instrumental in creating knowledge transfer mechanisms, bettering employee and organizational performance, reducing turnover, and strengthening organizational commitment. Higher trust can facilitate collective action among employees.

Leadership is an important determinant of trust among employees. To instill trust, a leader needs to demonstrate a high degree of integrity, values, and ethics. Trust between the leaders and employees is vital for creating an engaged work culture. Organizations that take a bottom-up approach rather than only a top-down approach to communicate with staff can engage people across the board. An official from County B shared how the county administrator was always available for the staff. He noted:

He [administrator] is a model of open doors policy. He is like, you can come in and talk to me. [...] You don't have to make an appointment. Although he's busy, he would say, “you can tell me when you don't like something." He doesn't respond badly. 
Trust is built by demonstrating actions and gestures leaders execute while engaging with their staff. Leaders are genuine in accepting their mistakes and openly communicate that to the staff. An official from County B shared an incident about how the administrator sent a group email regarding a staffing decision. Although the decision affected the official's staffing, the administrator had not consulted with her. The administrator later apologized to her personally. Servant leaders do not get entangled in the ego issues since they are led by an ethic to serve others. The official elaborated:

I actually know there was one time where he made a staffing decision without talking to me. That directly impacted me. And I got copied on a memo where he told everybody about it. And I was really mad. Actually, he came to me before I went to him. He said, "Leslie, I'm, [...] I'm really sorry I did that." And I said, thank you. It just made up. So that's another thing that he did and eventually, he realized, and he came himself.

\section{Organizational Culture}

There are several features of organizational culture that are significant for the manifestation of servant leadership and organizational social capital. The leader can shape the organizational culture, which can have implications for the emergence of organizational social capital. Three features of the organizational culture recurred through the three case study sites: collaboration among departments; shared vision, mission, and goals; and innovative methods to facilitate employee performance.

Collaboration (between senior management personnel)

An organizational environment of collaboration between senior management personnel is a feature of organizational culture that facilitates collaboration and trust 
among them. Once again, the public administrator can play a crucial role in connecting the personnel. An open, fair, and trustworthy leadership can foster successful collaborations among different departments. Public administrators can create opportunities for such collaborations by bringing together personnel from the different departments to work together. Conversations among the personnel can break the siloed environments and enhance organizational social capital. Isolation of senior management can promote a bunker mentality that is not fruitful for organizational social capital. As the County B administrator narrated:

I think public administration is where you have to be thoughtful. You could get circumstances where the senior team is isolated. They do not interface with each other. But the whole key of innovation is collaboration. You don't collaborate with one or two, but you collaborate with many. I say this more from having worked at all the other organizations: the key is to make sure that your senior management doesn't get too isolated.

Collaboration, inclusivity, and joint working was a part of the organizational culture in County A as well. The administrator explicitly said that they have ingrained the "team concept" across the organization. As he explained:

We have a team process of being inclusive. We have a team concept with all the directors, and we help each other out and we work together on things. And the commissioners want to be part of that. Here it is very open. Anybody can interact with anybody. Our commissioners will call 
my road and bridge manager directly. But then they'll call me and let me know. There is not a communication gap.

\section{Cross-Functional Environment (between departments)}

Traditionally, local government departments are organized in siloes. One department is generally not privy to the functioning of other departments. Although the senior management may hold conversations, the departments themselves may not collaborate among themselves. Joint working and collaboration in cross-functional environments are challenging because of the different objectives and functional routines that the departments entail. Collaboration may indeed not be helpful if the departments are significantly different in the functions they perform. An official from County B maintained:

Getting a bunch of people and departments together may have common things. But then there's a lot of departments which are really very different. Some are very service-oriented, and they are building something or fixing something. That's very different than say a customer service where you're just taking their tax bills which is almost like a retail function. Then there are folks like economic development, and you know, our customer base is almost non-governmental. Bringing together management and the organization with that many different delivery models is sometimes not helpful. It is not because you don't care. The art form is to pick something, that is common. 
Despite the stark differences between departments, there is scope for collaboration since the departments need to all meet the overall mission of the local government. All the departments need to be aligned to the broad organizational mission. Centralized services (such as human resources, procurement, or information technology) provide scope for interdepartmental collaboration. The centralized services become a shared resource that the departments have to collaborate with. Small cross-functional teams across the departments can also build bridges across the departments. The teams, by their very nature, require members with different expertise from various departments. The cross-functional teams can be instrumental in providing a unified front to the external community stakeholders. As an official from County A explained:

We do things in a collaborative effort because we don't want to just rely on one person. So, we've really worked over the last five years to build that team in a cross-function environment. The neighborhood relations team knows who the PR is for the different projects. PR is assigned by the department. If they are working with public works on a project out in the community, they know that Andrea is the PR. Then they are working with her because they understand the community. [ $\mathrm{PR}=$ public relations person]

\section{Shared Vision, Mission, and Strategic Objectives}

A common vision and mission align the different departments and personnel toward achieving organizational goals. The mission integrates different systems within the organization toward a common goal. The vision provides collective responsibility among the staff to achieve that goal. The shared goals can drive cognitive organizational social capital. Shared interpretations of mission and organizational values guide the 
employees. For example, in County A, the mission of 'community prosperity' aligns all the departments and provides focus to employees. Communication of the mission is critical for the alignment of different departments and employees.

\section{Sharing the Vision (Organizational alignment)}

Leadership and communication are fundamental to creating a culture of shared vision across the organizational teams. Leaders should be able to translate the vision or mission in a plain language and communicate the significance of the vision. The vision, as well as its communication, is critical to align the different units within the organization toward a common purpose. The vision can connect employees from all levels. The importance of sharing mission and goals was highlighted especially in County A. An official from the county explained that the mission has to be shared by the staff at all levels, not just the top management team. This creates a strongly connected and committed workforce throughout the organization which is engaged and has a full understanding of where the organization is heading. It also creates a sense of purpose and aligns the employees work with the overall mission. One official described it as follows:

Get the employees engaged and involve them in having a true and full understanding of what you're defining as your mission. And what it really means. And how and what they do within the organization. How they play a part in the overall mission. [Say] I'm a part of the janitorial staff here in this building for cleaning. How does that relate back to the overall county mission of community prosperity? You got to make those connections. So that folks believe that everything that is being done has its place. 
Another official from County A shared how they translated community prosperity to economic prosperity, service expectations, and goals:

We all from the county administrator and down, know that it is all about community prosperity. So, we translate that as economic prosperity to the community, which has worked well. I am very clear about what our service expectations are, what our goals are, and what the mission of the county is. I like how they've got the diagram which all rolls up to community prosperity. [The diagram is presented in Figure 25]

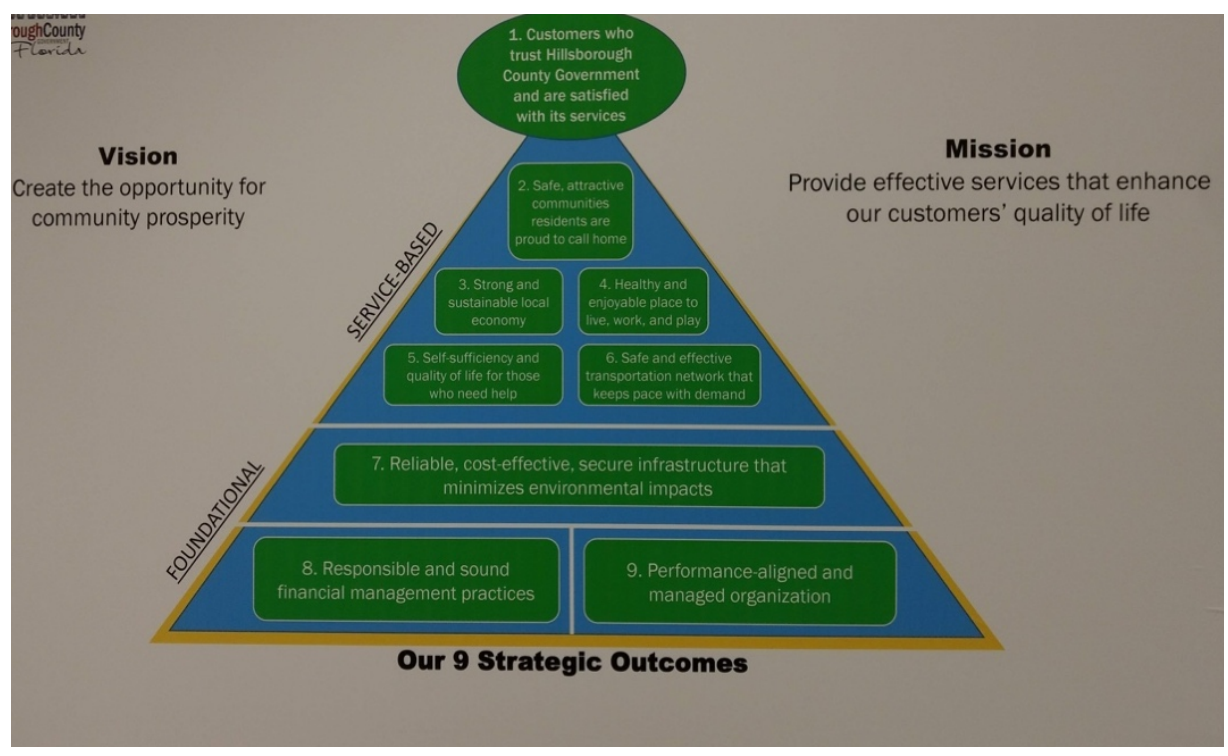

Figure 25. County A's Community Prosperity Vision Triangle

Better Communications (Why and how we are doing it).

Besides creating an organization's vision and mission, and strategy, it is also important that leaders communicate the vision. Communication is necessary to facilitate the sharing of vision and purpose among organization members. Sharing the vision aligns the departments and the people to the overall organizational goals. However, leaders 
should not only be able to articulate the vision, but also translate the vision into concrete ways of why and how departmental activities and projects are carried out. The administrator explained how he instilled a culture of sharing goals and objectives:

It takes a long time to get there, especially if your culture in the past has been like "I'm telling you to do and therefore you must do it." The culture shift into we all own our goals takes a while. What I do is that I meet regularly with all my staff and talk about how we're doing.

Another department director from the county explained how he translated the vision into concrete actions:

What we do is that we link ourselves to the prosperity outcomes. How can we within parks and recreation align ourselves with these prosperity outcomes? What I do within my department is that we've established four pillars, which are community building, health, environmental sustainability, and economic impact. So, our mission is to enhance lives through people, parks, and enjoyable experiences. Our vision is to be the best parks and recreation department in the country. And for every program that my staff develops, they have to submit a program proposal and they have to show how it aligns with the county's community prosperity outcomes with our four pillars. Then tell how we are going to deliver the program. So, I think that's how we align ourselves with the county administrator's overall vision. 
Using symbols and visual representations for the organization's mission communication approach can be compelling (Figure 26). The vision, mission, and purpose of the government have to be shared across the departments. The departments can then communicate it to the lower levels by constantly sharing and reinforcing across all levels of the organization. The purpose is to avoid isolation of the leadership team and create a shared perspective. Unclear communications create confusion among the team. As one official from County A explained:
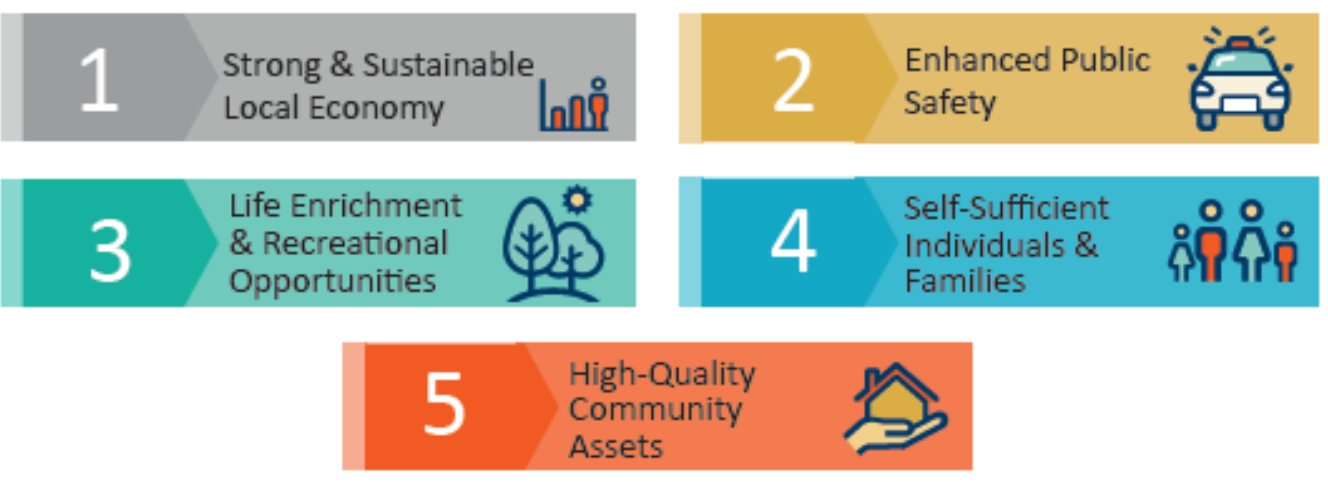

Figure 26. County A’s Five Pillars of Community Prosperity

Sometimes it is good to make the change because we learn more. Some people may say that things changed but they don't know why it changed or how it changed. And so maybe if we communicated that better, $[\ldots]$ people could understand why we're talking about community prosperity, but now we're talking about sustainability for example. It is because we're changing some terms and it made a lot of sense when we did that. 


\section{Employee Performance and Innovation}

Employee performance is leadership driven. Leaders can employ innovative methods to enhance employee and organizational performance. Servant leaders are oriented toward developing followers. Their evaluations of employee performance are thus set toward developing the employees' potential. Servant leaders exhibit the following traits towards the employees: empowerment, emotional healing, putting the employees first, helping employees grow and succeed, and behaving ethically. Followers led by servant leaders emulate to become servant leaders based on an authentic and trustworthy relationship between them (Liden et al., 2014; Ehrhart, 2004). For servant leaders, employees' performance is a reflection of themselves and what they have achieved.

Moreover, government leaders are bound by rules and have to set standards of fairness, justice, and equality. Governments do not have the flexibility as the private sector in terms of managing human resources. Public sector leaders with servant leadership behavior should be able to recognize the potential of their employees and find opportunities to reward them fairly. Employee empowerment is the key. County B administrator shared his approach to empowering employees,

The government is not as nimble with human resources. That's the word I'm searching for. Personnel decisions go back to the old civil service. The ability of the government, in general, to say, "Hey, that's a superstar." ...

The government has a lot of rules, and they are there for lots of good reasons. But I can only say that I've been good at recognizing good talent and within the bounds of our rules, and I've tried to reward them with timely promotions and raises. 
Both counties A and B have taken an innovative approach to the overall performance system. They have implemented the balanced scorecard approach to streamline their departments and their processes. In County A, the Administrator appointed the chief innovation officer to align departments goals and objectives with the organizational goal. All the departments have scorecards that align their performance with the overall mission. County A's department's scorecards offer the details of their services to the residents. Each department's scorecard identifies the customers served and expounds on the quality and the value of what the department provides. The scorecard addresses costs and sets performance standards. The evaluation is done at the departmental level, not the individual employee level.

The strength of a balanced scorecard lies in balancing between competing performance measures. It provides four perspectives of performance measurement: customer (outcome orientation), internal (business process), innovation and learning (improving and creating public value), and financial (the costs of process or projects). The balanced scorecard provides enough flexibility for the leaders to gauge their progress dynamically. In County A and B, the administrator implemented the balanced scorecard in various departments to enhance innovation and learning:

We do balance scorecard. I haven’t seen in government generally doing these innovative things. We are now doing this, and this is his [administrator] another innovation and it is about open learning.

\section{Discussion}

This chapter sought to understand the impact of servant leadership behavior (SLB) on organizational social capital (OSC) in the context of county and city 
governments in Florida. The examination was based on a survey of local governments and three case studies. It tested the hypothesis that servant leadership behavior would contribute to higher organizational social capital. HLM analysis was conducted to test the hypothesis. The analysis shows that SLB is indeed a significant determinant of organizational social capital. The finding highlights that servant leadership is significant even when controlled for ethical leadership traits. Servant leadership traits are important for public agencies from an organizational social capital perspective. The findings align with the core principle of servant leadership that underscores serving the needs of their followers (Greenleaf, 1977; Liden et al., 2014). The finding reaffirms the new public service (NPS) paradigm's perspective that public servants must look beyond their selfinterest toward the larger public interest by engaging in the longer-term perspective (Denhardt \& Denhardt, 2000).

The case studies layout two important aspects concerning the relationship of servant leadership with organizational social capital. First, employee engagement is a consistent theme across the case studies. Within this category, the dominant themes are social connections, informal and formal communications, and bridging and bonding trust. Second, three features of the organizational culture recurred in the case studies: collaboration among departments; shared vision, mission, and goals; and innovative methods to facilitate employee performance. Servant leaders played a critical role in enabling these features of organizational social capital to emerge

The case study findings are diagrammatically presented in Figure 27. The figure illustrates the main characteristics of servant leadership such as genuine care for people, understanding and listening, and conceptual skills that impact the OSC. The impact of 
servant leadership on OSC takes effect through the three intervening mechanisms:

negotiation, communication, and building trust. Servant leaders use these mechanisms to enable the factors related to OSC (see green outline boxes in Figure 27 in the next page). 


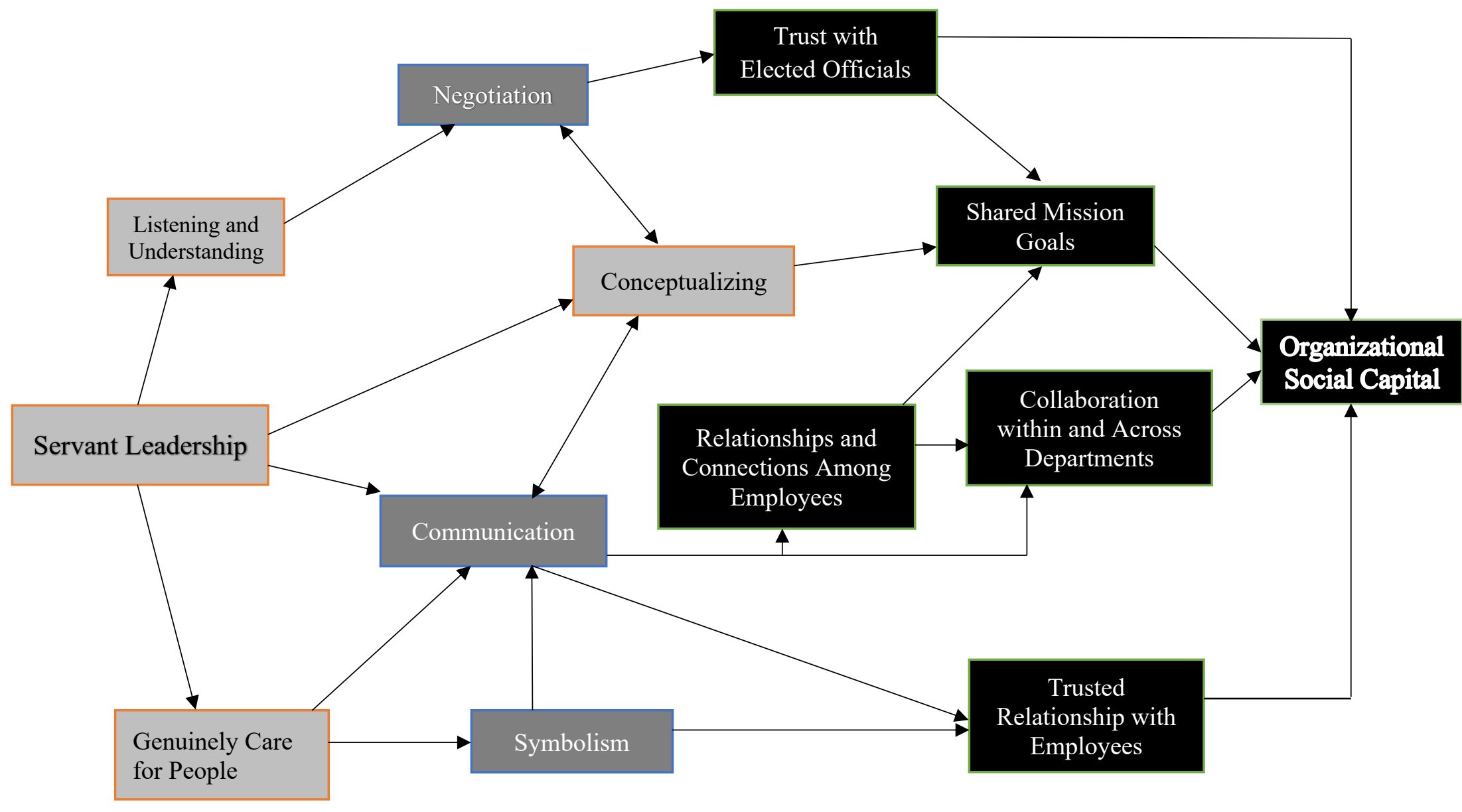

Figure 27: Impact of Servant Leadership on Organizational Social Capital Note. Orange outlines represent servant leadership dimensions, blue for intermediate processes, and green are OSC dimensions. 


\section{Conclusion}

Overall, this chapter's findings demonstrate that servant leadership is positively correlated with organizational social capital. Both the quantitative and qualitative findings were consistent in suggesting that the county and city governments led by servant leaders enhance a positive and trustworthy work environment which is imperative for sustained relationships and collaboration among employees and departments at all levels of the organization. Servant leaders are creative and open-minded to embrace and implement innovative systems towards managing the performance of employees. This enables collaboration across teams. By creating a culture of sharing and open communication, county and city managers who are servant leaders align the organization's both internal (employees, elected officials) and external stakeholders (nonprofits, community organizations, citizens) with the organization's vision, mission, goals, and objectives.

The study has both theoretical and empirical implications. First, with regards to enhancing social capital measured as social relationships, trust, and shared goals, servant leadership theory is a vital resource in public organizations. It is in line with the argument of the new public service paradigm that public administrators' core responsibility is to serve and empower citizens. Such public administrators develop connected and engaged groups of community and civil society by setting aside their interests and work for the community. In particular, servant leadership theory extends the literature on public administrative theory by pointing out that selfless and service-oriented public administrators are essential for having a socially connected and trusted workforce in public organizations to create engaged organizational citizenship. 
Second, servant leaders in local governments are adept at resolving contemporary leadership challenges such as building collaborative relationships and social networks. Servant leaders genuinely care for organizational members through effective listening and communication. They especially act as a bridge between conflicting interests of the different parties in local governments and hence can create a sustained and trusted workforce. They are also able to build the bonding social capital between employees in the organization.

This study offers lessons for practitioners as well. County and city governments led by servant leaders develop an engaged and trusted workforce. Therefore, public organizations could have mechanisms to hire and develop servant leaders. Public managers can use servant leadership as a comprehensive leadership training and development approach. Specifically, public managers can learn about mechanisms such as how servant leaders communicate to develop interpersonal relationships and trust to manage conflict between different parties. This is valuable in local governments for the county and city managers' most challenging bridge-building role. Many county and city managers fail to develop confidence in employees and elected officials. It results in a huge cost to the government with employee turnover and compromises on local government performance. Servant leadership theory offers a solution to that. 


\section{CHAPTER 6: \\ Why, How, and What of Servant Leadership in Public Administration: Lessons for Theory and Practice}

This research demonstrated that servant leadership is an inclusive approach in public administration, considering both its theoretical and practical applications. From a theoretical vantage point, three contributions emerge from this study. First, servant leadership theory is comprehensive for public administration in comparison to other widely studied leadership approaches such as transformational, ethical, and collaborative. Second, servant leadership aligns with the new public service paradigm in redefining the role of a new age public servant who is a 'community custodian'. Third, servant leadership emerges as an inclusive theory particularly for local governments, given its multi-stakeholder focus. County and city managers have a bridging and bonding role in managing relationships with multiple stakeholders both inside (e.g., employees, elected officials) and outside (e.g., community, nonprofits, private sector) the organization. Based on this study, a servant leadership framework for local governments is advanced. This framework could serve as a foundation for developing servant leaders in local government organizations.

This chapter summarizes the findings concerning the individual-level attributes and the organizational level attributes of servant leadership. The organizational level attributes include both co-production and organizational social capital. The servant leadership approach is then juxtaposed with other leadership styles and governance debates. Lastly, the implications of the dissertation findings for the theory and practice of public administration are discussed along with strengths, limitations, and directions for future research of this study. 


\section{Individual Attributes of Servant Leadership}

Chapter 3 uncovered the individual attributes of servant leadership by using complementary quantitative and qualitative methods. The quantitative methods include analysis of survey data responses $\left(\mathrm{N}_{\text {city-county governments }}=155, \mathrm{~N}_{\text {employees }}=337\right)$. The qualitative method encompassed three case studies (two counties and one village). This chapter posited servant identity and moral potency as the two core attributes of servant leadership. Servant identity is defined as the leader's self-identification of 'being the servant first.' Moral potency is defined as the leader's moral behavior to 'not only own the moral responsibility but ability to act morally in situations of a moral dilemma.' Hierarchical Linear Modelling (HLM) analysis of the survey data revealed the significance of servant identity and moral potency for servant leadership behavior among county and city managers.

The three case studies provide a deeper explanation of understanding the nuances associated with individual attributes. These case studies show that servant identity among the county and city managers is driven by the self-concept of certain dimensions (e.g., life experience, beliefs, values, who am I, and what I do) of a leader's servant identity. The self-concept of 'being a servant' translates into their servant leadership behavior. In the case studies, the moral potency attribute was salient in terms of knowing that ethical behavior is vital for county and city managers. Ethical behavior is manifested as a consequence, i.e. in the form of achieving an ideal end goal, rather than a pre-set ethical norm. With regards to the ethical action component of moral potency, there were limited instances to understand how county and city managers act ethically during situations of an ethical dilemma. 


\section{Organizational Attributes of Servant Leadership}

Chapter 4 examined how servant leadership impacts the external organizational attribute of co-production. Co-production measures the government's effort to enhance citizen's partnership in public service provisions. In basic terms, co-production occurs when both government and citizens work together to enhance the experience of public service provision. The HLM analysis of the survey data responses $\left(\mathrm{N}_{\text {city-county }}\right.$ governments $=101, \mathrm{~N}_{\text {employees }}=228$ ), demonstrated a positive and significant impact of servant leadership on the co-production of public services. Service climate has a partial mediating effect on co-production. The data from the three case studies supported the quantitative findings. The three case study sites, which were rated high on servant leadership, showed that there are many instances of co-production activities that are affected by the leaders. These leaders take a community-centric leadership approach exercising a range of community engagement activities. They use various communications methods for effectively delivering their messages and to get feedback on their activities. Tenure of the leaders and the size of the organization matter for how effectively the leader's servant leadership behavior is apparent to the stakeholders, both within and outside the government organizations.

In chapter 5, the relationship between servant leadership and the internal organizational attribute of organizational social capital is examined. Organizational social capital is a measure of social relationships, trust, collaboration, and understanding of shared vision and goals among the organizational members. In the HLM analysis of the survey data $\left(\mathrm{N}_{\text {city-county governments }}=101, \mathrm{~N}_{\text {employees }}=228\right)$, the findings demonstrated that servant leadership predicted a positive and significant impact on organizational social 
capital in county and city governments. The three case studies explain that servant led county and city governments possess a high level of organizational social capital. The case studies mainly suggest that county and city managers who are servant leaders foster two strategies for enhancing OSC. First, at the individual level, they establish effective social connections, open communication, and trust mechanisms. They use methods such as effective listening, genuine concern for employees, and consistent and open communication. They act as providers of both bridging (connecting outside stakeholders and internal actors) and bonding (connecting leaders within the organization) social capital. Second, they affect a conducive organizational culture that creates a crossdepartmental collaborative approach of working, develops clarity, and a shared perspective about the organization's vision and mission. As a result, servant led county and city governments have a satisfied workforce, less employee turnover and sustained organizational performance.

In all, the county and city managers who are servant leaders use various mechanisms to enhance citizen engagement in their government. First, they utilize negotiation to engage with external partners such as community organizations, nonprofits, and neighborhood associations to enhance citizen engagement in public service provisions. They also encourage department directors to take a community-centric approach in various public service provision activities. Second, they strategize their communication approach with both internal and external stakeholders to facilitate community-engaged culture in their organization. For example, they share a vision of community prosperity with the elected officials and among the employees within and across departments by taking a bottom-up approach. Lastly, they create a service climate 
in their organization to enhance the quality of service experience for citizens and other external partners. As a result, it creates an overall community-engaged culture both within and outside the organization for the well-being of the community.

\section{Quantitative vs Qualitative Findings of Servant Leadership Behavior}

In contrasting the findings from both the online survey and the three explanatory case studies two critical issues emerge. First, the servant leadership ratings from the online survey served as the deciding factor for choosing the three-county and city governments as the case study sites. In all, the three case studies rated scores of 6.1,5.8, and 5.9 out of 7 for the servant leadership behavior. The selection of case studies based on the high servant leadership score is appropriate since the focus is on understanding how leaders with traits of servant leadership behavior achieve their goals in local governments.

The case studies depicted organizational size as an important factor in the manifestation of servant leadership behavior. The behavior is palpable in small jurisdictions more easily than large ones. Servant leaders needed to negotiate between politics and administration very often in the case studies. They need to balance the political demands of the elected officials and community stakeholders while managing the day to day affairs of the organization. This factor wasn't accounted for in the online survey. On the whole, both the quantitative and qualitative phases of the study were complementary to each other. They served to deconstruct the nuances and identify subtle factors associated with servant leadership manifestation in county and city governments.

In chapter 3, servant identity emerged as a predictor of servant leadership behavior among county and city managers, both in the survey and case studies. The moral 
potency attribute is a better predictor of servant leadership in the survey than the case studies. The case studies revealed that county and city managers considered ethics as highly vital for the organization. They took several initiatives to train employees to abide by the laws and rules. However, there were very few instances to explain how county and city managers really behaved in times of ethical dilemmas.

In chapters 4 and 5, both the quantitative and qualitative phases supplemented the findings. The survey predicted a significant positive relationship between servant leadership with co-production and organizational social capital. The findings from the case studies explained how servant leadership behavior enhances co-production and organizational social capital. The case studies served as an effective method for uncovering the nuanced processes and intervening mechanisms that servant leaders utilize. This would not be possible to identify by only using the online survey.

Thus, the online survey and the case studies were complementary in this dissertation. The online survey showed the correlations between servant leadership behavior and the outcome variables (co-production or organizational social capital) on a broad scale. The case studies complemented the online survey by unraveling the nuances of servant leadership behavior that contribute to the outcome variables of co-production and organizational social capital.

\section{Significance of Servant Leadership for Public Administration}

In public administration scholarship, the studies on transformational, ethical, and collaborative leadership have appeared frequently. While these approaches are impactful, they are not sensitive to the needs of public service which demands community service orientation with integrity and empathy. For example, transformational leadership has 
been a gold standard in public administration scholarship (Wright et al., 2012; Fernandez \& Rainey, 2006). Transformational leaders focus on organizational performance, productivity, and goal achievement which can sometimes occur at the cost of employee and community well-being. Transformational leaders can be inward-looking, selfinterested, and sometimes narcissistic in their behavior (Van Wart, 2013). To satisfy organizational and personal goals, such leaders could indulge in corrupt behaviors. This jeopardizes the growth of the organizational members and could have serious negative consequences for the overall well-being of the community. This approach can negatively impact the values of ethics, integrity, and service orientation in public service and democratic governance. In contrast to the transformational approach, servant leadership is other-oriented. As conceptualized by Greenleaf (1970):

a servant leader wants to serve first, the difference manifests itself in the care taken by the servant - first to make sure that other people's highest priority needs are being served. The best test is: do those being served, grow as persons; do they, while being served, become healthier, wiser, more autonomous, more likely themselves to become a servant? (p.4).

Unlike performance and productivity-focused transformational leadership, which 'sometimes sacrifices the wellbeing of people on the altar of profit and growth,' servant leaders focus on the sustainable performance of the organization by empowering employees, who can also become servant leaders for the long-term growth of the overall community and the society (Sendjaya, 2016, p.4). Servant leadership promotes inclusive practices and diverse organizational culture in organizations by establishing a climate for inclusion. They do so by embodying the dimensions of humility, interpersonal 
acceptance, and empowerment of people with multiple values and social identities (Gotsis \& Grimani, 2016). In this way, servant leaders encourage the values of public service and democratic citizenship over narrow performance-centric organizational agenda often pursued by traditional transformational or transactional leaders. Consequently, servant leaders pursue a long-term and broad-based agenda of building an environment of inclusive engagement of citizens in public service.

A servant leader's core focus is on service orientation - an inherent desire to build the serving community of people both within and outside the organization. Servant leaders nurture their community by building trust, strong personal relationships, and collaboratively working with others. The servant leader's mindset is to impact the larger community's health and well-being by strengthening organizational values of empathy, ethical behavior, and service orientation in all their actions. However, a servant leader's focus on serving the employees and community does not come at the cost of organizational needs. Servant leaders manage the task at hand and are adept in problemsolving to fulfill the organizational requirement. Thus, servant leadership is highly inclusive for public administration when compared with transformational leadership.

Apart from transformational leadership, ethical leadership style has received significant attention from the public administration scholars (Hassan, 2013). An ethical leader is a 'moral manager' and demonstrates honesty while managing their subordinates. While ethical leadership is vital to maintain ethics in public service organizations, it does not encompass the values of serving people and elevating their overall wellbeing. Ethical leadership is conceptually distinct from servant leadership and only takes care of one dimension of public service, which is compliance with rules and normative standards of 
ethics and moral management of organizational members. Ethical leadership is deontological in following a specific set of ethical norms; servant leadership is a consequentialist approach in focusing on the ethical outcomes. As the dissertation shows, servant leadership qualities are more pronounced than ethical leadership in how they impact co-production and organizational social capital.

During the last decade, collaborative leadership emerged as an important focus of leadership studies in public administration (Crosby \& Bryson, 2010). Collaborative leadership gained attention due to the changing imperative of public administrators to collaborate and develop public-private partnerships. The focus is on creating systems and processes in an organization that facilitates collaboration with external partners. This style encompasses only one dimension of building collaboration in public service. It is utility-driven in as much as it does not have a normative ethical basis. In comparison to this, servant leadership is a highly inclusive approach by providing a holistic focus on values such as ethical behavior, service orientation, building trust and relationship with internal and external stakeholders, and creating values for the community. Thus, servant leadership emerges as much more comprehensive in addressing the needs of public administration in comparison to either transformation, ethical, or collaborative.

\section{Servant Leadership and Governance Debates}

Denhardt and Denhardt (2000) were instrumental in showing how the new public management (NPM) has a very narrow approach to governance. They argued for a new public service (NPS) paradigm that emphasizes serving, rather than steering. NPS values democratic governance over market approaches. In the governance debates between NPM and NPS, the servant leadership approach aligns highly with NPS. Servant 
leadership starts with the premise of serving others. To reiterate, there are seven core dimensions of servant leadership: emotional healing, creating value for the community, conceptual skills, empowering, helping subordinates grow and succeed, putting subordinates first, and behaving ethically (Liden et al., 2008). These dimensions highly correlate with the core attributes of NPS as elaborated below.

(1) Serve rather steer - serve citizens, not customers. The public sector is about serving the needs of the community at all times by helping the citizens to articulate their needs and shared interests rather than control or steer them in a certain direction. This view is reinforced in the servant leadership theory. Servant leaders possess a genuine concern for helping the community (Liden et al., 2008). They are sensitive to the needs of the multiple stakeholders, which includes the larger community and society (Graham, 1991). In the words of Greenleaf (1977), the role of servant leaders in serving the needs of the community is highlighted as:

all that is needed to rebuild community as a viable life form for large numbers of people is for enough servant-leaders to show the way, not by mass movements, but by each servant-leader demonstrating his or her unlimited liability for quite specific community-related group. (p.53)

Servant leaders can be important catalysts in rebuilding the local community. By focusing on every individual within and outside the organization who help directly or indirectly in the public service delivery process, servant leaders recognize their potential and commit to every individual's personal, professional, and spiritual growth. In the NPS paradigm, the public servant as a servant leader asserts not only to provide services to the citizens but changes the narrative saying that "let's work together to figure out what 
we're going to do, then make it happen.' This is about reinforcing not only the public service delivery role but the role of a public servant as a conciliator, mediator, and adjudicator. Thus, servant leaders assume multifaceted role of a new age public servant.

(2) The public interest is the aim and not the byproduct. Accountability is not simple. This perspective characterizes public interest as a shared interest and a shared responsibility both by the public servants as well as citizens. Public interest should be established as a vision for a society that is created by having widespread dialogues among multiple parties. Public agencies should foster a culture of engagement in which public administrators, elected officials, and citizens, with due process of deliberation, create a direction for their community and in turn the nation. It is also the utmost responsibility of public agencies to carry out the process of engagement ensuring fairness and justice to all the parties. This view is strengthened by the servant leadership theory in many ways. For example, servant leaders enhance trust among their stakeholders. The concept of service before self is manifested by servant leaders in the workplace, home, and community.

Servant leaders build self-confidence, serve as a role model, inspire trust, share interests of the followers, provide information, feedback, and resources to create processes (Liden, Wayne \& Sparrow, 2000). In Greenleaf's (1977) servant leadership approach, several themes are consistent with the role of public administrators to create a process of shared public interest among all the stakeholders. For instance, in Greenleaf's 'servant as leader,' the focus is on what an individual leader does to make a difference in the community. The servant leaders show the way to others, create an overarching purpose, and a visionary concept to move forward. This is not possible without listening and understanding every stakeholder in the public service process. 
In the process of engagement with multiple parties, disagreements and mutual misunderstandings are bound to come up. The most important thing about servant leaders is that they establish an understanding through continuous dialogue, communication, and listening to turn the confrontation into collaboration. Servant leaders are adept at understanding the linguistic nuances and the imagination and experiences of communications. They use their skills for enabling the best form of communication between the parties. Besides, servant leaders accept and empathize with everyone who is led. Even though they may be imperfect or inept occasionally, servant leaders help grow the people around them by leading them wisely and are hence trustworthy.

Serving the interest of the public by creating the platform for multi-stakeholder discourse and dialogue is captured in the idea of having 'institutions as a servant' or 'a servant organization' in servant leadership theory (Greenleaf, 1977; Laub, 1999; Spears, 2010). Institution as a servant is about developing an institutional philosophy of serving first. To create a caring and loving society for its people, serving institutions are needed with a capacity to serve. Greenleaf (1977) noted:

governments rely too much on coercion and too little on persuasion, leadership, and example. Although they render services, they too often impose upon society a bureaucracy that is oppressive and corrupting. Rarely does conceptual and inspired leadership comes from the government. This is my thesis: caring for persons, the more able and the less able, serving each other is the rock upon which a good society is built....If a better society is to be built, one that is more just and more loving, one that provides greater creative opportunity for its people, then 
the most open course is to raise both the capacity to serve and the very performance as a servant of existing major institutions (p.49).

(3) Think strategically and act democratically. Under this premise, governments need to create actionable and achievable strategic outcomes to realize the shared vision. It is about engaging parties not only to create a shared vision but also to implement the vision while engaging the stakeholders in the process. This can be done by engaging both the political and administrative leadership in recognizing the importance of civic education. Community and civic leadership are required to strengthen civic responsibility at many levels within and outside the government by having opportunities for participation, collaboration, and community. Such an approach entails government which is open, accessible, responsive and facilitates the grassroots opportunity for responsible community actions. This aspect is echoed by the servant leadership theory. To give an example, the servant leader can know the unknowable - foresee the unforeseeable. This is not a mystical or a supernatural gift but an intuitive ability, but a feel for patterns to generalize and make decisions based on what happened previously (Greenleaf, 1977; Graham, 1991). It is an ability for strategic analysis of information for conceptual decision making.

Such servant leaders are also referred to as 'sensitives' who can process information and have the ability to develop strategic thinking. Servant leaders do not lose focus on service orientation towards the people they work with (e.g., employees) and work for (e.g. community) at all times. They possess the conceptual skills to be able to reflect and strategically use their competency in solving problems and understanding the 
organizational goals (van Dierendonck \& Nuijten, 2011; Liden et al., 2008; Ehrhardt, 2004; Barbuto \& Wheeler, 2006).

(4) Value citizenship and public service above productivity and entrepreneurship. This view underscores the importance of leaders in public administration to have the ability to manifest a shared and collaborative leadership approach in networked governance. To develop responsible, engaged, and civic-minded employees and citizens, leaders should pay attention to the varied values and interests of the stakeholders. Especially in the difficult times of complexity, a balance in making the routine management systems efficient and developing the ability to deal with the dynamic and changing needs of the organization is needed. Public servants must be motivated beyond just doing a bureaucratic job for pay and security and aim to make a difference in people's lives (Perry \& Wise, 1990; Vinzant, 1998).

A shared leadership among the employees and citizens is central for asserting the public service values. Such leadership, which is achieved by working with people that transforms the leaders themselves, is key for advancing the ideas within and outside the organization. There are two thematic ideas in servant leadership which are consistent with the shared leadership concept in the New Public Service: (1) servant leadership is comprehensive in engaging employees within the organization both emotionally and spiritually, so that they are empowered and grow into their full potential; (2) servant leaders utilize and grow the organizational resources, both financial and others, and serve as stewards to the employees and the community (van Dierendonck, 2011).

In the $21^{\text {st }}$ century public administration, servant leaders are the best fit as they rely heavily on a multifaceted approach of utilizing resources within and across 
departments in the organization as well as outside the organization in understanding, developing, and designing what is best for their employees and the community they serve. Servant leadership encompasses the themes of discourse-oriented democracy and citizenship reinforcing the participation and empowerment of all parties in serving the public interest. Figure 28 shows the alignment between servant leadership and the New Public Service paradigm.

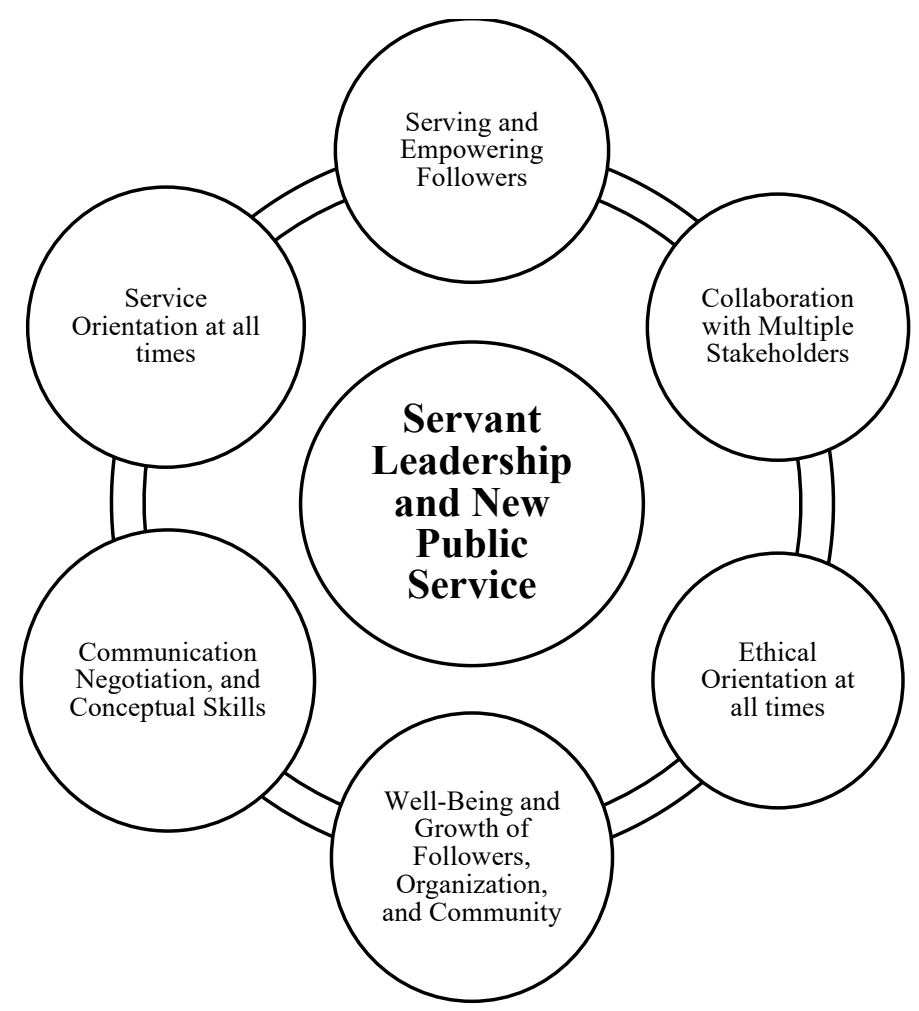

Figure 28. Servant Leadership in New Public Service

\section{Servant Leadership Framework for Local Governments: A Proposal}

Local government leaders face a host of challenges in the $21^{\text {st }}$ century. Most important among them is the ability to create a fine balance between the competing values of the market-based approaches along with the reassertion of the values of public 
administration. This conflict of values is visible in the county and city managers' role when they have to continuously navigate the political acceptability and administrative sustainability of their decision in the interest of the community. To balance these competing values, but at the same time be the enablers of employee and community wellbeing, servant leadership emerges as a very strong fit (Figure 29).

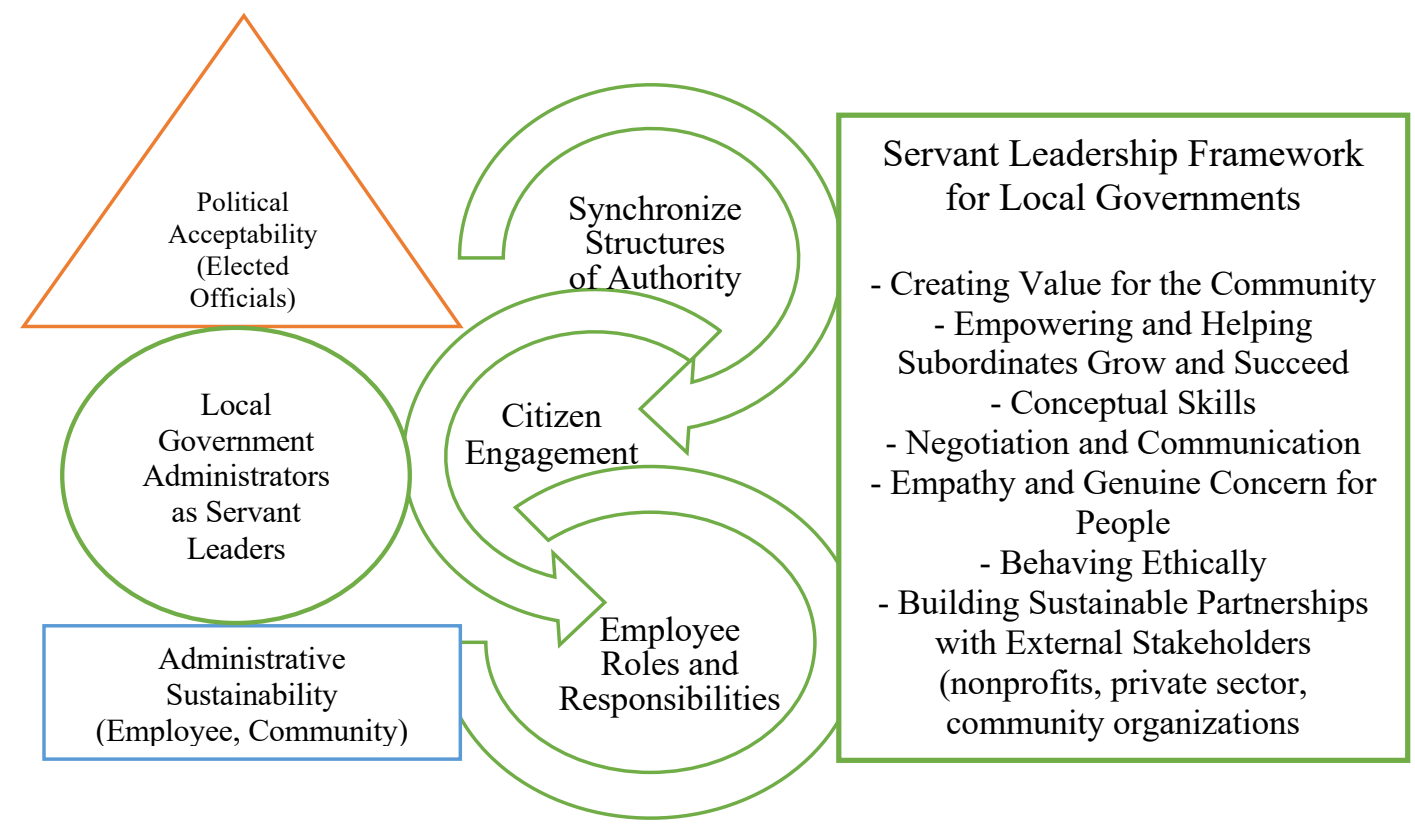

Figure 29. Servant Leadership Framework for Local Governments

Leadership is about the personality and behavior of an individual, as much it is about the context, structure, and culture. Servant leadership offers a potential model of leadership for local governments because of its community-centric nature. Community is not an after-thought for servant leaders; it is primary.

There are three key findings from this study that provide a foundation for the emerging servant leadership framework for local governments. 
(1) Council-Managers as Servant Leaders. Servant leadership style fits well with the council-manager structure of local government. The city/county manager in a councilmanager form of government has administrative powers and can execute policies and decisions that empower their employees. They have executive powers to create systems and processes in the organizations in the best interest of the community. Thus, a county and city manager who is a servant leader would be highly valuable for strengthening democratic citizenship in local governments with a council manager form.

(2) Servant Leadership's Core Dimensions. Liden et al. (2008) highlighted seven core dimensions of servant leadership. These dimensions can be adapted to guide county and city managers. Liden et al. (2008) highlighted emotional healing, which can be read as empathy and genuine concern for people in the context of local governments. Servant leaders need to be skillful negotiators given their smart understanding of people. Negotiation and diplomacy emerged repeatedly as core abilities of the servant leaders in this study. When it is essential, servant leaders are also tough decision-makers. They are capable of dealing with situations that could potentially compromise the organization's mission and core values. Servant leaders are not weak because they put their subordinate's needs first. Servant leaders can compartmentalize their style of leadership to what is appropriate in a situation. They are led by the ethic of consequentialism.

County and city managers who are servant leaders are adept in understanding and utilizing diverse and subtle ways of communication to build trust and interpersonal relationships with multiple stakeholders within (elected officials, employees) and outside the organization (community, nonprofits, private sector). The servant-leader is an able manager of people as their life purpose is to create value for the people and the 
community. It is central to the bridging role of the county and city administrators. An effective county or city manager is a servant leader. They serve to the needs of the elected officials and employees while keeping the community service the highest priority. This helps bridge relationships among multiple stakeholders by creating effective structures of authority, roles, responsibilities, and processes for high-quality service delivery. This framework highlights the need for servant leadership behavior in local governments. Servant leaders help their subordinates to nurture their servant leadership qualities. Local government agencies need structured internal systems for recruitment, selection, and training for servant leaders to create a culture of service.

(3) Servant Leader's Bridging Role. Bridging political acceptability and administrative sustainability are critical for successful local government leadership. Local government leaders work close to the community. They engage with citizens on a routine basis. The servant leadership approach offers solutions to $21^{\text {st }}$-century local government challenges. Due to their inclusive approach, servant leaders address issues of representation, social equity, and efficient service delivery. Servant leadership application in local governments addresses the lack of comprehensive and inclusive leadership. For local government practitioners, the servant leadership framework opens avenues for succession planning, recruitment, training, and leadership development among employees. Servant leadership theory extends the local government leadership model in dealing with the issues of collective concern. It enables a platform for community engagement and democratic citizenship. In essence, servant leadership squarely focuses on public service values such as integrity, ethics, and service orientation. Therefore, is highly comprehensive approach for local governance. 


\section{Implications for Theory and Practice}

There are four main implications of this study. First, from a theoretical standpoint, a servant leadership framework for county and city governments emerges from this research. Undoubtedly, leadership is also not about 'one size fits all' and it differs based on situations and contexts. The emerging servant leadership framework for county and city governments from this study is oriented toward public administrators working in local governments. Servant leadership may have a different set of characteristics when adapted to other contexts such as business or non-profit administration.

The servant leadership framework takes into consideration the competing values of political acceptability and administrative sustainability faced by county and city managers. Besides, skills such as negotiation and communication emerge as vital characteristics of servant leadership to manifest in county and city governments. The servant leadership framework adds a new approach to the extant body of public administration leadership literature.

Second, from a practical standpoint, this study provides an understanding of how to develop servant leaders in county and city governments. The servant leadership framework serves as a template for county and city governments to take a structured approach to design and conduct servant leadership training and development workshops. For example, the human resource development department in county and city governments can test the individual attributes of servant leadership behavior for managerial positions. Based on this assessment, the training methods for developing servant leadership can be instituted. An ideal approach will be to conduct in-house servant leadership workshops by inviting servant leadership development experts or 
consultants. As a result, a servant leadership culture will be established, which could hold long-lasting dividends for county and city governments in strengthening their role as community custodians.

Third, the servant leadership framework can be utilized in hiring and performance evaluations. This will further enhance the acclimatization of servant leadership culture in all the managerial positions. Servant leaders could establish trustworthy relationships and sustainable partnerships both with internal (elected officials and employees) as well as external stakeholders (nonprofits, community organizations, citizens). They use mechanisms such as negotiation, communication, and diplomacy to develop sustainable engagement with multiple stakeholders. This can also enhance organizational performance in county and city governments. Moreover, servant leaders are critical to ensure the public service values of equity, integrity, and service to create value for the community. Thus, local governments can consider implementing servant leadership model in departments and the organization as a whole.

Fourth, this dissertation reinforces the new public service paradigm's argument about reinventing the role of local governments. Citizens are active partners in public service provisions, and leaders should facilitate the active role of citizens in partnering with governments. Servant leadership emerges as one such mechanism that will support local governments to actively engage with the community stakeholders. The broader implications of this study are in redesigning the human resource development practices in local governments such as hiring, training, leadership development, performance evaluation, and succession planning. 


\section{Strengths, Limitations, and Directions for Future Research}

The main substantive strength of this dissertation is that it is perhaps among the first comprehensive empirical examination of servant leadership in public administration in the United States. The sparse literature that exists on servant leadership in public administration comes from the Chinese context. There is no publication on servant leadership in leading journals such as Public Administration Review or Journal of Public Administration Research and Theory. In this context, this dissertation offers an alternative to the mainstream leadership approaches emphasized in the literature.

The main methodological strength of this dissertation is the mixed-methods approach, using complementary quantitative and qualitative methods of research. The qualitative findings add value in terms of providing nuance. It also contributes theoretically by parsing the finer dimensions of servant leadership behavior. It is vital as the servant leadership model is context specific.

There are several limitations to this research. From a quantitative analysis perspective, there are five limitations. First, only two individual attributes (servant identity and moral potency) of servant leadership were investigated in this dissertation. Although they are the core dimensions, future research can identify both positive and negative individual attributes such as extraversion, conscientiousness, emotional labor, emotional intelligence, and narcissism (Liden et al., 2014). Thus, it is important not only to identify the positive correlates of servant leadership but also to highlight the negative correlates. Likewise, the dissertation focused on only two organizational attributes of servant leadership (co-production and organizational social capital). Local governments are multi-faceted, and they have to deal with many more organizational issues. Such 
issues include service delivery performance, government and community relations as perceived by the community, employees' innovative behavior, organizational innovation, organization's adaptation to sustainability practices. Future research should take into consideration these organizational outcomes of local governments as well.

Second, for servant leadership to manifest, several other organizational factors impact, besides those identified in this dissertation. Such factors include the history of the organization, organizational structure, form of government (strong mayor or councilmanager), size of the organization, and the leadership styles of elected officials. The study did not take into consideration the effect of these factors. Although the case studies touched upon these dimensions peripherally. Future research can consider these limitations more centrally.

Third, the data obtained for this study is cross-sectional, which is a limitation in making causal claims. The cross-sectional data does not address reverse relationships. It does not facilitate how servant leadership can be endured in local governments. Studying the servant leadership model in local governments for a longer time will allow understanding the sustained impact of servant leadership in local governments. For example, future studies may select a few case studies of the county and city managers and conduct a longitudinal study in diverse contexts for a robust understanding of the benefits and downsides of servant leadership.

Fourth, in the survey sample, both the county and city governments were merged. City governments are relatively smaller in size than county governments and the size mattered for servant leadership to manifest. This finding came up consistently during interviews and was parsed in the survey analysis. Considering the diversity of employees 
and the population being served by a particular city or county government may yield further insights on the impact of servant leadership.

Lastly, from many of the county and city governments, only one employee (follower) responded. This reduces the variability in servant leadership behavior scores across the many county and city governments in the study. However, significance tests with two or more employees were similar to the overall sample. This permits to make conclusions cautiously and ruling out the possibility of type II error due to the low participation of team members in team-based studies (Timmerman, 2005).

From a qualitative analysis perspective, the study has few strengths and limitations as well. Qualitative methods offered deeper insights, but do not lend themselves to generalizability. Hence, the study's findings should be applied with caution. There are some limitations for credibility, transferability, and confirmability (Yin, 2009; Whittemore, Chase, and Mandle, 2001).

To establish credibility for both the county and city managers and their executive team members, triangulation was used. The narratives were sought from multiple sources of data such as in-depth interviews, participant observations, and archival document analysis. Participant observation method allowed for informal and prolonged engagements with the executive team members of the county and city managers, which also allowed for member checks. "Member checks" refers to providing the findings to the participants to elicit feedback and limit errors of interpretation (Porter, 1991; Becker, 1958; Lincoln \& Guba, 1985).

The "member-check" process was followed throughout the study with an arbitrary selection of participants during observations as well as informal and formal conversations 
during interviews. The consistent engagement limited potential reactivity or interaction effects from the presence of an outside researcher (Brink, 1993; Lowes \& Prowse, 2001). The disconfirming evidence — data that did not support the causal patterns as identified (i.e. the counter as well as negative perspectives) - was actively sought. When identified, the disagreements among participants were explicitly reported in the findings. This step permitted competing interpretations and explanations for thorough and accurate investigation to identify patterns and relationships.

To ensure transferability, which refers to the degree to which the findings of the study apply to other contexts. The findings in this study come from three case studies that have a diverse history and demography. This allowed for studying the servant leadership phenomenon in a more intensely grounded manner. Since the data comes from only a certain period for which the particular county and city administrator has been serving in the present county or city, it limited the understanding of how or why servant leadership behavior will manifest over time and its effect on the organization's sustainability.

Multiple case studies allowed for a wider exploration of the research questions and theoretical replication (Hanna, 2005; Eisenhardt \& Graebner, 2007). County A is in the North Central part of Florida with a distinctive historical and demographic background. It is large in terms of the number of employees. County B is located in South East Florida with different demography and history; it is a mid-sized jurisdiction. Village $\mathrm{C}$ is located in South Florida and is a very small municipality that was recently incorporated. These differences across the case study settings allowed for exploring the complex and multifaceted nature of the servant leadership phenomenon. Hence, the 
findings provide an understanding of theoretical constructs and relationships explored herein (Yin, 2009), laying the foundation for future scholarship.

Lastly, confirmability in research allows the findings to be corroborated by others in the future. There are several techniques to ensure that others can validate the findings. These techniques include reflexivity, triangulation, providing verbatim transcriptions, and utilizing the computer-aided qualitative data analysis software. Reflexive journaling is an approach to acknowledge and identify the personal perspectives, interpretations, and assumptions of the observer apart from the descriptive observations which are straightforward. In this study, reflexive journaling was adopted on an ongoing basisoften at the end of interviews - by frequently documenting thoughts, feelings, perceptions, and/or interpretations (see Appendix K for a reflexivity statement). The verbatim transcriptions of the audio interview recordings are available for others to derive their codes and themes based on the actual words spoken by the participants.

For future research, this study provides four recommendations. First, to understand the sustained effect of servant leadership in local governments, longitudinal surveys and case studies will be helpful. Second, servant leadership is an affective type of leadership style. Servant leaders engage in emotional labor (Liden et al., 2014; Newman, Guy, \& Mastracci, 2009). Future studies can explore the emotional labor of servant leaders, especially in local government administration (Kiel \& Watson, 2009). Third, servant leadership research has been investigated in the U.S. business context. Scholars can explore the application of servant leadership in a cross-cultural context. Fourth, apart from local governments, servant leadership can be tested in state/federal agencies, as well as specific departments such as tourism, culture, policing, corrections, social services etc. 


\section{REFERENCES}

Agranoff, R. (2006). Inside collaborative networks: Ten lessons for public managers. Public administration review, 66, 56-65.

Agranoff, R., \& McGuire, M. (2003). Collaborative public management: New strategies for local governments. Georgetown University Press.

Alford, J. (1998). A public management road less travelled: Clients as co-producers of public services. Australian Journal of Public Administration, 57(4), 128-137.

Allen, S., Winston, B. E., Tatone, G. R., \& Crowson, H. M. (2018) Exploring a model of servant leadership, empowerment, and commitment to nonprofit organizations. Nonprofit Management and Leadership.

Allman, T. D. (2013). Finding Florida: The true history of the sunshine state. Open Road+ Grove/Atlantic.

Althaus, C. (2016). The administrative Sherpa and the journey of public service leadership. Administration \& Society, 48(4), 395-420.

Ammons, D. N., \& Newell, C. (1989). City executives: Leadership roles, work characteristics, and time management. SUNY Press.

Andrews, R. (2010). Organizational social capital, structure and performance. human relations, 63(5), 583-608.

Andrews, R. (2011). Exploring the impact of community and organizational social capital on government performance: Evidence from England. Political Research Quarterly, 64(4), 938-949.

Ansell, C., \& Gash, A. (2008). Collaborative governance in theory and practice. Journal of public administration research and theory, 18(4), 543-571.

Ashforth, B. E., \& Mael, F. (1989). Social identity theory and the organization. Academy of management review, 14(1), 20-39.

Avolio, B. J., Gardner, W. L., Walumbwa, F. O., Luthans, F., \& May, D. R. (2004). Unlocking the mask: A look at the process by which authentic leaders impact follower attitudes and behaviors. The leadership quarterly, 15(6), 801-823.

Bailey, S. K. (1964). Ethics and the public service. Public Administration Review, 234243. 
Barbera, C., Sicilia, M., \& Steccolini, I. (2016). The participatory budgeting as a form of co-production. In Co-production in the Public Sector (pp. 27-39). Springer, Cham.

Barbuto Jr, J. E., \& Wheeler, D. W. (2006). Scale development and construct clarification of servant leadership. Group \& Organization Management, 31(3), 300-326.

Barbuto Jr, J. E., Gottfredson, R. K., \& Searle, T. P. (2014). An examination of emotional intelligence as an antecedent of servant leadership. Journal of Leadership \& Organizational Studies, 21(3), 315-323.

Barron, R. M., \& Kenny, D. A. (1986). The moderator-mediator variable distinction in social psychological research: Conceptual, strategic, and statistical considerations. Journal of personality and social psychology, 51(6), 1173-1182.

Bass, B. M. (1990). From transactional to transformational leadership: Learning to share the vision. Organizational dynamics, 18(3), 19-31.

Bass, B. M. (2000). The future of leadership in learning organizations. Journal of leadership studies, 7(3), 18-40.

Bass, B. M. (2008). The Bass handbook of leadership: Theory, research, \& managerial applications (4th ed.). New York, NY: Free Press.

Bass, B. M., \& Bass Bernard, M. (1985). Leadership and performance beyond expectations.

Bass, B. M., \& Steidlmeier, P. (1999). Ethics, character, and authentic transformational leadership behavior. The leadership quarterly, 10(2), 181-217.

Beck, C. D. (2014). Antecedents of servant leadership: A mixed methods study. Journal of Leadership \& Organizational Studies, 21(3), 299-314.

Beeri, I., Dayan, R., Vigoda-Gadot, E., \& Werner, S. B. (2013). Advancing ethics in public organizations: The impact of an ethics program on employees' perceptions and behaviors in a regional council. Journal of business ethics, 112(1), 59-78.

Boodhoo, R., \& Purmessur, R. D. (2009). Justifications for qualitative research in organisations: a step forward. The Journal of Online Education (New York).

Bovaird, T. (2007). Beyond engagement and participation: User and community coproduction of public services. Public administration review, 67(5), 846-860.

Boyle, D., A. Coote, C. Sherwood and J. Slay. 2010. Right Here, Right Now: Taking coproduction into the mainstream. London: nef, The Lab, NESTA. 
Boynton, R. P., \& Wright, D. S. (1971). Mayor-manager relationships in large councilmanager cities: A reinterpretation. Public Administration Review, 31(1), 28-36.

Brandsen, T., \& Honingh, M. (2016). Distinguishing different types of coproduction: A conceptual analysis based on the classical definitions. Public Administration Review, 76(3), 427-435.

Brandsen, T., \& Honingh, M. (2018). Definitions of Co-production and Co-creation. In Co-Production and Co-Creation (pp. 9-17). Routledge.

Brannan, Tessa, John, Peter and Stoker, Gerry. 2006. Active citizenship and effective public services and programmes: How can we know what really works? Urban Studies, 43:5/6, 993-1008.

Braun, V., \& Clarke, V. (2006). Using thematic analysis in psychology. Qualitative research in psychology, 3(2), 77-101.

Brewer, G. A. (2003). Building social capital: Civic attitudes and behavior of public servants. Journal of Public Administration Research and Theory, 13(1), 5-26.

Brook, A. T., Garcia, J., \& Fleming, M. (2008). The effects of multiple identities on psychological well-being. Personality and Social Psychology Bulletin, 34, 15881600. doi:10.1177/0146167208324629

Brown, M. E., \& Treviño, L. K. (2006). Ethical leadership: A review and future directions. The leadership quarterly, 17(6), 595-616.

Brown, M. E., Treviño, L. K., \& Harrison, D. A. (2005). Ethical leadership: A social learning perspective for construct development and testing. Organizational behavior and human decision processes, 97(2), 117-134.

Brown, P. R., \& Head, B. W. (2019). Navigating tensions in co-production: a missing link in leadership for public value. Public Administration, 97(2), 250-263.

Brudney, J. L., \& England, R. E. (1983). Toward a definition of the coproduction concept. Public administration review, 59-65.

Bryson, J. M., \& Crosby, B. C. (2006). Leadership for the common good. Creating a culture of collaboration, 367-396.

Bryson, J. M., Crosby, B. C., \& Stone, M. M. (2006). The design and implementation of Cross-Sector collaborations: Propositions from the literature. Public administration review, 66, 44-55.

Campbell, J. D., Trapnell, P. D., Heine, S. J., Katz, I. M., Lavallee, L. F., \& Lehman, D. R. (1996). Self-concept clarity: Measurement, personality correlates, and cultural boundaries. Journal of personality and social psychology, 70(1), 141. 
Caron, D. J., \& Giauque, D. (2006). Civil servant identity at the crossroads: new challenges for public administrations. International Journal of Public Sector Management, 19(6), 543-555.

Chen, Z., Zhu, J., \& Zhou, M. (2015). How does a servant leader fuel the service fire? A multilevel model of servant leadership, individual self-identity, group competition climate, and customer service performance. Journal of Applied Psychology, 100(2), 511.

Choudhary, A. I., Akhtar, S. A., \& Zaheer, A. (2013). Impact of transformational and servant leadership on organizational performance: A comparative analysis. Journal of business ethics, 116(2), 433-440.

Chrislip, D. D., \& Larson, C. E. (1994). Collaborative leadership: How citizens and civic leaders can make a difference (Vol. 24). Jossey-Bass Inc Pub.

Chung, J. Y., Jung, C. S., Kyle, G. T., \& Petrick, J. F. (2010). Servant Leadership and Procedural Justice in the US National Park Service: The Antecedents of Job Satisfaction. Journal of Park \& Recreation Administration, 28(3).

Coffé, H., \& Geys, B. (2005). Institutional performance and social capital: An application to the local government level. Journal of Urban Affairs, 27(5), 485-501.

Conger, J. A., \& Kanungo, R. N. (1988). Behavioral dimensions of charismatic leadership.

Cooper, T. (1982). The Responsible Administrator. Port Washington.

Cooper, T. L., \& Gulick, L. (1984). Citizenship and professionalism in public administration. Public Administration Review, 44, 143-151.

Cooper, T. L., \& Wright, N. D. (Eds.). (1992). Exemplary public administrators: Character and leadership in government. Jossey-Bass.

Copestake, P., Sheikh, S., Johnston, S. and Bollen, A. (2014). Removing Barriers, Raising Disabled People's Living Standards. London: OPM.

Creswell, J. W. (2013). Steps in conducting a scholarly mixed methods study.

Crosby, B. C., \& Bryson, J. M. (2005). Leadership for the common good: Tackling public problems in a shared-power world (Vol. 264). John Wiley \& Sons.

Crosby, B. C., \& Bryson, J. M. (2010). Integrative leadership and the creation and maintenance of cross-sector collaborations. The Leadership Quarterly, 21(2), 211-230. 
Crosby, B. C., \& Bryson, J. M. (2014). Public integrative leadership. The Oxford handbook of leadership and organizations, 57-72.

Currie, G., Grubnic, S., \& Hodges, R. (2011). Leadership in public services networks: Antecedents, process and outcome. Public administration, 89(2), 242-264.

De Clercq, D., Bouckenooghe, D., Raja, U., \& Matsyborska, G. (2014). Servant leadership and work engagement: The contingency effects of leader-follower social capital. Human Resource Development Quarterly, 25(2), 183-212.

De Rubio, A. R., \& Kiser, A. G. (2015). Gender and age differences in servant leadership. Academy of Business Research Journal, 1, 49-63.

Denhardt, R. B. (1993). The pursuit of significance: Strategies for managerial success in public organizations. Wadsworth Publishing Company.

Denhardt, R. B., \& Denhardt, J. V. (2000). The new public service: Serving rather than steering. Public administration review, 60(6), 549-559.

Doig, A., \& Wilson, J. (1998). What price new public management? The Political Quarterly, 69(3), 267-276.

Duffy, M. (2016). Gung Ho, Marine! Servant Leadership, Evans Carlson, and the 2nd Marine Raider Battalion. Servant Leadership: Theory \& Practice, 3(1), 5.

Dunleavy, P., Margetts, H., Bastow, S., \& Tinkler, J. (2006). New public management is dead-long live digital-era governance. Journal of public administration research and theory, 16(3), 467-494.

Ebener, D. R., \& O'Connell, D. J. (2010). How might servant leadership work? Nonprofit Management and Leadership, 20(3), 315-335.

Ehrhart, M. G. (2002). Leadership and justice climate as antecedents of unit-level organizational citizenship behavior.

Ehrhart, M. G. (2004). Leadership and procedural justice climate as antecedents of unitlevel organizational citizenship behavior. Personnel psychology, 57(1), 61-94.

Emerson, K., \& Nabatchi, T. (2015). Evaluating the productivity of collaborative governance regimes: A performance matrix. Public Performance \& Management Review, 38(4), 717-747.

Eva, N., Robin, M., Sendjaya, S., van Dierendonck, D., \& Liden, R. C. (2019). Servant leadership: A systematic review and call for future research. The Leadership Quarterly, 30(1), 111-132. 
Fernandez, S., Cho, Y. J., \& Perry, J. L. (2010). Exploring the link between integrated leadership and public sector performance. The Leadership Quarterly, 2l(2), 308323.

Fink, A. \& Kosecoff, J. (1985). How to conduct surveys: A step-by-step guide. London, UK, Sage Publications.

Fischer, P., Jong, D. (2017). The Relationship between Teacher Perception of Principal Servant Leadership Behavior and Teacher Job Satisfaction. Servant Leadership: Theory \& Practice. 4(2), 53-84.

Fisher, I., \& Ziviani, J. (2004). Explanatory case studies: Implications and applications for clinical research. Australian Occupational Therapy Journal, 51(4), 185-191.

Fledderus, J., Brandsen, T., \& Honingh, M. (2014). Restoring trust through the coproduction of public services: A theoretical elaboration. Public Management Review, 16(3), 424-443.

Flynn, C. B., Smither, J. W., \& Walker, A. G. (2016). Exploring the relationship between leaders' core self-evaluations and subordinates' perceptions of servant leadership: A field study. Journal of Leadership \& Organizational Studies, 23(3), 260-271.

Folz, D. H. (1991). Recycling program design, management, and participation: a national survey of municipal experience. Public Administration Review, 222-231.

Garber, J. S., Madigan, E. A., Click, E. R., \& Fitzpatrick, J. J. (2009). Attitudes towards collaboration and servant leadership among nurses, physicians and residents. Journal of Interprofessional Care, 23(4), 331-340.

Getha-Taylor, H., \& Morse, R. S. (2013). Collaborative leadership development for local government officials: Exploring competencies and program impact. Public Administration Quarterly, 71-102.

Getha-Taylor, H., Blackmar, J., \& Borry, E. L. (2016). Are competencies universal or situational? A state-level investigation of collaborative competencies. Review of Public Personnel Administration, 36(3), 306-320.

Getha-Taylor, H., Fowles, J., Silvia, C., \& Merritt, C. C. (2015). Considering the effects of time on leadership development: A local government training evaluation. Public Personnel Management, 44(3), 295-316.

Giampetro-Meyer, A., Brown, S. T., Browne, M. N., \& Kubasek, N. (1998). Do we really want more leaders in business?. Journal of Business Ethics, 17(15), 1727-1736.

Gotsis, G., \& Grimani, K. (2016). The role of servant leadership in fostering inclusive organizations. Journal of Management Development, 35(8), 985-1010. 
Graham, J. W. (1991). Servant-leadership in organizations: Inspirational and moral. The Leadership Quarterly, 2(2), 105-119.

Graham, J. W. (1995). Leadership, moral development, and citizenship behavior. Business ethics quarterly, 43-54.

Grant, A. M., Molinsky, A., Margolis, J., Kamin, M., \& Schiano, W. (2009). The performer's reactions to procedural injustice: When prosocial identity reduces prosocial behavior 1. Journal of Applied Social Psychology, 39(2), 319-349.

Grant, A. M., Parker, S., \& Collins, C. (2009). Getting credit for proactive behavior: Supervisor reactions depend on what you value and how you feel. Personnel Psychology, 62(1), 31-55.

Greenleaf, R. K. (1970). The servant as leader. Newton Centre. MA: Robert K. Greenleaf Center.

Greenleaf, R. K. (1977). Servant leadership. Mahwah, NJ: Paulist Press

Greenleaf, R. K. (2008). Who is the servant-leader? The International Journal of ServantLeadership, 4(1), 29-37.

Gregory Stone, A., Russell, R. F., \& Patterson, K. (2004). Transformational versus servant leadership: A difference in leader focus. Leadership \& Organization Development Journal, 25(4), 349-361.

Grint, K. (2005). Problems, problems, problems: The social construction of 'leadership'. Human relations, 58(11), 1467-1494.

Griset, P. L. (2002). New sentencing laws follow old patterns:: A Florida case study. Journal of Criminal Justice, 30(4), 287-301.

Han, Y., Kakabadse, N. K., \& Kakabadse, A. (2010). Servant leadership in the People's Republic of China: A case study of the public sector. Journal of Management Development, 29(3), 265-281.

Hanbury, G. L., Sapat, A., \& Washington, C. W. (2004). Know yourself and take charge of your own destiny: The "fit model" of leadership. Public Administration Review, 64(5), 566-576.

Hannah, S. T., \& Avolio, B. J. (2010). Moral potency: Building the capacity for character-based leadership. Consulting Psychology Journal: Practice and Research, 62(4), 291.

Hannah, S. T., \& Avolio, B. J. (2010). Ready or not: How do we accelerate the developmental readiness of leaders? Journal of Organizational Behavior, 31(8), 1181-1187. 
Hannah, S. T., Avolio, B. J., \& May, D. R. (2011). Moral maturation and moral conation: A capacity approach to explaining moral thought and action. Academy of Management Review, 36(4), 663-685.

Hannah, S. T., Avolio, B. J., \& Walumbwa, F. O. (2011). Relationships between authentic leadership, moral courage, and ethical and pro-social behaviors. Business Ethics Quarterly, 21(4), 555-578.

Hannah, S. T., Woolfolk, R. L., \& Lord, R. G. (2009). Leader self-structure: a framework for positive leadership. Journal of Organizational Behavior, 30(2), 269-290.

Harmon, M. M. (1995). Responsibility as paradox: A critique of rational discourse on government.

Hart, D. K. (1984). The virtuous citizen, the honorable bureaucrat, and" public" administration. Public Administration Review, 44, 111-120.

Hassan, S., Wright, B. E., \& Yukl, G. (2014). Does ethical leadership matter in government? Effects on organizational commitment, absenteeism, and willingness to report ethical problems. Public Administration Review, 74(3), 333-343.

Hassett, W. L., \& Watson, D. J. (2002). Long-serving city managers: Practical application of the academic literature. Public Administration Review, 62(5), 622629.

Hill, P. L., \& Roberts, B. W. (2010). Propositions for the study of moral personality development. Current Directions in Psychological Science, 19(6), 380-383.

Hitt, M. A., \& Duane, R. (2002). The essence of strategic leadership: Managing human and social capital. Journal of Leadership \& Organizational Studies, 9(1), 3-14.

Hoch, J. E., Bommer, W. H., Dulebohn, J. H., \& Wu, D. (2018). Do ethical, authentic, and servant leadership explain variance above and beyond transformational leadership? A meta-analysis. Journal of Management, 44(2), 501-529.

Hood, C., \& Dixon, R. (2015). 1. Title: What We Have To Show for 30 Years of New Public Management: Higher Costs, More Complaints. Governance, 28(3).

Horton, S. (2006). New public management: its impact on public servant's identity: An introduction to this symposium. International Journal of Public Sector Management, 19(6), 533-542.

Horton, S., Caron, D. J., \& Giauque, D. (2006). Civil servant identity at the crossroads: new challenges for public administrations. International Journal of Public Sector Management. 
Horton, S., van Bockel, J., \& Noordegraaf, M. (2006). Identifying identities: performance-driven, but professional public managers. International Journal of Public Sector Management.

House, R. J. (1996). Path-goal theory of leadership: Lessons, legacy, and a reformulated theory. The Leadership Quarterly, 7(3), 323-352.

Howard, J., \& Sweeting, D. (2007). Addressing the legitimacy of the council-manager executive in local government. Local Government Studies, 33(5), 633-656.

Hsiao, C., Lee, Y. H., \& Chen, W. J. (2015). The effect of servant leadership on customer value co-creation: A cross-level analysis of key mediating roles. Tourism Management, 49, 45-57.

Hu, J., \& Liden, R. C. (2011). Antecedents of team potency and team effectiveness: An examination of goal and process clarity and servant leadership. Journal of Applied psychology, 96(4), 851.

Hunter, E. M., Neubert, M. J., Perry, S. J., Witt, L. A., Penney, L. M., \& Weinberger, E. (2013). Servant leaders inspire servant followers: Antecedents and outcomes for employees and the organization. The Leadership Quarterly, 24(2), 316-331.

Huxham, C., \& Vangen, S. E. (2005). Managing to collaborate. Abingdon: Taylor \& Francis.

Irving, J. A., \& Longbotham, G. J. (2007). Team effectiveness and six essential servant leadership themes: A regression model based on items in the organizational leadership assessment. International Journal of Leadership Studies, 2(2), 98-113.

Jakobsen, M. (2013). Can government initiatives increase citizen coproduction? Results of a randomized field experiment. Journal of Public Administration Research and Theory, 23(1), 27-54.

Janet, D. V., \& Robert, D. B. (2007). The new public service: Serving, not steering. $M E$ Sharpe New Jork.

Jaramillo, F., Grisaffe, D. B., Chonko, L. B., \& Roberts, J. A. (2009). Examining the impact of servant leadership on sales force performance. Journal of Personal Selling \& Sales Management, 29(3), 257-275.

Jo, S., \& Nabatchi, T. (2016). Getting Back to Basics: Advancing the Study and Practice of Coproduction. International Journal of Public Administration, 39(13), 11011108 .

Keast, R., \& Mandell, M. (2014). The collaborative push: moving beyond rhetoric and gaining evidence. Journal of management \& governance, 18(1), 9-28. 
Kiel, L. D., \& Watson, D. J. (2009). Affective leadership and emotional labor: A view from the local level. Public Administration Review, 69(1), 21-24.

Kickert, W. J., Klijn, E. H., \& Koppenjan, J. F. (Eds.). (1997). Managing complex networks: Strategies for the public sector. Sage.

Kim, S. (2018). Public Service Motivation, Organizational Social Capital, and Knowledge Sharing in the Korean Public Sector. Public Performance \& Management Review, 41(1), 130-151.

King, C. S., \& Stivers, C. (1998). Citizens and administrators: Roles and relationships.

Kolo, J., \& Watson, R. (1992). Local economic development and growth management in Florida. Economic Development Review, 10(3), 68.

Lasthuizen, K. M. (2008). Leading to integrity: Empirical research into the effects of leadership on ethics and integrity.

Laub, J. (2010). The servant organization. In Servant Leadership (pp. 105-117). Palgrave Macmillan, London.

Leana, C. R., \& Pil, F. K. (2006). Social capital and organizational performance: Evidence from urban public schools. Organization Science, 17(3), 353-366.

Lemoine, G. J., Hartnell, C. A., \& Leroy, H. (2019). Taking stock of moral approaches to leadership: An integrative review of ethical, authentic, and servant leadership. Academy of Management Annals, 13(1), 148-187.

Levine, C. H., \& Fisher, G. (1984). Citizenship and service delivery: The promise of coproduction. Public Administration Review, 44, 178-189.

Liden, R. C., Wayne, S. J., \& Sparrowe, R. T. (2000). An examination of the mediating role of psychological empowerment on the relations between the job, interpersonal relationships, and work outcomes. Journal of applied psychology, 85(3), 407.

Liden, R. C., Wayne, S. J., Liao, C., \& Meuser, J. D. (2014). Servant leadership and serving culture: Influence on individual and unit performance. Academy of Management Journal, 57(5), 1434-1452.

Liden, R. C., Wayne, S. J., Zhao, H., \& Henderson, D. (2008). Servant leadership: Development of a multidimensional measure and multi-level assessment. The leadership quarterly, 19(2), 161-177.

Linda Parris, D., \& Welty Peachey, J. (2012). Building a legacy of volunteers through servant leadership: A cause-related sporting event. Nonprofit Management and Leadership, 23(2), 259-276. 
Ling, Q., Lin, M., \& Wu, X. (2016). The trickle-down effect of servant leadership on frontline employee service behaviors and performance: A multilevel study of Chinese hotels. Tourism Management, 52, 341-368.

Litwin, G. H., \& Stringer, R. A. (1968). Motivation and organizational climate.

Liu, B., Hu, W., \& Cheng, Y. C. (2015). From the west to the east: Validating servant leadership in the Chinese public sector. Public Personnel Management, 44(1), 2545.

Lu, X., \& Guy, M. E. (2014). How emotional labor and ethical leadership affect job engagement for Chinese public servants. Public Personnel Management, 43(1), 324.

Maak, T. (2007). Responsible leadership, stakeholder engagement, and the emergence of social capital. Journal of Business Ethics, 74(4), 329-343.

Mansbridge, J. J. (Ed.). (1990). Beyond self-interest. University of Chicago Press.

Marschall, M. J. 2004. "Participation and the Neighborhood Context: A New Look at the Coproduction of Local Public Goods.” Political Research Quarterly 57(2): 231244.

Mastracci, S. (2017). Beginning nurses' perceptions of ethical leadership in the shadow of mid staffs. Public Integrity, 19(3), 250-264.

Mayer, D. M., Aquino, K., Greenbaum, R. L., \& Kuenzi, M. (2012). Who displays ethical leadership, and why does it matter? An examination of antecedents and consequences of ethical leadership. Academy of Management Journal, 55(1), 151171.

Meal, F. A., \& Ashforth, B. E. (1989). Social identity and the organization. Academy of Management Review, 14, 20-39.

Menzel, D. C. (1997). Teaching ethics and values in public administration: Are we making a difference?. Public Administration Review, 224-230.

Menzel, D. C. (2015). Research on ethics and integrity in public administration: Moving forward, looking back. Public Integrity, 17(4), 343-370.

Menzel, Donald C. (2015) "Leadership in Public Administration: Creative and/or Ethical?." Public Integrity 17(4), 315-318.

Miao, Q., Newman, A., Schwarz, G., \& Xu, L. (2014). Servant leadership, trust, and the organizational commitment of public sector employees in China. Public Administration, 92(3), 727-743. 
Miller, D. Y., \& Fox, C. J. (2015). Postmodern public administration. Routledge.

Molina-Azorin, J. F., \& Fetters, M. D. (2019). Building a better world through mixed methods research.

Morgan, D. F., \& Cook, B. J. (Eds.). (2014). New public governance: A regime-centered perspective. ME Sharpe.

Morgan, D. R., \& Watson, S. S. (1992). Policy leadership in council-manager cities: Comparing mayor and manager. Public Administration Review, 438-446.

Morse, R. S. (2010). Integrative public leadership: Catalyzing collaboration to create public value. The Leadership Quarterly, 21(2), 231-245.

Morse, R. S. (2014). Developing public leaders in an age of collaborative governance. In Innovations in public leadership development (pp. 91-112). Routledge.

Moynihan, D. P., Pandey, S. K., \& Wright, B. E. (2013). Transformational leadership in the public sector: Empirical evidence of its effects. In Public administration reformation (pp. 101-118). Routledge.

Murphy, J., Rhodes, M. L., Meek, J. W., \& Denyer, D. (2017). Managing the entanglement: complexity leadership in public sector systems. Public Administration Review, 77(5), 692-704.

Nabatchi, T., Sancino, A., \& Sicilia, M. (2017). Varieties of participation in public services: The who, when, and what of coproduction. Public Administration Review, 77(5), 766-776.

Nahapiet, J., \& Ghoshal, S. (2000). Social capital, intellectual capital, and the organizational advantage. In Knowledge and social capital (pp. 119-157).

Nalbandian, J. (1999). Facilitating community, enabling democracy: New roles for local government managers. Public Administration Review, 187-197.

Nalbandian, J., O'Neill Jr, R., Michael Wilkes, J., \& Kaufman, A. (2013). Contemporary challenges in local government: Evolving roles and responsibilities, structures, and processes. Public Administration Review, 73(4), 567-574.

Neubert, M. J., Hunter, E. M., \& Tolentino, R. C. (2016). A servant leader and their stakeholders: When does organizational structure enhance a leader's influence?. The Leadership Quarterly, 27(6), 896-910.

Neubert, M. J., Kacmar, K. M., Carlson, D. S., Chonko, L. B., \& Roberts, J. A. (2008). Regulatory focus as a mediator of the influence of initiating structure and servant leadership on employee behavior. Journal of applied psychology, 93(6), 1220. 
Newman, M. A., Guy, M. E., \& Mastracci, S. H. (2009). Beyond cognition: Affective leadership and emotional labor. Public Administration Review, 69(1), 6-20.

Newman, A., Schwarz, G., Cooper, B., \& Sendjaya, S. (2017). How servant leadership influences organizational citizenship behavior: The roles of LMX, empowerment, and proactive personality. Journal of Business Ethics, 145(1), 49-62.

Obodaru, O. (2012). The self not taken: How alternative selves develop and how they influence our professional lives. Academy of Management Review, 37(1), 34-57.

O'Leary, R., \& Bingham, L. B. (Eds.). (2009). The collaborative public manager: New ideas for the twenty-first century. Georgetown University Press.

O'Neill Jr, R. J., \& Nalbandian, J. (2018). Change, complexity, and leadership challenges. Public Administration Review, 78(2), 311-314.

Orazi, D. C., Turrini, A., \& Valotti, G. (2013). Public sector leadership: new perspectives for research and practice. International Review of Administrative Sciences, 79(3), 486-504.

Orr, K., \& Bennett, M. (2017). Relational leadership, storytelling, and narratives: Practices of local government chief executives. Public Administration Review, 77(4), 515-527.

Osborne, D., \& Gaebler, T. (1993). Reinventing government: The five strategies for reinventing government.

Osborne, D., \& Plastrik, P. (1997). Banishing Bureaucracy: The Five Strategies for Reinventing Government. Addison-Wesley Publishing Company, Inc., 1 Jacob Way, Reading, MA 01867.

Osborne, S. P. (2006). The new public governance

Ospina, S. M. (2017). Collective leadership and context in public administration: Bridging public leadership research and leadership studies. Public Administration Review, 77(2), 275-287.

Ostrom, E. (1972). Metropolitan reform: Propositions derived from two traditions. Social Science Quarterly, 474-493.

Ostrom, E. (1996). Crossing the great divide: coproduction, synergy, and development. World development, 24(6), 1073-1087.

Ostrom, V., Ostrom, E., \& Savas, E. S. (1977). Public goods and public choices. 1977, 749. 
Paarlberg, L. E., \& Lavigna, B. (2010). Transformational leadership and public service motivation: Driving individual and organizational performance. Public administration review, 70(5), 710-718.

Parolini, J., Patterson, K., \& Winston, B. (2009). Distinguishing between transformational and servant leadership. Leadership \& Organization Development Journal, 30(3), 274-291.

Parris, D. L., \& Peachey, J. W. (2013). A systematic literature review of servant leadership theory in organizational contexts. Journal of business ethics, 113(3), 377-393.

Parry, K. W. (1999). Enhancing adaptability: Leadership strategies to accommodate change in local government settings. Journal of Organizational Change Management.

Pastoriza, D., \& Ariño, M. A. (2013). Does the ethical leadership of supervisors generate internal social capital?. Journal of Business Ethics, 118(1), 1-12.

Peat, J., Mellis, C., Williams, K. and Xuan W. (2002), Health Science Research: A Handbook of Quantitative Methods, London: Sage

Percy, S. L. (1978). Conceptualizing and measuring citizen co-production of community safety. Policy Studies Journal, 7, 486.

Perry, J. L. (1997). Antecedents of public service motivation. Journal of public administration research and theory, 7(2), 181-197.

Perry, J. L. (2000). Bringing society in: Toward a theory of public-service motivation. Journal of public administration research and theory, 10(2), 471-488.

Perry, J. L., \& Wise, L. R. (1990). The motivational bases of public service. Public administration review, 367-373.

Peterson, S. J., Galvin, B. M., \& Lange, D. (2012). CEO servant leadership: Exploring executive characteristics and firm performance. Personnel Psychology, 65(3), $565-596$.

Pollitt, C. (1990). Managerialism and the public services: The Anglo-American experience. Blackwell.

Pollitt, C., \& Bouckaert, G. (2004). Public management reform: A comparative analysis. Oxford University Press, USA.

Purdue, D. (2001). Neighbourhood governance: Leadership, trust and social capital. Urban Studies, 38(12), 2211-2224. 
Putnam, R. D. (1995). Tuning in, tuning out: The strange disappearance of social capital in America. PS: Political science \& politics, 28(4), 664-683.

Putnam, R. D. (2000). Bowling alone: America's declining social capital. In Culture and politics (pp. 223-234). Palgrave Macmillan, New York.

Rainie, L., \& Perrin, A. (2019). Trusts, facts, and democracy reports: Key findings about Americans declining trust in government, Pew Research Center.

Reed, L. (2015). Servant Leadership, Followership, and Organizational Citizenship Behaviors in 9-1-1 Emergency Communications Centers: Implications of a National Study. Servant Leadership: Theory \& Practice. 2(1), 71-94.

Reinke, S. J. (2004). Service before self: Towards a theory of servant-leadership. Global Virtue Ethics Review, 5(3), 30-57.

Remler, D. K., \& Van Ryzin, G. G. (2010). Research methods in practice: Strategies for description and causation. Sage Publications.

Reynolds, S. J., \& Ceranic, T. L. (2007). The effects of moral judgment and moral identity on moral behavior: an empirical examination of the moral individual. Journal of applied psychology, 92(6), 1610.

Rohr, J. A. (1989). Ethics for bureaucrats: an essay on law and values. New York: M. NY: Marcel Dekker.

Russell, E. J. (2016). Servant leadership's cycle of benefit. Servant Leadership: Theory \& Practice, 3(1), 3.

Russell, E. J., Broomé, R. E., \& Prince, R. (2016). Discovering the servant in fire and emergency services leaders. Servant Leadership: Theory \& Practice, 2(2), 4.

Sandel Michael, J. (1996). Democracy's Discontent: America in Search of a Public Philosophy.

Schneider, B., Salvaggio, A. N., \& Subirats, M. (2002). Climate strength: a new direction for climate research. Journal of applied psychology, 87(2), 220.

Schneider, S. K., Jacoby, W. G., \& Coggburn, J. D. (1997). The structure of bureaucratic decisions in the American states. Public Administration Review, 240-249.

Schwarz, G., Newman, A., Cooper, B., \& Eva, N. (2016). Servant leadership and follower job performance: The mediating effect of public service motivation. Public Administration, 94(4), 1025-1041.

Sendjaya, S. (2005). Morality and leadership: Examining the ethics of transformational leadership. Journal of Academic Ethics, 3(1), 75-86. 
Sendjaya, S. (2005). Development and validation of the servant leadership behavior scale. Monash University.

Sendjaya, S. (2016). Personal and organizational excellence through servant leadership. Springer International $\mathrm{Pu}$.

Sendjaya, S., \& Cooper, B. (2011). Servant leadership behaviour scale: A hierarchical model and test of construct validity. European Journal of Work and Organizational Psychology, 20(3), 416-436.

Sendjaya, S., \& Pekerti, A. (2010). Servant leadership as antecedent of trust in organizations. Leadership \& Organization Development Journal, 31(7), 643-663.

Sendjaya, S., Sarros, J. C., \& Santora, J. C. (2008). Defining and measuring servant leadership behaviour in organizations. Journal of Management studies, 45(2), $402-424$.

Shamir, B., House, R. J., \& Arthur, M. B. (1993). The motivational effects of charismatic leadership: A self-concept-based theory. Organization science, 4(4), 577-594.

Sharp, E. B. (1980). Toward a new understanding of urban services and citizen participation: The coproduction concept. Midwest Review of Public Administration, 14(2), 105-118.

Shim, D. C., Park, H. H., \& Eom, T. H. (2016). Public servant leadership: Myth or powerful reality?. International Review of Public Administration, 21(1), 3-20.

Sicilia, M., Guarini, E., Sancino, A., Andreani, M., \& Ruffini, R. (2016). Public services management and co-production in multi-level governance settings. International Review of Administrative Sciences, 82(1), 8-27.

Smith, B. N., Montagno, R. V., \& Kuzmenko, T. N. (2004). Transformational and servant leadership: Content and contextual comparisons. Journal of Leadership \& Organizational Studies, 10(4), 80-91.

Spears, L. C. (2010). Servant leadership and Robert K. Greenleaf's legacy. In Servant Leadership (pp. 11-24). Palgrave Macmillan, London.

Spears, Larry C. (1998). "Tracing the growing impact of servant-leadership." Insights on Leadership ed. by Larry C. Spears. New York, NY: John Wiley and Sons, Inc, 112.

Spicer, M. W. (2001). Value pluralism and its implications for American public administration. Administrative Theory \& Praxis, 23(4), 507-528. 
Stentz, J. E., Clark, V. L. P., \& Matkin, G. S. (2012). Applying mixed methods to leadership research: A review of current practices. The Leadership Quarterly, 23(6), 1173-1183.

Stivers, C. (1994). The listening bureaucrat: Responsiveness in public administration. Public Administration Review, 364-369.

Stone, A. G., Russell, R. F., \& Patterson, K. (2004). Transformational versus servant leadership: A difference in leader focus. Leadership \& Organization Development Journal.

Stryker, S., \& Burke, P. J. (2000). The past, present, and future of an identity theory. Social psychology quarterly, 284-297.

Sullivan, H., Downe, J., Entwistle, T., \& Sweeting, D. (2006). The three challenges of community leadership. Local Government Studies, 32(4), 489-508.

Sun, P. Y. (2013). The servant identity: Influences on the cognition and behavior of servant leaders. The Leadership Quarterly, 24(4), 544-557.

Svara, J. H. (1985). Dichotomy and duality: Reconceptualizing the relationship between policy and administration in council-manager cities. Public administration review, 221-232.

Svara, J. H. (1987). Mayoral leadership in council-manager cities: Preconditions versus preconceptions. The Journal of Politics, 49(1), 207-227.

Svara, J. H. (1999). Conflict and cooperation in elected-administrative relations in large council-manager cities.

Svara, J. H. (1999). The shifting boundary between elected officials and city managers in large council-manager cities. Public Administration Review, 44-53.

Svara, J. H. (2006). Complexity in political-administrative relations and the limits of the dichotomy concept. Administrative Theory \& Praxis, 28(1), 121-139.

Tantardini, M., \& Kroll, A. (2015). The role of organizational social capital in performance management. Public Performance \& Management Review, 39(1), 83-99.

Terry, L. C. (1982). The Responsible Administrator.

Terry, L. D. (1998). Administrative leadership, neo-managerialism, and the public management movement. Public Administration Review, 194-200.

Thomas, J. C. (2013). Citizen, customer, partner: Rethinking the place of the public in public management. Public Administration Review, 73(6), 786-796. 
Thorpe, R., Gold, J., \& Lawler, J. (2011). Locating distributed leadership. International journal of management reviews, 13(3), 239-250.

Treviño, L. K., Brown, M., \& Hartman, L. P. (2003). A qualitative investigation of perceived executive ethical leadership: Perceptions from inside and outside the executive suite. Human relations, 56(1), 5-37.

Trochim, W. (1989). Outcome pattern matching and program theory. Evaluation and program planning, 12(4), 355-366.

Trong Tuan, L. (2017). Knowledge sharing in public organizations: The roles of servant leadership and organizational citizenship behavior. International Journal of Public Administration, 40(4), 361-373.

Trottier, T., Van Wart, M., \& Wang, X. (2008). Examining the nature and significance of leadership in government organizations. Public administration review, 68(2), 319333.

Uhl-Bien, M. (2006). Relational leadership theory: Exploring the social processes of leadership and organizing. The leadership quarterly, 17(6), 654-676.

Van Bockel, J., \& Noordegraaf, M. (2006). Identifying identities: Performance-driven, but professional public managers. International Journal of Public Sector Management, 19(6), 585-597.

Van Damme, Jan Didier Caluwaerts , and Marleen Brans . 2016 . Coproduction in Health Planning: Challenging the Need for "Open" Policy-Making Processes. International Journal of Public Administration 39 ( 13 ): 1056 - 66.

Van Dierendonck, D. (2011). Servant leadership: A review and synthesis. Journal of management, 37(4), 1228-1261.

Van Dierendonck, D., \& Nuijten, I. (2011). The servant leadership survey: Development and validation of a multidimensional measure. Journal of business and psychology, 26(3), 249-267.

Van Dierendonck, D., \& Patterson, K. (2010). Servant leadership: Developments in theory and research. Springer.

Van Teijlingen, E. R., \& Hundley, V. (2001). The importance of pilot studies.

Van Wart, M. (2013). Administrative leadership theory: A reassessment after 10 years. Public Administration, 91(3), 521-543.

Van Wart, M. (2013). Lessons from leadership theory and the contemporary challenges of leaders. Public Administration Review, 73(4), 553-565. 
Van Wart, M. (2015). Evaluating transformational leaders: The challenging case of Eric Shinseki and the US Department of Veterans Affairs. Public Administration Review, 75(5), 760-769.

Van Wart, M. V. (2003). Public-Sector leadership theory: An assessment. Public administration review, 63(2), 214-228.

Verdorfer, A. P. (2016). Examining mindfulness and its relations to humility, motivation to lead, and actual servant leadership behaviors. Mindfulness, 7(4), 950-961.

Verschuere, B., Brandsen, T., \& Pestoff, V. (2012). Co-production: The state of the art in research and the future agenda. VOLUNTAS: International Journal of Voluntary and Nonprofit Organizations, 23(4), 1083-1101.

Vinzant, J. C. (1998). Where values collide: Motivation and role conflict in child and adult protective services. The American Review of Public Administration, 28(4), 347-366.

Vogel, R., \& Masal, D. (2015). Public leadership: A review of the literature and framework for future research. Public Management Review, 17(8), 1165-1189.

Von Fischer, P., \& De Jong, D. (2017). The relationship between teacher perception of principal servant leadership behavior and teacher job satisfaction. Servant Leadership: Theory \& Practice, 4(2), 14.

Waldo, D. (1952). Development of the theory of democratic administration. American Political Science Review, 46(1), 81-103.

Waldo, D. (1968). Public administration in a time of revolutions. Public Administration Review, 28(4), 362-368.

Walumbwa, F. O., Hartnell, C. A., \& Oke, A. (2010). Servant leadership, procedural justice climate, service climate, employee attitudes, and organizational citizenship behavior: a cross-level investigation. Journal of applied psychology, 95(3), 517.

Walumbwa, F. O., Muchiri, M. K., Misati, E., Wu, C., \& Meiliani, M. (2018). Inspired to perform: A multilevel investigation of antecedents and consequences of thriving at work. Journal of Organizational Behavior, 39(3), 249-261.

Wang, M., Kwan, H. K., \& Zhou, A. (2017). Effects of servant leadership on workfamily balance in China. Asia Pacific Journal of Human Resources, 55(4), 387407.

Warner, M. E. (2010). The Future of Local Government: Twenty-First-Century Challenges. Public Administration Review, 70, s145-s 147. 
Wart, M. V. (2003). Public-Sector leadership theory: An assessment. Public administration review, 63(2), 214-228.

Washington, R. R., Sutton, C. D., \& Feild, H. S. (2006). Individual differences in servant leadership: The roles of values and personality. Leadership \& Organization Development Journal, 27(8), 700-716.

Weinstein, R. B. (2013). Servant leadership and public administration: Solving the public sector financial problems through service. Journal of Management Policy and Practice, 14(3), 84-91.

West, J. P., \& Berman, E. M. (2004). Ethics training in US cities: Content, pedagogy, and impact. Public Integrity, 6(3), 189-206.

Williams Jr, W. A., Brandon, R. S., Hayek, M., Haden, S. P., \& Atinc, G. (2017). Servant leadership and followership creativity: The influence of workplace spirituality and political skill. Leadership \& Organization Development Journal, 38(2), 178-193.

Wilson, W. (1981). The Study of Administration, Political Science Quarterly (June 1887), reprinted in Frederic C. Mosher, Basic Literature of American Public Administration, 1787-1950.

Wren, J. T. (1995). The historical and contemporary contexts of leadership: A conceptual model.

Wren, J. T. (1995). The Problem of Cultural Leadership: The lessons of the dead leaders society and a new definition of leadership. Journal of Leadership Studies, 2(4), 122-139.

Wright, B. E., \& Pandey, S. K. (2009). Transformational leadership in the public sector: Does structure matter? Journal of public administration research and theory, 20(1), 75-89.

Wright, B. E., Moynihan, D. P., \& Pandey, S. K. (2012). Pulling the levers: Transformational leadership, public service motivation, and mission valence. Public Administration Review, 72(2), 206-215.

Wright, T. A., \& Goodstein, J. (2007). Character is not "Dead" in management research: A review of individual character and organizational-level virtue. Journal of Management, 33(6), 928-958.

Wu, Y., \& Hendrick, R. (2009). Horizontal and vertical tax competition in Florida local governments. Public Finance Review, 37(3), 289-311.

Wybron, I., \& Paget, A. (2016). Pupil power. 
Yin, R. K. (2009). Case study research: Design and methods fourth edition. Los Angeles and London: $S A G E$.

Yin, R. K. (2014). Case study research: Design and methods (applied social research methods). Thousand Oaks, CA: Sage publications.

Yin, R. K. (2018). Case study research and applications. Design and methods, $6^{\text {th }}$ edition.

Zhang, Y. (2014). The city manager's role in policymaking: A perspective beyond substitution and collaboration models. The American Review of Public Administration, 44(3), 358-372.

Zhang, Y., \& Feiock, R. C. (2010). City managers' policy leadership in council-manager cities. Journal of Public Administration Research and Theory, 20(2), 461-476.

Zhou, Y., \& Miao, Q. (2014). Servant leadership and affective commitment in the Chinese public sector: The mediating role of perceived organizational support. Psychological Reports, 115(2), 381-395. 


\section{APPENDICES}

APPENDIX A

Studies on Servant Leadership in Public Administration

\begin{tabular}{|c|c|c|c|c|c|c|}
\hline Studies & $\begin{array}{l}\text { Individual } \\
\text { Attributes }\end{array}$ & $\begin{array}{l}\text { Intervening } \\
\text { Mechanism } \\
\end{array}$ & $\begin{array}{l}\text { Employee } \\
\text { Attributes } \\
\end{array}$ & $\begin{array}{l}\text { Organizational } \\
\text { Attributes }\end{array}$ & Journal Publication & Context \\
\hline $\begin{array}{l}\text { Zhou \& Miao } \\
\text { (2014) }\end{array}$ & ---- & $\begin{array}{l}\text { Perceived } \\
\text { organizational } \\
\text { support }\end{array}$ & $\begin{array}{l}\text { Organizational } \\
\text { commitment } \\
\text { (affective) }\end{array}$ & ---- & Psychological Reports & $\begin{array}{l}\text { Chinese Public } \\
\text { Administration }\end{array}$ \\
\hline $\begin{array}{l}\text { Miao, } \\
\text { Newman, } \\
\text { Schwarz, \& } \\
\text { Xu (2014) }\end{array}$ & ---- & Affective trust & $\begin{array}{l}\text { Normative and } \\
\text { affective } \\
\text { organizational } \\
\text { commitment }\end{array}$ & ---- & Public Administration & $\begin{array}{l}\text { Chinese Public } \\
\text { Administration }\end{array}$ \\
\hline $\begin{array}{l}\text { Liu, Hu, \& } \\
\text { Cheng (2015) }\end{array}$ & ---- & ---- & $\begin{array}{l}\text { Public service } \\
\text { motivation (PSM) }\end{array}$ & ---- & $\begin{array}{l}\text { Public Personnel } \\
\text { Management }\end{array}$ & $\begin{array}{l}\text { Chinese Public } \\
\text { Administration }\end{array}$ \\
\hline $\begin{array}{l}\text { Shim, Park, \& } \\
\text { Eom, (2016) }\end{array}$ & ---- & ---- & $\begin{array}{l}\text { Trust, procedural } \\
\text { justice, } \\
\text { organizational } \\
\text { citizenship } \\
\text { behavior (OCB), }\end{array}$ & ---- & $\begin{array}{l}\text { International Review of } \\
\text { Public Administration }\end{array}$ & $\begin{array}{l}\text { Korean Public } \\
\text { Sector }\end{array}$ \\
\hline $\begin{array}{l}\text { Schwarz, } \\
\text { Newman, } \\
\text { Cooper, \& } \\
\text { Eva (2016) }\end{array}$ & & PSM & Job performance & ---- & Public Administration & $\begin{array}{l}\text { Chinese Public } \\
\text { Administration }\end{array}$ \\
\hline Tuan (2017) & ---- & $\begin{array}{l}\text { Entrepreneurial } \\
\text { orientation }\end{array}$ & OCB & $\begin{array}{l}\text { Knowledge } \\
\text { Sharing }\end{array}$ & $\begin{array}{l}\text { International Journal of } \\
\text { Public Administration }\end{array}$ & $\begin{array}{l}\text { Vietnamese Public } \\
\text { Organizations }\end{array}$ \\
\hline $\begin{array}{l}\text { Chung, Jung, } \\
\text { Kyle, \& Petrik } \\
(2010)\end{array}$ & ---- & $\begin{array}{l}\text { Procedural } \\
\text { justice }\end{array}$ & Job Satisfaction & ---- & $\begin{array}{l}\text { Journal of Parks and } \\
\text { Recreation }\end{array}$ & $\begin{array}{l}\text { U.S. Parks and } \\
\text { Recreation }\end{array}$ \\
\hline Reinke (2004) & ---- & ---- & Employee Trust & ---- & $\begin{array}{l}\text { Global Virtue Ethics } \\
\text { Review }\end{array}$ & $\begin{array}{l}\text { U.S. County } \\
\text { Government }\end{array}$ \\
\hline $\begin{array}{l}\text { Weinstein } \\
(2013)\end{array}$ & ---- & ----- & ---- & ---- & $\begin{array}{l}\text { Journal of Management } \\
\text { Policy and Practice }\end{array}$ & $\begin{array}{l}\text { Fiscal Challenges } \\
\text { in State and Local } \\
\text { Government }\end{array}$ \\
\hline
\end{tabular}




\section{APPENDIX B}

\section{Consent to Participate in Online Survey}

Greetings.

My name is Pallavi Awasthi, a Ph.D. Candidate in Public Affairs at Florida International University in Miami. I am doing a study of the impact of leadership behavior on employee and community engagement in the county and municipal governments of the State of Florida. This study will facilitate a service-oriented culture and evidence-based recruitment and leadership training in the county and municipal governments. I would appreciate your responses to the survey questions below. It should take no more than 10 minutes to complete.

If you would like to know more about this research, I can speak to you on phone and explain how this study will enhance county and municipal government performance. I can also share my research findings with you after this research is complete.

Your participation in the survey is voluntary and your responses will be kept anonymous and confidential. By proceeding, you will be giving consent to participating in the survey. If you have any questions regarding this research study, you may contact the principal investigator Dr. Sukumar Ganapati or Ms. Pallavi Awasthi.

Sukumar Ganapati

Professor of Public Policy and Administration.

Department of Public Administration

Florida International University, Modesto A. Maidique

11200 SW 8th Street, Miami, FL - 33199

Email: ganapati@fiu.edu, Phone: 305.348.6275

Pallavi Awasthi

Ph.D. Candidate and Graduate Assistant

Department of Public Administration

Florida International University

Modesto A. Maidique PCA - 250B

11200 SW 8th Street, Miami, FL - 33199

Email: pawas001@fiu.edu, Phone: 786.683.3084 


\section{APPENDX C}

Online Survey Items

\begin{tabular}{|c|c|}
\hline \multicolumn{2}{|c|}{$\begin{array}{l}\text { Survey for Executive Team Members of the county and city Administrators } \\
\text { (Followers) } \\
\begin{array}{l}\text { On a scale of } 7 \text { (strongly disagree }=1 \text { to strongly agree }=7 \text { ), please indicate the } \\
\text { degree to which you agree or disagree with the following statements. }\end{array}\end{array}$} \\
\hline Variables & Items \\
\hline Background & $\begin{array}{l}\text { - Please specify the name of the county and city you } \\
\text { current work with? } \\
\text { - Are you the county and city manager of your } \\
\text { county/municipal government? } \\
\text { 1. Yes } \\
\text { 2. No }\end{array}$ \\
\hline $\begin{array}{l}\text { Servant Leadership } \\
\text { Behaviors (Liden et } \\
\text { al., 2014) }\end{array}$ & $\begin{array}{l}\text { Think about the typical actions of your current county and city } \\
\text { manager and rate your level of agreement with how each } \\
\text { statement applies to your manager's behavior. } \\
\text { - My manager can tell if something work-related is going } \\
\text { wrong. } \\
\text { - My manager makes my career development a priority. } \\
\text { - I would seek help from my manager if I had a personal } \\
\text { problem. } \\
\text { - My manager emphasizes the importance of giving back } \\
\text { to the community. } \\
\text { - My manager puts my best interests ahead of his/her } \\
\text { own. } \\
\text { - My manager gives me the freedom to handle difficult } \\
\text { situations in the way that I feel is best. } \\
\text { - My manager would NOT compromise ethical } \\
\text { principles in order to achieve success. }\end{array}$ \\
\hline $\begin{array}{l}\text { Moral Potency } \\
\text { (or moral conation) } \\
\text { (Hannah \& Avolio, } \\
\text { 2010) }\end{array}$ & $\begin{array}{l}\text { In answering items MP1 through MP7, think about the typical } \\
\text { actions of your county and city manager and rate your level of } \\
\text { agreement with how each statement applies to your manager's } \\
\text { behavior. } \\
\text { - My manager confronts their peers if he/she commits an } \\
\text { unethical act. } \\
\text { - My manager confronts their leader if he/she commits } \\
\text { an unethical act. } \\
\text { - My manager always states their views about ethical } \\
\text { issues with his/her leaders. } \\
\text { - My manager goes against the group's decision } \\
\text { whenever it violates his/her ethical standards. }\end{array}$ \\
\hline
\end{tabular}


- My manager assumes responsibility to take action when he/she sees an unethical act.

- My manager does not accept anyone in his/her group behaving unethically.

- My manager takes charge to address ethical issues when he/she knows someone has done something wrong.

In answering items MP8 through MP12, think about your county and city manager's knowledge, skills, and abilities and indicate your level of confidence in his/her ability to accomplish each item below:

- My manager demonstrates that he/she is confident that he/she can confront others who behave unethically to resolve the issue.

- My manager demonstrates that he/she is confident that they can readily see the moral/ethical implications of the challenges I face.

- My manager demonstrates that he/she is confident that he/she can work with others to settle moral ethical disputes.

- My manager demonstrates that he/she is confident that he/she can take decisive action when addressing the moral/ethical decision.

- My manager demonstrates that he/she is confident that he/she can determine what needs to be done when he/she face moral/ethical dilemmas.

Servant Identity (SI) (Sun, 2013)
Think about the typical actions of your county and city manager and rate your level of agreement with how each statement applies to your manager's behavior.

- My manager strongly believes that one's vocation and mission in life is to serve others.

- My manager derives spiritual satisfaction from serving others.

- My manager searches for opportunities that help others to fulfill his/her calling as a servant.

- My manager values the skills and capabilities of others.

- My manager's position and accomplishments do not stop him/her from learning or receiving criticism from others.

- My manager's position and power are unimportant when he/she is dealing with others.

- My manager is happy for others to benefit from his/her work and accomplishments. 
- My manager is aware of the emotional states of others even if they don't explicitly disclose them to him/her.

- People go to my manager for advice and support when they are down;

- Helping others in their time of need is not a waste of time for my manager.

- My manager loves others as much as he/she loves himself/herself.

- Loving others fulfills my manager's spiritual need.

- When others suffer, my immediate manager wants to do something about it.

Ethical Leadership (Brown \& Trevino, 2005)
Think about the typical actions of your county and city manager and rate your level of agreement with how each statement applies to your manager's behavior.

- My manager listens to what department employees have to say.

- My manager disciplines employees who violate ethical standards.

- My manager conducts his/her personal life in an ethical manner.

- My manager has the best interest of employees in his mind.

- My manager makes fair and balanced decisions.

- My manager can be trusted.

- My manager discusses ethics or values with employees.

- My manager sets an example of how to do right things in terms of ethics.

- My manager defines success not just by results but also the way they are obtained.

- My manager asks, "what is the right thing to do" when making decisions

Organizational Social

Capital (OSC)

(Andrews, 2010,

2011)
Please think about your county and city government, while rating the statements below.

- In this organization, coordination and joint working with other departments is a major part of our approach to the organization of the services.

- In this organization, cross-departmental/cross-cutting working is important in driving service improvement.

- In this organization, there is high-level trust between the top management and staff.

- In this organization, there is a high level of trust between officers and elected officials. 
- In this organization, the authority's mission, values, and objectives are clearly and widely understood and owned by all staff in service.

- In this organization, the authority concentrates on achieving its mission values and objectives

Co-Production of Public Service (COPR) (created from the literature)

Please think about your county and city government, while rating the statements below.

- In this organization, there is a high-level of community outreach.

- In this organization, there is high-level of interaction between authorities and staff with community members.

- In this organization, authorities and staff regularly seek feedback from community members to improve public services.

- In this organization, authorities implement the feedback received from the community members to improve public services.

- In this organization, authorities and staff understand how its decisions affect the community.

- In this organization, authorities and staff provide useful information to the community for making information decisions.

- In this organization, authorities and staff are accountable to the community for its actions.

- In this organization, authorities and staff let the community know what it is doing and why it is doing it.

Service Climate (Sngheider \& Ingram, 1998)
The statements mentioned below describe the extent to which

your county and city government expects, desires, and rewards superior public service. For statement, indicate the extent to which you agree or disagree using the scale: 1=poor, 2=fair, $3=$ good, $4=$ very good, $5=$ excellent. How would you rate-------

- ---The job knowledge and skills of employees in your organization to deliver superior quality work and service?

- ---Efforts to measure and track the quality of work and service in your organization?

- ---The recognition and rewards employees receive in your organization for the delivery of superior work and service?

- ---The overall quality of service provided by your organization. 
- ---The leadership shown by management in your organization in supporting the service quality effort.

- ---The effectiveness of your organization's communication efforts to both employees and community?

- ---The tools, technology, and other resources provided to employees in your organization to support the delivery of superior quality work and service?

Demographics

- What is your education level?

1. Associate degree or some college

2. Bachelor's degree

3. Master's degree

4. Doctorate degree

5. Professional degree

- What is your age?

1. 25-34 years old

2. 35-44 years old

3. $45-54$ years old

4. 55-64 years old

5. 65 or older

- From the options below, choose the department you are currently working with.

1. Police/Public safety

2. Economic Development \& Public Housing

3. Parks \& Recreation

4. Finance \& Budget

5. Emergency Management

6. Human Resource

7. City/County Administration

8. Community Service \& Redevelopment

9. Solid/Waste Management/Utilities

10. Public Works/Building

11. IT/Communications

12. Other (Please Specify)

- What is your gender?

1. Male

2. Female

3. Rather not say

- What is your current job position?

1. Deputy Manager

2. Assistant Manager

3. Department Director

4. Other (Please Specify) 
- How many years of experience you have with local governments?

1. Less than 5 years

2. 6-15 years

3. 16-25 years

4. 26-35 years

5. 35 or more years

- What is your ethnicity?

1. American Indian/ Alaskan Native

2. Asian

3. Black or African American

4. Hispanic/Latino

5. White

6. Other (Please Specify)

- Do you report directly to the county and city manager?

1. Yes

2. No

- In your current role, how many years have you been serving with this county and city government?

1. 1 year or less

2. 2-5 years

3. 6-10 years

4. More than 10 years

\section{Survey for County and City Administrators (Leaders)}

Background
- Please specify the name of the county and city you current work with?

- Are you the county and city manager of your county/municipal government?

3. Yes

4. No
Moral Potency (or moral conation) (Hannah \& Avolio, 2010)
In answering items MP1 through MP7, think about your typical actions and rate your level of agreement with how each statement applies to your behavior.

- I confront my peers if they commit an unethical act.

- I confront my leader if he/she commits an unethical act.

- I always state my views about ethical issues to my leaders.

- I go against the group's decision whenever it violates my ethical standards.

- I assume responsibility to take action when I see an unethical act.

- I do not accept anyone in my group behaving unethically. 
- I take charge to address ethical issues when I know someone has done something wrong.

In answering items MP8 through MP12, think about your knowledge, skills, and abilities and indicate your level of confidence in your ability to accomplish each item below:

- I am confident that I can confront others who behave unethically to resolve the issue.

- I am confident that I can readily see the moral/ethical implications of the challenges I face.

- I am confident that I can work with others to settle moral/ethical disputes.

- I am confident that I can take decisive action when addressing the moral/ethical decision.

- I am confident that I can determine what needs to be done when I face moral/ethical dilemmas.

\begin{tabular}{|c|c|}
\hline $\begin{array}{l}\text { Servant Identity (SI) } \\
\text { (Sun, 2013) }\end{array}$ & $\begin{array}{l}\text { Think about your typical actions and rate your level of } \\
\text { agreement with how each statement applies to your behavior. } \\
\text { - I strongly believe that one's vocation and mission in } \\
\text { life is to serve others. } \\
\text { - I derive spiritual satisfaction from serving others. } \\
\text { - I search for opportunities that help others to fulfill his } \\
\text { or her calling as a servant. } \\
\text { - I value the skills and capabilities of others. } \\
\text { - My position and accomplishments do not stop me from } \\
\text { - learning or receiving criticism from others. } \\
\text { - My position and power are unimportant when dealing } \\
\text { - Ith others. } \\
\text { - I am happy for others to benefit from my work and } \\
\text { - I'm aware of the emotional states of others even if they } \\
\text { don't explicitly disclose them to me. } \\
\text { - People come to me for advice and support when they } \\
\text { are down; } \\
\text { - Helping others in their time of need is not a waste of } \\
\text { time. } \\
\text { - I love others as much as I love myself; } \\
\text { When others suffer, I want to do something about it. }\end{array}$ \\
\hline Demographics & $\begin{array}{l}\text { - What is your education level? } \\
\text { 1. Associate degree or some college } \\
\text { 2. Bachelor's degree } \\
\text { 3. Master's degree } \\
\text { 4. Doctorate degree }\end{array}$ \\
\hline
\end{tabular}


5. Professional degree

- What is your age?

1. 25-34 years old

2. 35-44 years old

3. 45-54 years old

4. 55-64 years old

5. 65 or older

- What is your gender?

1. Male

2. Female

3. Rather not say

- How many years of experience you have with local governments?

1. Less than 5 years

2. 6-15 years

3. 16-25 years

4. 26-35 years

5. 35 or more years

- What is your ethnicity?

1. American Indian/ Alaskan Native

2. Asian

3. Black or African American

4. Hispanic/Latino

5. White

6. Other (Please Specify)

- For how many years have you been serving as a county and city manager in this county and city government?

1. 1 year or less

2. 2-5 years

3. 6-10 years

4. More than 10 years 


\section{APPENDIX D}

List of Florida Counties Included in Survey Sample ${ }^{4}$

\begin{tabular}{lll}
\hline Rank & County & Population \\
\hline 1 & Broward County & $1,909,151$ \\
2 & Palm Beach County & $1,446,277$ \\
3 & Hillsborough County & $1,378,883$ \\
4 & Orange County & $1,321,194$ \\
5 & Pinellas County & 957,875 \\
6 & Lee County & 718,679 \\
7 & Polk County & 668,671 \\
8 & Brevard County & 576,808 \\
9 & Volusia County & 527,634 \\
10 & Pasco County & 510,593 \\
11 & Seminole County & 455,086 \\
12 & Sarasota County & 412,144 \\
13 & Manatee County & 373,853 \\
14 & Collier County & 363,922 \\
15 & Marion County & 348,371 \\
16 & Osceola County & 338,619 \\
17 & Lake County & 335,362 \\
18 & Escambia County & 311,522 \\
19 & St. Lucie County & 305,591 \\
20 & Leon County & 288,102 \\
21 & Alachua County & 263,148 \\
22 & St. Johns County & 235,503 \\
23 & Clay County & 207,291 \\
24 & Okaloosa County & 200,737 \\
25 & Hernando County & 182,696 \\
26 & Bay County & 182,482 \\
27 & Charlotte County & 176,954 \\
28 & Santa Rosa County & 170,442 \\
29 & Martin County & 157,581 \\
30 & Indian River County & 150,984 \\
31 & Citrus County & 143,087 \\
32 & Sumter County & 120,999 \\
33 & Highlands County & 102,101 \\
34 & Nassau County & 80,578 \\
35 & Monroe County & 76,325 \\
\hline
\end{tabular}

${ }^{4}$ (7 counties - Duval, Calhoun, Liberty, Lafayette, Union, Miami-Dade, and Flagler were not included in the sample as there was no appointed county administrator position. United States Census Bureau Annual Estimates of the Resident Population: April 1, 2010 to July 1, 2018. U.S. Census Bureau, Population Division. May 2019. http://www.census.gov/ ) 


\begin{tabular}{lll}
\hline Rank & County & Population \\
\hline 36 & Putnam County & 72,766 \\
37 & Columbia County & 69,105 \\
38 & Walton County & 65,858 \\
39 & Jackson County & 48,472 \\
40 & Gadsden County & 46,017 \\
41 & Suwannee County & 43,924 \\
42 & Okeechobee County & 40,572 \\
43 & Hendry County & 40,127 \\
44 & Levy County & 39,961 \\
45 & DeSoto County & 36,399 \\
46 & Wakulla County & 31,877 \\
47 & Baker County & 27,785 \\
48 & Hardee County & 27,228 \\
49 & Bradford County & 26,979 \\
50 & Washington County & 24,566 \\
51 & Taylor County & 22,098 \\
52 & Holmes County & 19,430 \\
53 & Madison County & 18,474 \\
54 & Gilchrist County & 17,615 \\
55 & Dixie County & 16,437 \\
56 & Gulf County & 16,055 \\
57 & Hamilton County & 14,269 \\
58 & Jefferson County & 14,105 \\
59 & Glades County & 13,363 \\
60 & Franklin County & 11,736 \\
\hline
\end{tabular}




\section{APPENDIX E}

List of Florida Municipalities Included in Survey Sample (Retrieved from Florida League of Cities Municipal Directory)

\begin{tabular}{|c|c|c|}
\hline Rank & City & Population \\
\hline 1 & Tallahassee & 187,996 \\
\hline 2 & Fort Lauderdale & 175,123 \\
\hline 3 & Port St. Lucie & 174,132 \\
\hline 4 & Cape Coral & 166,508 \\
\hline 5 & Pembroke Pines & 159,922 \\
\hline 6 & Hollywood & 144,926 \\
\hline 7 & Miramar & 132,096 \\
\hline 8 & Gainesville & 127,955 \\
\hline 9 & Coral Springs & 124,282 \\
\hline 10 & Clearwater & 110,679 \\
\hline 11 & Miami Gardens & 109,951 \\
\hline 12 & Palm Bay & 107,481 \\
\hline 13 & Pompano Beach & 106,260 \\
\hline 14 & Lakeland & 101,517 \\
\hline 15 & Davie & 96,908 \\
\hline 16 & Miami Beach & 91,714 \\
\hline 17 & Sunrise & 88,630 \\
\hline 18 & Boca Raton & 87,766 \\
\hline 19 & Palm Coast & 87,607 \\
\hline 20 & Deltona & 87,497 \\
\hline 21 & Largo & 80,747 \\
\hline 22 & Melbourne & 79,600 \\
\hline 23 & Boynton Beach & 78,050 \\
\hline 24 & Deerfield Beach & 76,662 \\
\hline 25 & Fort Myers & 72,395 \\
\hline 26 & Lauderhill & 69,651 \\
\hline 27 & Homestead & 69,533 \\
\hline 28 & Kissimmee & 66,592 \\
\hline 29 & Daytona Beach & 63,534 \\
\hline 30 & Delray Beach & 63,175 \\
\hline 31 & North Miami & 62,380 \\
\hline 32 & Tamarac & 62,264 \\
\hline 33 & North Port & 62,235 \\
\hline 34 & Wellington & 59,860 \\
\hline 35 & Jupiter & 59,108 \\
\hline 36 & Port Orange & 58,656 \\
\hline 37 & Ocala & 58,355 \\
\hline 38 & Sanford & 56,900 \\
\hline
\end{tabular}




\begin{tabular}{|c|c|c|}
\hline Rank & City & Population \\
\hline 39 & Coconut Creek & 56,593 \\
\hline 40 & Margate & 55,851 \\
\hline 41 & Doral & 55,660 \\
\hline 42 & Pinellas Park & 53,098 \\
\hline 43 & Sarasota & 52,905 \\
\hline 44 & Palm Beach Gardens & 50,521 \\
\hline 45 & Bonita Springs & 46,568 \\
\hline 46 & Titusville & 45,325 \\
\hline 47 & Cutler Bay & 44,867 \\
\hline 48 & North Miami Beach & 43,533 \\
\hline 49 & Oakland Park & 43,390 \\
\hline 50 & Altamonte Springs & 43,325 \\
\hline 51 & North Lauderdale & 43,232 \\
\hline 52 & Fort Pierce & 42,119 \\
\hline 53 & St. Cloud & 41,316 \\
\hline 54 & Ocoee & 40,171 \\
\hline 55 & Ormond Beach & 40,013 \\
\hline 56 & Winter Garden & 39,871 \\
\hline 57 & Greenacres & 38,943 \\
\hline 58 & Hallandale Beach & 38,424 \\
\hline 59 & Lake Worth Beach & 38,267 \\
\hline 60 & Winter Haven & 38,085 \\
\hline 61 & Lake Worth & 37,674 \\
\hline 62 & Aventura & 37,473 \\
\hline 63 & Oviedo & 36,819 \\
\hline 64 & Royal Palm Beach & 36,731 \\
\hline 65 & Plant City & 36,710 \\
\hline 66 & Panama City & 35,835 \\
\hline 67 & Dunedin & 35,783 \\
\hline 68 & Winter Springs & 34,901 \\
\hline 69 & Lauderdale Lakes & 34,201 \\
\hline 70 & Riviera Beach & 33,953 \\
\hline 71 & Cooper City & 33,176 \\
\hline 72 & Clermont & 32,348 \\
\hline 73 & Dania Beach & 30,644 \\
\hline 74 & DeLand & 30,493 \\
\hline 75 & Miami Lakes & 30,209 \\
\hline 76 & Estero & 30,118 \\
\hline 77 & Winter Park & 28,967 \\
\hline 78 & Parkland & 28,128 \\
\hline 79 & Casselberry & 27,614 \\
\hline 80 & Rockledge & 26,165 \\
\hline 81 & Temple Terrace & 25,567 \\
\hline 82 & Key West & 24,663 \\
\hline
\end{tabular}




\begin{tabular}{|c|c|c|}
\hline Rank & City & Population \\
\hline 83 & Tarpon Springs & 24,421 \\
\hline 84 & New Smyrna Beach & 24,285 \\
\hline 85 & Palmetto Bay & 23,843 \\
\hline 86 & Sebastian & 23,137 \\
\hline 87 & Jacksonville Beach & 22,805 \\
\hline 88 & Haines City & 22,660 \\
\hline 89 & Palm Springs & 22,282 \\
\hline 90 & Sunny Isles Beach & 22,295 \\
\hline 91 & Venice & 21,418 \\
\hline 92 & Edgewater & 20,958 \\
\hline 93 & Fort Walton Beach & 20,869 \\
\hline 94 & DeBary & 20,002 \\
\hline 95 & Naples & 19,527 \\
\hline 96 & Eustis & 19,432 \\
\hline 97 & Lynn Haven & 19,287 \\
\hline 98 & Pinecrest & 18,408 \\
\hline 99 & Cocoa & 18,313 \\
\hline 100 & Seminole & 18,231 \\
\hline 101 & Bartow & 18,205 \\
\hline 102 & Punta Gorda & 17,675 \\
\hline 103 & Opa-locka & 17,528 \\
\hline 104 & Belle Isle & 17,467 \\
\hline 105 & Belle Glade & 17,448 \\
\hline 106 & Safety Harbor & 17,103 \\
\hline 107 & Maitland & 17,007 \\
\hline 108 & Marco Island & 16,728 \\
\hline 109 & Stuart & 16,110 \\
\hline 110 & Lake Mary & 15,905 \\
\hline 111 & New Port Richey & 15,351 \\
\hline 112 & Lake Wales & 15,011 \\
\hline 113 & Zephyrhills & 15,010 \\
\hline 114 & Auburndale & 14,832 \\
\hline 115 & Callaway & 14,681 \\
\hline 116 & West Park & 14,499 \\
\hline 117 & Niceville & 13,774 \\
\hline 118 & Destin & 12,730 \\
\hline 119 & South Daytona & 12,538 \\
\hline 120 & North Palm Beach & 12,206 \\
\hline 121 & Cocoa Beach & 11,737 \\
\hline 122 & Holly Hill & 11,712 \\
\hline 123 & Orange City & 11,569 \\
\hline 124 & Lantana & 10,705 \\
\hline 125 & Satellite Beach & 10,403 \\
\hline 126 & Alachua & 9,949 \\
\hline
\end{tabular}




\begin{tabular}{|c|c|c|}
\hline Rank & City & Population \\
\hline 127 & Barefoot Bay Recreation District & 9,808 \\
\hline 128 & Milton & 9,425 \\
\hline 129 & Groveland & 8,729 \\
\hline 130 & Orange Park & 8,510 \\
\hline 131 & Indian Harbour Beach & 8,225 \\
\hline 132 & Palm Beach & 8,041 \\
\hline 133 & Southwest Ranches & 7,981 \\
\hline 134 & Brooksville & 7,780 \\
\hline 135 & Arcadia & 7,772 \\
\hline 136 & Wildwood & 7,473 \\
\hline 137 & Green Cove Springs & 7,043 \\
\hline 138 & St. Augustine Beach & 7,026 \\
\hline 139 & Perry & 7,016 \\
\hline 140 & Longboat Key & 6,845 \\
\hline 141 & Treasure Island & 6,790 \\
\hline 142 & Fort Myers Beach & 6,264 \\
\hline 143 & Indiantown & 6,083 \\
\hline 144 & Lauderdale-By-The-Sea & 6,056 \\
\hline 145 & Bay Harbor Islands & 5,552 \\
\hline 146 & Okeechobee & 5,534 \\
\hline 147 & Starke & 5,442 \\
\hline 148 & Mascotte & 5,401 \\
\hline 149 & Lake Alfred & 5,322 \\
\hline 150 & Kenneth City & 5,040 \\
\hline 151 & Wauchula & 5,001 \\
\hline 152 & Fruitland Park & 4,214 \\
\hline 153 & Indian Rocks Beach & 4,203 \\
\hline 154 & Dundee & 3,974 \\
\hline 155 & Belleair & 3,889 \\
\hline 156 & Umatilla & 3,805 \\
\hline 157 & Davenport & 3,786 \\
\hline 158 & Highland Beach & 3,600 \\
\hline 159 & Lake Clarke Shores & 3,375 \\
\hline 160 & Frostproof & 3,273 \\
\hline 161 & Loxahatchee Groves & 3,203 \\
\hline 162 & Madison & 3,061 \\
\hline 163 & Ponce Inlet & 3,047 \\
\hline 164 & Eagle Lake & 2,708 \\
\hline 165 & Oakland & 2,624 \\
\hline 166 & Bal Harbour Village & 2,513 \\
\hline 167 & Trenton & 2,067 \\
\hline 168 & Atlantis & 2,001 \\
\hline 169 & Hillsboro Beach & 1,867 \\
\hline 170 & Zolfo Springs & 1,803 \\
\hline
\end{tabular}




\begin{tabular}{lll}
\hline Rank & City & Population \\
\hline 171 & Lake Butler & 1,797 \\
172 & Polk City & 1,623 \\
173 & Keystone Heights & 1,367 \\
174 & South Palm Beach & 1,366 \\
175 & Westlake & 1000 \\
176 & White Springs & 763 \\
177 & Briny Breezes & 653 \\
178 & Sopchoppy & 482 \\
179 & St Marks & 319 \\
180 & Golf & 252 \\
181 & Glen Ridge & 243 \\
\hline
\end{tabular}




\section{APPENDIX F}

Interview Protocol

\section{Questions for Executive Team Members of the County and City Administrators}

\begin{tabular}{|c|c|}
\hline Categories & Questions \\
\hline Background & $\begin{array}{l}\text { - Can you tell me about your role, what you do here? } \\
\text { - How do you exercise your leadership in your } \\
\text { role/department? } \\
\text { - What is your experience of your county and city manager's } \\
\text { leadership? }\end{array}$ \\
\hline Servant Identity & $\begin{array}{l}\text { - What are the most important values of your county and } \\
\text { city administrator, for example being a public servant? } \\
\text { - Does your county and city manager have concerns for } \\
\text { employees, is he helping? } \\
\text { - In times of personal need, can you approach the county } \\
\text { and city manager for help and advice? } \\
\text { - Is your county and city manager open for criticism, } \\
\text { explain? }\end{array}$ \\
\hline Moral Potency & $\begin{array}{l}\text { - What do you think about the importance of ethics in } \\
\text { government? } \\
\text { - How do you encourage it in your department? } \\
\text { - Does ethics matter for your county and city manager? } \\
\text { - How does he/she ensure ethical behavior among his/her } \\
\text { staff? } \\
\text { - Can you explain any situation when the county and city } \\
\text { manager was faced with an ethical dilemma and how did } \\
\text { he/she acted and resolved it? }\end{array}$ \\
\hline $\begin{array}{l}\text { Servant } \\
\text { Leadership }\end{array}$ & $\begin{array}{l}\text { - How will you define the leadership of your county and city } \\
\text { manager? } \\
\text { - Is your county and city manager approachable (or not), } \\
\text { when staff members really need his/her help? } \\
\text { - What qualities of your county and city manager help } \\
\text { nurture and enhance supportive and trustworthy } \\
\text { relationship among employees?? } \\
\text { - Does your county and city manager think of the } \\
\text { community before making decisions that impact them, } \\
\text { explain? } \\
\text { - Does your county and city manager take accountability of } \\
\text { decisions that impact community? }\end{array}$ \\
\hline
\end{tabular}




\begin{tabular}{|c|c|}
\hline $\begin{array}{l}\text { Organizational } \\
\text { Social Capital }\end{array}$ & $\begin{array}{l}\text { - How many people you have a very strong connection } \\
\text { among your staff members? } \\
\text { - How many people you trust in your department? } \\
\text { - What qualities of your leader help nurture and enhance } \\
\text { supportive and trustworthy relationship in the department? } \\
\text { - How does leadership encourage/discourage collaboration } \\
\text { and engagement of community members in policy } \\
\text { decisions/implementation/service delivery? }\end{array}$ \\
\hline $\begin{array}{l}\text { Co-production of } \\
\text { public service }\end{array}$ & $\begin{array}{l}\text { - What is the level of community engagement in your } \\
\text { organization? } \\
\text { - What kind of community engagement activities you have } \\
\text { in your organization and department? } \\
\text { - Do community feedback matters to you? } \\
\text { - How do you use community feedback to improve public } \\
\text { service provisions? } \\
\text { - How do you provide information to community about what } \\
\text { their government is doing? }\end{array}$ \\
\hline Service Climate & $\begin{array}{l}\text { - Is ensuring service quality is important for you in your } \\
\text { organization? } \\
\text { Do you ensure that your employees have the knowledge } \\
\text { and resources to deliver superior quality work service? } \\
\text { - How do you measure the quality of service provide by } \\
\text { your organization? } \\
\text { - What is your communication strategy to both employees } \\
\text { and the community? } \\
\text { Are you satisfied by the quality of service provided by } \\
\text { your organization? }\end{array}$ \\
\hline \multicolumn{2}{|c|}{ Questions for the County and City Administrators } \\
\hline Categories & Questions \\
\hline Background & $\begin{array}{l}\text { - Can you tell a little bit about your background - } \\
\text { educational, career, life experiences? } \\
\text { - What are some main activities of your leadership role? } \\
\text { - What is most important for you as a county and city } \\
\text { manager? }\end{array}$ \\
\hline Servant Identity & $\begin{array}{l}\text { - Why did you choose a public service career? } \\
\text { - What it means to you as a public servant? } \\
\text { - Do you have any spiritual beliefs? } \\
\text { - Does your choice of public service have any spiritual } \\
\text { leanings? } \\
\text { - Does serving the needs of your employees and } \\
\text { empowering them is important for you? How do you do } \\
\text { that? }\end{array}$ \\
\hline
\end{tabular}




\begin{tabular}{|c|c|}
\hline & $\begin{array}{l}\text { - Can you provide instances when you nurtured these values } \\
\text { while performing your duties in your leadership role? }\end{array}$ \\
\hline Moral Potency & $\begin{array}{l}\text { - Is ethics important for you? } \\
\text { - How do you encourage it in your organization? } \\
\text { - How much being ethically upright is important as a county } \\
\text { and city manager? }\end{array}$ \\
\hline $\begin{array}{l}\text { Servant } \\
\text { Leadership }\end{array}$ & $\begin{array}{l}\text { - If you have to, how would you define your leadership as a } \\
\text { county and city manager? } \\
\text { - What are the most important leadership skills one needs as } \\
\text { a county and city manger? } \\
\text { - What are the most important values you identify with, in } \\
\text { your leadership role for employee empowerment and } \\
\text { engagement? } \\
\text { - How do you engage with elected officials? } \\
\text { - How do you encourage it in your organization? } \\
\text { community? How do you do it? }\end{array}$ \\
\hline $\begin{array}{l}\text { Organizational } \\
\text { Social Capital }\end{array}$ & $\begin{array}{l}\text { What are you views on social connections and } \\
\text { relationship? } \\
\text { Does trust matter to you? How do you encourage it among } \\
\text { your employees or organization as a whole? } \\
\text { - Is it important for you to share organizations mission and } \\
\text { strategy with your employees? } \\
\text { - How do you make sure that your team members } \\
\text { understand the mission, values and direction of the } \\
\text { organization? }\end{array}$ \\
\hline $\begin{array}{l}\text { Co-production of } \\
\text { public service }\end{array}$ & $\begin{array}{l}\text { - How do you make sure you are a community engaged } \\
\text { government? } \\
\text { - Give examples of some activities you encourage in your } \\
\text { organization for community engagement at the department } \\
\text { level? } \\
\text { - What kind of community outreach/collaboration activities } \\
\text { you have in your organization and department? } \\
\text { - How does these activities facilitate in public service } \\
\text { provisions or service delivery mechanisms? Provide } \\
\text { examples. } \\
\text { - How do you engage with external stakeholders? } \\
\text { - How important it is for you to engage with communities in } \\
\text { your municipality/department in service delivery/policy } \\
\text { issues (decisions/design/implementation). }\end{array}$ \\
\hline
\end{tabular}


- In what policy areas you seek community inputs or engagement and what is the intensity of engagement community, please elaborate with examples?

Service Climate

- Is ensuring service quality is important for you in your organization?

- Do you ensure that your employees have the knowledge and resources to deliver superior quality work service?

- How do you measure the quality of service to community?

- What is your communication strategy for employees and the community?

- Are you satisfied by the quality of service provided by your organization? 


\section{APPENDIX G}

Case Study Timeline

Weeks from Jan $25^{\text {th }}-$ September $4^{\text {th }}, 2019$

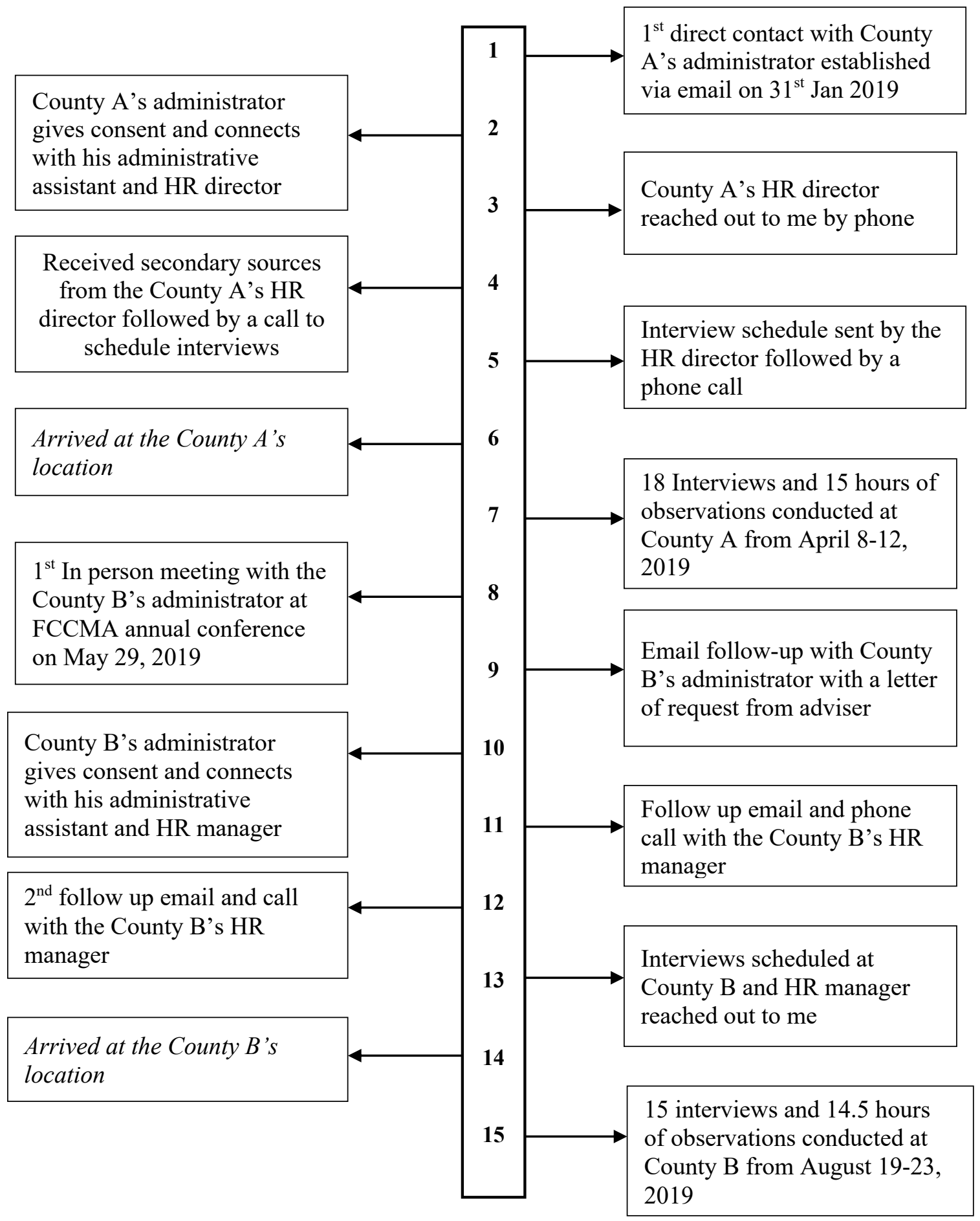




\section{$1^{\text {st }}$ in person meeting with the Village C manager at the FCCMA conference May 30, 2019}

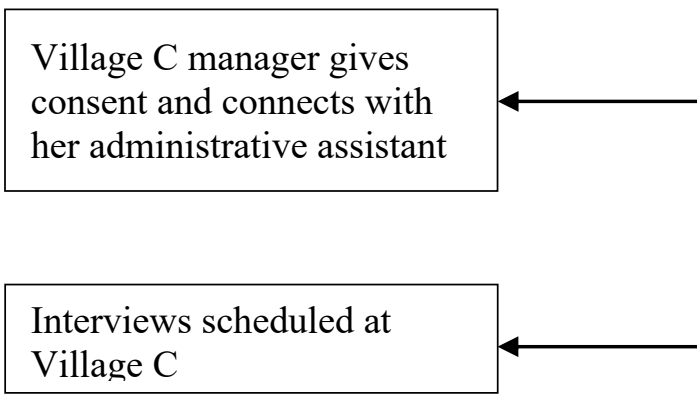

17 Interviews and 15 hours of observations conducted at Village C from $16^{\text {th }}-25^{\text {th }}$ July 2019
16

17

Email follow up with Village

$\mathrm{C}$ manager with a letter of request from adviser

18

19

Follow up email with the

Village C manager's

administrative assistant

20

21 Arrived at Village $C$ 


\section{APPENDIX H}

Observation Sites

\begin{tabular}{|c|c|c|c|}
\hline Observation Site & $\begin{array}{l}\text { Estimated } \\
\text { hours }\end{array}$ & Who was observed & What was observed \\
\hline $\begin{array}{l}\text { Community events } \\
\text { conducted by } \\
\text { county and city } \\
\text { governments } \\
(n=5)\end{array}$ & 15.5 & $\begin{array}{l}\text { county and city } \\
\text { department officers and } \\
\text { employees, external } \\
\text { partner agency officials, } \\
\text { community members }\end{array}$ & $\begin{array}{l}\text { county and city } \\
\text { government-citizen } \\
\text { interactions, interaction } \\
\text { among government } \\
\text { officials and employees, } \\
\text { interactions with external } \\
\text { stakeholders }\end{array}$ \\
\hline $\begin{array}{l}\text { Department review } \\
\text { meetings }(n=3)\end{array}$ & 5.5 & $\begin{array}{l}\text { county and city manager, } \\
\text { department directors, } \\
\text { employees in county and } \\
\text { city administration, }\end{array}$ & $\begin{array}{l}\text { county and city manager } \\
\text { and department directors' } \\
\text { interactions, interaction } \\
\text { among administration } \\
\text { staff }\end{array}$ \\
\hline $\begin{array}{l}\text { Informal employee } \\
\text { meetings }(n=6)\end{array}$ & 12 & $\begin{array}{l}\text { county and city manager, } \\
\text { employees, department } \\
\text { directors }\end{array}$ & $\begin{array}{l}\text { Interaction among } \\
\text { employees }\end{array}$ \\
\hline $\begin{array}{l}\text { Board of county } \\
\text { and city } \\
\text { commission } \\
\text { meetings }(n=3)\end{array}$ & 5 & $\begin{array}{l}\text { elected officials, } \\
\text { community members, } \\
\text { county and city manager }\end{array}$ & $\begin{array}{l}\text { county and city manager } \\
\text { and elected officials' } \\
\text { interaction, elected } \\
\text { officials-community- } \\
\text { county and city manager } \\
\text { interactions }\end{array}$ \\
\hline
\end{tabular}




\section{APPENDIX I}

Archival Records

\begin{tabular}{ll}
\hline Category & What was analyzed \\
\hline $\begin{array}{l}\text { County and city } \\
\text { manager's emails to } \\
\text { employees }(n=20)\end{array}$ & $\begin{array}{l}\text { Leaders values, beliefs, vision for organization, concern for } \\
\text { employees, communication tone, direction for organization, } \\
\text { empowerment }\end{array}$ \\
$\begin{array}{l}\text { Strategic vision } \\
\text { mission documents } \\
(n=5)\end{array}$ & $\begin{array}{l}\text { Organization's core values, mission, strategic priorities, } \\
\text { objectives, goals, priorities for employee and community } \\
\text { engagement, organization's performance review }\end{array}$ \\
$\begin{array}{l}\text { Employee and } \\
\text { Community survey } \\
(n=3)\end{array}$ & $\begin{array}{l}\text { Priorities to identify employee and community needs, } \\
\text { community participation and feedback to improve public } \\
\text { service }\end{array}$ \\
$\begin{array}{l}\text { Community } \\
\text { engagement documents } \\
(n=5)\end{array}$ & $\begin{array}{l}\text { Priorities for community prosperity, past achievement and } \\
\text { goals for customer service } \\
(n=2)\end{array}$ \\
$\begin{array}{l}\text { Pepartment scorecards } \\
\text { assessment of departments overall alignment with community } \\
\text { prosperity, performance, setting up priorities and goals. }\end{array}$ \\
$\begin{array}{l}\text { Leaders interaction with employees, informal employee } \\
\text { events, community events, organizational aesthetics, symbols } \\
\text { of communication to employees and community about } \\
\text { organizational mission and culture. }\end{array}$ \\
\hline
\end{tabular}




\author{
APPENDIX J \\ Interview Transcription Protocol \\ (McLellan, Macqueen, and Neidig, 2003.)
}

\title{
TEXT FORMATTING
}

\section{General Instructions}

The transcriber shall transcribe all individual and focus group interviews using the following formatting:

1. Arial 10-point face-font

2. One-inch top, bottom, right, and left margins

3. All text shall begin at the left-hand margin (no indents)

4. Entire document shall be left justified

\section{Labeling for Individual Interview Transcripts}

Individual interview transcript shall include the following labeling information left justified at the top of the document:

Example:

Participant ID:

Interview Name:

Interviewee Category/Subgroup:

Site/Location:

Date of Interview:

Interviewer ID:

Transcriber:

The transcriber shall insert a single blank line between the file labeling information and the actual interview transcription. A double pound sign (\#\#) shall precede and follow each participant identification label (i.e., Source ID). A single hard return shall be inserted immediately after the Source ID. The individual's comment/response shall begin on the next line.

\section{Example:}

Participant ID: C071

Interview Name: Vaccine Interview

Interviewee Subgroup \#: Trial Participant

Site: UIC

Date of Interview: 11/14/91 
Interviewer ID: IC003

Transcriber: John Smith

\#\#IC003\#\#

OK, before we begin the interview itself, I'd like to confirm that you have read and signed the informed consent form, that you understand that your participation in this study is entirely voluntary, that you may refuse to answer any questions, and that you may withdraw from the study at any time.

\#\#C071\#\#

Yes, I had read it and understand this.

\#\#IC003\#\#

Do you have questions before we proceed?

Labeling for Focus Group Transcripts

Focus group transcripts shall include the following labeling information:

Example:

Site:

\#Participants:

Focus Group Sample: (e.g., Men or Women)

Focus Group Interview No.

Date of Interview:

Facilitator ID:

Recorder ID:

Transcriber:

\section{End of Interview}

In addition, the transcriber shall indicate when the interview session has reached completion by typing END OF INTERVIEW in uppercase letters on the last line of the transcript along with information regarding the total number of audiotapes associated with the interview and verification that the second side of the tape is blank. A double space should precede this information.

Example:

\#\#IC003\#\#

Is there anything else that you would like to add?

\#\#C071\#\#

Nope, I think that about covers it.

\#\#IC003\#\# 
Well, thanks for taking the time to talk with me today. I really appreciate it. END OF INTERVIEW-(3 TAPES TOTAL); VERIFIED THAT SIDE BOF

TAPE 2 IS BLANK

\section{SOURCE LABELING}

\section{Individual Interviews}

Source IDs shall begin with the alpha character that designates the data collection site/location followed by the individual's three-digit identification number (e.g., FI00 = Fenway interviewee \#100).

Example:

Site designators for individual interviews are:

$\mathrm{C}=\mathrm{UIC}$ interviews

$\mathrm{F}=\mathrm{FCHC}$ interviews

$\mathrm{H}=\mathrm{HBHC}$ interviews

All interviewer Source IDs shall begin with the alpha character I followed by the appropriate site/location designator and three-digit interviewer identification number (e.g., IF002 = Fenway interviewer \#002).

\section{Focus Group Interviews}

All focus group participants and facilitators shall be assigned a unique Source ID. The transcriber shall be provided with a list of focus groups participants and recorder notes with each set of focus group audiotapes.

\section{Example:}

R500 = Rhode Island focus group participant \#500

The group facilitator Source IDs shall begin with the alpha character $\mathbf{F}$ followed by the appropriate site/location designator and a three-digit facilitator identification number.

\section{Example:}

FR101 = Rhode Island focus group facilitator \#101

The focus group recorder (note taker) Source ID shall begin with the alpha character $\mathbf{R}$ followed by the appropriate site/location designator and a three-digit recorder identification number.

\section{Example:}

RR002 $=$ Rhode Island focus group recorder \#002 
The transcriber shall be provided a list of data collection sites/locations and one to three alpha character prefix for each site/location.

For focus group participants who cannot be readily identified, the transcriber shall type the alpha character that designates in which site the focus group was conducted, the focus group number for that site, and -UNKNOWN (e.g., RI-UNKNOWN = Rhode Island unidentifiable participant for focus group \#1). UNKNOWN is not to be used in the individual interviews.

\section{CONTENT}

Audiotapes shall be transcribed verbatim (i.e., recorded word for word, exactly as said), including any nonverbal or background sounds (e.g., laughter, sighs, coughs, claps, snaps fingers, pen clicking, and car horn).

- Nonverbal sounds shall be typed in parentheses, for example, (short sharp laugh), (group laughter), (police siren in background).

- If interviewers or interviewees mispronounce words, these words shall be transcribed as the individual said them. The transcript shall not be "cleaned up" by removing foul language, slang, grammatical errors, or misuse of words or concepts. If an incorrect or unexpected pronunciation results in difficulties with comprehension of the text, the correct word shall be typed in square brackets. A forward slash shall be placed immediately behind the open square bracket and another in front of the closed square bracket.

\section{Example:}

I thought that was pretty pacific [/specific/], but they disagreed.

- The spelling of key words, blended or compound words, common phrases, and identifiers shall be standardized across all individual and focus group transcripts. Enunciated reductions (e.g., betcha, cuz, 'em, gimme, gotta, hafta, kinda, lotta, oughta, sorta, wanna, coulda, could've, couldn't, coudn've, couldna, woulda, would've, wouldn't, wouldn've, wouldna, shoulda, should've, shouldn't, shouldn've, shouldna) plus standard contractions of is, am, are, had, have, would, and not shall be used.

- Filler words such as hm, huh, mm, mhm, uh huh, um, mkay, yeah, yuhuh, nah huh, ugh, whoa, uh oh, ah, and ahah shall be transcribed.

-Word or phrase repetitions shall be transcribed. If a word is cut off or truncated, a hyphen shall be inserted at the end of the last letter or audible sound (e.g., he wen- he went and did what I told him he should've). 


\section{Inaudible Information}

The transcriber shall identify portions of the audiotape that are inaudible or difficult to decipher. If a relatively small segment of the tape (a word or short sentence) is partially unintelligible, the transcriber shall type the phrase "inaudible segment." This information shall appear in square brackets.

\section{Example:}

The process of identifying missing words in an audiotaped interview of poor quality is [inaudible segment].

If a lengthy segment of the tape is inaudible, unintelligible, or is "dead air" where no one is speaking, the transcriber shall record this information in square brackets. In addition, the transcriber shall provide a time estimate for information that could not be transcribed.

\section{Example:}

[Inaudible: 2 minutes of interview missing]

Overlapping Speech

If individuals are speaking at the same time (i.e., overlapping speech) and it is not possible to distinguish what each person is saying, the transcriber shall place the phrase "cross talk" in square brackets immediately after the last identifiable speaker's text and pick up with the next audible speaker.

\section{Example:}

Turn taking may not always occur. People may simultaneously contribute to the conversation; hence, making it difficult to differentiate between one person's statement [cross talk]. This results in loss of some information.

\section{Pauses}

If an individual pause briefly between statements or trails off at the end of a statement, the transcriber shall use three ellipses. A brief pause is defined as a two-to-five second break in speech.

\section{Example:}

Sometimes, a participant briefly loses . . . a train of thought or . . . pauses after making a poignant remark. Other times, they end their statements with a clause such as but then ....

If a substantial speech delay occurs at either beginning or the continuing a statement occurs (more than two or three seconds), the transcriber shall use "long pause" in parentheses. 


\section{Example:}

Sometimes the individual may require additional time to construct a response. (Long pause) other times, he or she is waiting for additional instructions or probes.

\section{Questionable Text}

If the transcriber is unsure of the accuracy of a statement made by a speaker, this statement shall be placed inside parentheses and a question mark is placed in front of the open parenthesis and behind the close parenthesis.

Example:

\#\#B3003\#\#

I went over to the? (club on Avalon)? to meet with the street outreach team to talk about joining up for the study.

\section{Sensitive Information}

If an individual uses his or her own name during the discussion, the transcriber shall replace this information with the appropriate interviewee identification label/ naming convention.

\section{Example:}

\#\#3003\#\#

My family always reminds me, "B3003, think about things before you open your mouth."

\#B3014\#\#

Hey B3003, don't feel bad; I hear the same thing from mine all the time. If an individual provides others' names, locations, organizations, and so on, the transcriber shall enter an equal sign immediately before and after the named information. Analysts will use this labeling information to easily identify sensitive information that may require substitution.

\section{Example:}

\#\#B3014\#\#

We went over to $=$ John Doe's $=$ house last night and we ended up going to $=$ O'Malley's Bar $=$ over on $=22$ nd Street $=$ and spending the entire night talking about the very same thing.

\section{STORAGE OF AUDIO RECORDINGS}

When a tape is not actively being transcribed or reviewed, the transcriber/proofreader shall ensure that it will be stored in a locked cabinet. 


\section{REVIEWING FOR ACCURACY}

The transcriber/proofreader shall check (proofread) all transcriptions against the audiotape and revise the transcript file accordingly. The transcriber/proofreader shall adopt a three-pass-per-tape policy whereby each tape is listened to three times against the transcript before it is submitted. All transcripts shall be audited for accuracy by the interviewer who conducted the interview or by the study data manager.

\section{SAVING TRANSCRIPTS}

The transcriber shall save each transcript as an individual MSWORD or ASCII text file with a .txt extension or a rich text file with an .rtf extension. Individual interview transcript files shall be assigned the interview name followed by the participant ID (e.g., VaxC071.txt $=$ Vaccine Interview for UIC participant\#071).

For focus groups, the second character shall be a number designating the focus group number for the site/location. The remaining characters shall designate the sample population (e.g., ClWOMEN.rtf = UIC focus group \#1, women)

\section{BACKUP TRANSCRIPT FILES}

All transcript files shall be backed up on diskettes or CD. The diskettes/CDs shall not be stored in the same location as the audiotapes.

\section{DESTROYING AUDIO RECORDS}

Unless a specific timeframe is designated in the research protocol for retaining of audiotapes, they will be destroyed. Once audiotapes have been reviewed for accuracy and the corrected transcription file saved and backed up, the audiotapes will be erased using an audiotape eraser. Recycling of audiotapes shall be permitted provided that sound quality is tested, and new labels are affixed to the tapes.

\section{NOTE}

1. According to the Health Resources and Services Administration (2001), The Secretary of Health and Human Services (HHS) may issue Certificates of Confidentiality under Section 301(d) of the Public Health Service Act (42 USC 241[d]). These Certificates are intended to protect researchers from compelled disclosure of the identities of research subjects. The Secretary has delegated the authority to issue these Certificates to all Public Health Service (PHS) agencies that perform or support biomedical research. 


\section{APPENDIX K \\ Reflexivity Statement}

Before joining the doctoral program in public affairs, I worked in academic research, teaching, and consulting for about 8 years in my home country, India. During all these years, my academic interests were inclined towards understanding and exploring human behavior in organizations. I pursued two academic projects on leadership in organizations. First was on developing the 'case study of a visionary leader' who was the first ever Indian to break the glass ceiling as a CEO of a multi-national consulting firm in the United States. This leader later founded a top ranked business school in India, the Indian School of Business (ISB), where I had an opportunity to work as a research and teaching assistant. Second was on 'understanding the leadership development needs of the Indian Administrative Service (IAS) Officers' (public servants recruited in All India Union Public Service Commission).

IAS is a premier civil service organization which inherited the administration from the British colonial rule. IAS work culture was old fashioned, mired into bureaucratic red tape and corrupt practices. Citizens perceived civil servants as wooden, inflexible, self-perpetuating, and inward looking. The trust deficit was high between citizen and government. The attitude of a civil servant was perceived as one of indifference and insensitivity to the needs of citizens. However, with the advent of globalization, information technology, citizens became more aware and vocal about their rights, resulting in the need for reforms in the IAS. The 'Leadership in Indian Administrative Services' project was motivated by the need for reforms in the IAS. My interest in this project was partially driven by my experiences of leadership among Indian 
Administrative Service officers, as a citizen of India. In my younger years, as a child, and also as a college student, there were several occasions when I or my family members approached an Indian Administrative Service agency (generally a District office equivalent to a County government) or its subsidiary as a common citizen. A cold, callous, uninterested response of the government official was a regular for a Citizen to experience. The scenario was such as if the government was not for serving the people, but people are for serving the vested interests of the government officials. Corruption was deeply ingrained into the Indian Civil Service culture. During such encounters, I questioned if there was any solution to such deep problems in the Indian governance system and how can I contribute in addressing or resolving these problems.

The project on 'leadership development of IAS officers' was an opportunity for me to build on my long-standing desire to contribute in Indian governance. During the leadership project I interviewed IAS officers to understand the leadership gaps - what they and their training at the National Academy of Administration. There were wide gaps between the two. The focus of the IAS training academy was more on learning about the legislation, laws, and rules of the government, but less about the attitude and leadership development. The intention was to address the leadership needs of the IAS. However, the project eventually ended up copying the leadership models from the business management and how the government leadership is in other countries and apply them in the IAS without understanding the contextual needs.

When I arrived in the United States to pursue the doctoral studies, my intention was to not only obtain a doctoral degree but do the research and understand the factors of leadership in government that has implications for both policy and practice. I knew I 
wanted to build on my knowledge of the 'Leadership Development Model for the Indian Administrative Service Officers' which can subsequently inform the training and development policy of the Public Service Leadership in India. In addition, my experience of achievement centric, capitalistic, and diminishing social relationship issues in the United States reinforced me to select a topic which can inform policies to resolve these issues. I chose to study 'Servant Leadership in Local Governments of the United States' as my doctoral dissertation topic. Local government systems in the United States are much advanced than in India. While choosing to study this topic, I was sure that this topic will allow me to address public service leadership issues both in India and the United States. It will enable me to draw lessons from the best practices from the U.S. local government leadership and transfer in the public service leadership context in India. Apart from this, my quest for personal development of my own leadership behavior and life perspective was a motivation to pursue this topic for my doctoral dissertation.

When I arrived in the United States, my challenge was to drop my dominant Indian female housemaker and a mother identity, acquire the identity of a professional independent female from India, and adapt to a new multicultural higher education environment predominant in the United States. Adapting to this cultural change needed a deeper critical and emotional reflection, which is also a hallmark of the leadership development process. While conducting the field work for this research, there were several occasions when I was challenged about my language barriers and the Indian gender identity. My English language communication has an Indian overtone, it was difficult for me to understand how U.S. local government professionals communicated or pronounced a certain word or certain slangs they used. During interviews there were 
several occasions when I had to repeat questions and get to the level of the interviewee to make him/her understand what I wanted to communicate. My professional etiquettes, clothing, and ornaments I wore had an Indian ethnic touch, for which some female interviewees commented, sometimes in good humor and sometimes awkward. All of this needed adapting and adjusting to a new reality.

During the field work, especially interviews, exploring the complexities of leadership behavior was challenging. Time availability of the top executives was a constraint. Understanding the nuances of leadership is a time-consuming process and needed a prolonged engagement with the professionals which was not possible during this research. Exploring the factors such as leader's identity was very limited in a onehour conversation with the leader and his top-level executives. Although this was complemented by the data from 50 interviews in three case studies which allowed for replication and confirmability.

During interviews with the top-executives, asking direct questions about their city-county manger's leadership behavior was awkward and needed an informal conversational approach. As an interviewer, was consistently reflective of my interviewing techniques, communication style, body language to develop rapport with the interviewees. This allowed me to navigate the understanding of the nuances of leadership behavior of the city-county manager and how they develop employee and community relations. I was constantly vigilant to find opportunities of informal conversation with the city and county administration staff. It was needed to verify the opinions of the employees about the leader. In addition, everyday note taking of the observations and 
interviews was consistently followed to validate the findings from different data resources and methods.

While conducting the field work, I got acclimatized to the local government work culture. Especially, understanding how local governments can make the real difference in the lives of local communities and how an effective leader creates a happy employee workforce, connected communities, and creative and learning organizations. As an international scholar from India, I learnt that in comparison to India, local government culture in the United States is highly community centric and enjoys more independence. Not only the higher leadership but also the frontline workforce is more qualified. The higher leadership is diverse in their professional experience. These findings are obvious. India is a developing and emerging economy, and just 70 years old in its independence from British Colonial rule, while the U.S. is more advanced and developed economy.

On the whole, this project opened doors for me as a merging ground for knowledge exchange on municipal leadership development in east-west cultures. Mainly two knowledge development dimensions emerged from the case study field work. First, enhancing local government work culture is fundamental for having satisfied and connected communities. This has long-term effect on sustainable community development in local communities. The role of city-county managers leadership is foundational in making a difference in local community's life. However, traditionally local governments had a personnel management system which still prevails. There is a need for having a structured leadership development policy in local governments. This leads to the future directions to create an inhouse 'servant leadership development 
workshop module' for local governments. Subsequently, pursue local governments to adopt one.

Second, in comparison to India, the United States local government system is responsive towards community. There are best practices that can be transferred to the Indian municipal governance. My future goal is to develop an international center for municipal leadership and community action. The focus of the center will be on training municipal government officials in India, both frontline and middle-level and prepare them more responsive towards the community. This can be done by creating a joint platform for integration and knowledge exchange between Indian municipal government officers and local governments in the United States. India can learn from the United States, but India's philosophical knowledge and systems of social integration can help the American mindset grow over the highly capitalistic and consumer-oriented culture. In the words of Rudyard Kipling:

Oh, East is East, and West is West, and never the twain shall meet, Till Earth and Sky stand presently at God's great Judgment Seat; But there is neither East nor West, Border, nor Breed, nor Birth, When two strong men stand face to face, though they come from the ends of the earth. 
VITA

\section{PALLAVI AWASTHI}

Born, India

2000

2016

2017

2017

2018

2018

2018

2019

2020

2020

Master of Labor Laws and Personnel Management University of Lucknow, India.

Graduate Scholarly Forum Award, Florida International University, Miami.

Master of Public Administration

Florida International University. Miami.

International Young Scholar Fellowship, American Society for Public Administration.

Doctoral Scholar Award,

Greenleaf Center for Servant Leadership.

Equity and Inclusion Fellowship,

Association for Public Policy Analysis Management.

Morris and Anita Broad Fellowship, Florida International University, Miami.

Dissertation Evidence Acquisition Fellowship, University Graduate School, Florida International University, Miami.

Dissertation Writing Year Fellowship, University Graduate School, Florida International University, Miami

Ph.D. in Public Affairs

Florida International University, Miami. 


\section{PUBLICATION}

Awasthi, P. (2019). India. In Mary E. Guy, Sharon H. Mastracci \& Seung-Bum Yang (Eds.), The Palgrave Handbook of Global Perspectives on Emotional Labor in Public Service (pp. 267-298), Springer International Publishing AG.

https://doi.org/10.1007/978-3-030-24823-9_12

Kroll, A., Remington, C., Awasthi, P., Ganapati, E. N. (2020) "Mitigating the Negative Effects of Emotional Labor: A Study of Disaster Response and Recovery Workers after the 2010 Haiti Earthquake." Governance. https://doi.org/10.1111/gove.12476

Awasthi, P. (2017). East-West Knowledge Transfer: Resolving Paradoxes in Public Service. PATimes Online: American Society for Public Administration.

http://patimes.org/east-westknowledge-transfer-resolving-paradoxes-public-service/

Awasthi, P. (2020) Lateral Entry Scheme: Path to Civil Service Reforms in India. Occasional Paper Series, Section on Comparative Public Administration, ASPA.

Awasthi, P. (2020) Developing Servant Leaders in Local Governments. Public Management Magazine. ICMA. 